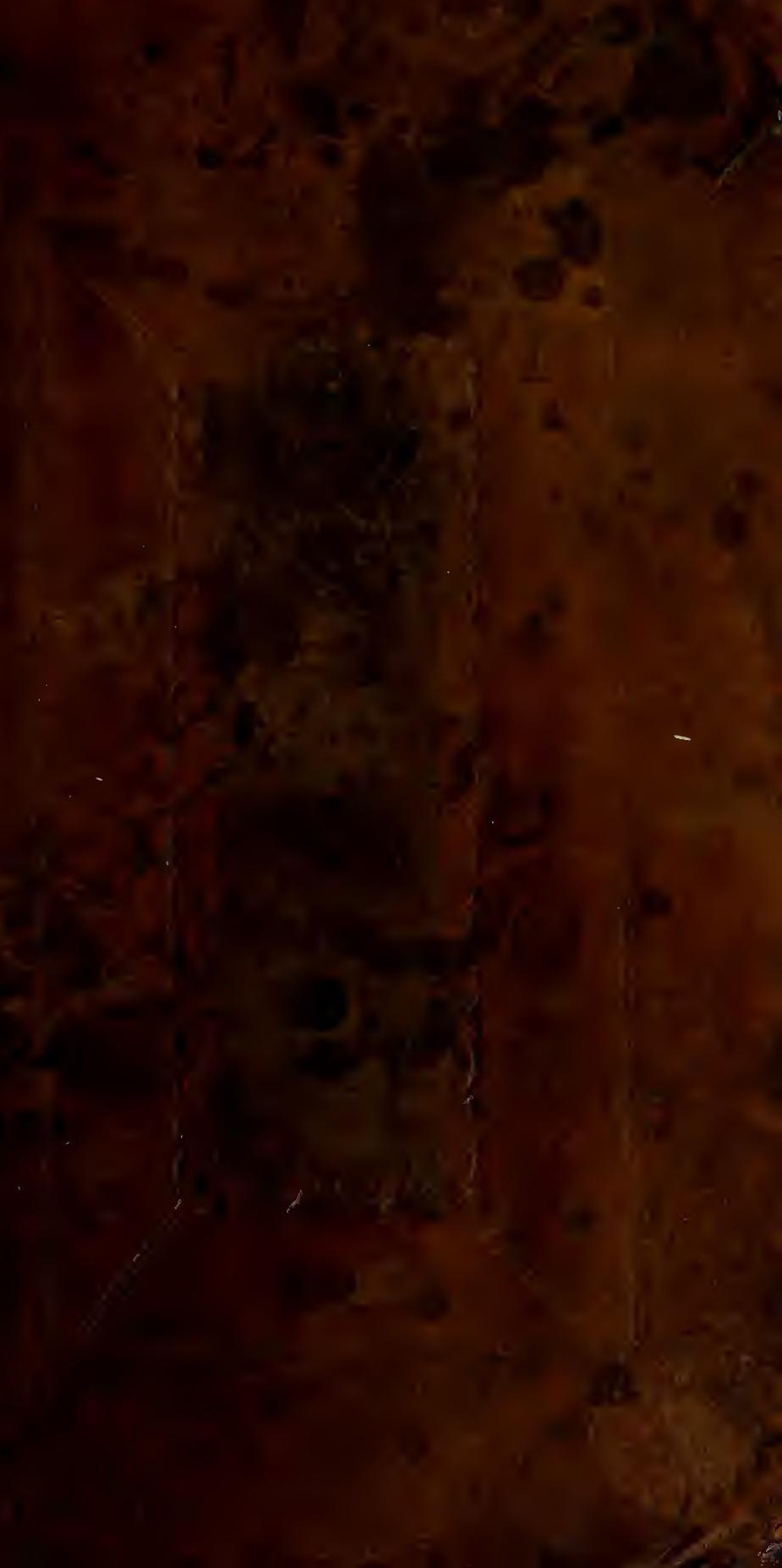


$\frac{q}{2}$

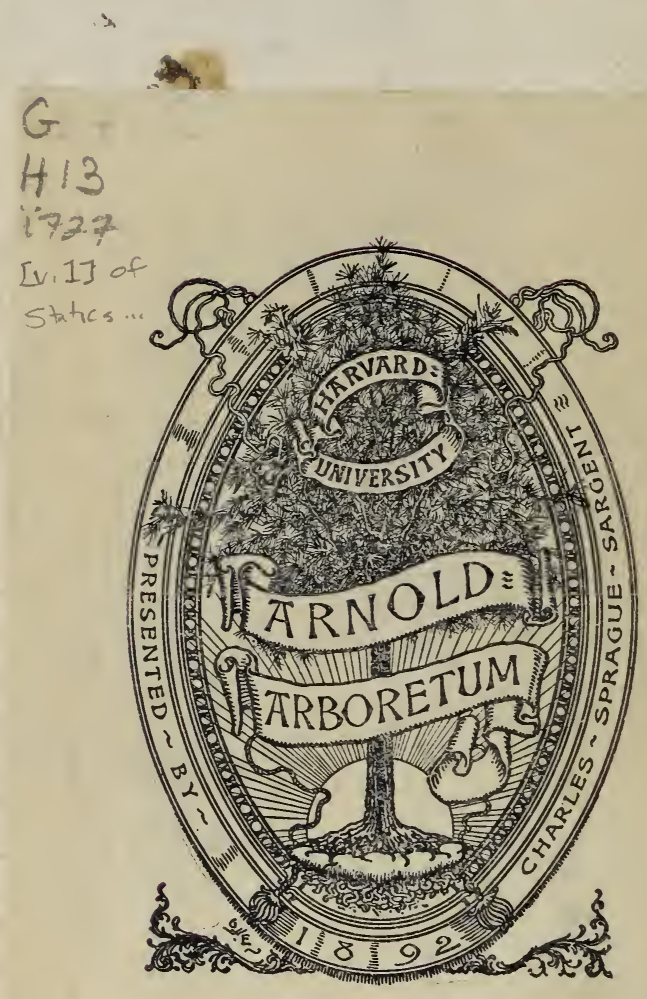



Digitized by the Internet Archive . in 2015 


\section{VEGETABLE STATICKS:}

Or, An Account of fome

\section{Statical Experiments \\ ON THE}

\section{SAP in VEGETABLES:}

Being an ESSAY towards a

\section{Natural Hiftory of Vegetation.} - Alfo, a SPECIMEN of

An Attempt to Analyfe the Arr;

By a great Variety of

CHYMIO-STATICAL EXPERTYMENTS;

Which were read at feveral Meetings before the ROYAL SOCIETY.

2uid eft in bis, in quo non nature ratio intelligentis appareat? Tul. de Nat. Deor.

Etenim Experimentorum longe major eft fubtilitas, quam fenfüs ipfrus I Itaque eo rem deducimus, ut fenfus tantum de Experimento, Experimentum de re judicet。 Fran. de Verul. Inftauratio magna.

By $S \mathcal{T E P H .}{ }^{-} H A L E S$, B. D. F.R. S. Rector of Farringaton, Hampjoire, and Minifter of Teddington, Middlejex.

\section{- LONDON:}

Printed for W. and J. INNYs, at the Weft End of St. Paul's: and T. WOODWARD, over-againit St. Dinftan's Church in Fleetfreet. M, DCC, XXVII. 
Ret $14 k+1407$

Feb. $16,172 \frac{6}{7}$. Imprimatur

Is a AC NEw ton. Pr. Reg. Soc; 
T O

\section{His Royal Highnefs}

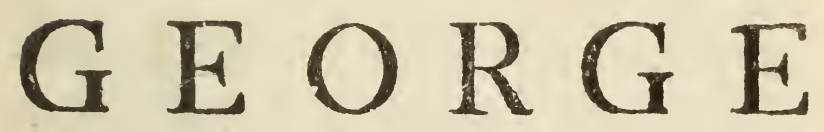

\section{Prince of WALES.}

May it pleafe your Royal Highne s,

Humbly offer the following Experiments to Your Highnefs's Patronage, to protect them from the reproaches

$$
\text { A } 2 \text { that }
$$




\section{DEDICATION.}

that the ignorant are apt unreafonably to caft on refearches of this kind, notwithftanding they are the only folid and rational means whereby we may ever hope to make any real advance in the knowledge of Nature: A knowledge worthy the attainment of Princes.

And as Solomon, the greateft and wifeft of men, deigned not to inquire into the nature of Plants, from the Cedar in Lebanon, to the Hyffop that Springeth out of the wall: So it will not, I prefume, be an unacceptable entertainment to

Your 


\section{$D E D I C A T I O N$.}

Your Royal Highnefs, at leaft at Your leifure hours; but will rather add to the pleafure, with which vegetable Nature in her prime verdure charms us: To fee the fteps the takes in her productions, and the wonderful power the therein exerts: The admirable provifion the has made for them, not only vigoroufly to draw to great heights plenty of nourifhment from the earth; but alfo more fublimed and exalted food from the air, that wonderful fluid, which is of fuch importance to the life of Vegetables and Animals:

$$
\text { A } 3 \text { And }
$$




\section{$D E D I C A T I O N$.}

And which by infinite combinations with natural bodies, produces innumerable furprizing effects; many inftances of which I have here produced.

The fearching into the works of Nature, while it delightsand inlarges the mind, and ftrikes us with the ftrongeft affurance of the wifdom and power of the divine Architect, in framing for us fo beautiful and well regulated a world, it does at the fame time convince us of his conftant benevolence and goodnefs towards us. 


\section{DEDICATION.}

That this great Author of Nature may fhower down on Your Royal Highnefs an abundance of his Bleffings, both Spiritual and Temporal, is the fincere prayer of

\section{TourRoyal Highness's}

\section{Moft Obedient}

Humble Servant,

Stephen Hales,

A 4. TH 


\section{T $\mathrm{H} \mathrm{E}$}

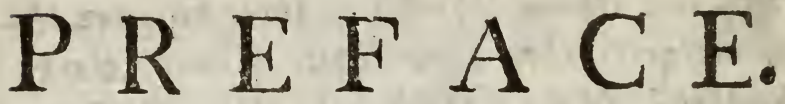

$7 H E R E$ bave been within less than a Century very great and ufeful difcoveries made in the amazingly beautiful fructure and nature of the animal ceconomy; neither bave Plants paffed unobferved in this inquifitive age; which has with fuch diligerice extended itsinquiries in fome degree, into almoft every branch of nature's inexbaultible fund of wonderful works.

We find in the Philosophical Transactions, and in the Fiffory of the Royal Academy of Sciences, accounts of many curious Experiments and Obfervations made from time to time on Vegetables, by Jeveral ingenious and inquiffitive Perfons: But our countryman Dr. Grew and Malpighi were the firft, who, tho in very diftant countries, did nearly at the Same time, unknown to each ot her, ingage in a very diligent and thorough inquiry into the Aructure of the veffels of Plants; a province, which till then had layn uncultivated. 
They have givers us very accurate and faithful accounts of the ftructure of the parts; which they carefully traced, from their firft minute origin, the feminal Plants, to their full groweth and maturity, thto' their Roots, Trunk, Bark, Branches, Gems, Shoots, Leaves, Blofoms and Fruit. In all which they obferved an exact and regular fymetry of 'Parts moft curiouly wrought in fuch manner, that the great work of Vegetation might effectually be carried on, by the uniform ci-operation of the feveral $P$ arts, according to the different offices afign ed them by nature.

Had they fortuned to have fallen into this fatical way of inquiry, perfons of their great application and Jagacity had doubtless made confderable advances in the knoweledge of the nature of Plants. This is the only fure way to meafure the "everal quantities of nourifioment, which Plants imbibe and perppire, and thereby to see what influence the different ftates of Air have on them. This is the likelieft method to find out the Sap's velocity, and the force with which it is imbibed: As alfo to eftimate the great power that nature exerts in extending and pughing forth her productions, by the expanfion of the Sap. 
About zo years fince, I made feveral bemaftatical Experimentson Dogs, and 6 years afterward's repeated the Jame on Horfes and other Animals, in order to find out the real force of the blood in the Arteries, fome of which are mentioned in the third chapter of this book: At which times I wibhed I could have made the like Experiments, to difcover the force of the Sap in Vegetables; but defpaired of ever effecting it, till about feven years fince, by mere accident I bit upon it, while $I$ was endeavouring by feveral ways to Atop the bleeding of an old ftem of a Vine, which was cut too near the bleeding feafon, which I feared might kill it: Having, after ot her means proved ineffectual, tyed a piece of bladder over the tranfucrfe cut of the Stem, I found the force of the Sap did greatly extend the bladder; whence I concluded, that if a long glafs Tube sere fixed there in the fame manner, as I had before done to the Arteries of feveral living Animals, I frould thereby obtain the real afcending force of the Sap in that Stem, which fucceeded according to my expectation, and hence it is, that I have been infenfibly led on, to make farther and farther refearches by varisty of Experiments. 


\section{The PREF A C E.}

As the art of Phyfick has of late years been such improved by a greater knowledge of the animal aconomy; fo doubtless a farther infight into the vegetable ceconomy mult needs proportionably improve our skill in Agriculture and Gardening, which gives me reajon to bope, that inquiries of this kind will be acceptable to many, who are intent upon improving thofe innocent, delightful, and beneficial Arts : Since they cannot be infenfible that the moft rational ground for Success in this lawdable purfuit mult arife from a greater infight into the nature of Plants.

Finding by many Experiments in the fifth chapter, that the Air is plentifully infpired by Vegetables, not only at their roots, but alfo thro' Several parts of their Trunks and Branches; this put me upon making a more particular inquiry into the nature of the Air; and to difcover, if poffible, wherein its great importance to the life and Jupport of Vegetables might confift ; on which account I was obliged to delay the publication of the reft of thefe Experiments, which revere read two years fince before the Royal Society, till I had made fome progress in this inquiry. An accoint of which I have given in the faxth chapter. 


\section{$\checkmark$ The P R E F C E.}

Where it appears by many chymio. ftatical Experiments, that there is diffued thro all natural, mutually attracting bodies, a large proportion of particles; which, as the firft great Author of this important difcovery, Sir Ifaac Newton $0:$ ferves, are capable of being thrown off from dense bodies by beat or fermentation into a vigoroufly elaftick and permanently repelling ftate: And alfo of returning by fermentation and Sometimes without it, into dense bodies; It is by this amphibious pro. perty of the air, that the main and principal operations of Nature are carried on; for a snals of mutually attracting particles, without being blended with a due proportion of elaftick repelling ones, would in many cafes foon coalefce into a luggifh lump. It is by the fe properties of the particles of matter that he folves the principal P bonomena of Nature. And Dr. Freind bas from the fame principles given a very ingenious Rationale of the chief operations in Chymiftr. It is therefore of importance to bave the fe vcry operative properties of natural bodies further afcertained by more Experiments and Obfervations: And it is with Satisfaction that we See them more and more confirmed to us, by every farther enquiry 


\section{The $P$ R E F A E.}

we make; as the following Experiments will plainly prove, by Gherwing how great the power of the attraction of acid Sulphureous particls muft be at fome little diftance from the point of contact, to be able moft readily to fubdue and fix elaftick aereal particles, which repell with a force fuperior to vaft incumbent preffures: Which particles we find are thereby changed from a Arongly repelling, to as frongly an attracting ftate: And that elafticity is no immutable property of air, is further evident from thefe Experiments; becaufe it were impolfible for fuch great quantities of it to be confined in the fubftances of Animals and Vegetables, in an elaftick ftate, without rending their conftituent parts with a vaft explofion.

I have been careful in making, and fait hful in relating the refult of thefe Experiments, and wish I could be as bappy in drawing the proper inferences from them. However I may fall Short at firf fetting out in thisftatical way of inquiring into the nature of Plants, yet there is good reafon to believe that confiderable advan. ces in the knowiledge of their zature may in process of time be made, by refearches of this kind. 
And 1 hope the publication of this Specimen of what I have bitherto done, will put ot hers upon the fame purfuits, there being in fo large a field, and among fuch an innumerable variety of fubjects, abundant room for many beads and hands to be employed in the work: For the wonderful and fecret operations of Nature are fo involved and intricate, fo far out of the reach of our fenfes, as they prefent themfelves to us in their natural order, that it is impoffible for the moft ragacious and penetrating genius to pry into them, unless be will be at the pains of analy/ing Nature, by a numerous and regular feries of Experiments; which are the only foild foundation whence we may reafonably expect to make any advance, in the real knowledge of the nature of things.

Imuft not omit bere publickly to acknowledge, that I have in Several respects been much ob. liged to my ingenious and learned neighbour. and friend Robert Mathers of the Middle Temple, Efq; for bis affiftance berein.

\section{$E R R A T A$.}

PAGE 30. for 3, read $\frac{3}{4}$. p. 32. 1. 6. r. harden, p. 46. 1. 9. r. Fig. 8. p. 48.1 1. 12. r. nocre grafied the. p. 62. 1. 6 r. myrtles. p. 74.1.26,27. 5. brancbes. p. 84. 1. I1. dele above. p. 111 . 1. 3. r. Experiment xxxviii. p. 145. 1. 6. r. disburked. ibid. 1. 13. r. plase. p. 176. 1. 18. r. nearly $\frac{1}{3}$ p. 247. 1. 22. r. Experiment cviii. p. 341. 1. 3. r. for bcny or. p. 344 ? I. 18. dele 8 . 


\section{T $\mathrm{H} \mathrm{E}$}

\section{CONTENTS.}

C H A P. I.

4 Xperiments, Jewing the quantities of L. moifture imbibed and perspired by Plants and Trees.

p. 4 .

\section{H A P. II.}

Experiments, whereby to find out the force with which Trees imbibe moifture. p. 76 .

\section{H A P. III.}

Experiments, Shewing the force of the Sap in the Vine in the bleeding reafon. p. 100.

\section{H A P. IV.}

Experiments, Shewing the ready lateral motion of the Sap, and conjequently, the lateral communication of the Sap.vefJels. The free paffage of it, from the fmall Branches towards 


\section{The CONTENTS.}

towards the Stem, as well as from the Stem to the Branches, with an account of fome Experiments, relating to the Circulation, or Non-Circulation of the Sap.

p. I21.

\section{H A P. V.}

Experiments, whereby to prove, that a confiderable quantity of air is infpired by Plants.

p. 148 .

\section{H A P. VI.}

$A$ Specimen of an attempt to analyfe the Air by chymio-ftatical Experiments, which foew, in bow great a proportion Air is wrought into the compofition of Animal, Vegetable and Mineral Subftances: And withal, how readily it refumes its elaftick State, when in the diffolution of thofe Subftances it is difingaged from them. p. Iss.

C H A P. VII.

of Vegetation.

P. $317 \%$

The Conclufion.

p. 358.

T H E 


\section{T H E}

\section{INT RODUCTION.}

7 HE farther refearches we make into this admirable fcene of things, the more beauty and harmony we fee in them: And the ftronger and clearer convictions they give us, of the being, power and wifdom of the divine Architect, who has made all things to concur with a wonderful conformity, in carrying on, by various and innumerable combinations of matter, fuch a circulation of caufes, and effects, as was neceffary to the great ends of nature.

And fince we are affured that the all wife Creator has obferved the moft exact proportions, of number, weight and meafure, in the make of all things; the moft likely way, therefore, to get any infight into the na. ture of thofe parts of the creation, which come within our obfervation, muft in all reafon be to number, weigh and meafure. And we have much encouragement to pur- 
fue this method, of fearching into the nature of things, from the great fuccefs that has attended any attempts of this kind.

Thus, in relation to thofe Planets which revolve about our Sun, the great Philofopher of our age has, by numbering and meafuring, difcovered the exact proportions that are obferved in their periodical revolutions and diftances from their common centers of motion and gravity: And that God has not only comprehended the duft of the earth in a meafure, and weighed the mountains in fiales, and the bills in a balance, Ifa. xl. 12. but that he alfo holds the vaft revolving Globes, of this our folar Synem, moft exactly poired on their common center of gravity.

And if we refrect upon the difcoveries that have been made in the animal oconomy, we fhall find that the mort confiderable and rational accounts of it have been chiefly owing to the ftatical examination of their fluids, viz. by enquiring what quantity of fluids, and folids difiolved into fluids, the animal daily takes in for its fupport and nourifhment: And with what force and different rapidities thofe fluids are carried 


\section{Vegetable Staticks.}

fied about in their proper channels, according to the different fecretions that are to be made from them: And in what proportion the recrementitious fluid is conveyed away, to make room for frefh fupplies; and what portion of this recrement nature allots to be carried off, by the feveral kinds of emunctories and excretory ducts.

And fince in vegetables, their growth and the prefervation of their vegetable life is promoted and maintained, as in animals, by the very plentiful and regular motion of their fluids, which are the vehicles ordained by nature, to carry proper nutriment to every part; it is therefore reafonable to hope, that in them alfo, by the fame method of inquiry, confiderable difcoveries may in time be made, there being, in many refpects, a great analogy between plants and animals. 


\section{H A P. I.}

Experiments, fherwing the quantities imbibed and perspired by Plants and Trees.

\section{EXPERIMENT I.}

TULY 3. 1724. in order to find out the $\int$ quantity imbibed and perfpired by the Sun-Flower, I took a garden-pot (Fig. I.) with a large Sun-Flower, $a, 3$ feet $+\frac{1}{2}$ high, which was purpofely planted in it when young.

I covered the pot with a plate of thin milled lead, and cemerted all the joints faft, fo as no vapor could pafs, but only air, thro a fmall glafs tube $d$ nine inches long, which was fixed purpofely near the ftem of the plant, to make a free communication with the outward air, and that under the leaden plate.

I cemented alfo another fhort glass tube $g$ into the plate, two inches long and one inch in diameter. Thro' this tube I watered the plant, and then fopped it up with a cork; I itopped up alfo the holes $i_{2} l$ at the bottom of the pot with corks.

I weighed 


\section{Vegetable Staticks.}

I weighed this pot and plant morning and evening, for fifteen feveral days, from Fuly 3. to Aug. 8. after which I cut off the plant clofe to the leaden plate, and then covered the ftump well with cement; and upon weighing found there perfpired thro' the unglazed porous pot two ounces every twelve hours day, which being allowed in the daily weighing of the plant and pot, I found the greateft perfpiration of twelve hours in a very warm dry day, to be one pound fourteen ounces; the middle rate of perfpiration one pound four ounces. The perfpiration of a dry warm night, without any fenfible dew, was about three ounces; but when any fenfible, tho' fimall dew, then the perfpiration was nothing; and when a large dew, or fome little rain in the night, the plant and pot was increafed in weight two or three ounces. N. B. The weights I made ufe of were Avoirdupoife weights.

I cut off all the leaves of this plant, and laid them in five feveral parcels, according to their feveral fizes, and then meafured the furface of a leaf of each parcel, by laying over it a large lattice made with threads, in which the little fquares were $\frac{T}{4}$ of an inch

$$
\text { B } 3 \text { each: }
$$


each; by numbering of which I had the furface of the leaves in fquare inches, which multiplied by the number of the leaves in the correfponding parcels, gave me the area of all the leaves; by which means I found the furface of the wholeplant, above ground, to be equal to s6I6 fquare inches, or 39 fquare fect.

I dug up another Sun-flower, nearly of the fame fize, which had eight main roots, reaching fifteen inches deep and fideways from the ftem : It had befides a very thick bufh of lateral roots, from the eight main roots, which extended every way in a Hemifphere, about nine inches from the ften and main roots.

In order to get an eftimate of the length of all the roots, I took one of the main roots, with its laterals, and meafured and weighed them, and then weighed the other feven roots, with thcir laterals, by which means I found the fum of the length of all the roots to be no lefs than 1448 feet.

And fuppofing the periphery of thefe roots at a medium, to be $\frac{x}{7} \frac{0}{6}$ of an inch, then their furface will be 2286 fquare inches, or I 5.8 fquate 


\section{Vegetable Staticks.}

fquare feet; that is, equal to $\frac{3}{8}$ of the furface of the plant above ground.

If, as above, twenty ounces of water, at a medium, perfpired in twelve hours day $(i, e$.$) thirty four cubick inches of water$ (a cubick inch of water weighing 254 grains) then the thirty four cubick inches divided by the furface of all the roots, is $=2286$ fquare inches; (i.e.) $\frac{34}{2 \frac{4}{2}} \frac{1}{6}$ is $=\frac{7}{6} 7$, this gives the depth of water imbibed by the whole furface of the roots viz. $\frac{x}{67}$ part of an inch.

And the furface of the plant above ground, being 5616 fquare inches, by which divid-

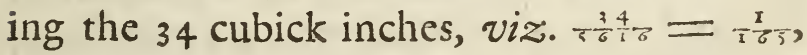
this gives the depth perfpired by the whole furface of the plant above ground, viz. $\frac{x}{1} \cdot \frac{5}{5}$ part of an inch.

Hence, the velocity with which water enters the furface of the roots to fupply the expence of perfiration, is to the velocity, with which the fap perfpires, as $165: 67$, or as $\frac{x}{67}: \frac{x}{56}$, or nearly as $5: 2$.

The area of the tranfverfe cut of the mid. dle of the ftem is a fquare inch; therefore the areas, on the furface of the leaves, the roots, and ftem, are 56I6, 2286. I.

The velocities, in the furface of the leaves,

$$
\text { B } 4
$$

roots, 
roots, and tranfverfe cut of the ftem, are gained by a reciprocal proportion of the furfaces.

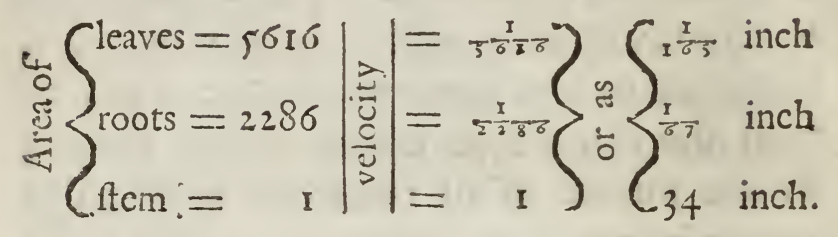

Now, their perfpiring 34 cubick inches in twelve hours day, there muft fo much pafs thro the ftem in that time; and the velocity would be at the rate of 34 inches in swclve hours, if the ftem were quite hollow.

In order therefore to find out the quantity of folid matter in the ftem, Fuly 27 th at 7. a. $m$. I cut up even with the ground a Sulifower; it weighed 3 pounds, in thirty days; it was very diry, and had wafted in all 2 pounds 4 ounces; that is $\frac{3}{4}$ of its whole weigat: So here is a fourth part left for folid parts in the ftem, (by throwing a piece of green Sun-flower ftem into water, I found it very near of the fame fpecifick gravity with water) which filling up fo much of the ftem, the velocity of the fap muft be increafed proportionably, viz. $\frac{\frac{\pi}{3}}{3}$ part more, (by 


\section{Vegetable Staticks.}

reafon of the reciprocal proportion) that 34 cubick inches may pafs the ftem in twelve hours; whence its velocity in the ftem will be $45 \frac{\pi}{3}$ inches in twelve hours, fuppofing there be no circulation nor return of the fap downwards.

If there be added to 34 , (which is the leaft velocity) $\frac{x}{3}$ of it $=I_{\frac{1}{3}}$, this gives the greateft velocity, viz. $45 \frac{1}{3}$. The fpaces being as 3 : 4. the velocities will be $4: 3:: 45 \frac{\pi}{3}: 34$.

But if we fuppofe the pores in the furface of the leaves to bear the fame proportion, as the area of the fap veffels in the ftem do to the area of the ftem; then the velocity, both in the leaves, root and ftem, will be increafed in the fame proportion.

A pretty exact account having been taken, of the weight, fize, and furface of this plant, and of the quantities it has imbibed and perfpired, it may not be improper here, to enter into a comparifon, of what is taken in and perfpired by a human body, and this plant.

The weight of a well fized man is I 60 pound: The weight of the Sunflower is three pounds, fo their weights are to each other as $560: 3$, or as $53:$ I. 
The furface of fuch human body is is fquare feet, or 2 I 60 fquare inches.

The furface of the Sun-flower is 5616 fquare inches, fo its furface is to the furface of a human body as 26 : 10.

The quantity perfpir'd by a man in twenty four hours is 3 I ounces, as Dr. Keill found, vide Medicina Statica Britannica, p. I4.

The quantity perfoired by the plant, in the fame time, is 22 ounces, allowing two ounces for the perpiration of the beginning, and ending of the night in $\mathcal{F} u l y$, viz. after even. ing and before morning weighing, juft before and after night.

So the perfirition of a man to the Sunflower is as I $4 \mathrm{I}: 100$.

Abating the fix ounces of the thirty one ounces, to be carried off by refpiration from the lungs in the twenty four hours; (which I have found by certain experiment to be fo much if not more) the twenty five ounces multiplied by $437+\frac{1}{2}$. the number of grains in an ounce Avoirdupois, the product is $10937^{\frac{1}{2}}$ grains; which divided by 254 , the number of grains in a cubick inch of water gives 43 cubick inches perfpired by a man: Which divided by the furface of his body, 


\section{Vegetable Staticks.}

vis. 2160 fquare inches, the quotient is $\frac{x}{5}$ - part of a cubick inch perfpired off a fquare inch in twenty four hours. Therefore in equal furfaces and equal times the man perfpires $\frac{x}{50}$, the plant $\frac{x}{1 \frac{5}{5}}$, or as $50:$ is .

Which excefs in the man is occafioned by the very different degrees of heat in each : For the heat of the plant cannot be greater than the heat of the circum-ambient air, which heat in fummer is from 25 to $3 s^{\prime}$ degrees above the freezing point, (vide Exp. 20.) but the heat of the warmeft external parts of a man's body is 54 fuch degrecs; and the heat of the blood 64 degrees; which is nearly equal to water heated to fuch a degree, as a man can well bear to hold his hand in, ftirring it about; which heat is fufficient to make a plentiful evaporation.

2u. Since then the perfpirations of equal areas, in a man and a Sunflower, are to each other as 165 : so. or as $3 \frac{x}{3}: I$; and fince the degrees of heat are as $2: I$, muft not the fum or quantity of the areas of the pores lying in equal furfaces, in the man and Sunflower, be as $16: I$ ? for it feems that the quantities of the evaporated fluid will be as the degrees of heat, and the fum of the areas of the pores taken together.

Dr。 


\section{I2 Vegetable Staticks.}

Dr. Keill, by eftimating the quantities of the feveral evacuations of his body, found that he eat and drank, every 24 hours, 4 pounds ro ounces.

The Sunflower imbibed and perfpired in the fame time twenty two ounces, fo the man's food, to that of the plant, is as 74 ounces to 22 ounces, or as $7: 2$.

But compared bulk for bulk, the plant imbibes feventeen times more freth food than the man: For deducting five ounces, which Dr. Keill allows for the faces alvi, there will remain fixty nine ounces of frefh liquor, which enters a man's vcins; and an equal quantity paffes off every 24 hours. Then it will be found, that feventeen times more new fluid enters the fap veffels of the plant, and pafies off in 24 hours, than there enters the veins of a man, and paffes off in the fame time.

And fince, compared bulk for bulk, the plant perfires feventeen times more than the man, it was therefore very neceffary, by giving it an extenfive furface, to make a large provifion for a plentiful perfpiration in the plant, which has no other way of difcharging fuperfluities; whereas there is provifion made 


\section{Vegetable Staticks.}

made in man, to carry off above half of what he takes in, by other evacuations.

For fince neither the furface of his body was extenfive enough to caufe fufficient exhalation, nor the additional wreak, arifing from the heat of his blood, could carry off above half the fluid, which was neceffary to be difcharged every twenty four hours; there was a neceflity of providing the kidneys, to percolate the other half thro'.

And whereas it is found, that feventeen times more enters, bulk for bulk, into the fap veffels of the plant, than into the veins of a man, and goes off in twenty four hours: One reafon of this greater plenty of frefh fluid, in the vegetable than the animal body, may be, becaufe the fluid which is filtrated thro' the roots immediately from the earth, is not near fo full fraighted with nutritive particles as the chyle which enters the lacteals of animals; which defect it was neceffary to rupply by the entrance of a much greater quantity of fluid.

And the motion of the fap is thereby much accelerated, which in the heartlefs vegetable would otherwire be very flow; it ha-

ving 
ving probably only a progreflive and not a circulating motion, as in animals.

Since then a plentiful perfpiration is found fo neceffary for the health of a plant or tree, 'tis probable that many of their diftempers are owing to a ftoppage of this perfpiration, by inclement air.

The perfpiration in men is often ftopped to a fatal degree; not only by the inclemency of the air, but by intemperance, and violent heats and colds. But the more temperate vegetable's perfpiration can be ftopped only by inclement air; unlefs by an unkindly foil, or want of genial moifture it is deprived of proper or fufficient nourifhment.

As Dr. Keill obferved in himfelf a confiderable latitude of degrees of healthy perfpiration, from a pound and half to 3 pounds; I have alfo obferved, a healthy latitude of perfpiration in this Sun-flower, from fixteen to twenty eight ounces in twelve hours day. The more it was watered, the more plentifully it peripired, (ceteris paribus) and with fcanty watering the perfpiration much abated.

EXPERIMENT II.

From Fuly 3d. to Aug. 3d. I weighed for 


\section{Vegetable Staticks.}

for nine feveral mornings and evenings a middle fized Cabbage plant, which grew in a garden pot, and was prepared with a leaden cover as the Sunflower, Exper. Iff. Its greateft perfpiration in 12 hours day was I pound 9 ounces; its middle perfpiration 1 pound 3 ounces, $=32$ cubick inches. Its furface 2736 fquare inches, or 19 fquare feet. Whence dividing the 32 cubick inches by 2736 fquare inches, it will be found that a little more than the $\frac{\pi}{86}$ of an inch depth perfpires off its furface in I 2 hours day.

The area of the middle of the Cabbage ftem is $\frac{\pi}{5} \frac{0}{5} 5$ of a fquare inch; hence the velocity of the fap in the ftem, is to the velocity of the perfpiring fap, on the furface of the leaves, as $2736: \frac{10}{8} \frac{0}{5}:: 4268: 1$. for $\frac{2736 \times 156}{100}=4268$. But if an allowance is to be made for the folid parts of the ftem, (by which the paffage is narrowed) the velocity will be proportionably increafed.

The length of all its roots $470 \mathrm{feet}$, their periphery at a medium $\frac{\pi}{2 \pi}$ of an inch, hence their area will be 256 fquare inches nearly; which being fo fmall, in proportion to the area of the leaves, the fap muft go with 


\section{I6 Vegetable Staticks.}

near eleven times the velocity thro' the fur? face of the roots, that it does thro' the furface of the leaves.

And fetting the roots at a medium at 12 inches long, they muft occupy a hemifphere of earth two feet diameter, that is $2.1 \mathrm{cll}-$ bick feet of earth.

By comparing the furfaces of the roots of plants, with the furface of the fame plant above ground, we fee the neceffity of cutting off many branches, from a tranfplanted tree : for if 256 fquare inches of root in furface was neceffary to maintain this Cabbage in a healthy natural ftate: fuppofe upon digging it up, in order to tranfplant, half the roots be cut off (which is the cafe of molt young tranfplanted trees) then it's plain, that but half the ufual nourifhment can be carried up, through the roots, on that account; and a very much lefs proportion on account of the fmall hemifphere of earth, the new planted thortened roots occupy; and on account of the loofe pofition of the new turned carth, which touches the roots at firft but in few points. This (as well as experience) ftrongly evinces the great necef: fity of well watering new plantations. 


\section{Vegetable Staticks.}

Which yet muft be done with caution, for the skilful and ingenious Mr. Philip Miller, Gardiner of the Botanick garden at Chelfea, in his very ufeful Gardiners and Florifts Dictionary, fays, "That he has often "feen trees, that have had too much water "given them after planting, which has rotted " all the young fibres, as faft as they have "been pufhed out; and fo many times has " killed the tree." Supplement Vol. II. of planting. And I obferved, that the dwarf pear-tree, whofe root was fet in water, in Exper. 7. decreafed very much daily in the quantity imbibed; viz. becaufe the fap veffels of the roots, like thofe of the cut off boughs, in the fame experiment, were fo faturated and clogged with moifture, by ftanding in water, that more of it could not be drawn up to fupport the leaves.

\section{EXPERIMENT III.}

From Fuly 28. to Aug. 25. I weighed for twelve feveral mornings and evenings, a thriving Vine growing in a pot; I was furnifhed, with this and other trees, from his Majefty's garden at Haimpton-court, by the 


\section{8 \\ Vegetable Staticks.}

favour of the eminent Mr. Wife. This vine was prepared with a cover, as the Sunflower was. Its greateft perfpiration in $\mathbf{I} 2$ hours day, was 6 ounces +240 grains; its middle perfpiration 5 ounces +240 grains $=$ to $9 \frac{T}{s}$ cubick inches.

The furface of its leaves was 1820 fquare inches, or 12 fquare feet +92 fquare inches; whence dividing $9 \frac{1}{2}$ cubick inches, by the area of the leaves, it is found that ro part of an inch depth, perfpires off in I 2 hours day.

The area of a tranfverfe cut of its ftem, was equal to $\div$ of a fquare inch : hence the fap's velocity here to its velocity on the furface of the leaves, will be as $1820 \times 4=$ $7280: I$. Then the real velocity of the fap's motion in the ftem is $=\frac{7289}{1 y 1}=38$ inches in twelve hours.

This is fuppofing the ftem to be a hollow tube: but by drying a large vine branch (in the chimney corner) which I cut off, in the bleeding feafon, I found the folid parts were ${ }_{4}^{3}$ of the ftem; hence the cavity thro' which the fap paffes, being fo much narrowed, its velocity will be 4 times as great, viz. I 22 inches in 52 hours. 


\section{Vegetable Staticks.}

But it is further to be confidered, that if the fap moves in the form of vapor and not of water, being thereby rarified, its velocity will be increafed in a direct proportion of the fpaces, which the fame quantity of water and vapor would occupy: And if the vapor is fuppofed to occupy Io times the fpace which it did, when in the form of water, then it mult move Io times fafter; fo that the fame quantity or weight of each may pafs in the fame time, thro: the fame bore or tube: 'And fuch allowance ought to be made in all thefe calculations concerning the motion of the fap in vegetables.

\section{EXPERIMENT IV.}

From Fuly 29. to Aug. 25. I weighed for 12 feveral mornings and evenings, a pao. radife ftock Apple-tree, which grew in a garden pot, covered with lead, as the Sunflower: it had not a buthy head full of leaves, but thin fpread, being in all but 163 leaves; whofe furface was equal to is 89 fquare inches, or I I fquare feet $+s$ fquare inches.

The greateft quantity it perfpired in I 2 C 2 hours 
hours day, was II ounces, its middle quantity 9 ounces, or $15 \frac{\pi}{2}$ cubick inches.

The I $5 \frac{1}{2}$ cubick inches perfpired, divided by the furface 1589 fquare inches, gives the depth perfpired off the furface in 12 hours day, viz. $\frac{\pi}{x^{\circ}}$ of an inch.

The area of a tranfverfecut of itsfem, $\frac{1}{4}$ of an inch fquare, whence the fap's velocity here, will be to its velocity on the furface of the leaves as I589 $54=6356: \mathrm{I}$.

\section{EXPERIMENT V.}

From July 28. to Aug. 25. I weighed for io feveral mornings and evenings a very thriving Limon-tree, which grew in a garden pot, and was covered as above: Its greateft perfpiration in I 2 hours day was 8 ounces, its middle perfpiration 6 ounces, cqual to I $\frac{x}{3}$ cubick inches. In the night it perfpired fometimes half an ounce, fometimes nothing, and fometimes increafed I or 2 ounces in weight, by large dew or rain.

The furface of its leaves was 2557 fquare inches, or 17 fquare feet +59 fquare inches; dividing then the $10 \frac{x}{2}$ cabick inches perfpired by this furface, gives the 


\section{Vegerable Staticks.}

depth perfpired in I 2 hours day, viz. $\frac{\mathrm{I}}{243}$ of an inch.

So the feveral foregoing perfpirations in equal areas are,

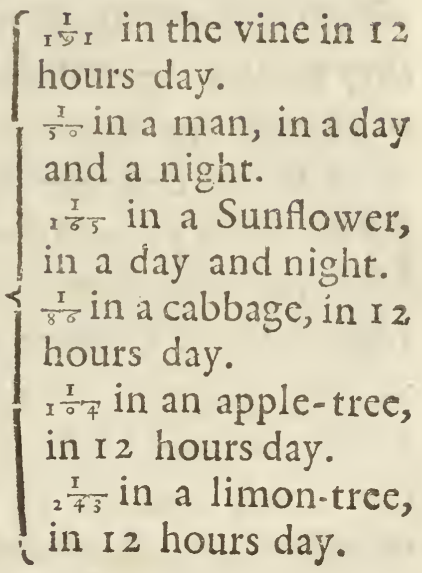

The area of the tranfverfe cut of the ftem of this Limon-tree was $=\mathrm{r} .44$ of a fquare inch; hence the fap's velocity here, will be to its velocity on the furface of the leaves, as 1768 : I for $\frac{2557 \times 100}{144}=17688^{\circ}$ This is fuppofing the whole ftem to be a hollow tube; but the velocity will be increafed both in the ftem and the leaves, in proportion as the paffage of the fap is narrowed by the folid parts.

By comparing the very different degrees of perfpiration, in thefe 5 plants and trees, 


\section{2 \\ Vegetable Staticks.}

we may obferve, that the limon-tree, which is an ever-green, perfpires much lefs than the Sunflower, or than the Vine or the Apple-tree, whofe leaves fall off in the winter; and as they perfpire lefs, fo are they the better able to furvive the winter's cold, beeaufe they want proportionably but a very fmall fup: ply of freth nourifhment to fupport them: Like the exangueous tribe of animals, frogs, toads, tortoifes, ferpents, infects, \& c. which as they perfire little; fo do they live the whole winter without food. And this I find holds true in I other different forts of ever-greens, on which I have made Experiments.

The above mentioned Mr. Miller made the like experiments in the Botanick-garden at Chelfea, on a plantain-tree, an aloe, and a paradife apple-tree; which he weighed morning, noon, and night, for feveral fucceflive days. I thall here infert the diaries of them, as he communicated them to me, that the influence of the different temperatures of the air, on the perfpiration of thefe plants, may the better be feen.

The pots which be made ufe of were glazed, and had no holes in their bottoms, as garden 


\section{Vegetable Staticks.}

garden pots ufually have; fo that all the moifture, which was wanting in them upon weighing, muft neceffarily be imbibed, by the roots of thofe plants, and thence per. fpired off thro' their leaves.

$A$ diary of the perfpiration of the Mura Ar: bor, or Plantain-tree of the Went-Indies. The whole furface of the plant was 14 square feet, $8+\frac{1}{2}$ inches. The different degrees of beat of the air, are bere noted by the degrees above the freezing point in my Thermom. defcrib'd in Exp. 20.

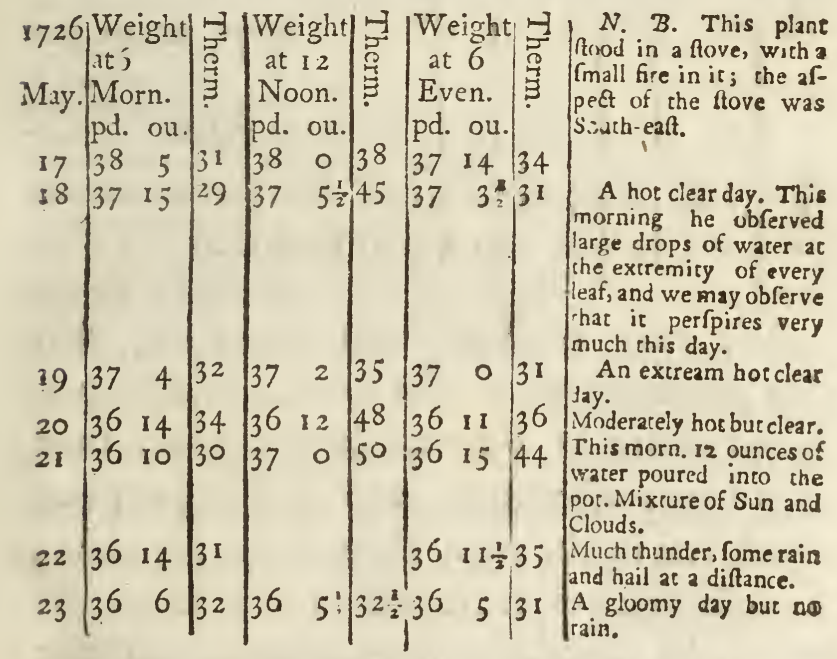

This evening 12 ounces of water were poured into the pot; and it was removed from the ftove into a cool room, where it had a free air but no Sun, the windows being North-waft. 
24 Vegetable Staticks.

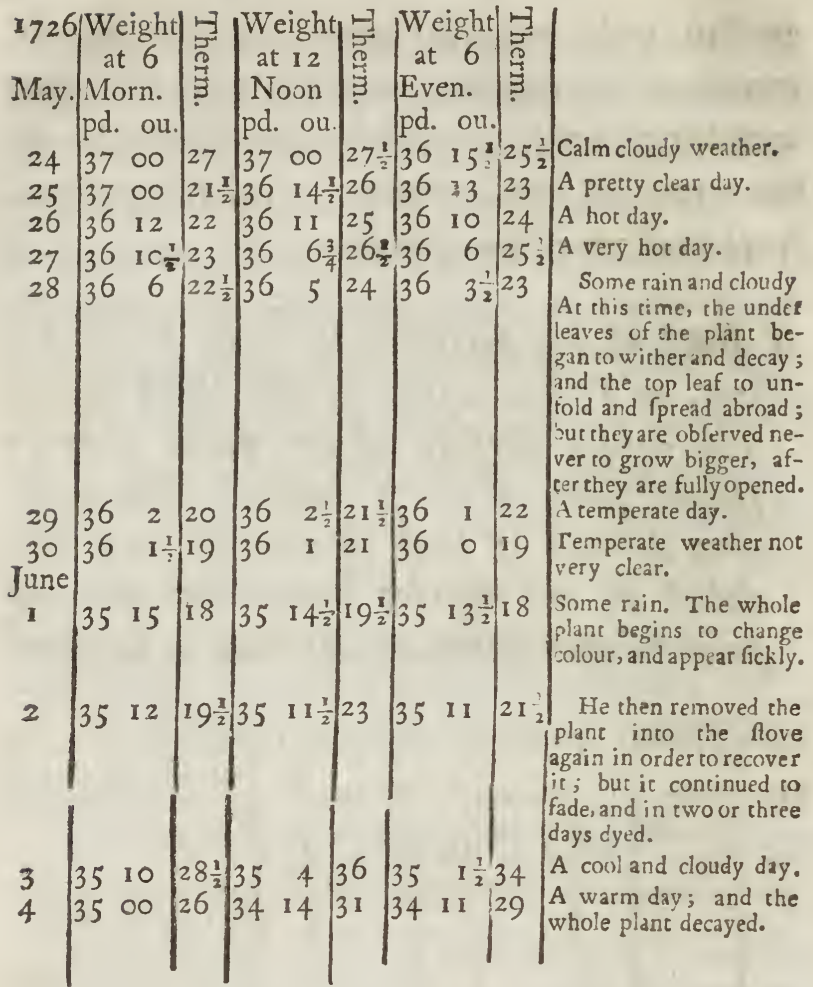

We may obferve from this diary, that this plant, when in the ftove, ufually perfpired more in $\sigma$ hours before noon than in 6 hours afternoon; and that it perfpired much lefs in the night than in the day time: And fometimes increafed in weight in the night, by imbibing the moifture of the ambient air; and that both in the ftove and 
in the cool room. Upon making an crimate, of the quantity perfpired off a fquare inch of this plant, in $\mathrm{I} 2$ hours day, it comes but to $\frac{r}{1+2}$ of a cubick inch; on the I 8 th day of May, when by far its greateft perfpiration was; for on feveral other days it was much lefs.

\section{$A$ diary of the Aloc Africana Caulefcens} foliis Jpinofis, maculis ab utraque parte Al. bicantibus notatis, Conmelini hort. Amft. commonly called the Carolina Aloe. It was a large plant of its kind. It ftood in a glass-cafe, which bad a South afpeit without a fire.

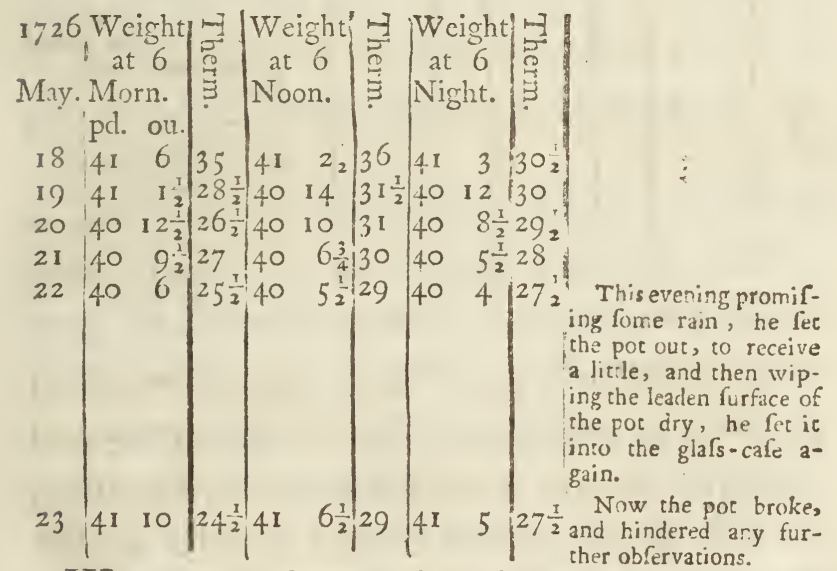

We may obferve, that this Aloe increafed in weight molt nights, and perfpired moft in the morning. 
A diary of a frall Paradife. Apple, with one upright ftem 4 feet high; and two Jmall lateral branches about 8 inches long. This plant flood under a cover of wood which was open on all fides.

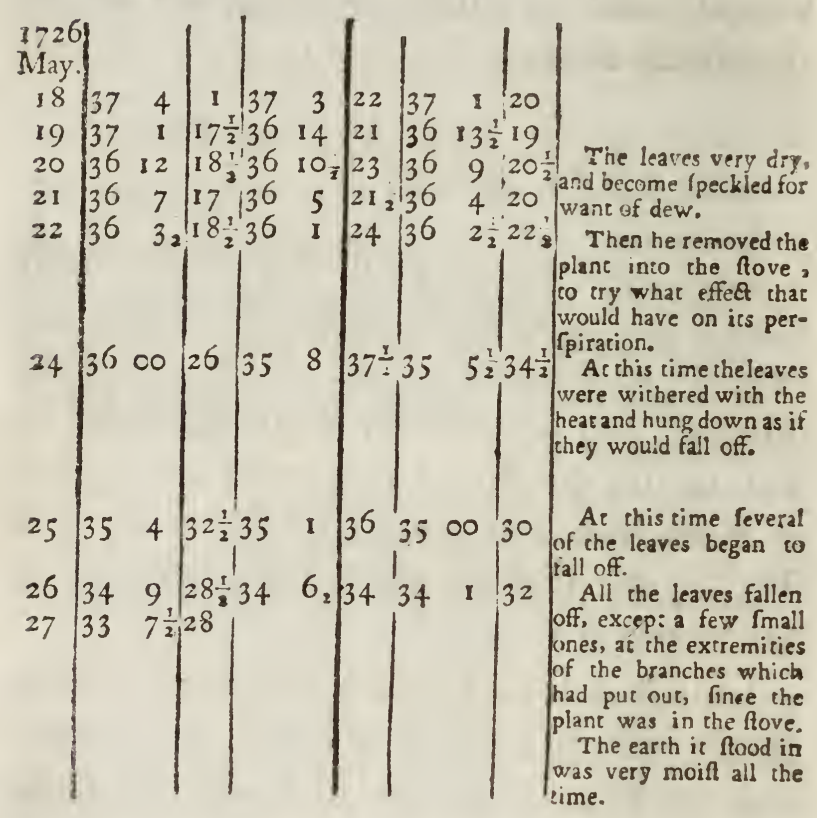

In Oitober 1725. Mr. Miller took up an African Briony-root, which when cleared from the mould weighed 8 pound $\frac{2}{2}$ ounce; he laid it on a thelf in the ftove, where it remained till the March following; when upon weighing he found it had loft of its 


\section{Vegetable Staticks.}

weight. In April it thot aus 4 branches, two of which were $3 \frac{1}{2}$ feet long, the other two were one of them 14 inches, the other 9 inches, in length: Thefe all produced fair large leaves, it had loft $I_{+}^{3}$ ounce in weight, and in three weeks more it loft $2 \frac{1}{4}$ ounces more, and was much withered.

\section{EXPERIMENT VI.}

Spear-mint being a plant that thrives moft kindly in water, (in order the more accurately to obferve what water it would imbibe, and perfpire by night and day, in wet or dry weather) I cemented at $r$ a plant of it $m$, into the inverted fyphon $r y x b$ (Fig. 2.) the fyphon was $\frac{1}{4}$ inch diam. at $b$, but larger at $r$.

I filled it full of water, the plant imbib. ed the water fo as to make it fall in the day, (in March) near an inch and half from $b$ to $t$, and in the night $\frac{1}{4}$ inch from $t$ to $i$ : but one night, when it was fo cold, as to make the Thermometer link to the freezing point, then the mint imbibed nothing, but hung down its head; as did alfo the young beans in the garden, their fap being great- 


\section{$28 \quad$ Vegetable Staticks.}

iy condenfed by cold. In a rainy day the mint imbibed very little.

I purfued this Experiment no farther, Dr. Woodward having long fince, from feveral curious experiments and obfervations, given an account in the Philofophical Tranfactions, of the plentiful perfpirations of this plant.

\section{EXPERIMENT VII.}

In Auguft, I dug up a large dwarf Peartree, which weighed $7 \mathrm{I}$ pounds 8 ounces; I fet its root in a known quantity of water; it imbibed Is pounds of water in 10 hours day, and perfpired at the fame time Is pounds 8 ounces.

In Fuly and Auguft, I cut off reveral branches of Apple-trees, Pear, Cherry, and Apricock-trees, two of a fort; they were of feveral fizes from 3 to 6 feet long, with proportional lateral branches; and the tranfverfe cut of the largeft part of their ftems was 2bout an inch diameter.

I ftripped the leaves off of onc bough of each fort, and then fet their ftems in feparate glaffes, pouring in known quantities of watcr. 


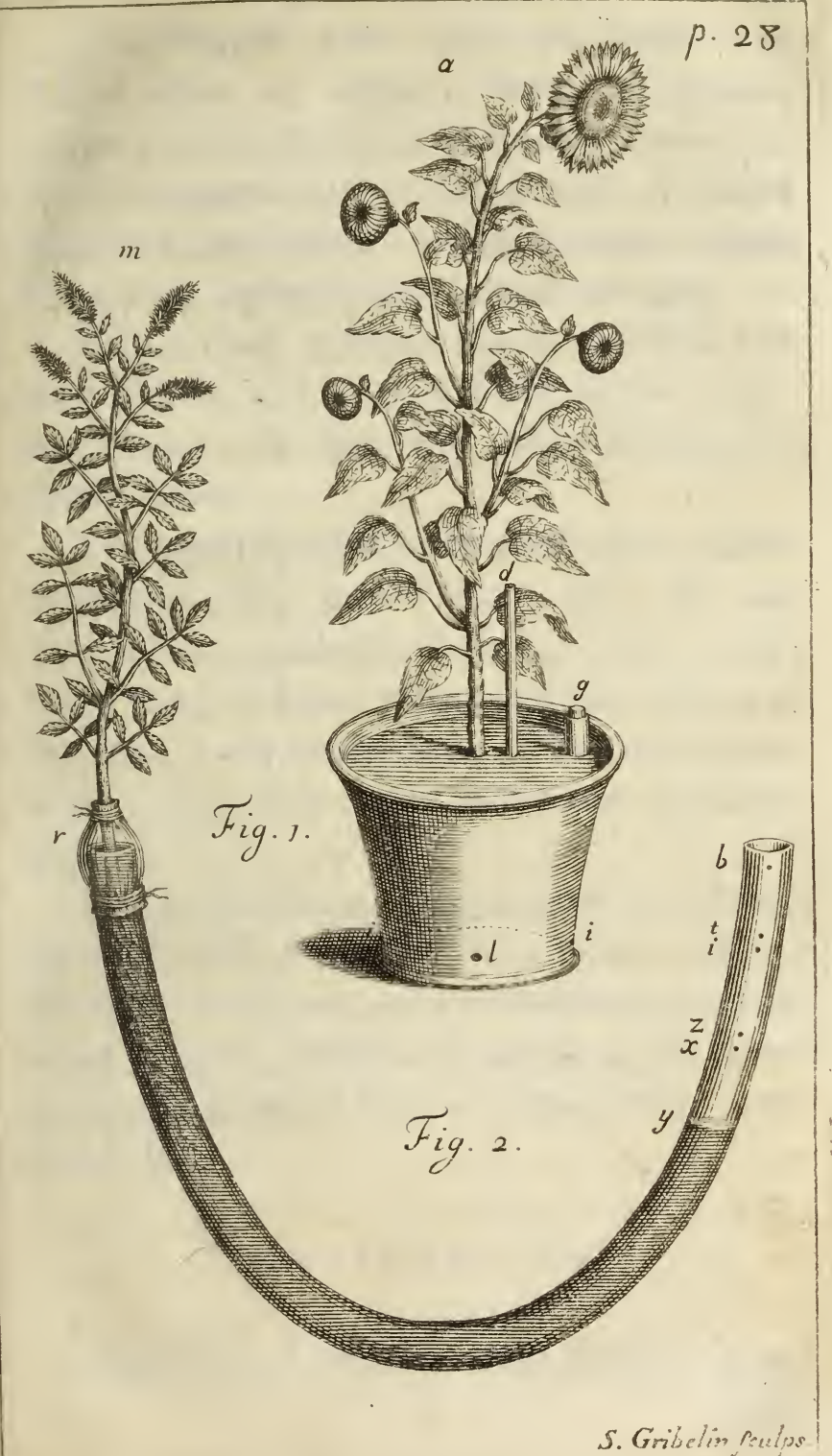




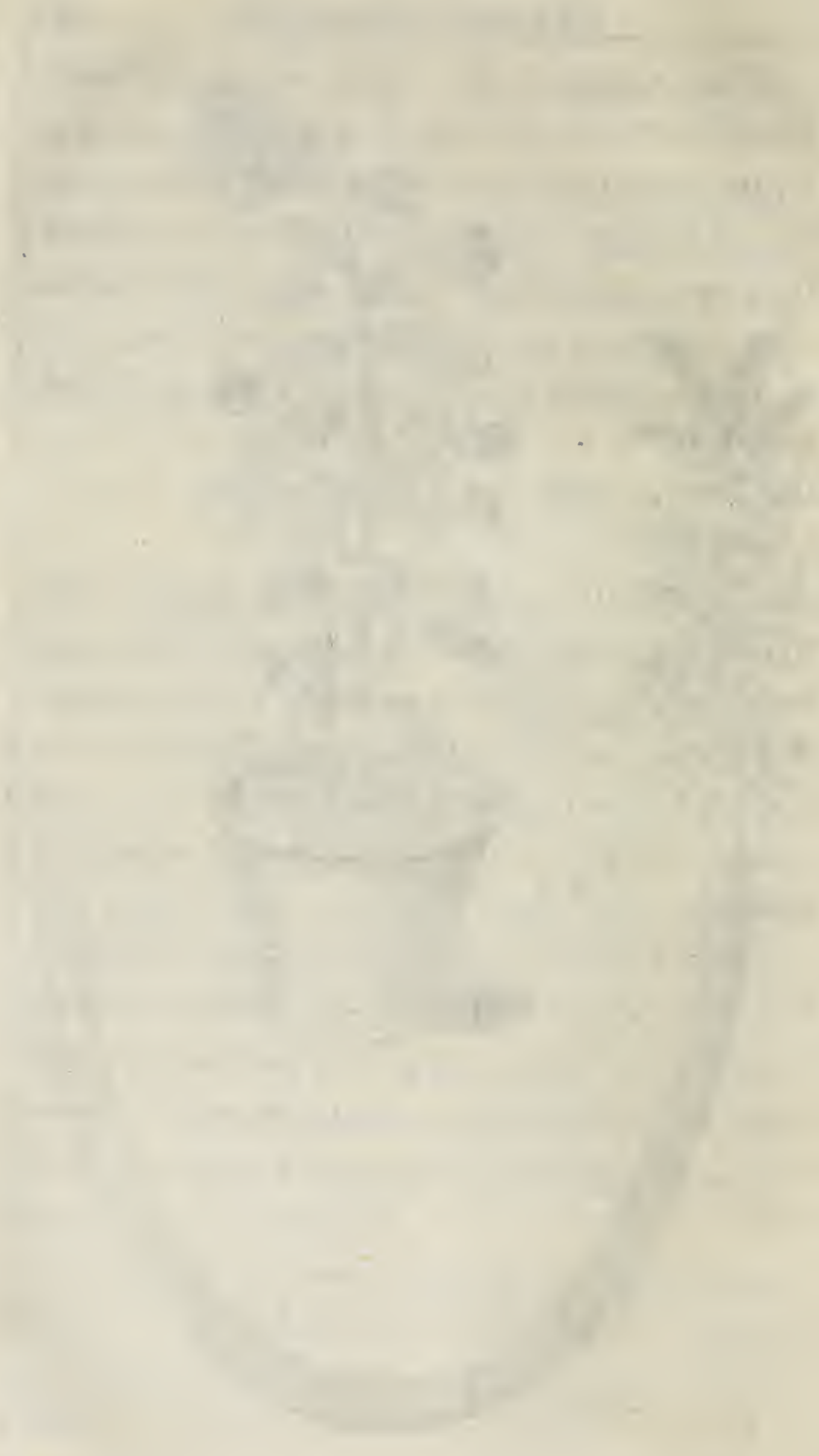




\section{Vegetable Staticks.}

The boughs with leaves on them imbibed fome is ounces, fome 20 ounces, 25 or 30 ounces in 12 hours day, more or lefs in proportion to the quantity of leaves they had; and when I weighed them at night they were lighter than in the morning.

While thofe without leaves imbibed but one ounce, and were heavier in the evening than in the morning, they having perfpired little.

The quantity imbibed by thore with leaves decreafed very much every day, the fap veffels being probably hrunk, at the tranfverfe cut, and too much faturate with water, to let any more pafs; fo that ufually in 4 or 5 days the leaves faded and withered much.

I repeated the fame experiment with Elmbranches, Oak, Ofier, Willow, Sallow, Afpen, Curran, Goosberry, and Philbud branches; but none of thefe imbibed fo much as the foregoing, and feveral forts of ever-greens very much lels.

EXPERIMENT VIII。

Aluguft I s. I cut off a large Ruflet-pippin, with 
with two inches ftem, and its 12 adjoining leaves; I fet the ftem in a little viol of water it imbibed and perfipired in three days $\frac{4}{3}$ of an ounce.

At the fame time I cut off from the fame tree another bearing twig of the fame length, with $\mathrm{I} 2$ leaves on it, but no apple; it imbibed in the fame three days near $\frac{3}{4}$ of an ounce.

About the fame time I fet in a viol of water a hort ftem of the fame tree, with two large apples on it without leaves; they imbibed near $\frac{3}{4}$ ounce in two days.

So in this Experiment, the apple and the leaves imbibe $\frac{4}{5}$ ounce; the leaves alone near 3 , but the two large apples imbibed and perfpired but $\frac{3}{3}$ part fo much as the I 2 leaves; then one apple imbibed the $\frac{3}{6}$ part of what was imbibed by the 12 leaves, therefore two leaves imbibe and perfpire as much as one apple; whence their perfpirations feem to be proportionable to their furfaces; the furface of the apple being nearly equal to the fum of the upper and under furfaces of the two leaves.

Whence it is probable, that the ure of thefe leavcs, (which are placed, juft where the 


\section{Vegetable Staticks.}

the fruit joins to the tree) is to bring nou? rifhment to the fruit. And accordingly I obferve that the leaves, next adjoining to bloffoms, are, in the fpring, very much expanded, when the other leaves, on barren fhoots, are but beginning to thoot: And that all peach leaves are pretty large before the bloffom goes off: And that in apples and pears the leaves are one third or half grown, before the bloffom blows : So provident is nature in making timely provifion for the nourifhing the yet embrio fruit.

\section{EXPERIMENT IX.}

Fuly I s. I cut off two thriving Hop-vines near the ground, in a thick fhady part of the garden, the pole ftill ftanding; I ftriped the leaves off one of thefe vines, and fet both their ftems, in known quantities of water, in little bottles; that with leaves imbibed in I 2 hours day 4 ounces, and that without leaves $\frac{3}{4}$ ounce.

I took another hop pole with its vines on it, and carried it out of the hop ground, into a free open expofure; thefe imbibed and perfipired as much more as the former 


\section{Vegetable Staticks.}

in the hop-ground: Which is doubtlefs the reafon why the hop-vines on the outfides of gardens, where moft expored to the air, are thort and poor, in comparifon of thofe in the middle of the ground; viz. becaufe being much dried, their fibres hardens fooner, and therefore they cannot grow fo kindly as thofe in the middle of the ground; which by thade are always kept moifter, and more ductile.

Now there being 1000 hills in an acre of hop ground, and cach hill having three poles, and each pole three vines, the number of vines will be 9000 ; each of which imbibing 4 ounces, the fum of all the ounces, imbibed in an acre in $\mathrm{I} 2$ hours day, will be 36000 ounces, $=$ I 5750000 grains $=$ 62007 cubick inches or 220 gallons; which divided by 6272640 , the number of fquare inches in an acre, it will be found, that the quantity of liquor perfpired by all the hopvines, will be equal to an area of liquor, as broad as an acre, and $\frac{\mathrm{r}}{\mathrm{r} O \mathrm{~T}}$ part of an inch deep, befides what cvaporated from the earth.

And this quantity of moifure in a kindly ftate of the air is daily carried off, in 


\section{Vegetable Staticks.}

a fufficient quantity, to keep the hops in a healthy ftate; but in a rainy moift ftate of air, without a due mixture of dry weather, too much moifture hovers about the hops, fo as to hinder in a good meafure the kindly perfpiration of the leaves, whereby the ftagnating fap corrupts, and breeds moldy fen, which often fpoils valt quantities of flourifhing hop-grounds. This was the cafe in the year 1723 , when 10 or 14 days almoft continual rains fell, about the latter

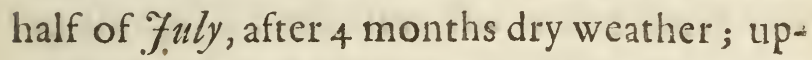
on which the moft flourifhing and promifing hops were all infected with mold or fen, in their leaves and fruit, while the then poor and unpromifing hops efcaped, and pro. duced plenty; becaure they being fmall, did not perfpire fo great a quantity as the others; nor did they confine the perfpired vapor, fo much as the large thriving vines did, in their Thady thickets.

This rain on the then warm earth made the grafs fhoot out, as faft as if it were in a hot bed; and the apples grew fo precipitately, that they were of a very flainy conftitution, fo as to rot more remarkably than had ever been remembred. 
The planters obferve, that when a mold or fen has once feized any part of the ground, it foon runs over the whole; and that the grafs and other herbs, under the hops, are infected with it.

Probably becaufe the fmall feeds of this quick growing mold, which foon come to maturity, are blown over the whole ground: Which fpreading of the feed may be the reafon why fome grounds are infected with fen for feveral years fucceflively; viz. from the feeds of the laft years fen: Might it not then be advifeable to burn the fenny hopvines as foon as the hops are picked, in hopes thereby to deftroy fome of the feed of the mold?

"Mr. Auftin of Canterbury obferves fen " to be more fatal to thofe grounds that " are low and fheltered, than to the high " and open grounds; to thofe that are thel"ving to the North, than to the fhelving " to the South; to the middle of grounds, "than to the outfides; to the dry and "gentle grounds, than to the moift and ftiff " grounds. This was very apparent through" out the Plantations, where the land had " the fame workmanfhip, and help beftow- 


\section{Vegetable Staticks.}

"ed upon it, and was wrought at the fame " time; but if in either of thefe cafes there " was a difference, it had a different effect; " and the low and gentle grounds, that lay " neglected, were then feen lefs diftemper" ed, than the open and moift, that were " carefully managed and looked after. "The honey dews are obferved to come " about the I I of Fune, which by the middle " of Fuly turn the leaves black, and make " them ftink.

I have in $\mathcal{F}$ uly (the feafon for fire blafts, as the planters call them) feen the vines in the middle of a hop-ground all fcorched up almoft from one end of a large ground to the other, when a hot gleam of Sunfhine has come immediately after a thower of rain; at which time the vapors are often feen with the naked eye, but efpecially with reflecting Telefcopes, to afcend fo plentifully, as to make a clear and diftinet. object become immediately very dim and tremulous. Nor was there any dry gravelly vein in the ground, along the courfe of this fcorch. It was therefore probably ow. ing to the much greater quantity of fcorch. ing vapors, in the middle than outfides of 


\section{Vegetable Staticks.}

the ground, and that being a denfer medium, it was much hotter than a more rare medium.

And perhaps, the great volume of afcending vapor might make the Sun-beams converge a little toward the middle of the ground, that being a denfer medium, and thereby increafe the heat confiderably; for I obferved, that the courfe of the fcorched hops was in a line at right angles, to the Sunbeams about a II a clock, at which time the hot gleam was: The hop-ground was in a valley which run from South-weft to North-eaft: And to the beft of my remembrance, there was then but little wind, and that in the courfe of the fcorch; but had there been fome other gentle wind, either North or South, 'tis not improbable but that the North wind gently blowing the Volume of rifing wreak on the South-fide of the ground, that fide might have been molt fcorched, and fo vice verfa.

As to particular fire-blafts, which fcorch here and there a few hop-vines, or one or two branches of a tree, without damaging the next adjoining; what Aftronomers obferve, may hint to us a no very improbable

caufe 


\section{Vegetable Staticks.}

caufe of it; viz. They frequently obferve (efpecially with the reflecting Telefcopes) fmall feparate portions of pellucid vapors floating in the air; which tho' not vifible to the naked cye, are yet confiderably denfer than the circumambient air: And vapors of fuch a degree of denfity may very probably, either acquire fuch a fcalding heat from the Sun, as will feorch what plants they rouch, efpecially the more tender: An effect, which the gardiners about London have too often found to their cont, when they have incautioufly put bell.glaffes over their Collyflowers, early in a frofty morning, before the dew was evaporated off them; which dew being raifed by the Sun's warmth, and confined within the glafs, did there form a denfe tranfparent fcalding vapor, which burnt and killed the plants. Or perhaps, the upper or lower furface of thefe tranfparent feparate fiying volumes of vapors may, among the many forms they revolve into, fomctimes approach fo near to a hemifphere, or hemicylinder, as thereby to make the Sun-beams converge enough, often to feorch the more tender plants they fhall fall on: And fometimes alfo, parts of the more hardy plants 
38 Vegetable Staticks.

and trees, in proportion to the greater or lefs convergency of the Sun's rays.

The learned Boerbaave, in his Theory of Chemiftry, p. 245. obferves, "That thofe " white clouds which appear in fummer" time, are as it were fo many mirrours, " and occafion exceffive heat. There cloudy " mirrours are fometimes round, fome" times concave, polygonous, \& $c$. when " the face of heaven is covered with fuch "white clouds, the Sun fhining among " them, muft of neceflity produce a vehe" ment heat; fince many of his rays, which "would otherwife, perhaps, never touch " our earth, are hereby reflected to us; thus " if the Sun be on one fide, and the clouds " on the oppofite one, they will be per"feet burning glaffes. And hence the phx" nomena of thunder.

"I have fometimes (continues he) ob" ferved a kind of hollow clouds, full of " hail and fnow, during the continuance " of which the heat was extreme; fince by " fuch condenlation they were enabled to " refled much more ftrongly. After this " came a tharp cold, and then the clouds " difcharged their hail in great quantity; 


\section{Vegetable Staticks.}

" to which fucceeded a moderate warnth. "Frozen concave clouds therefore, by their " great reflections, produce a vigorous heat, " and the fame when refolved exceffive " cold.

Whence we fee that blafts may be occafioned by the reflections of the clouds, as well as by the above mentioned refraction of denfe tranfparent vapors.

Fuly 2 r. I obferved that at that feafon the top of the Sunflower being tender, and the flower near beginning to blow, that if the Sun rife clear the flower faces towards the Eaft, and the Sun continuing to thine, at noon, it faces to the South, and at 6 in the evening to the Weft: And this not by turning round with the Sun, but by nutation; the caufe of which is, that the fide of the ftem next the Sun perfpiring moft, it fhrinks, and this plant perfpires much.

I have obferved the fame in the tops of Ferufalem-artichokes and of garden-beans in very hot Sun-thine.

\section{EXPERIMENTX.}

Fuly 27. I fixed an Apple-branch m, 3 D 4 feet 


\section{0 \\ Vegetable Staiicks:}

fect long $\frac{2}{2}$ inch diametcr, full of leaves, and lateral fhoots to the tube $t, 7$ feet long $\frac{5}{8}$ diameter. (Fig. 3.) I filled the tube with water, and then immerfed the whole branch as far as over the lower end of the tube, into the veffel $u u$ full of water.

The water fubfided 6 inches the firft two hours (being the firft filling of the fap veffels) and 6 inches the following night, 4 inches the next day; and $2-1-\frac{1}{2}$ the following night.

The third day in the morning I took the branch out of the water; and hung it with the Tube affixed to it in the open air; it imbibed this day $27+\frac{1}{2}$ inches in 12 hours.

This Experiment thews the great power of perfpiration; fince when the branch was immerfed in the veffel of water, the 7 feet column of water in the tube, above the furface of the water, could drive very little thro' the leaves, till the branch was expofed to the open air.

This alfo proves, that the perfpiring matter of trees is rather actuated by warmth, and fo exhaled, than protruded by the force of the fap upwards. 


\section{Vegetable Staticks.}

And this holds true in animals, for the perfiration in them is not always greateft in the greateft force of the blood; but then often leaft of all, as in fevers.

I have fixed many other branches in the fame manner to long tubes, without im. merfing them in water; which tubes, being filled with water, I could fee precifely, by the defcent of the water in the tube $t$, how faft it perfpired off; and how very little perfpired in a rainy day, or when there were no leaves on the branches.

EXPERIMENT XI.

Aug. 17. At is $a: m$, I cemented to the tube $a b$ (Fig. 4.) 9 feet long, and $\frac{x}{2}$ inch diameter an Apple-branch $d s$ feet long $\frac{6}{\delta}$ inch diameter; I poured water into the tubc, which it imbibed plentifully, at the rate of 3 feet length of the tube in an hour. At I a clock I cut off the brarich at $c, I_{3}$ inches below the glafs tube. To the bottom of the remaining ftem I tyed a glafs ciftern $z$, covered with ox-gut, to kecp any of the water which droped from the ftem $c b$ from evaporating. At the fame time I fet the branch 
branch $d r$ which I had cut off in a known quantity of water, in the veffel $x$, (Fig. 5.) the branch in the veffel $x$ imbibed 18 ounces of water, in 18 hours day and 12 hours night; in which time only 6 ounces of water had paffed thro' the ftem $c \quad b$ (Fig. 4.) which had a column of water 7 feet high, preffing upon it all the time.

This again thews the great power of perfpiration; to draw three times more water, in the fame time, thro' the long flender parts of the branch $r$ (Fig. 5.) than was preffed thro' a larger ftem $c b$ (Fig. 4.) of the fame branch; but 13 inches long with 7 feet preffure of water upon it, in the tube $a b$.

I tryed in the fame manner another apple-branch, which in 8 hours day imbibed 20 ounces, while only 8 ounces paffed thro' the ftem $c b$, (Fig. 4.) which had the column of water on it.

The fame I tried with a quince branch, which in 4 hours day imbibed 2 ounces + $\frac{x}{3}$, while but $\frac{x}{3}$ ounce paffed thro' the ftem $c b$ (Fig. 4.) which had 9 feet weight of water preffing on it.

Note, All thefe (under this Experiment II.) were made the firft day, before the ftem 


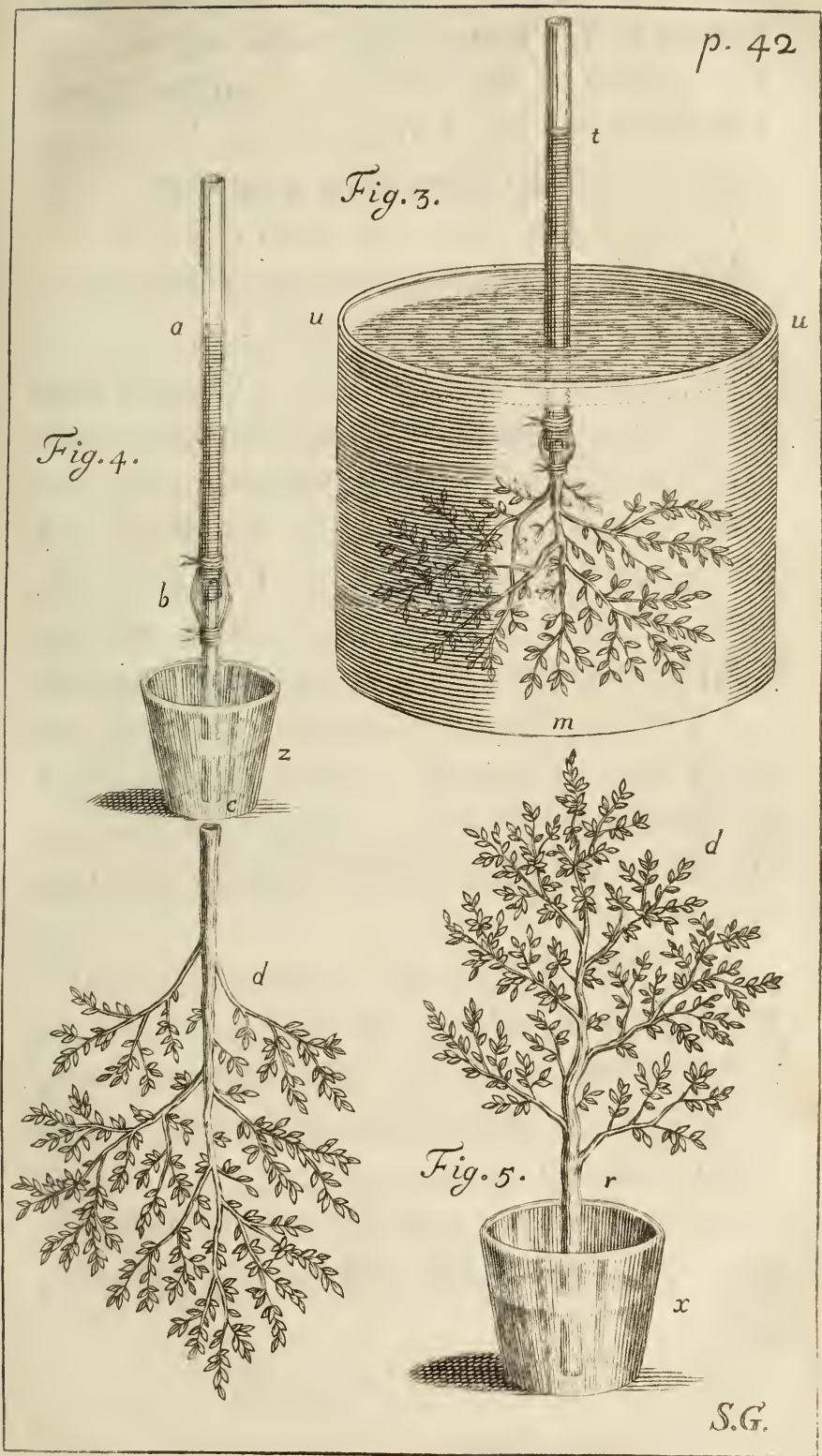



ftem could be any thing faturate with water, or the fap-veffels thrunk fo as to hinder its paffage.

\section{EXPERIMENT XII.}

I cut off from a dwarf Apple-tree e w the top of the branch $l$, (Fig. 6.) which was an inch diameter, and fixed to the ftem $l$, the glars-tube $l b$ : then I poured water into the tube, which the branch would imbibe, fo as to drink down 2 or 3 pints in a day, efpecially if I fucked with my mouth at the top of the tube $b$, fo as that a few air bubbles were drawn out of the ftem $l$; then the water was imbibed fo faft, that if I immediately ferewed on the mercurial gage, $m r y z$, the mercury would be drawn up to $r, 12$ inches higher than in the other leg.

At another time I pcured into the tube $l$, fixed to a golden Renate-tree, a quart of high rectified fpirit of wine, camphorated, which quantity the ftem imbibed in 3 hours space; this killed one half of the tree : this I did to try if I could give a flavour of camphire to the apples which were in great plenty 


\section{Vegetable Staticks.}

plenty on the branch. I could not perceive any alteration in the tafte of the apples, tho' they hung feveral weeks after; but the fmell of the camphire was very ftrong in the ftalks of the leaves, and in every part of the dead branch.

I made the fame experiment on a vine, with frongly feented orange-flower-water; the event was the fame, it did not penetrate into the grapes, but very fenfibly into the wood and ftalks of the leaves.

I repeated the fame experiment on two diftant branches of a large Catharine peartree, with ftrong decoctions of faffafras, and of elder flowers, about 30 days before the pears were ripe; but I could not perceive any tafte of the decoctions in the pears.

Tho' in all there cafes the fap-veffels of the ftem were ftrongly impregnated with a good quantity of thefe liquors; yet the capillary fap-veffels near the fruit were fo fine, that they changed the texture of, and aflimilated to their own fubftance thofe high tafted and perfumed liquors; in the fame manner as graffs and buds change the very different fap of the ftock to that of their own Specifick nature. 


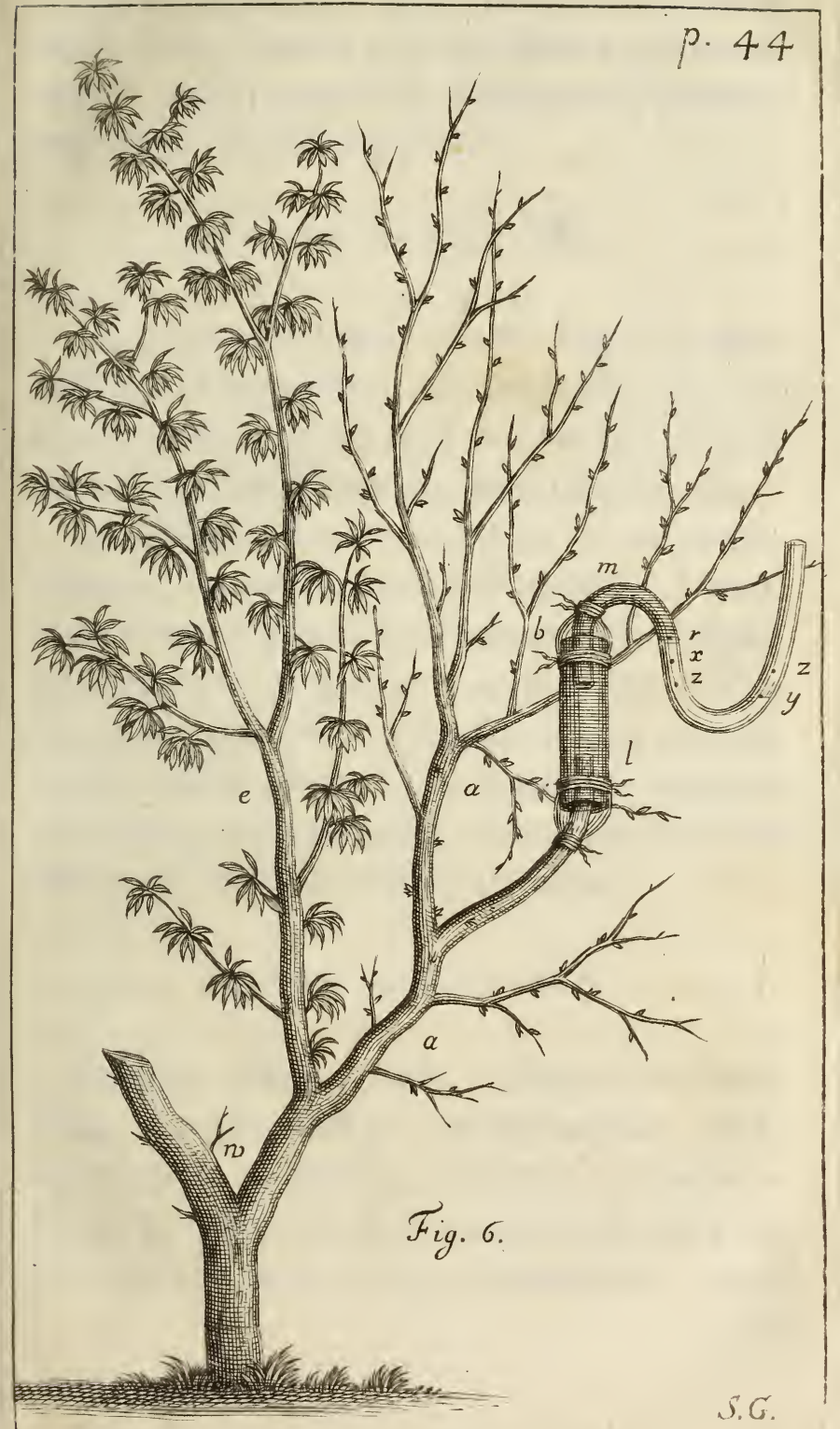




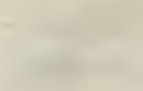

$\sim$

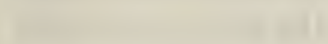




\section{Vegetable Staticks.}

This experiment may fafely be repeated with well fcented and perfumed common water, which trees will imbibe at $l /$ without any danger of killing them.

\section{EXPERIMENT XIII.}

In order to try whether the capillary fapveffels had any power to protrude fap out at their extremities, and in what quantity, I made the three following experiments, viz.

In Auguft I took a cylinder of an applebranch, I 2 inches long $\frac{7}{8}$ diameter: I fet it with its great end downwards in a mint glals, (full of water) tyed over with ox-gut. The top of the ftick was moint for Io days, while another ftick of the fame branch (but out of water ) was very dry. It evaporated an ounce of water in thofe ro days.

\section{EXPERIMENT XIV.}

In Sept. I fix'd a tube $t$ (Fig. 7.) 7 feet long, to a like ftem $\int$, as the former, and fet the ftem in water $x$, to try if" "as the water evaporated out of the top of the ftem $r$, it would rife to any height in the tube $t$; but 


\section{Vegetable Staticks.}

it did not rife at all in the tube, tho the top of the ftem was wet: I then filled the tube with water, but it paffed freely into the veffel $x$.

\section{EXPERIMENT XV.}

Sept. 10. $2 t_{2}^{x}$ feet from the ground, I cut off the top of a half ftandardDuke Cherrytree againft a wall, and cemented on it the neck of a Florence flask $f$, (Fig. 3.) and to that flask neck a narrow tube $g$, $s$ feet long, in order to catch any moifture that thould arife out of the trunk $y$; but none arofe in 4 hours, except a little vapor that was on the flask's neck.

I then dug up the tree by the roots, and fet the root in water, with the glaffes affixed to the top of the ftem; after feveral hours nothing rofe but a little dew, which hung on the infide of $f$; yet it is certain by many of the foregoing experiments, that if the top and leaves of this tree had been on; many ounces of water would in this time have paffed thro' the trunk, and been eva. porated thro' the leaves. 


\section{Vegetable Staticks.}

I have tryed the fame experiment with feveral vine branches cut off, and fet in water thus, but no water rofe into $f$.

Thefe three laft experiments all fhew, that tho' the capillary fap veffels imbibe moifture plentifully; yet they have little power to protrude it fatther, without the affiftance of the perfpiring leaves, which do greatly promote its progrefs.

\section{EXPERIMENT XVI.}

In order to try whether any fap rofe in the winter, I took in Fanuary feveral parcels of Filberd-fuckers, Vine-branches, green Jeffamine-branches, Philarea and Laurel-branches, with their leaves on them, and dipped their tranfverfe cuts in melted cement, to prevent any moifture's evaporating thro' the wounds; I tyed them in feparate bundles and weighed them.

The Philberd-fuckers decrealed in 8 days (fome part of which were very wer, but the laft 3 or 4 days drying winds) the I Ith part of their whole weight.

The vine-cuttings in the fame time the 24 part. 
The Jeflamine in the fame time the $\frac{x}{6}$ part The Philarea decreafed the $\frac{1}{4}$ part in $s$ days.

The L aurel the $\frac{1}{4}$ part in 5 days, and more.

Here is a confiderable daily wafte of fap, which mut therefore neceffarily be fupplied from the root; whence it is plain that fome fap rifes all the winter, to fupply this continual wafte, tho' in much lefs quantity than in fummer.

Hence we fee good reafon why the Ilex, (and the Cedar of Libanus, which were the firft on an Englifi-oak, the other on the Larix) were verdant all the winter, notwithftand. ing the oak and Larix leaves were decayed and fallen off; for tho' when the winter came on, there did not fap enough rife to maintain the Oak and Larix leaves, yet by this prefent experiment we fee, that fome fap is continually rifing all the winter; and by experiment the sth on the Lime-tree, and by feveral other the like experiments, on many forts of ever-greens, we find that they perfpiring little, live and thrive with little nourifhment; the Ilex and Cedar might well therefore continue green all the winter, notwithftanding the leaves of the trees 


\section{Vegetable Staticks.}

they were grafted on fell off. See the curious and induftrious Mr. Fairchild's account of thefe graftings in Mr. Miller's, Gardi: ner's Diztionary. Vol. II. Supplement Sap.

\section{EXPERIMENT XVII。}

Having by many evident proofs in the foregoing experiments feen the great quantities of liquor that were imbibed and perfpired by trees, I was defirous to try if I could get any of this perfpiring matter; and in order to it; I took feveral glafs chymical retorts, $b a p$ (Fig. 9.) and put the boughs of feveral forts of trees, as they were growing with their leaves on, into the retorts, ftoping up the mouth $p$ of the retorts with bladder. By this means I got feveral ounces of the perfpiring matter of Vincs, Fig-trees, Apple-trees, Cherry-trees, Apricot and Peachtrees; Rue, Horfe-radifh, Rheubarb, Parfnip; and Cabbage leaves: the liquor of all of them was very clear, nor could I difcover any different tafte in the feveral liquors: But if the retort ftand expofed to the hot fun, the liquor will tafte of the coddled leaves. Its fpecifick gravity, was nearly the 
fame with that of common water; nor did I find many air bubbles in it, when placed in the exhaufted receiver, which I expected to have found; but when referved in open viols, it ftinks fooner than common water; an argument that it is not pure water, but has fome heterogeneous mixtures with it.

I put alfo a large Sun-flower full blown; and as it was growing, into the head of a glafs-fill, and put its roftrum into a bottle, by which means there diftilled a good quantity of liquor into the bottle. It will be very eafy in the fame manner to collect the perfirations of fweet fcented Flowers, tho' the liquor will not long retain its grateful odor, but ftink in few days.

This experiment would be very proper to begin the learned Boerbaave's clear and very rational chymical proceffes with, as being a degree more fimple than his firft procefs, the diftillation in a cold ftill : For this is undifturbed nature's own method of diftilling.

\section{EXPERIMENT XVIII.}

In order to find out what ftores of moifture 


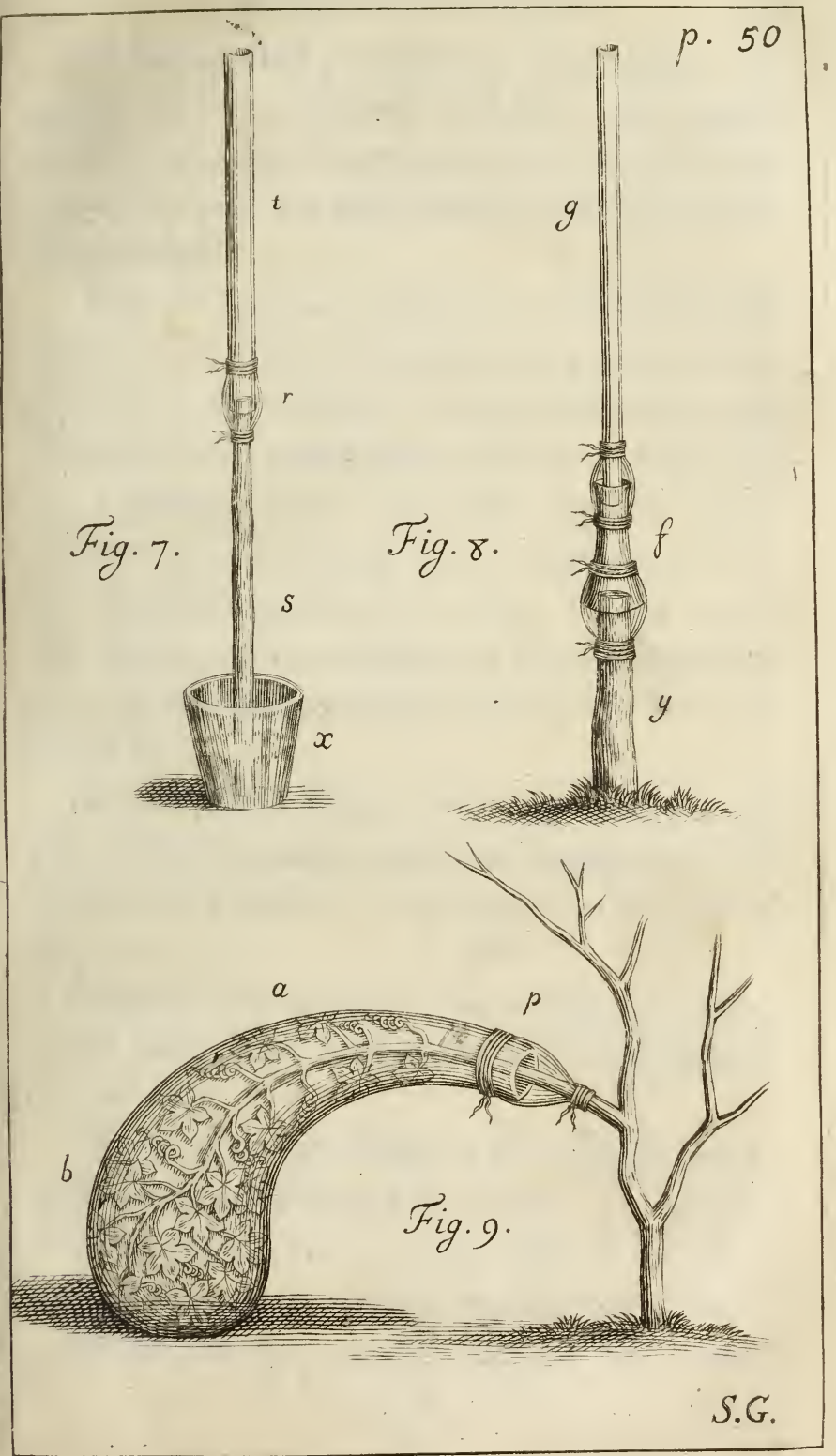





\section{Vegetable Staticks.}

iture nature had provided in the earth; ( $a$ gaint the dry fummer feafon, ) that might anfwer this great expence of it, which is fo neceffary for the production and fupport of vegetables.

Fuly 3 r. 1724. I dug up a cubick foot of earth in an alley, which was very little trampled on; it weighed (after deducting the weight of the containing verfel) I04 pounds +4 ounces $+\frac{x}{3}$. A cubick foot of water weighs $59+\frac{1}{2}$, which is little more than hale the fpecifick gravity of earth. This was a dry feafon, with a mixture of fome few thowers, fo that the grafs-plat adjoyning was not burnt up.

At the fame time I dug up another cubick foot of earth, from the bottom of the former, it weighed 106 pound +6 ounces; $+\frac{2}{3}$.

I dug up alfo a third cubick foot of earth; at the bottom of the two former, it weighed III pounds $+\frac{1}{3}$.

Thefe three feet depth were a good brick earth, next to which was gravel, in which at 2 feet depth, viz. 5 feet below the fur: face of the earth, the fprings did then run.

When the firft cubick foot of earth was

$$
\text { E } 2
$$




\section{Vegetable Staticks.}

fo dry and dufty, as to be unfit for vegetation I weighed it, and found it had loft 6 pound + I I ounces, or 194 cubick inches of water, near $\frac{x}{8}$ part of its bulk.

Some days after, the fecond cubick foot being dryer than either the firt or third, was decreafed in weight ro pounds.

The third cubick foot, being very dry and dufty, had loft 8 pounds +8 ounces, or 247 cubick inches, viz. $\frac{x}{7}$ part of its bulk.

Now fuppofing the roots of the Sun-flower (the longeft of which reached is inches every way from the ftem) to occupy and draw nourithment from 4 cubick feet of earth, and fuppofe each cubick foot of earth to afford 7 pounds of moifture, before it be too dry for vegetation; the Plant imbibing and perfpiring 22 ounces every 24 hours, that will be 28 pounds of water, which will be drawn off in 21 days and 6 hours; after which the Plane would perith, if there were not frein fupplies to thefe 4 cubick feet of earth, either from dew or moifture arifing from below is inches (the depth of the roots) up into the earth occupied by the roots. 


\section{Vegetable Staticks.}

\section{EXPERIMENT XIX.}

In order to find out the quantity of Dere that fell in the night, Aug. I s. at 7.p.m. I chofe two glazed earthen Pans, which were three inches deep, and $\mathrm{I} 2$ inches diameter in furface; I filled them with pretty moift earth taken off the furface of the earth; they increafed in weight by the night's dew I 80 grains, and decreafed in weight by the evaporation of the day $\mathrm{I}$ ounce +282 grains.

N. B. I fet thefe Pans in other broader Pans, to prevent any moifture from the earth fticking to the bottoms of them. The moifter the earth, the more Dew there falls on it in a night, and more than a double quantity of Dew falls on a furface of water, than there does on an equal furface of moift earth. The evaporation of a furface of water in 9 hours winter's dry day is $\frac{1}{2} x$ of an inch. The evaporation of a furface of Ice, fet in the fhade during nine hours day, was $\frac{1}{3 x}$.

So here are 540 grains more evaporated from the earth every 24 hours in fummer, than falls in Dew in the night; that is, in $2 I$ days near 26 ounces, from a circular area 


\section{4 Vegetable Staticks.}

of a foot diameter; and circles being as the fquares of their diameters ro pounds +2 ounces, will in $2 \mathrm{I}$ days be cvaporated from the hemifphere of 30 inches diameter, which the Sunflower's root occupies: Which with the 29 pounds drawn off by the Plant in the fame time, makes 39 pounds, that is 9 pounds and $\frac{3}{4}$ out of every cubick foot of carth, the Plant's roots occupying more than 4 cubick feet; but this is a much greater degree of drynefs than the furface of the earth ever fuffers for Is inches depth, even in the dryeft reafons in this country.

In a long dry fcalon, therefore, efpecially within the Tropicks, we muft have recourfe for fufficicnt moifture (to keep Plants and 'Tiecs alive) to the moift ftrata of earth, which lay next bclow that in which the roots are. Now moint bodies always communicate of their moifure to more dry adjoyning bodies; but this flow motion of the afcent of moifture is much accelerated by the Sun's heat to confiderable depths in the earth, as is probable from the following zoth experiment.

Now I 80 grains of Dew falling in one night, on a circle of a foot diameter, $=$ I 3 fquare 


\section{Vegetable Staticks.}

II 3 fquare inches; thefe I 80 grains being equally fpread on this furface, its depth will be ${ }_{1} \frac{x}{5}$, part of an inch $=\frac{180}{\text { II } 3 \times 254}$.I found the depth of Dew in a winter night to be the 90 part of an inch; fo that if we allow I $S \mathrm{~L}$ nights for the extent of thefummer's Dew, it will in that time arife to one inch depth. And reckoning the remaining 2 I 4 nights, for the extent of the winter's Dew, it will produce 2. 39 inches depth, which makes the Dew of the whole year amount to 3.39 inches depth.

And the quantity which evaporated in a fair fummer's day from the fame furface, being I ounce +282 grains, gives $\frac{x}{4 \circ}$ part of an inch depth for evaporation, which is four times as much as fell at night.

I found, by the fame means, the evaporation of a winter's day to be nearly the fame as in a fummer's day; for the earth being in winter more faturate with moifture, that excefs of moifture anfwers to the excefs of heat in fummer.

Nic. Cruquius No $38 \mathrm{I}$. of the Philorophical Tranfactions, found that 28 inches depth evaporated in a whole year from wa-

$$
\text { E } 4
$$




\section{s6 Vegetable Staticks."}

ter, i.e. $\frac{x}{12}$ of an inch each day, at a mean rate; but the earth in a fummer's day evaporates $\frac{x}{40}$ of an inch; fo the evaporation of a furface of water, is to the evaporation of a furface of earth in fummer, as $10: 3$.

The quantity of Rain and Dew which falls in a year is at a medium 22 inches: 'The quantity of the earth's evaporation in a year is at leaft $9+\frac{x}{2}$ inches, fince that is the rate; at which it evaporates in a fummer's day: From which $9+\frac{1}{2}$ inches is to be deducted 3.39 inches for circulating daily Dew; there remains 6. 2 inches, which 6.2 inches deducted from the quantity of Rain which falls in a year, there remains at leaft 16 inches depth, to replenifh the earth with moifture for vegetation, and to fupply the Springs and Rivers.

In the cafe of the hop-ground, the evaporation from the hops may be confidered only for 3 months at $\frac{x}{5}-$ part of an inch each day, which will be $\frac{?}{\mathrm{~T}}$ o of an inch; but before we allow 6.2 inches vapor to evaporate from the furface of the ground, which added to $\frac{\text { ? }}{5}$ inch gives, 7. I inches, which is the utmolt that can be evaporated from a furface of hop-ground in a year. 
So that of 22 inches depth of rain, there remains is inches to fupply fprings; which are more or lefs exhaufted, according to the drynefs or wetnefs of the ycar. Hence we find that 22 inches depth of rain in a year is fufficient for all the purpofes of nature, in fuch flat countries as this about Teddington near Hampton-court. But in the hill countries, as in Lancaßbire, there falls 42 inches depth of rain-water; from which deducting 7 inches for evaporation, there remains 35 inches depth of water for the fprings; befides great fupplies from much more plentiful dews, than fall in plain coun. tries: Which valt ftores feem fo abundantly fufficient to anfwer the great quantity of water, which is conveyed away, by rprings and rivers, from thofe hills, that we need not have recourfe, for fupplics, to the great A yy/s, whofe furface, at high water, is furmounted fome hundreds of feet by ordinary hills, and fome thoufands of feet by thofe vaft hills, from whence the longeft and greateft rivers take their rife.

EXPER? 


\section{EXPERIMENT XX.}

I provided me 6 Thermometers, whofe ntems werc of different lengths, viz. from I 8 inches to 4 feet. I graduated them all by one proportional fcale, beginning from the freezing point; which may well be fixed, as the utmoft boundary of vegetation on the fide of cold, where the work of vegetation ceafes, the watry vehicle beginning then to condenfe and be fixed; tho' many trees, and fomc plants, as grafs, mors, duc. do furvive it; yet they do not vegetate at: that time.

The greatef degree of heat, which I marked on my Thermometers, was cqual to that of water, when heated to the greateft degree, that I could bear my hand in it, with ont ftirring it about. A degree of heat, which is the middle, between the freezing point, and the heat of boiling water, which being too great for vegetation, may therefore be fixed, as the utmont boundary of vegetation, on the warm fide; beyond which plants will rather fade than vegetate, fucin a degrce of heat feparating and difperfing, inftead 


\section{Vegetable Staticks.}

inftcad of congregating, and uniting the nutritive particles.

This fpace I divided into 90 degrecs on all the Thermometers, beginning to number from the freezing point. Sixty four of thefe degrees is nearly equal to the heat of the blood of animals; which I found by the rule given in the Philofophical Tranfactions, Vol. II. p. 1. of Mr. Motte's Abridgment, viz. by placing one of the Thermometers in water heated to the greateft degree, that I could bear my hand in it, ftirring it about : And which I was further affured of, by placing the ball of my Thermometer in the flowing blood of an expiring $O x$. The heat of the blood to that of boiling water is as 14 $+\frac{3}{3}$ to 33 .

By placing the ball of one of thefe Thermometers in my bofom, and under an armpit, I found the external heat of the body s4 of thefe degrees. The heat of milk, as it comes from the Cow, is 55 degrees, which is nearly the fame with that for hatching of eggs. The heat of urine 58 degrees. The common temperate point in Thermometers is about i 8 degrees. 
60 Vegetable Staticks.

The hotteft Sun-thine in the year 1724; gave to the Thermometer, expored to it, a heat equal to that of the blood of animals, viz. 64 degrees: And tho' plants endure this and a confiderably greater heat, within the tropicks, for fome hours each day, yet the then hanging of the leaves of many of them thews that they could not long fubfint under it, were they not frequently refrefhed by the fucceeding evening and night.

The common noon-tide heat in the Sun in Fuly is about so degrees: The heat of the air in the fhade in " $f u l y$ is at a medium 38 degrees. The May and fune heat is, from 17 to 30 degrees; the molt genial heat, for the generality of plants, in which they fourif moft, and make the greatert progiefs in their growth. The autumnal and vernal heat may be reckoned from io to 20 degrees. The winter heat from the freczing point to 10 degrees.

The fcorching heat of a hot bed of horfedung, when too hot for plants, is 75 degrees and more, and hereabout is probably the heat of blood in high fevers. 
The due healthy heat of a hot bed of horfe-dung, in the fine mold, where the roots of thriving Cucumber-plants were, in Feb. was 56 degrees, which is nearly the bofom heat, and that for hatching of eggs.' The heat of the air under the glafs-frame of this hot-bed was 34 degrees; fo the roots had 26 degrees more heat, than the plants above ground. The heat of the open air was then 17 degrecs.

It is now grown a common and very reafonable practice; to regulate the heat of ftoves and green-houfes, by means of Thermometers, hung up in them. And for greater accuracy, many have the names of fome of the principal exoticks, written upon their Thermometers, over-againf, the feveral degrees of heat, which are found $b y$ experience to be propereft for them. And I am informed that many of the moft curirious Gardiners about London have agreed to make ufe of Thermometers of this fort; which are made by Mr. Fobn Fowler in Swithins-alley, near the Royal-Exchange; which have the names of the following plants, oppoite to their refpedive moft kindly degrees of heat; which in my Thermome- 
62 Vegetable Staticks.

ters anfwer nearly to the following degrees of heat above the freezing point, viz. Melon-thiftle 3 I, Ananas 29, Piamento 26, Euphorbium 24, Cereus $2 \mathrm{I}_{2}^{\frac{1}{2}}$, Aloe 19, Indian - fig I $6 \frac{1}{2}$, Ficoides 14 , Oranges I2, Miftles 9.

Mr. Boyle, by placing a Thermometer in a cave which was cut ftrait into the bottom of a cliff, fronting the Sea, to the depth of I 30 feet, found the fpirit ftoo'd both in winter and fummer at a fmall divifion above temperate; the cave had 80 feet depth of earth above it. Boyle's Works, Vol. III. p. 54 .

I marked my 6 Thermometers numerically, I, 2, 3, 4, 5, 6. The Thermometer numb. I. which was fhorteft, I placed with a South afpect, in the open air; the ball of numb. 2, I fet two inches under ground; that of numb. 3 , four inches under ground, numb. 4,8 inches; numb. S, 16 inches; and numb. 6,24 inches under ground. And that the heat of the earth, at thefe feveral depths, may the more accurately be known, it is proper to place near each Thermometer a glafs-tube fealed at botly ends, of the fame length with the ftems of the feveral Ther- 


\section{Vegetable Staticks.}

mometers; and with tinged fpirit of wine in them, to the fame height, as in each correfponding Thermometer; the fcale of degrees, of each Thermometer, being marked on a fliding ruler, with an index at the back of it, pointing to the correfponding tube. When at any time an obfervation is to be made, by moving the index, to point to the top of the fpirit in that tube, an accurate allowance is hereby made, for the very different degrees of heat and cold, on the ftems of the Thermometers, at all depths; by which means the fale of degrees will thew truly the degrees of heat in the balls of the Thermometers, and confequently, the refpective heats of the earth, at the feveral depths where they are placed. The ftems of thefe Thermometers, which were above ground, were fenced from weather and injuries, by fquare wooden tubes; the ground they were placed in was a brick earth in the middle of my garden.

Fuly 30. I began to keep a regifter of their rife and fall. During the following month of Auguft, I obferved that when the fpirit in the Thermometer numb. I, (which was expofed to the Sun) was 


\section{$64 \quad$ Vegetable Staticks.}

about noon rifen to 48 degrces, then the fecond Thermometer was 45 degrees, the 5 th 33 , and the 6 th $3 \mathrm{I}$, the $3 \mathrm{~d}$ and 4 th at intermediate degrees. The sth and 6 th Thermometer kept nearly the fame degree of heat, both night and day, till towards the latter end of the month; when as the days grew fhorter and cooler, and the nights longer and cooler, they then fell to 25 and 27 degrees.

Now, fo confiderable a heat of the Sun, at two feet depth, under the earth's furface, muft needs have a ftrong influence, in railing the moifture at that and greater depths; whercby a very great and continual wreak muft always be afcending, during the warm fummer feafon, by night as well as day; for the heat at two feet depth is nearly the fame night and day : The impulfe of the Sun-beams giving the moifture of the earth a brisk undulating motion, which watery particles, when feparated and rarified by heat, do afcend in the form of vapour: And the vigour of warm and confined vapour, (fuch as is that which is 1,2 , or 3 feet deep in the earth) muft be very confiderable, fo as to penetrate the roots with fome vigour; as we 


\section{Vegetable Staticks.}

may reafonably fuppofe, from the vaft force of confined vapor in Elipiles, in the digefter of bones, and the engine to raife water by fire.

If plants were not in this manner fupplied with moifure, it were impolfible for them to fubfit, under the fcorching heats, within the tropicks, where they have no rain for many months together: For tho" the dews are much greater there, than in thefe more Northern climates; yet doubtlefs where the heat fo much exceeds ours, the whole quantity evaporated in a day there, does as far exceed the quantity that falls by night in dew, as the quantity evaporated here in a fummer's day, is found to exceed the quantity of dew which falls in the night. But the dew, which falls in a hot fummer feafon, cannot poffibly be of any benefit to the roots of trees; becaufe it is remanded back from the earth, by the following day's heat, before fo fmall a quantity of moifture can have foaked to any confiderable depth. The great benefit therefore of dew, in hot weather, munt be, by being plentifully imbibed into vegetables; thereby not only refrefhing them for the 


\section{Vegetable Staticks.}

prefent, but alfo furnifhing them with a frefh fupply of moifture towards the great expences of the fucceeding day.

'Tis therefore probable, that the roots of trees and plants are thus, by means of the Sun's-warmth, conftantly irrigated with frefh fupplies of moifture; which, by the fame means, infinuates it felf with fome vigour into the roots. For if the moifture of the earth were not thus aduated, the roots muft then reccive all their nourifhment meerly by imbibing the next adjoining moifture from the earth; and confequently the fhell of earth, next the furface of the roots, would always be confiderably drie: the nearer it is to the root; which I have not obferved to be fo. And by Exper. Is and 19, the roots would be very hard put to it, to imbibe fufficient moifure in dry fummer weather, if it were not thus conveyed to them, by the penctrating warmth of the Sun: Whence by the fame genial heat, in conjunction with the attraction of the capillary fap veffels, it is carried up thro' the bodies and branches of vegetables, and thence paffing into the leaves, it is there moft vigorouny acted upon, in thofe thin plates, 
plates, and put into an undulating motion, by the Sun's warmth, whercby it is moft plentifully thrown off, and perfpired thro' their furface; whence, as foon as it is difintangled, it mounts with great rapidity in the free air.

But when, towards the latter end of $\mathrm{OC}$ tober, the vigour of the Sun's influence is fo much abated, that the firf Thermometer was fallen to 3 degrees above the freezing point, the fecond to ro degrees, the fifth to I4 degrees, and the fixth Thermometer to I 6 degrees; then the brisk undulations of the moifture of the earth, and alfo of the afcending fap, much abating, the leaves faded and fell off.

The greatelt degree of cold, in the following winter, were in the firft 12 days of November; during which time, the fpirit in the firf Thermometer was fallen 4 degrees. below the freezing point, the decpeft Ther. mometer ro degrees, the ice on ponds was an inch thick, the Sun's greateft warmth, at the winter folftice, in a very ferene, calm, frofty-day, was, againft a South arpect of a wall, 19 degrees, and in a free open air, but a I I degrees above the freezing point. From

$$
\mathrm{F} 2 \text { the }
$$


68 Vegetable Staticks.

the roth of Fanuary to the 29th of March was a very dry feafon; when the green Wheat was generally the fineft that was ever remembred. But from the 29 th of March 1725, to the 29th of September following, it rained more or lefs almoft every day, except 10 or 12 days, about the beginning of fuly; and that whole feafon continued fo very cool, that the fpirit in the firft Thermometer rofe but to 24 degrees, except now and then a thort interval of Sunfhine; the fecond only to 20 degrees; the fifth and fixth to 24 and 23 degrees, with very little variation: So that during this whole fummer, thofe parts of roots which were two feet under ground, had 3 or 4 degrees more warmth than thofe which were but two inches under ground: And at a medium the general degree of heat, thro' this whole fummer, both above and under ground, was not greater than the heat of the middle of the preceding September.

The year 1725 , having been both in this Ifland, and in the neighbouring Nations, moft remarkably wet and cold; and the year 1723 , in the other extream, as remarably dry, as has ever been known; it may 
not be improper here to give a fhort account of them, and the influence they had on their productions.

"Mr. Miller, in the account which he " took of the year 1723 , oblerved that the " winter was mild and dry, except that in "February it rained almoft every day, which " kept the Spring backward. March, April, "May, fune, to the middle of fuly, proved " cxtreamly dry, the wind North-eaft moft "part of the time.' The fruits were for" ward and pretty good; but kitchen-ftuff, " efpecially Beans and Peafe, failed much. "The latter half of Fuly the weather prov" ed very wet, which caufed the fruits to " grow fo fant, that many of them rotted " on the trces; fo that the autumn fruits " were not good. There were great plenty " of Melons, very large, but not well tanted. "Great plenty of Apples; many kinds of " fruits bloffomed in Auguft, which produc" ed many fimall Apples and Pears in Oc"tober, as alfo Strawberries and Rafpber" ries in great plenty. Wheat was good, " little Barley, much of which was very un" equally ripe, fome not at all, becaufe fown « late, and no timely rain to fetch it up.

$$
\text { F } 3 \text { " There }
$$


"There were innumerable Warps; how it "fared with the hops this dry year, is men. $\because$ tioned under Exper. 9.

"The following winter 1724 , proved "very mild; the fpring was forward in "Fanuary, fo that the Snow-drops Crocus's, "Polyanthus's, Hepatica's, and Narciffus's, "were in Flower. And it was remarkable, " that moft of the Colliflower plants were " deftroyed by the mildew, of which there "was more, all this winter, than had been "known in the memory of man, In Febru"ary we had cold harp weather, which " did fome damage to the early crops, and " it continued variable till April; fo that et much of the carly Wall-fruit was cut off : "And again the 6th of May was a very " tharp froft, which much injured tender " plants and fruits. The fummer in geneec ral was moderately dry, the common fruits " proved pretty good, but late: Mclons " and Cucumbers were good for little: "Kitchen-ftuff was in great plenty in the $\because$ markets.

In the very wet and cold year 1725 , moft things were a full month backwarder than ufual. Not half the Wheat in by the 24th 
of Auguft, in the Southern parts of England; very few Melons or Cucumbers, and thofe not good. The tender Exoticks fared but ill; fearce any Grapes, thofe fmall, and of very unequal fizes, on the fame bunch, not ripe; Apples and Pears green and infipid; no fruit nor products of the ground good, but crude: Pretty good plenty of Wheat tho' coarfe, and long ftraw; Barley coarfe, but plenty of, it in the uplands. Beans and Peafe, mofe flourifhing and plentiful; few Warps or other infects, except Flies on hops. Hops were very bad thro' the whole Kingdom. Mr. Auftin of Canterbury fent me the following particular account, how it far'd with them there; where they had more than at Farnham, and mont other places, viz.

"At mid-April not half the fhoots ap: " peared above ground; fo that the plan" ters knew not how to pole them to the " beft advantage. This defect of the fhoot, " upon opening the hills, was found to be " owing to the multitude and variety of "vermin that lay preying upon the root; " the increafe of which was imputed to "the long and almoft uninterrupted feries " of dry weather, for three months paft:

$$
\text { F 4 Towards }
$$




\section{Vegetable Staticks.}

"Towards the end of April, many of the " hop-vines were infefted with the Flies. "About the 2oth of May there was a "very uncqual crop, fome Vines being " run feven feet, others not above three or "four feet; fome juft tied to the poles, and "fome not vifible: And this difpropor" tionate inequality in their fize conti"se nued thro" the whole time of their growth. "The Flies now appeared upon the leaves " of the forwardeft Vincs, but not in fuch " numbers here, as they did in moft other " places. About the middle of fune, the "Flies increafed, yet not fo as to cndan. "ger the crop; but in diftant planta" tions they were excecdingly multiplied, "fo as to fivarm towards the end of the " month. Fune 27 th fome fpecks of fen " appeared: From this day, to the gth of "Fuly, was very fine dry weather. At this " time, when it was faid that the hops in " moft other parts of the Kingdom look" ed black and fickly, and fecmed paft re" covery, ours held it out pretty well, in ec the opinion of the mont skilful Planters. "The great leaves were indeed difcoloures ed and a little withered, and the fen was "fome. 
"fomewhat increafed. From the 9th of "Fuly to the 23 d the Fen increafed a good " deal, but the Flies and Lice decreafed, it " raining daily much: In a week more the "Fen, which feemed to be almoft at a ftand, "was confiderably increafed, efpecially in " thofe grounds where it firft appeared. A" bout the middle of Auguft, the Vines had " done growing both in ftem and branch; " and the forwardeft began to be in Hop, " the reft in Bloom: the Fen continued " spreading, where it was not before per. " ceived, and not only the leaves, but many " of the Burrs alfo wcre tainted with it. "About the 20th of Auguft, fome of the "Hops were infected with the Fen, and "whole branches corrupted by it. Half the "Plantations had hitherto pretty well ef" caped, and from this time the Fen increa"fed but little : But feveral days violent "wind and rain, in the following week, fo " difordered them, that many of them be"gan to dwindle, and at laft came to no" thing; and of thofe that then remained " in bloom, fome never turned to Hops; " and of the reft which did, many of them "Were fo fmall, that they very little ex" ceedeed 


\section{$74 \quad$ Vegetable Staticks.}

" ceeded the bignefs of a good thriving "Burr. We did not begin to pick till the " 8 th of September, which was i 8 days later "than we began the year before: The crop "was little above two hundred on an acre " round, and not good." The beft Hops fold this year at Way-Hill Fair for fixteen pounds the hundred.

The almoft uninterrupted wetnefs and coldnefs of the year 1725 , very much affeeted the produce of the Vines the cnfuing year; and we have fufficient proof from the obfervations that the 4 or 5 laft years afford us, that the moifture or drynefs of the preceding year, has a confiderable influence on the productions of the Vine the following year. Thus in the year 1722 , there was a dry feafon, from the beginning of Auguft thro' the following autumn and winter, and the next fummer there was good plenty of Grapes. The year 1723 was a remarkably dry year, and in the following year 1724, there was an unufual plenty of Grapes. The year 1724 was moderately dry, and the following fpring the Vines produced a fufficient quantity of branches, but by reafon of the wetnefs and cold- 


\section{Vegetable Staticks.}

nefs of the year 1725 they preved abortive, and produced hardly any Grapes. This very wet year had an ill effect, not only upon its own productions, but alfo on thofe of the following year: For notwithftanding there was a kindly fpring and blooming feafon in the year 1726 . yet there were few bunches produced, except here and there in fome very dry foils. This, many Gardiners forefaw early, when upon pruning of the Vines, they obferved the bearing fhoots to be crude and immature; which was the reafon why they were not fruitful. The firft crop thus failing in many places, the Vines produced a fecond, which had not time to come to maturity, before the cold weather came on.

I have often obferved from thefe Thermometers, when that kind of hovering lambent Fog arifes, (either mornings or evenings) which frequently betokens fair weather, that the air which in the preceding day was much warmer, has upon the abfence of the fun become many degrees cooler than the furface of the earth; which being near I 500 times denfer than the air, cannot be fo foon affeeted with the alternacies of hot and cold $;$ whence tis probable, that thofe 
76 Vegetable Staticks.

vapours which are raifed by the warmth of the earth, are by the cooler air foon condenfed into a vifible form. And I have obferved the fame difference between the coolnefs of the air, and the warmth of water in a pond, by putting my Thermometer, which hung all night in the open air in fummer time, into the water, juft bcfore the rifing of the fun, when the like reek or fog was rifing on the furface of the water.

\section{H A P. II.}

Experiments, whereby to find out the force with which Trees imbibe moifture.

A VIN G in the If chapter feen many
proofs of the great quantities of Iiquor imbibed and perfpired by vegetables, I propofe in this, to enquire with what force they do imbibe moifture.

Tho' vegetables (which are inanimate) have not an engine, which, by its alterrate dilatations and contractions, does in animals forcibly drive the blood through the artetics and veins; yet has nature wonderfully contrived other means, moft powerfully to raife and keep in motion the fap, as will 


\section{Vegetable Staticks.}

in fome meafure appear by the experiments in this and the following chapter.

I thall begin with an experiment upon roots, which nature has providently taken care to cover with a very fine thick ftrainer; that nothing thall be admitted into them, but what can readily be carryed off by perfpiration, vegetables having no other provifion for difcharging their recrement.

\section{EXPERIMENT XXI。}

Auguft I 3. In the very dry year I723, I dug down $2+\frac{\pi}{2}$ feet deep to the root of a thriving baking Pear-tree, and layed bare a root $\frac{1}{2}$ inch diameter $n$. (Fig. IO.) I cut off the end of the root at $i$, and put the remaining ftump $i n$ into the glafs tube $d r$, which was an inch diameter and 8 inches long, cementing it faft at $r$; the lower part of the tube $d z$ was 18 inches long, and $\frac{z}{4}$ inch diameter in bore.

Then I turned the lower end of the tube $z$ uppermoft, and filled it full of water, and then immediately immerfed the fmall end $\approx$ into the ciftern of mercury $x$; taking away 
my finger, which ftopped up the end of the tube $z$.

The root imbibed the water with fo much vigor, that in 6 minutes time the mercury was raifed up the tube $d \approx$ as high as $z$, viz. 8 inches.

The next morning, at 8 a clock, the mercury was fallen to 2 inches height, and 2 inches of the end of the root $i$ were yet immerfed in water. As the root imbibed the water, innumerable air bubbles iffued out at $i$, which occupied the upper part of the tube at $r$ as the water left it.

\section{EXPERIMENT XXII.}

The eleventh experiment thews, with what great force branchesimbibe water, where a branch with leaves imbibed much more than a column of 7 feet height of water could in the fame time drive thro' 13 inches length of the biggeft part of its ftem. And in the following experiments we thall find a further proof of their ftrong imbibing power.

May 25, I cut off a branch of a young thriving Apple-tree b, (Fig. II.) about 3 


\section{Vegetable Staticks.}

feet long, with lateral branches; the diameter of the tranfverfe cut $i$, where it was cut off, was $\frac{3}{4}$ of an inch: The great end of this branch I put into the cylindrical glafs $e r$, which was an inch diamcter within, and eight inches long.

I then cemented faft the joynt $r$, firft folding a ftrap of theeps skin round the ftem, fo as to make it fit well to the tube at $r$; then I cemented faft the joynt with a mixture of Bees-wax and turpentine melted together in fuch a proportion, as to make a very fiffe clammy Pafte when cold, and over the cement I folded feveral times wet Bladders, binding it firm with Pack-thread.

At the lower end of the large tube $e$ was cemented, on a leffer tube $z e, \frac{1}{4}$ inch diameter in bore, and 18 inches long: The fubftance of this tube ought to be full $\frac{1}{8}$ of an inch thick, elfe it will too eafily break in making this experiment.

Thefe two tubes were cemented together at $e$, firft with common hard brick-duft cement to keep the tubes firm to each other ; but this hard cement would, by the different dilatations and contraations of the glafs and cement, feparate from the glars in hot wea- 
ther, fo as to let in air; to prevent which inconvenience, I further fecured the joynt with the cement of Bees-wax and Turpentine, binding a wet bladder over all.

When the branch was thus fixed, I turned it downwards, and the glars tube upwards, and then filled both tubes full of water; upon which Iimmediately applied the end of my finger to clofe up the end of the fmall tube, and immerfed it as faft as I could into the glars ciftern $x$, which was full of mercury and water.

When the branch was now uppermoft, and placed as in this figure, then the lower end of the branch was immerfed 6 inches in water, viz. from $r$ to $i$.

Which water was imbibed by the branch, at its tranfverfe cut $i$; and as the water afcended up the fap vefiels of the branch, fo the mercury afcended up the tube $e z$ from the ciftern $x$; fo as in half an hour's time the mercury was rifen $s$ inches and $\frac{3}{4}$ high up to $\approx$.

And this height of the mercury did in fome meafure fhew the force with which the fap was imbibed, tho' not near the whole force; for while the water was imbibing, 


\section{Vegetable Staicks. 8 I}

the tranfverfe cut of the branch, was covered with innumerable little hemifpheres of air, and many air bubbles iffucd out of the fap veffels, which air did in part fill the tube $e r$, as the water was drawn out of it ; fo that the height of the mercury could only be proportionable to the excefs of the quantity of water drawn off, above the quantity of air which iffued out of the wood.

And if the quantity of air, which iffued from the wood into the tube, had been equal to the quantity of water imbibed, then the mercury would not rife at all; becaufe there would be no room for it in the tube.

But if 9 parts in 12 of the water be imbibed by the branch, and in the mean time but 3 fuch parts of air iffue into the tube, then the mercury muft needsrife near 6 inches, and fo proportionably in different cafes.

I obferved in this, and moft of the following experiments of this fort, that the mercury rofe higheft, when the fun was very clear and warm; and towards evening it would fubfide 3 or 4 inches, and rife again the next day as it grew warm, but feldom to the fame height it did at firt. For I have always found the fap veffels grow every. 
82 Vegetable Staticks.

day, after cutting, lefs pervious, not only for water, but alfo for the fap of the vine, which never paffes to and fro fo freely thro' the tranfverfe cut, after it has been cut 3 or 4 days, as at firft; probably, becaufe the cut capillary veffels are fhrunk, the veficles alfo, and interffices between them, being faturate and dilated with extravafated fap, much more than they are in a natural fate.

If I cut an inch or two off the lower part of the ftem, which has been much faturated by ftanding in water, then the branch will imbibe water again afreh'; tho' not altogether fo freely, as when the branch was firft cut off the tree.

I repeated the fame experiment as this $22 \mathrm{~d}$, upon a great variety of branches of feveral fizes and of different kinds of trees, fome of the principal of which are as follow, viz.

\section{EXPERIMENT XXIII.}

Fuly 6th and 8 th, I repeated the fame experiment with feveral green thoots of the Vine, of this year's growth, each of them full two yards long. 


\section{Vegetable Staticks.}

The mercury rofe much more leifurely in thefe experiments, than with the Apple-tree branch; the more the fun was upon it, the farter and higher the mercury rofe, but the Vinebranches could not draw it above 4 inches the firft day, and 2 inches the third day.

And as the fun fet, the mercury fometimes fubfided wholly, and would rife again the next day', as the fun came on the Vinebranch.

And I obferved, that where fome of thele Vine-branches were fix'd on the north fide of the large trunk of a Pear-tree, the mercury then rofe moft in the evening about 6 a clock, as the fun came on the Vine-branch.

\section{EXPERIMENT XXIV.}

Auguft 9, at Io ante Merid. (very hot funfhine) Ifixed in the fame manner as Exp. 22. a Non-pareil branch, which had 20 Apples on it; it was 2 feet high, with lateral branches, its tranfverfe cut $\frac{5}{8}$ inch diameter: It immediately began to raife the mercury moft vigorouny, fo as in 7 minutes it was got up to $z \mathrm{I} 2$ inches high.

$$
G=\text { Mer- }
$$




\section{$84 \quad$ Vegetable Staticks.}

Mercury being $I_{3}+\frac{3}{3}$ times fpecifically heavier than water, it may eafily be eftimated to what height the feveral branches in thefe experiments would raife water; for if any branch can raife mercury $x 2$ inches, it will raife water I 3 feet +8 inches: $A$ further allowance being alfo made for the perpendicular height of the water in the tubes, between $r$ and $z$ the top of the colum of mercury, for that column of water is above lifted up by the mercury, be it more or lefs.

At the fame time, I tryed a Golden Renate branch 6 fect long, the mercury rofe but 4 inches, it rifing higher or lower in branches nearly of the fame fize and of the fame kind of tree, according as the air iffucd thro' the ftem, more or lefs freely. In the preceding experiment on the Nonparcil branch, I had fucked a little with my mouth at the fmall end of the tube, to get fome air bubbles out of it, before I immerfed it in the mercury; (but thefe air bubbles are beft got out by a fmall wire run to and fro in the tube) and this fuction made air bubbles arife out of the transverfe cut of the branch; but tho' the quan- 
tity of thofe air bubbles thus fucked out, was but fmall; yet in this and many other experiments, I found that after fuch fuction, the water was imbibed by the branch, much more greedily, and in much greater quantity than the bulk of the air was, which was fucked out. Probably therefore, thefe air bubbles, when in the fap veffels, do ftop the free afcent of the water, as is the cafe of little portions of air got between the water in capillary glafs tubes.

When the mercury is raifed to its greateft height, by precedent fuction with the mouth, (which height it reaches fometimes in 7 minutes, fometimes in half an hour or an hour) then from that time it begins to fall, and continues fo to do, till it is fallen 5 or 6 inches, the height the branch would have drawn it to, without fucking with the mouth.

But when in a very warm day, the mercury is drawn up $s$ or 6 inches, (withour precedent fuction with the mouth) then it will ufually hold up to that height for feveral hours, viz. during the vigorous warmth of the fun; becaufe the fun is all that time frongly exhaling moifture from the branch 
thro' the leaves, on which account it muft therefore imbibe water the more greedily, as is evident by many experiments in the firft chapter.

When a branch is fixed to a glafs tube fet in mercury, and the mercury fubfides at night, it will not rife the next morning (as the warmth of the fun increales upon it) unlefs you fill the tube firft full of water: For if half or $\frac{x}{4}$ of the large tube $c r$ be full of air, that air will be rarified by the fun; which rarefaction will deprefs the water in the tube, and confequently the mercury cannot rife.

But where little water is imbibed the firt day, (as in the cafe of the green thoots of the Vine, Exper. XXIII.) then the mercury will rife the fecond and third day, as the warmth of the fun comes on, without refilling the little water that was imbibed.

EXPER I MENT XXV.

In order to make the like experiment on larger branches (when I expected the mercury would have rifen much highcr than in fmall ones) I caufed glaf- 


\section{Vegetable Staticks.}

fes to be blown of the fhape of this here defcribed (Fig. I2.) of feveral dimenfions at $r$, from two to five inches diameter, with a proportionably large cavity $c$ : the ftem $z$ as near $\frac{1}{4}$ inch diameter as could be, the length of the ftem 16 inches.

I cemented one of thefe glafs veffels to a large fmooth barked thriving branch of an Apple-tree, which was I 2 feet long, I $+\frac{3}{4}$ inch diameter at $i$ : I filled the glafs tube with water, and immerfed the fmall end in the mercury $x$, which rofe but 4 inches, yet it imbibed water plentifully; but the air iffucd too faft out of the branch at $i$, for the mercury to rife high.

This, and many other experiments of this kind, convince me that branches of 2,3 , or 4 years old, are the beft adapted to draw the mercury higheft: The vefieis of thore that are older being too large and pervious to the air, which paffes moft freely thro the bark, efpecially at old eyes: As will be more fully proved in the fifth chapter.

EXPERIMENT XXVI.

Fuly 30 th at noon, a mixture of fun and

clouds, 
clouds, the day and night before, 24 hours continual rain: I cut off a branch of a Gol. den Pippin.tree, $b 6$ (Fig. I3.) about 3 feet long, with feveral large lateral branches; its diameter at the great end $p$ near an inch, which end I cemented well, and tyed over it a piece of wet bladder.

Then I cut off at $i$ the main top twig, where it yas $\frac{3}{2}$ inch diameter: I cemented the glafs tube $z r$, to the remaining branch $i r$, and then filling the tube with water, fet its lower end in the mercury $x$ : So that now the branch was placed with its top $i$ downwards in the water, in the Aqueomercurial gage.

It imbibed the water with fuch frength, as to raife the mercury with an almoft equable progreflion in $+\frac{x}{2}$ inches by 3 a clock, (the fun thining then very warm) at which time the water in the tube $r i$ being all imbibed; fo that the end $i$ of the branch was out of the water, then the air bubbles faffing more frecly down to $i$, and no water being imbibed, the mercury fubfided 2 or 3 inches in an hour.

At a quarter paft a a clock, I refilled the gage with water, upon which the mercury 


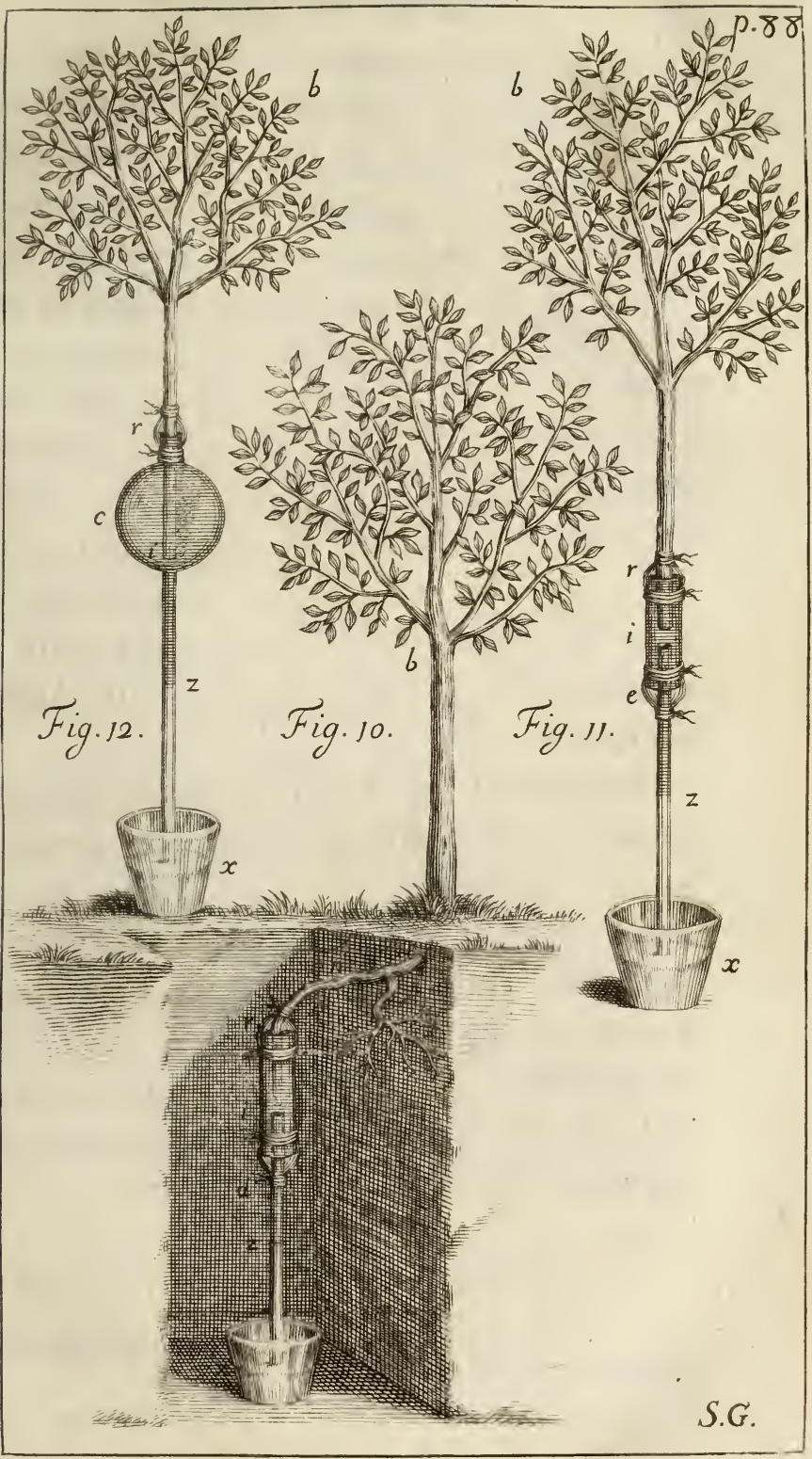




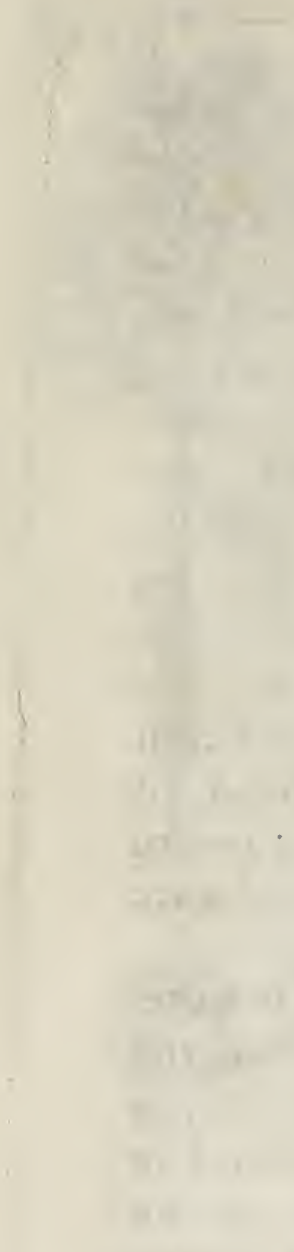


rofe afreh from the ciftern, viz. 6 inches the firft $\frac{s}{4}$ of an hour, and in an hour more the mercury reached the fame height as before, viz. I I $+\frac{1}{2}$ inches. And in an hour and $\frac{1}{4}$ more it rofe $\frac{1}{4}$ inch more than at firft; but in half an hour after this it began gently to fubfide; viz. becaufe the fun declining and fetting, the perfpiration of the leaves decreafed, and confequently the imbibing of the water at $i$ abated, for the end $i$ was then an inch in water.

Fuly 3 Ift. It raining all this day, the mercury rofe but 3 inches, which height it ftood at all the next night. Auguft ift fair fun-thine; this day the mercury rofe to 8 inches: This thews again the influence of the fun, in raifing the mercury.

This Experiment proves that branches will ftrongly imbibe from the fmall end immerfed in water to the great end; as well as from the great end immerfed in water to the fmall end; and of this we Thall have further proof in the fourth chapter.

EXPERTMENT XXVII.

In order to try, whether branches would imbibe 
imbibe wath the like force, with the bark off, I took two branches which I call $M$ and $N$; I fixed $M$ in the fame manner as the branch in the foregoing Experiment, with its top downwards, but firt I took off all the bark from $i$ to $r$. Then I fix'd in the fame manner the branch $N$, but with its great end downwards, having alfo taken off all the bark from $i$ to $r$; both the branches drew the mercury up to $z, 8$ inches; fo they imbibed with equal ftrength at either end, and that without bark.

\section{EXPERIMENT XXVIII.}

Auguf I 3. I ftripped the leaves off an Apple tree branch, and then fixed the great end of the ftem in the gage; it raifed the mercury $2+\frac{1}{2}$ inches, but it foon fubfided, for want of the plentiful perfpiration of the leaves, fo that the air came in almoft as faft as the branch imbibed water.

\section{EXPERIMENT XXIX.}

I tryed alfo with what force branches would imbibe, at their fmall ends, as they 


\section{Vegetable Staticks.}

are in their natural ftate growing to the trees.

Auguft $2 \mathrm{~d}$ I cemented faft the gage $r i z$ (Fig. 14) to the pliant branch $b$, of a dwarf Golden Pippin-tree, the fame from which I cut the branch in Experiment 26: As the $\operatorname{tranfverfe}$ cut $i$ imbibed the water, the mercury rofe $s$ inches obliquely in the tube $z$, and 4 inches perpendicular.

In this, as alfo in many of the preceding Experiments there were feveral wounds, in that part of the branch which was within the large tube $r i$; which were made by cutting off little lateral twigs, and fwelling eycs, that the branch might eafily enter the tube: And if thefe wounds (thro which the air always iffued plentifully) were well covered with theeps-gut, bound over with packthread, it would in a good meafure prevent the inconvenience: But I always found that my Experiments of this kind fucceeded beft, when that part of the branch which was to enter the tube $r i$, was clear of all knots or wounds; for when there were no knots, the liquor paffed moft freely, and lefs air iffued out. 
The fame day I fixed in the fame manner a gage to an Apricock.tree, it raifed the mercury 3 inches; and tho all the water was foon imbibed, yet the mercury rofe every day an inch, for many days, and fub. fided at night; fo that the branch muft daily imbibe thus much air, and remit it at night.

\section{EXPER IMENT XXX.}

We have a further proof of the influence of the leaves in raifing the fap in this following Experiment.

Anguft oth, I cut off a large Rufet Pippin $a$ (Fig. I 5.) with a ftalk $\mathrm{I}+\frac{\mathrm{k}}{2}$ inch long, and $\mathrm{I} 2$ adjoyning leaves $g$ growing to it.

I cemented the ftalk faft into the upper end of the tube $d$, which tube was 6 in. ches long, and $\frac{x}{4}$ inch diameter; as the ftalk imbibed the water, it raifed the mercury to $\approx$ four inches high.

I fix'd another Apple of the fame fize and tree, in the fame manner, but firft pulled of the leaves; it raifed the mercury but one inch; I fixed in the fame manner a like bearing $t w i g$ with $i 2$ leaves on it, but no spple; it raifed the mercury 3 inches.

I then 


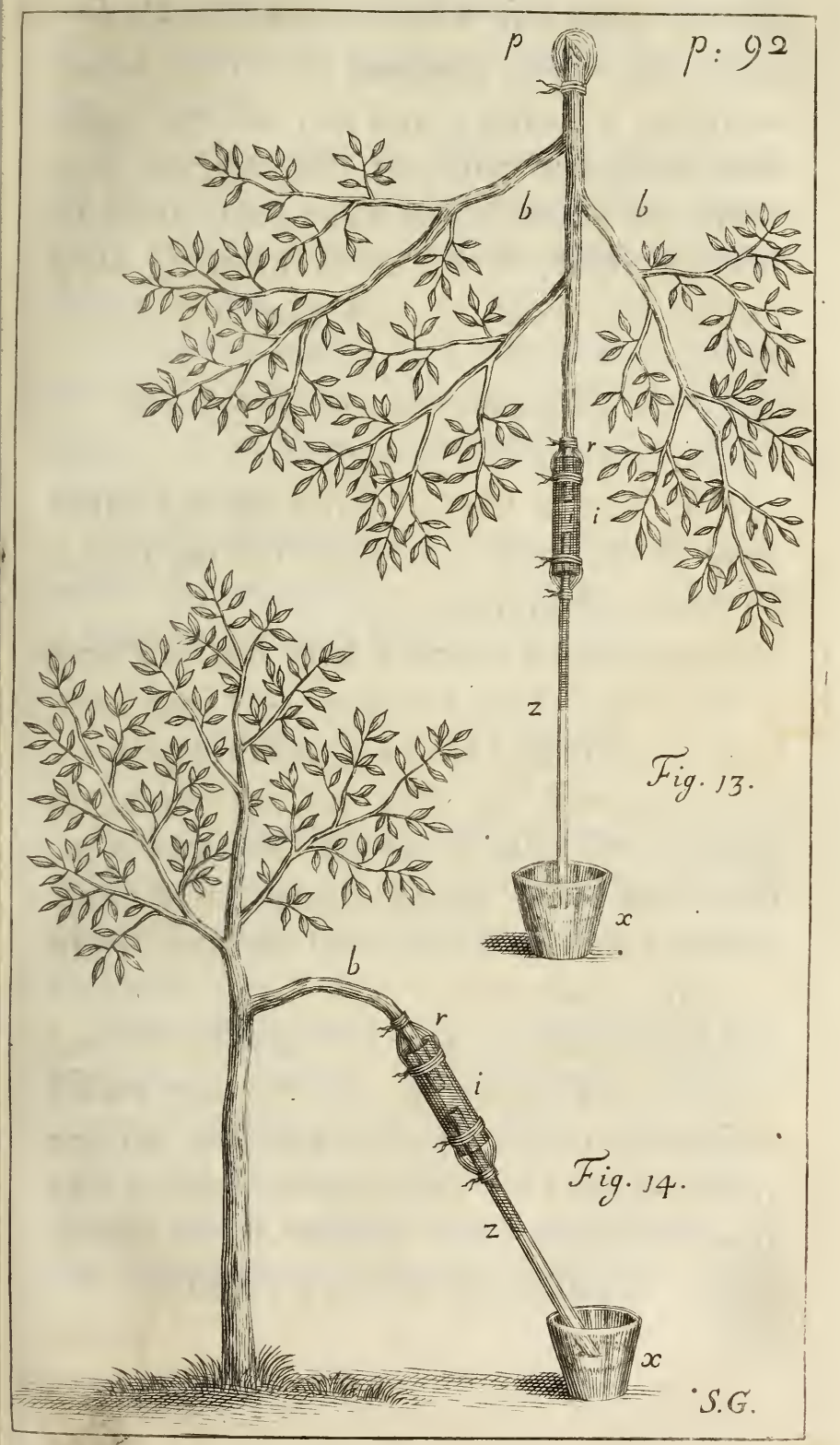





\section{Vegetable Staticks.}

I then took a like bearing twig, without either leaves or apple, it raifed the mercury $\frac{1}{4}$ inch.

So a twig, with an apple and leaves raifed the mercury 4 inches, one with leaves only 3 inches, one with an apple without leaves $I$ inch.

A Quince which had two leaves, juft at the twig's infertion into it, raifed the mercury $2+\frac{1}{2}$ inches, and held it up a confiderable time.

A fprig of Mint fix'd in the fame manner, raifed the mercury $3+\frac{x}{2}$ inch, equal to 4 feet $+s$ inches height of water.

\section{EXPERIMENT XXXI。}

I tryed alfo the imbibing force of a great variety of trees, by fixing Aquco-mercurial gages to branches of them cut off, as in Experiment 22.

The Pear, Quince, Cherry, Walnut, Peach, Apricock, Plumb, Black-thorns, Whitethorns, Goofeberry, Water-Elder, Sycamore, raifed the mercury from 6 to 3 inches high: Thofe which imbibed water moft freely, in the Experiments of the firt chapter, raifed 
94 Vegetable Staticks.

the mercury higheft in thefe Experiments, except the Horfe-Chefnut, which tho' it imbibed water moft freely, yet railed the mercury but one inch, becaufe the air paffed very faft thro' its fap-veffels into the gage.

The following raifed the mercury but I or 2 inches, viz. the Elm, Oak, HorfeCheinut, Filberd, Fig, Mulberry, Willow, Sallow, Ofier, Afh, Lynden, Currans.

The Evergreens, and following trees and plants, did not raife it at all. The Laurel, Rofemary, Laurus-Tjnus, Philarea, Fuz, Ruc, Berberry, Jeffamine, Cucumber-branch, Pumkin, Jerufalem Articnoke.

\section{EXPERIMENT XXXII.}

We have a further proof of the great force, with which vegetables imbibe moifture, in the following Experiment, viz. I filled bear full with Peafe and Water, the iron Pot (Fig. 37.) and layed on the Peafe a leaden cover, between which, and the fides of the Pot, there was room for the air which came from the Peare, to pafs freely. I then layed one hundred eighty four pounds weight on them, which (as the Peafe di- 


\section{Vegetable Staticks.}

lated by imbibing the water) they lifted up. The dilatation of the Peafe is always equal to the quantity of water they imbibe : For if a few Peafe be put into a Veffel, and that Veffel be filled full of water, tho' the Peafe dilate to near double their natural fize; yet the water will not flow over the Veffel, or at moft very incenfiderably, on account of the expanfion of little air bubbles, which are iffuing from the Peafe. Being defirous to try, whether they would raife a much greater weight, by means of a lever with weights at the end of it, I compreffed feveral frefh parcels of Peafe in the fame Pot, with a force equal to I 600,800 , and 400 pounds; in which Experiments, tho the Peafe dilated, yet they did not raife the lever, becaufe what they increafed in bulk was, by the great incumbent weight, preffed into the interftices of the Peare, which they adequately filled up, being thereby formed into pretty regular Dodecahedrons.

We fee in this Experiment the vaft force with which fwelling Peafe expand, and 'tis doubtlefs a confiderable part of the fame force which is exerted, not only in pufhing the Plume upwards into the air, but 
96 Vegetable Staticks.

alfo in enabling the firft thooting radicle of the Pea, and all its fubfequent tender Fibres; to penetrate and fhoot into the earth.

\section{EXPERIMENT XXXIII.}

We fee, in the Experiments of this chapter, many infeances of the great efficacy of attraction; that univerfal principle which is fo operative in all the very different works of nature; and is moft eminently fo in vegetables, all whofe minuteft parts are curioufly ranged in fuch order, as is beft adapted by their united force, to attract proper nourifhment.

And we thall find in the following Experiment, that the diffevered particles of vegetables, and of other bodies, have a ftrong attractive power when they lay confufed.

That the particles of wood are fpecifically heavier than water (and can therefore ftrongly attract it) is evident, becaufe feveral forts of wood fink immediately; others (even cork) when their interfices are well foaked, and filled with water; others (as the Peruvian Bark) fink when very finely 


\section{Vegetable Staticks.}

pulverized, becaufe all their cavities, which made them fivim, are thereby deftroyed.

In order to try the imbibing power of common wood afhes, I filled a glafs tube $\operatorname{cr} i, 3$ feet long, and $\frac{7}{3}$ of an inch diameter (Fig. I6.) with well dryed and fffted wood afhes; preffing them clofe with a rammer, I tyed a piece of linen over the end of the tube at $i$, to keep the afhes from falling otit; I then cemented the tube $c$ faft at $r$ to the Aqueo-mercurial gage $r z$, and when I had filled the gage full of water, I immerfed it in the ciftern of mercury $x$ : Then to the upper end of the tube $c$, at $o$ I fcrewed on the mercurial gage $a b$.

The afhes as they imbibed the water drew the mercury up 3 or 4 inches in a few hours towards $z$; but the three following days it rofe but I inch, $\frac{1}{2}$ inch, and $\frac{1}{4}$, and fo lefs and lefs, fo that in $s$ or 6 days it ceafed ri. fing: The higheft it rofe was 7 inches, which was equal to raifing water 8 feet high.

This had very little effect on the mercury in the gage $a b$, unlefs it were, that it would rife a little, viz. an inch or little more in the gage at $a$, as it were by the fuc- 


\section{Vegetable Staticks.}

tion of the afhes, to fupply fome of the air bubbles which were drawn out at $i$.

But when I feparated the tube $c o$ from the gage $r z$, and fet the end $i$ in water, then the mointure (being not reftrained as before) role fafter and higher in the athes $c 0$, and depreffed the mercury at $a$, fo as to be 3 inches lower than in the $\operatorname{leg} b$, by driving the air upwards, which was intermixed with the alhes.

I filled another tube 8 feet long, and $\frac{1}{2}$ inch diameter with red lead; and affixed it in the place of $c o$ to the gages $a b, r z$. The mercury rofe gradually 8 inches to $z$.

In both thefe Experiments, the end $i$ was covered with innumerable air bubbles, many of which continually paffed off, and were fucceeded by others, as at the tranfverfe cuts in the Experiments of this chapter. And as there, fo in there, the quantity of air bubbles decreafed every day, fo as at laft to have very few: The part $i$ immerfed in the water, being become fo faturate therewith, as ro leave no room for air to pafs.

After 20 days I picked the minium out of the tube, and found the water had rifen 3 fect 7 inches, and would no doubt have 


\section{Vegetable Staticks.}

rifen higher, if it had not been clogged by the mercury in the gage $z$. For which reafon the mointure rofe but 20 inches in the alhes, where it would otherwife have rifen 30 or 40 inches.

And as Sir Ifaac Newton (in his Opticks query 3 I.) obferves, "The water rifes "up to this height, by the action only of "thole particles of the afhes which are " upon the furface of the elevated water; " the particles which are within the water, " attracting or repelling it as much down"wards as upwards; and thercfore the ac"tion of the particles is very ftrong: But "the particles of the alhes being not fo "denfe and clofe together as thofe of "glafs, their action is not fo ftrong as that " of glafs, which keeps quick-filver fufpen" ded to the height of 60 or 70 inches, " and therefore acts with a force, which "would keep water furpended to the height " of above 60 feet.

"By the fame principle, a fponge fucks, " in water, and the glands in the bodies of " animals, according to their feveral na" tures and difpofitions, fuck in various " juices from the blood." 
And by the fame principle it is, that we fee in the preceding Experiments plants imbibe moifture fo vigorouny up their fine capillary veffels; which moifture, as it is carryed off in peripiration, (by the action of warmth, ) thereby gives the fap veffels liberty to be almont continually attracting of frelh fupplies, which they could not do, if they were full faturate with moifture: For without perfpiration the fap muft neceffarily ftagnate, notwithntanding the fap veffels are fo curiouny adapted by their excecding finenefs, to raife the fap to great heights, in a reciprocal proportion to their very minute diameters.

\section{H A P. III.}

Experiments, Shewing the force of the Sap in the Vine in the bleeding feafon.

W AVING in the firft chapter fhewn I many inftances of the great quantities imbibed, and perfpired by trees, and in the fecond chapter, feen the force with which they do imbibe moifture; I propore next, to give an account of thofe Experiments, which prove with what great force 


\section{Vegetable Staticks.}

the fap of the Vine is pufned forth, in the bleeding feafon.

\section{EXPERIMENT XXXIV.}

March 3 oth at $3 p$. m. I cut off a Vine on a weftern afpect, within feven inches of the ground, the remaining ftump $c$ (Fig. I 7 ) had no lateral branches: It was 4 or 5 years old, and $\frac{3}{4}$ inch diameter. I fix'd to the top of the fump, by means of the brais collar $b$, the glafs tube $b f$, feven feet long, and $\frac{x}{4}$ inch diameter; I fecured the joynt $b$ with ftiff cement made of melted Bceswax and Turpentine, and bound it faft over with fcveral folds of wet bladder and pack-thread: I then ferewed a fecond tibe $f g$ to the firft, and then a third $g a$ to 25 feet height.

The ftem not bleeding into the tube, I filled the tube two fect high with water, the water was imbibed by the ftem within 3 inches of the bottom, by 8 a clock that evening. In the night it rained a fmall thower. The next morning at $6+\frac{1}{2}$, the water was rifen three inches above what it was fallen to laft night at eight a clock. The Thermometer which hung in my porch 
was it degrecs above the freczing point, March in fit from $6+\frac{x}{2} a m$, to rop. $m$. the fap role $8+\frac{s}{4}$ inches, April int at $6 \mathrm{am}$. Thermometer 3 degrees above the freezing point, and a white hoar froft, the fap rofe from ten a clock laft night $3+\frac{1}{4}$ inches more; and fo continued rifing daily till it was above 2 I feet high, and would very probably have rifen higher, if the joynt 6 had not feveral times leaked: After ftopping of which it would rife fometimes at the rate of an inch in 3 minutes, fo as to rife 10 fect or more in a day. In the chier bleeding feafon it would continue rifing night and day, but much more in the day than night, and mort of all in the greateft heat of the day; and what little finking it had of 2 or 3 inches was always after fun fet, which I furpect was principaliy occafioncd by the furinking and contraction of the cement at $b$, as it grew cool.

When the fun thined hot upon the Vine, there was always a continued ferics of air bubbles, conftantly afcending from the ftem thro the fap in the sube, in fo great plenty as to make a large froth on the top of the fap, which hews the great quantity of 


\section{Vegetable Staticks.}

air which is drawn in thro' the roots and ftem.

From this Experiment we find a confiderable energy in the root to puth up fap in the bleeding feafon.

This put me upon trying, whether I could find any proof of fuch an energy, when the bleeding feafon was over, in order to which

EXPERIMENT XXXV.

Fuly 4 th at noon, I cut off within 3 inches of the ground, another Vine on a fouth afpect, and fixed to it a tube 7 fect high, as in the foregoing Experiment; Ifilled the tube with water, which was imbibed by the root the firft day, at the rate of a foot in an hour, but the next day much more flowly, yet it was continually finking, fo that at noon day I could not fee it fo much as ftationary.

Yet by Experiment the $3 \mathrm{~d}$, on the Vine in the garden pot, it is plain, that a very confiderable quantity of fap was daily prefo fing thro' this ftem, to fupply the perfpiration of the leaves, before I cut the vine off. And if this great quantity were carried up by

$\mathrm{H}_{4}$

pulfion 
pulfion or trufion, it muft needs have rifen out of the ftem into the tube.

Now fince this flow of fap ceafes at once, as foon as the Vine was cut off the ftem, the principal caule of its rife muft at the fame time be taken away, viz. the great perfpiration of the leaves.

For tho' it is plain by many Experiments, that the fap enters the fap veffels of plants with much rigour, and is probably carried up to great heights in thore reffels, by the vigorous undulations of the fun's warmth, which may reciprocally caufe vibrations in the veficles and fap veffels, and thereby make them dilate and contract a little; yet it feems as plain (from many Experiments, as particularly Exper. I 3, 14, I s. and Exper. 43. where tho' we are affured that a great quantity of water paffed by the notch cut 2 or 3 fect aboue the end of the ftem; yet was the notch very dry, becaufe the attraction of the peripiring leaves was much greater than the force of trufion from the column of water, From thefe Experiments, I fay, it reems cvident, that the capillary fap veffels, out of the blecding feafon, have little power to pro. trude 


\section{Tegetable Staticks.}

rude fap in any pienty beyond their orifices; but as any fap is evaporated off, they can by their ftrong attraction (affifted by the genial warmth of the fun) fupply the great quantitics of fap drawn off by perfpiration.

\section{EXPERIMENT XXXVI.}

April 6th at 9. a m. rain the evening before, I cut off a Vine on a fouthern afpect, at a (Fig. I 8.) two feet nine inches from the ground, the remaining ftem $a b$, had no lateral branches, it was $\frac{2}{8}$ inch diametcr, I fixed on it the mercurial gage $a y$. At i a $m$. the mercury was rifen to $z$, is inches higher than in the leg $x$, being puthed down at $x$, by the force of the lap which came out of the ftem at $a$.

At $4 p . m$. it was funk an inch in the leg $z y$. April 7 th at $8 \mathrm{a} . \mathrm{m}$. rifen very little, a fog : at I I a.m. 'tis 17 inches high, and the fog gone.

April 1 oth at 7 a. $m$. mercury I 8 inches high; I then added more mercury, fo as to make the furface $z 23$ inches higher than $x$; the fap retreated very little into the ftem, upon this additional weight, which fhews 


\section{6}

Vegetable Staticks.

with what an abfolute force it advances: at noon it was funk one inch.

April I i th at 7 a. m. $24+\frac{3}{4}$ inches high, fun-thine : at $7 p . m$. I 8 inches high.

April I th at $7 a \cdot m \cdot 20+\frac{s}{4}$ inches high, at 9 a. $m .22+\frac{1}{2}$, fine warm fun-Thine; here we fee that the warm morning fun gives a frefh vigour to the fap. At I I a.m. the fame day i $6+\frac{1}{2}$, the great perfpiration of the ftem makes it fink.

April i 6 th at $6 a$. $m$. I $9+\frac{3}{2}$ rain. At 4 p. $m$. 13 inches. The fap (in the foregoing Experiment, numb. 34) rifen this day fince noon 2 inches, while this funk by the perfpiration of the ftem; which there was little room for, in the very thort ftem of the other.

April I 7 at I I a.m.24+ $\frac{1}{4}$ inch high, rain and warm; at 7 p. $m .29+\frac{1}{2}$, fine warm rainy weather, which made the fap rife all day, there being little perfpiration by reafon of the rain.

April r 8th at 7 a. $m \cdot 32+\frac{2}{2}$ inches high, and would have rifen higher, if there had been more mercury in the gage; it being all forced into the $\operatorname{leg} y z$. From this time to May sth, the force gradually decreafed. 


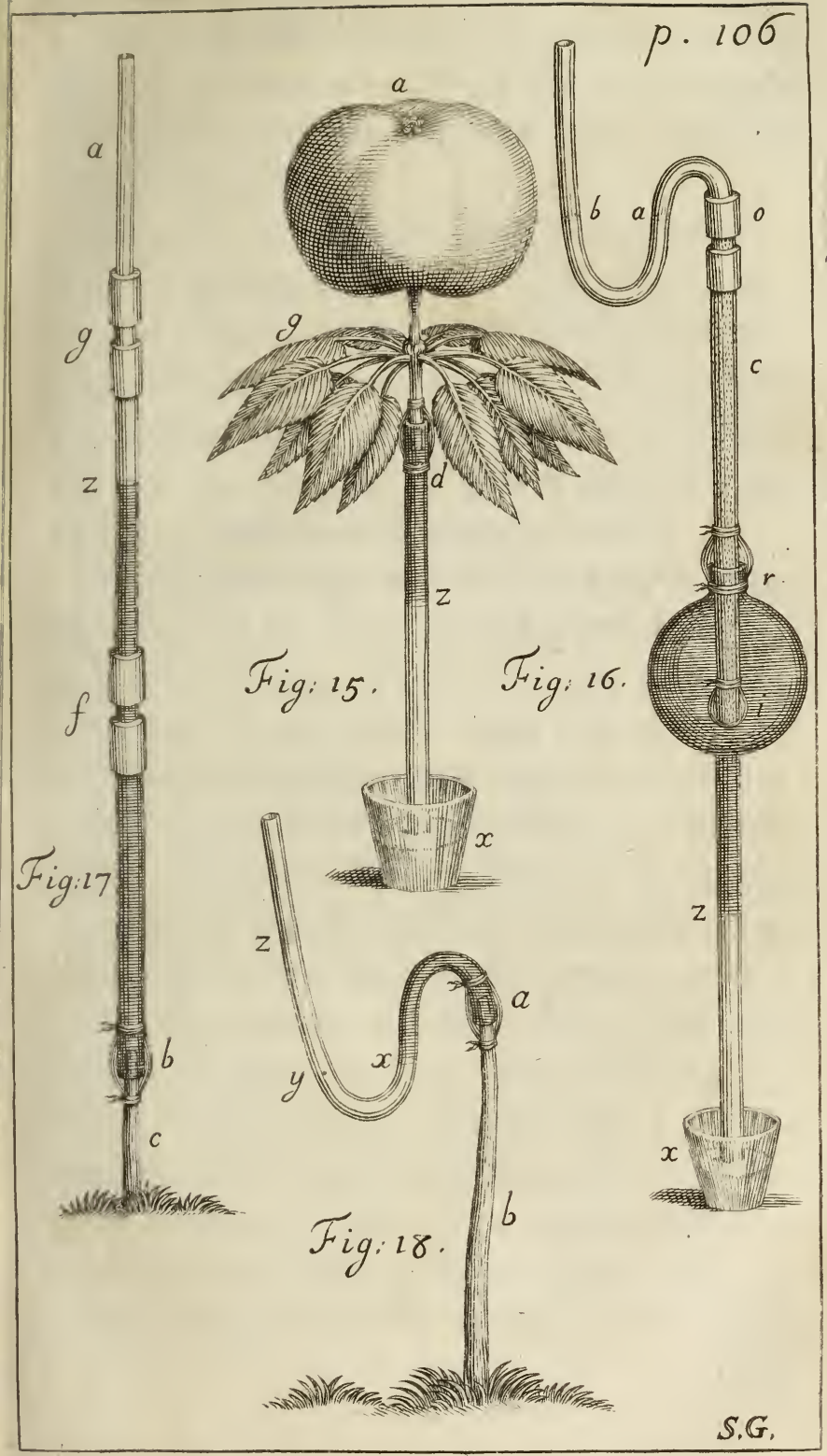





\section{Vegetable Staticks.}

The greateft height of the mercury be. ing $32+\frac{1}{2}$ inches; the force of the fap was then equal to 36 feet $5+\frac{1}{3}$ inches height of water.

Here the force of the rifing fap in the morning is plainly owing to the energy of the root and ftem. In another like mercurial gage, (fixed near the bottom of a Vine which run 20 feet high) the mercury was raifed by the force of the fap 38 inches equal to 43 fect +3 inches $+\frac{1}{3}$ height of water.

Which force is near five times greater than the force of the blood in the great crural artery of a Horfe; feven times greater than the force of the blood in the like artery of a Dog; and eight times greater than the blood's force in the fame artery of a fallow Doe: Which different forces I found by tying thofe feveral animals down alive upon their backs; and then laying open the great left crural artery, where it firt cnters the thigh, I fixed to it (by means of two brafs pipes, which run one into the other) a glafs tubc of above ten feet long, and $\frac{1}{8}$ th of an inch diameter in bore: In which tube the blood of one Horfe rofe eight feet, three inches, and the blood of another Horfe eight

feet, 
feet nine inches. The blood of a little Dog fix feet and half high : In a large Spaniel fe= ven feet high. The blood of the fallow Doe mounted five feet feven inches.

\section{EXPERIMENT XXXVII.}

April 4 th, I fixed three mercurial gages (Fig. 19.) $a, b, c$ to a Vine, on a fouth-eaft alpect, which was so feet long, from the root to the end $r u$. The top of the wall was I I $t-\frac{x}{2}$ feet high; from $i$ to $k, 8$ feet; from $k$ to $e, 6$ feet $+\frac{r}{2}$; from $e$ to $a$, I foot $f-10$ inches; from $e$ to 0,7 feet; From $o$ to $6,5+\frac{1}{2}$ feet; from $O$ to $c, 22$ feet 9 inches; from 0 to $u, 32$ feet 9 inches.

The branches to which $a$ and $c$ were fixed were thriving thoots two years old, but the branch $o b$ was much older.

When I firt fixed them, the mercury was puthed by the force of the fap, in all the gages down the legs 4, 5, I 3 , fo as to rife nine inches higher in the other legs.

The next mo:ning at $7 \mathrm{a}$. $\mathrm{m}$. the mercury in $a$ was puthed $14+\frac{x}{4}$ inches high, in $b$ I 2 $+\frac{5}{7}$, in $C$ I $3+\frac{\pi}{2}$. 


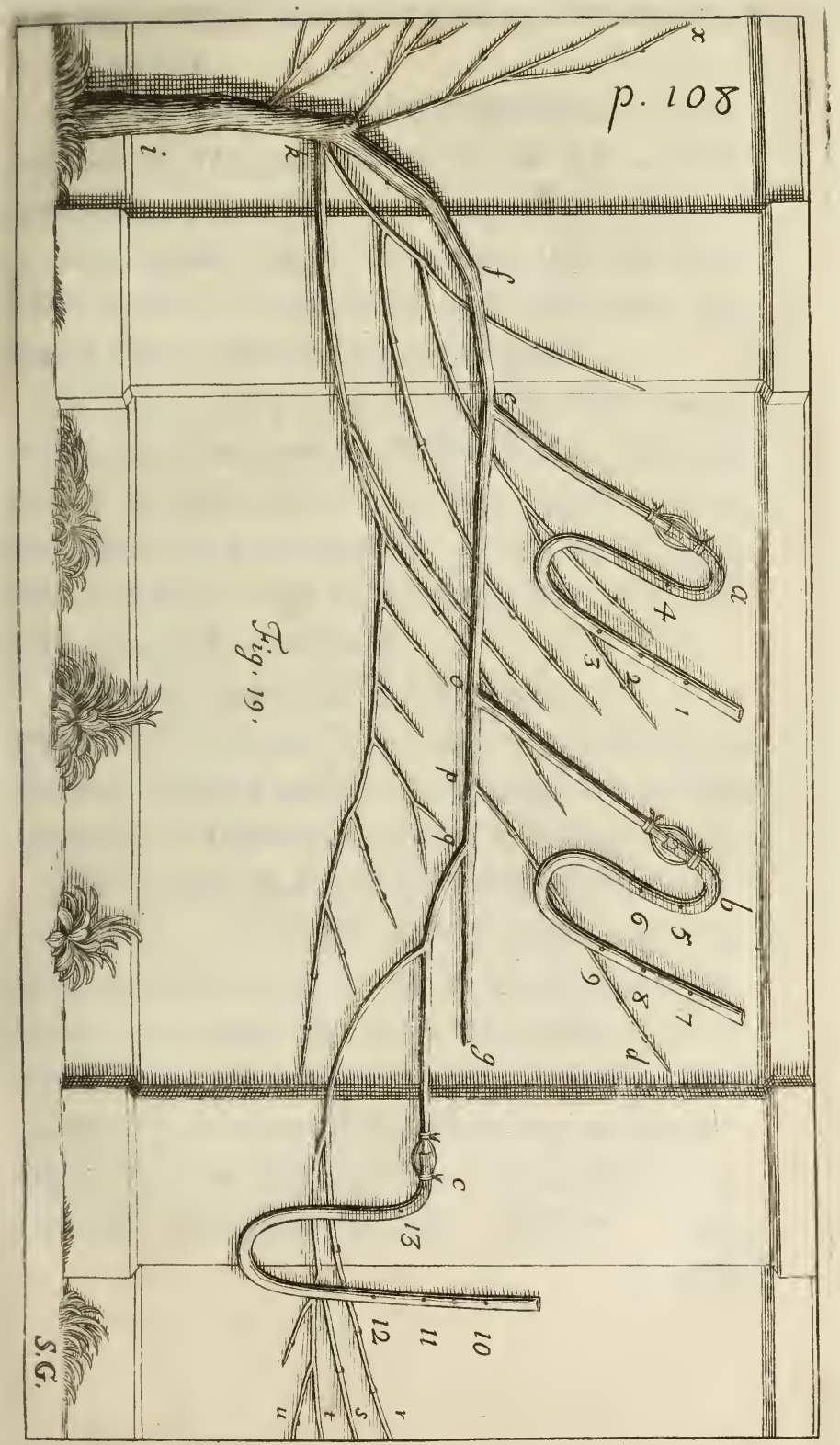




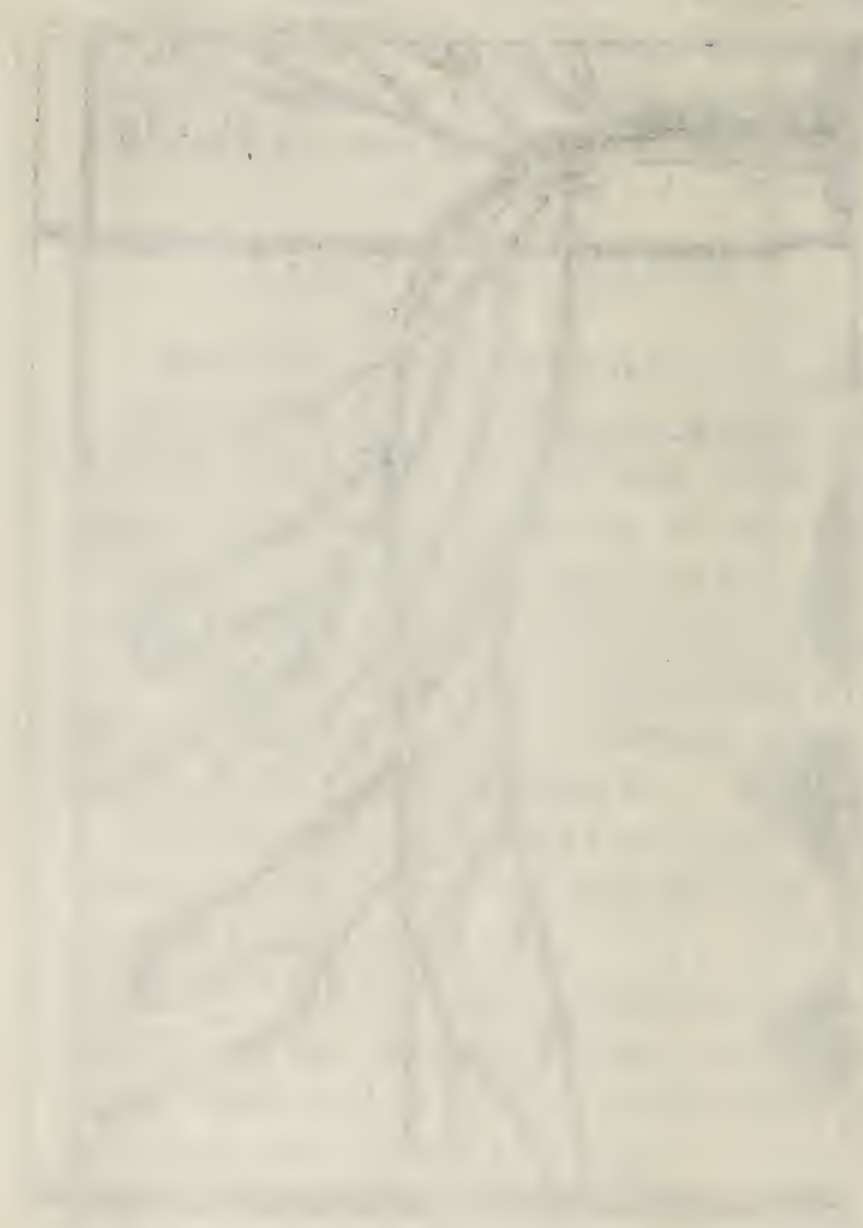




\section{Vegetable Staticks.}

The greateft height to which they puthed the fap feverally was $a 2$ I inches, $b 26$ inches, c 26 inches.

The mercury conftantly fubfided by the retreat of the fap about 9 or 10 in the morning, when the Sun grew hot; but in a very moift foggy morning the fap was later before it retreated, viz. till noon, or fome time after the fog was gone.

About 4 or 5 a clock in the afternoon, when the Sun went off the Vine, the fap began to pufh afrefh into the gages, fo as to make the mercury rife in the open legs; but it always rofe fafteft from Sun rife till 9 or 10 in the morning.

The fap in $b$ (the oldeft ftem) plaid the mont fieely to and fro, and was therefore fooneft affected with the changes from hot to cool, or from wet to dry, and vice ver $\int a$.

And April ro, toward the end of the bleed: ing reafon, $b$ began firft to fuck up the mercury from 6 to $s$, fo as to be 4 inches higher in that leg than the other. But April 24, after a night's rain, $b$ puthed the mercury 4 inches up the other leg, $a$ did not begin to fuck till April 29, viz. 9 days after $b ; c$ did not begin to fuck till May 3. viz. 
$1_{3}$ days after $b$, and 4 days after $a$. May 5 . at $7 \cdot a . m$. a puthed I inch, $c \mathrm{I}+\frac{1}{2}$, but towards noon they all three fucked.

I have frequently obferved the fame difference in other Vines, where the like gages have been fixed at the fame time, to old and young branches of the fame Vine, viz. the oldeft began firft to fuck.

In this Experiment we fee the great force of the fap, at 44 fect 3 inches diftance from the root, equal to the force of a column of water $30 \mathrm{fcet}+\mathrm{II}$ inches $+\frac{1}{4}$ high.

From this Experiment we fee too, that this force is not from the root only, but mut alfo proceed from fome power, in the ftem and branches: For the branch $b$ was much fooner influenced by changes from warm to cool, or dry to wet, and vice ver$\int a$, than the other two branches $i$ or $c$; and 6 was in an imbibing ftate, 9 days before $a$, which was all that time in a ftate of pufhing fap; and $c$ pulhed $I 3$ days after $b$ had ceafed puhing, and was in an imbibing fate.

Which imbibing ftate Vines and Appletrees continue in all the fummer, in every branch, 


\section{Vegetable Staticks.}

branch, as I have found by fixing the like gages to them in $\mathcal{F} u l y$.

\section{EXPERIMENT XXXIX.}

March 10, at the beginning of the bleeding feafon, (which is many days fooner or later, according to the coldnefs or warmth, moifture or drynefs of the feafon) I then cut off a branch of $a$ vine $b f c g$ at $b$, (Fig. 20.) which was 3 or 4 years old, and cemented faft on it a brafs-collar, with a fcrew in it ; to that I fcrewed another brafscollar, which was cemented faft to the glafs tube $z, 7$ feet long and $\frac{z}{4}$ inch diam. (which I find to be the propereft diam.) to that I fcrewed others, to 38 feet height. Thefe tubes were faftened and fecur'd in long wooden tubes, 3 inches fquare, one fide of which was a door opening upon hinges; the ufe of thofe wooden tubes was to preferve the glafs tubes from being broke by the freezing of the fap in them in the night. But when the danger of hard frofts was pretty well over, as at the beginning of April, then I ufually fixt the glaffes without the wooden tubes, faftening them to 


\section{2 Vegetable Staticks.}

fcaffold poles, or twolong iron fpikes drove into the wall.

Before I proceed to give an account of the rife and fall of the fap, in the tubes, I will firft defcribe the manner of cementing on the brafs-collar $b$, to the ftem of the Vine in which I have been often difappointed, and have met with difficulties; it mult therefore be done with great care.

Where I defign to cut the ftem, I firft pick off all the rough ftringy bark carefully with my nails to avoid making any wound thro' the green inner bark; then I cut off the branch at $i$, (Fig. $2 \mathrm{I}$.) and immediately draw over the ftem a piece of dried theepsgut, which I tye faft, as near the end of the ftem as I can, fo that no fap can get by it; the fap being confined in the gut $i f$ : Then I wipe the ftem at $i$ very dry with a warm cloth, and tye round the ftem a ftiff paper funnel $x i$, binding it faft at $x$ to the ftem; and pinning clofe the folds of the paper from $x$ to $i$ : Then I nide the brafs collar $r$ over the gut, and immediately pour into the paper funnel melted brickduft cement, and then fet the brafs-collar into it; which collar is warmed, and dipped before in the ce- 


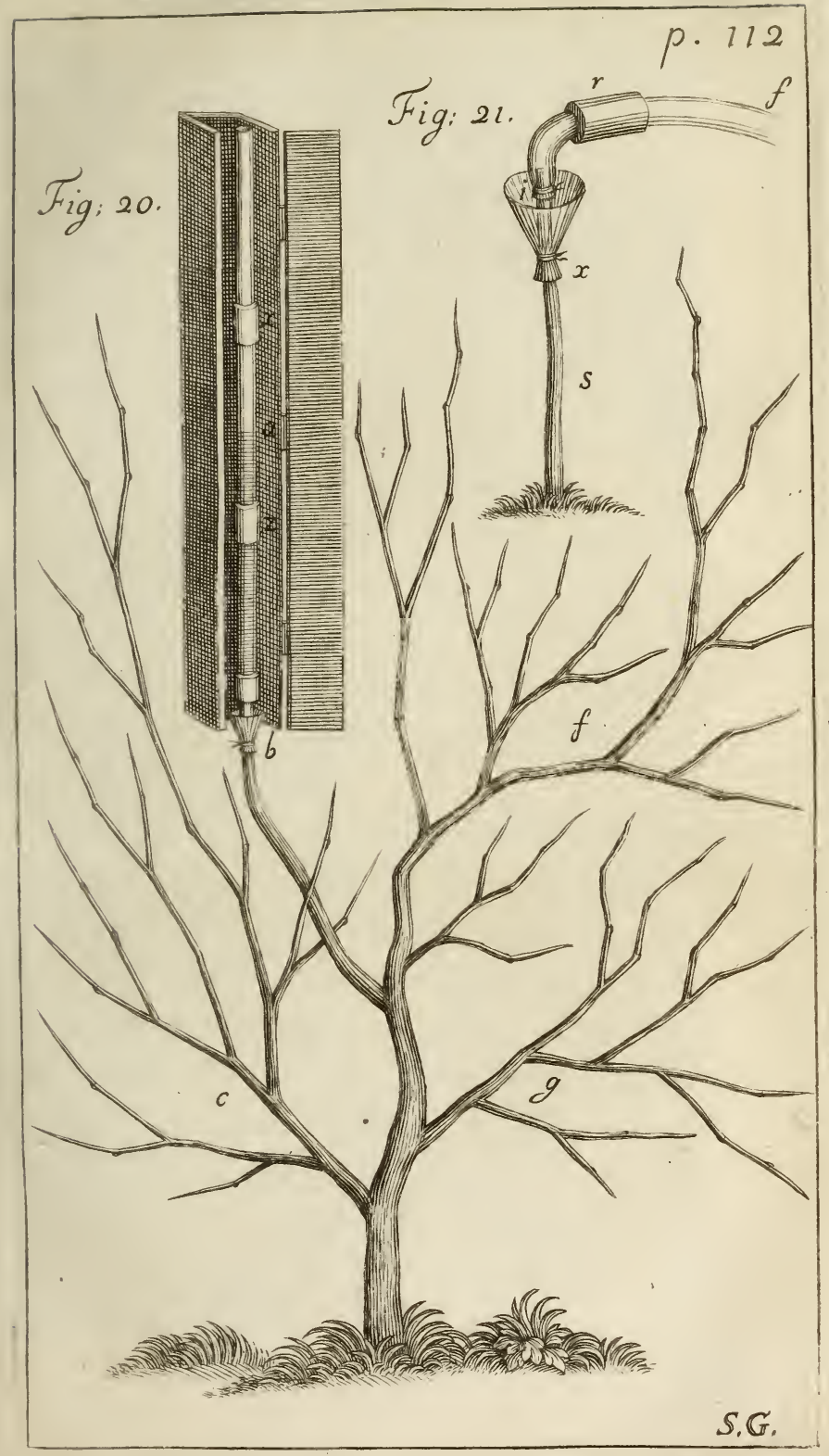





\section{Vegetable Staticks.}

cement, that it may the better now adhere: When the cement is cold, I pull away the gut, and ferew on the glafs tubes.

But finding fome inconvenience in this hot cement (becaufe its heat kills the fap veffels near the bark, as is evident by their being difcoloured) I have fince made ufe of the cold cement of Bees-wax and Turpentine, binding it faft over with wet bladder and packthread, as in Exper. 34.

Inftead of brafs-collars, which ferewed into each other, I often (efpecially with the Syphons in Exper. 37, and 38.) made ufe of two brafs-collars, which were turned a little tapering, fo that one entered and exactly fitted the other.

This joining of the two collars was effectually fecured from leaking, by firf anointing them with a foft cement; and they were fecured from being disjoined, by the force of the afcending fap, by twifting pack-thread round the protuberant knobs on the fides of the collars. When I would feparate the collars, I found it neceffary (except in hot Sunfhine) to melt the foft cement by applying hot irons on the outfide of the collars. 
It is needful to thade all the cemented joints from the Sun with loofe folds of paper, elfe its heat, will often melt them, and fo dilate the cement, as to make it be drove forcibly up the tube, which defeats the Experiment.

The Vines to which the tubes in this Experiment werefixed, were 20 feet high from the roots to their top; and the glafs tubes fixed at feveral heights $b$ from the ground, from fix to two feet.

The fap would rife in the tube the firf day, according to the different vigor of the bleeding ftate of the Vine, either I, 2, 5, I2, I s, or 25 feet; but when it had got to its greateft height for that day, if it was in the morning, it would conftantly begin to fub. fide towards noon.

If the weather was very cool about the middle of the day, it would fubfide only from II or $\mathrm{I}_{2}$, to two in the afternoon; but if it were very hot weather, the fap would begin to fubfide at 9 or 10 a clock, and continue fubfiding till 4,5 , or 6 in the evening, and from that time it would continue ftationary for an hour or two; after which it would begin to rife a little, but 


\section{Vegetable Staticks.}

not much in the night, nor till after the Sun was up in the morning, at which time it rofe faltert.

The frether the cut of the Vine was, and the warmer the weather, the more the fap would rife, and fubfide in a day, as 4 or 6 feet.

But if it were $s$ or $\sigma$ days fince the Vine was cut, it would rife or fubfide but little; the fap-veffels at the tranfverfe cut being faturate and contracted.

But if I cut off a joint or two off the ftem, and new fixed the tube, the fap would then rife and fubfide vigorouly.

Moifture and warmth made the fap moft vigorous.

If the beginning or middle of the bleeding feafon being very kindly, had made the motion of the fap vigorous; that vigour would immediately be greatly abated by cold eafterly winds.

If in the morning, while the fap was in a rifing ftate, there was a cold wind with a mixture of funthine and cloud; when the Sun was clouded, the fap would immediate. ly vifibly fubfide, at the rate of an inch in a minute for feveral inches, if the Suncontinued 


\section{I16 Vegetable Staticks.}

tinued fo long clouded: But as foon as the Sun-beams brokc out again, the fap would immediately return to its then rifing ftate, juft as any liquor in a Thermometer rifes and falls with the alternacies of heat and cold; whence 'tis probable, that the plentiful rife of the fap in the Vine in the bleeding feafon is effected in the fame manner.

When three Tubes were fixed at the fame time to Vines on an eaftern, a fouthcrn, and a weftern Afpect, round my porch; the fap would begin to rife in the morning, firft in the eaftern-tube, next in the fouthern, and laft in the weftern-tube: And towards noon it would accordingly begin to fubfide, firft in the caftern-tube, next in the fouthern, and laft in the weftern-tube.

Where two branches arofe from the fame old weftern trunk, is inches from the ground; and one of thefe branches was fpread on a fouthern, and the other on a weftern Afpect; and glafs-tubes were at the fame time fixed to each of them; the fap would in the morning, as the Sun came on, rife firft in the fouthern, then in the wefterntube; and would begin to fubfide, firft in the fouthern, then in the weftern-tube. 


\section{Vegetable Staticks.}

Rain and warmth, after cold and dry, would make the fap rife all the next day, without fubfiding, tho' it would rife then noweft about noon; becaufe in this cafe the quantity imbibed by the roor, and raifed from it, exceeded the quantity perspired.

The fap begins to rife fooner in the morn. ing in cool weather, than after hot days; the reafon of which may be, becaufe in hot weatler much being evaporated, it is not fo foon fupplied by the roots as in cool weather, when lels is evaporated.

In a prime bleeding feafon I fixt a tube 25 fect long to a thriving branch two years old, and two feet from the ground, where it was cut off; the fap flowed fo briskly, as in two hours to flow over the top of the Tube, which was 7 feet above the top of the Vine; and doubtlefs would have rifen higher, if I had been prepared to lengthen the tube.

When at the diftance of 4 or $s$ days, tubes were affixed to two different branches, which came from the fame ftem, the fap would life higheft in that which was laft fixed; yet if in the fixing the fecond tube there

$$
\text { I } 3
$$

was 


\section{i 8 Vegetable Staticks.}

was much fap lont, the fap would fubfide in the firt tube; but they would not afterwards have their fap in Equilibrio; i. e. the furface of the fap in each was at very unequal heights; the reafon of which is, becaure of the difficulty with which the fap paffes thro' the almoft faturate and contracted Capillarics of the firft cut ftem.

In very hot weather many air bubbles would rife, fo as to make a froth an inch deep, on the top of the fap in the tube.

I fixt a fmall air Pump to the top of a long Tube, which had 2 feet height of fap in it; when I pumped, great plenty of bubbles arofe, tho' the fap did not rife, but fall a little, after I had done pumping.

In Experiment 34. (where a Tube was fixed to a very fhort ftump of a Vine, without any lateral branches) we find the fap rofe all day, and fafteft of all in the greateft heat of the day: But by many obfervations under the $37^{\text {th }}$ and this 38 th Experiments, we find the fap in the tubes conftantly fubfided as the warmth came on towards the middle of the day, and fafteft in the greateft heat of the day. Whence we may reafonably conclude, (confidering the great perfpira- 


\section{Vegetable Staticks.}

fpirations of trees, thewn in the firf chapter) that the fall of the fap, in thefe fap gages, in the middle of the day, efpecially in the warmer days, is owing to the then greater perfpiration of the branches, which perfpiration decreafes, as the heat decreafes towards evening, and probably wholly ceafes when the dews fall.

But when towards the latter end of April, the fpring advances, and many young hoots are come forth, and the furface of the Vine is greatly increafed, and enlarged by the expanfion of feveral leaves; whereby the perfpiration is much increafed, and the fap more plentifully exhaulted, it then ceales to flow in a vifible manner, till the return of the following fpring.

And as in the Vine, fo is the cafe the fame in all the bleeding trees, which ceafe bleeding as foon as the young leaves begin to expand enough, to perfpire plentifully, and to draw off the redundant fap. Thus the bark of Oaks and many other trees moft cafily feparates, while it is lubricated with plenty of fap : But as foon as the leaves expand fufficiently to perfpire off plenty of fap, the bark will then nolonger run (as they term it) but adheres moft firmly to the wood.

$$
\text { I } 4
$$

Ex: 
I20 Vegetable Staticks.

EXPERIMENT XXXIX.

In order to try if I could perceive the ftem of the Vine dilate and contract with heat or cold, wet or dry, a bleeding or not bleeding feafon, fome time in February, I fixt to the ftem of a Vine an inftrument in fuch a manner, that if the Stem had dilated or contracted but the one hundredth part of an inch, it would have made the end of the inftrument, (which was a piece of frong brafs-wire, eighteen inches long) rife or fall very fenfibly about one tenth of an inch; but I could not perccive the inftrument to move, either by heat or cold, a bleeding or not bleeding feafon. Yct whenever it rained the ftem dilated fo as to raife the end of the inftrument or lever $\frac{3}{10}$ of an inch, and when the ftem was dry it fubfided as much.

This Experiment thews, that the fap (even in the bleeding feafon) is confined in its pro. per vefiels, and that it does not confufedly pervade every interftice of the ftem, as the rain does, which entering at the perfpiring pores, foaks into the intertices, and thereby dilates the ftem.

CHAP. 


\section{Vegetable Staticks.}

\section{H A P. IV.}

Experiments, fhewing the ready lateral motion of the Sap, and confequently the lateral communication of the fap veffels. The free palfage of it from the fmall branches towards the ftem, as well as from the ftem to the branches. With an account of fome Experiments, relating to the circulation or non circulation of the lap.

\section{EXPERIMENT XĹ.}

T $N$ order to find whether there was any I lateral communication of the fap and fap vcffels, as there is of the blood in animals, by means of the ramifications, and lateral communications of their veffels:

Auguft I sth, I took a young Oak branch $\frac{7}{8}$ inches diameter, at its tranverfe cut, 6 feet high, and full of leaves. Seven inches from the bottom, I cut a large gap to the pith, an inch long, and of an equal depth the whole length: And 4 inches above that, on the oppofite fide, I cut fuch another gap; I fet the great end of the ftem in water: It imbibed and perfeired in two nights and two, 


\section{2}

Vegetable Staticks.

days $\mathrm{I}_{3}$ ounces, while another like oak branch, fomewhat bigger than this, but with no notch cut in its ftem, imbibed 25 ounces of water.

At the fame time I tryed the like Exper. with a Duke-Cherry branch; it imbibed and perfpired 23 ounces in 9 hours the firft day, and the next day is ounces.

At the fame time I took another $\mathcal{D} u k e$ Cherry branch, and cut 4 fuch fquare gaps to the pith, 4 inches above each other; the Ift North, 2d Eaft, 3d South, 4th Weft: It had a long flender ftem, four feet length, without any branches, only at the very top; yet it imbibed in 7 hours day 9 ounces, and in two days and two nights 24 ounces.

We fee in thefe Experiments a moft free lateral communication of the fap and fap veffels, thefe great quantities of liquor ha. ving paffed laterally by the gaps; for by Experiment 13, 14, Is. (on Cylinders of wood) little evaporated at the gaps.

And in order to try, whether it would not be the fame in branches as they grew on trecs, I cut two fuch oppofite gaps in a Duke-Cherry branch, 3 inclies diftant from each other: The leaves of this branch con- 


\section{Vegetable Staticks.}

tinued green, within 8 or ro days, as long as the leaves on the other branches of the fame tree.

The fame day, viz. Auguft I sth, I cut two fuch oppofite gaps 4 inches diftant, in an horizontal young thriving Oak-branch; it was I inch diameter, I 8 days after many of the leaves begun to turn yellow, which none of the leaves of other boughs did then.

The fame day I cut off the bark for one inch length, quite round a like branch of the fame Oak; i 8 days after the leaves were as green as any on the fame tree; but the leaves fell off this and the foregoing branch early in the winter; yet continued on all the reft of the boughs of the tree (except the top ones) all the winter.

The fame day I cut four fuch gaps, 2 inches wide, and 9 inches diftant from each other, in the upright arm of a Golden-Renate tree; the diameter of the branch was $2+\frac{1}{2}$ inch, the gaps faced the 4 cardinal points of the compars; the apples and leaves on this branch flourifhed as well as thofe on other branches of the fame tree.

Here again we fee the very free lateral paffage 
paffage of the rap, where the direct paffage is feveral times intercepted.

\section{EXPERIMENT XLI.}

Auguft I3. At noon I took a large branch of an Apple-tree, (Fig. 22.) and cemented up the tranfverfe cut, at the great end $x$, and tyed a wet bladder over it : I then cut off the main top branch at $b$; where it was $\frac{6}{8}$ inch diameter, and fet it thus inverted into the bottle of water $b$.

In three days and two nights it imbibed and perfpired 4 pounds +2 ounces $+\frac{x}{2}$ of water, and the leaves continued green; the leaves of a bough cut off the fame tree at the fame time with this, and not fet in water, had been withered 40 hours before. This, as well as the great quantities imbibed and perfpired, hews, that the water was drawn from $b$ moft freely to $e, f, g, h$, and from thence down their refpective branches, and fo perfpired off by the leaves.

This Experiment may ferve to explain the reafon, why the branch 6 , (Fig. 23.) which grows out of the root $c a$, thrives very well, notwith" 


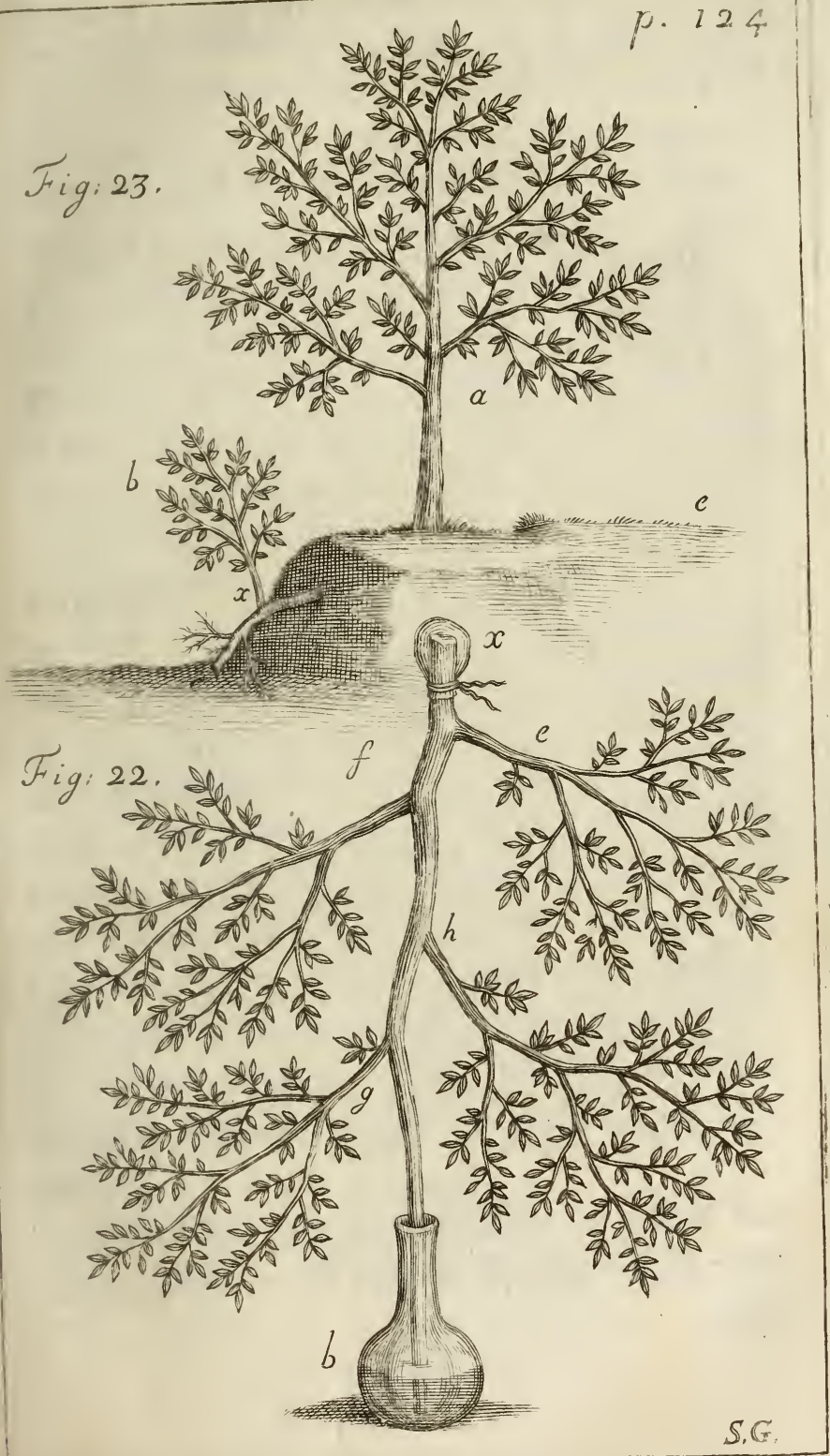





\section{Vegetable Staticks.}

notwithftanding the root $c x$ is here fup pofed to be cut off at $c$, and to be out of the ground: For by many Experiments in the firft and fecond chapters, it is evident, that the branch $b$ attracts fap at $x$ with great force: And by this prefent Experiment, 'tis as evident, that fap will be drawn as freely downwards from the tree to $x$, as from $c$ to $x$, in care the end $c$ of the root were in the ground; whence 'tis no wonder, that the branch $b$ thrives well, tho' there be no circulation of the fap.

This Experiment 4I, and Experiment 26, do alfo thew the rearon why, where thefe trees (Fig. 24) are inarched, and thereby incorporated at $x$ and $z$, the middle tree will then grow, tho' it be cut off from its roots; or the root be dug out of the ground, and fufpended in the air; viz. becaufe the middle tree $b$ attracts nourifhment ftrongly at $x$ and $z$, from the adjoyning trees $a c$, in the fame manner as we fee the inverted boughs imbibed water in thefe Exper. 26, and $4 \mathrm{I}$.

And from the fame reafon it is that Elders, Sallows, Willows, Briars, Vines, and 


\section{Vegetable Staticks.}

moft Shrubs will grow in an inverted ftate, with their tops downwards in the earth.

\section{EXPERIMENT XLII.}

Fuly 27 th, I repeated Monfieur Perault's Experiment, viz. I took Duke Cherry, $A p$ ple and Curran-Boughs, with two branches each, one of which $a c$ (Fig. 25.) I immerfed in the large veffel of water $e d$, the other branch hanging in the open air : I hung on a rail, at the fame time, other branches of the fame forts, which were then cut off. After three days, thofe on the rails were very much withered and dead, but the branches 6 were very green; in 8 days the branch 6 of the Duke-Cherry was much withered; but the Currans and Apple-branch $b$ did not fade till the eleventh day: Whence 'tis plain, by the quantities that muft be perfpired in elcven days, to keep the leaves $b$ green fo long, and by the wafte of the water, out of the vefiel, that thefe boughs 6 muft have drawn much water, from and thro' the other boughs and leaves $c$, which were im. merfed in the veffel of water. 


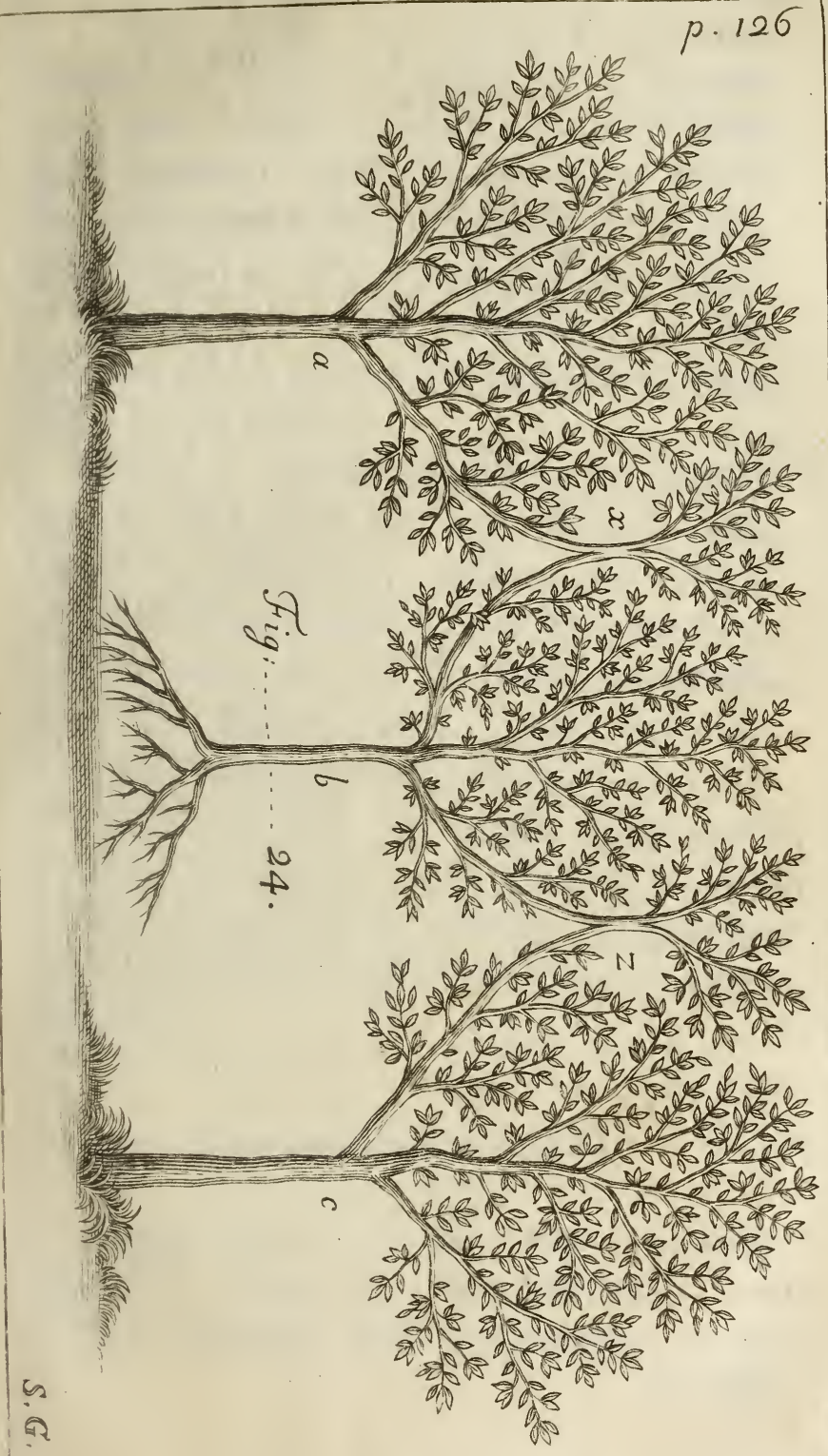





\section{Vegetable Staticks.}

I repeated the like Experiment on the branches of Vines and Apple-trees, by running their boughs as they grew into large glafs chymical retorts full of water, where the leaves continued green for feveral weeks, and imbibed confiderable quantities of water.

This thews how very probable it is, that rain and dew is imbibed by vegetables, efpecially in dry feafons.

Which is further confirmed by Experiments lately made on new planted trees; where by frequently walhing the bodies of the moft unpromifing, they have out-ftripped the other trees of the fame plantation. And Mr. Miller advifes " Now and then " in an evening to water the head, and with ss a brufh to wafh and fupple the bark all " round the trunk, which (fays he) I have " often found very ferviceable." Supplement to his Gardener's Dictionary, Vol. II. under Planting.

\section{EXPERIMENT XLIII.}

Auguft 2oth at I p. m. I took an Applebranch b, (Fig. 26.) nine feet long, I + $\frac{1}{4}$ inch diameter, with proportional lateral

branches, 


\section{8 \\ Vegetable Staticks.}

branches, I cemented it faft to the tube a, by means of the leaden Syphon $l$ : But firft I cut away the bark, and laft year's ringlet of wood, for 3 inches length to $r$. I then fifled the tube with water, which was I 2 feet long, and $\frac{1}{2}$ inch diameter, having firft cut a gap at $y$ thro the bark, and laft year's wood, I 2 inches from the lower end of the ftem: the water was very freely imbibed, viz. at the rate of $3+\frac{2}{2}$ inches in a minute. In half and hour's time I could plainly perceive the lower part of the gap $y$ to be moifter than before; when, at the fame time, the upper part of the wound looked white and dry.

Now in this care the water muft neceffarily afcend from the tube, thro' the innermoft wood, becaufe the laft year's wood was cut away, for 3 inches length all round the ftem; and confequently, if the fap in its natural courfe defcended by the laft year's ringlet of wood, and between that and the bark (as many have thought) the water fhould have defcended by the laft year's wood,or the bark, and fo have firft moiftened the upper part of the gap $y$; but on the contrary, the lower part was moiften'd, and not the upper part. 


\section{p. 128}

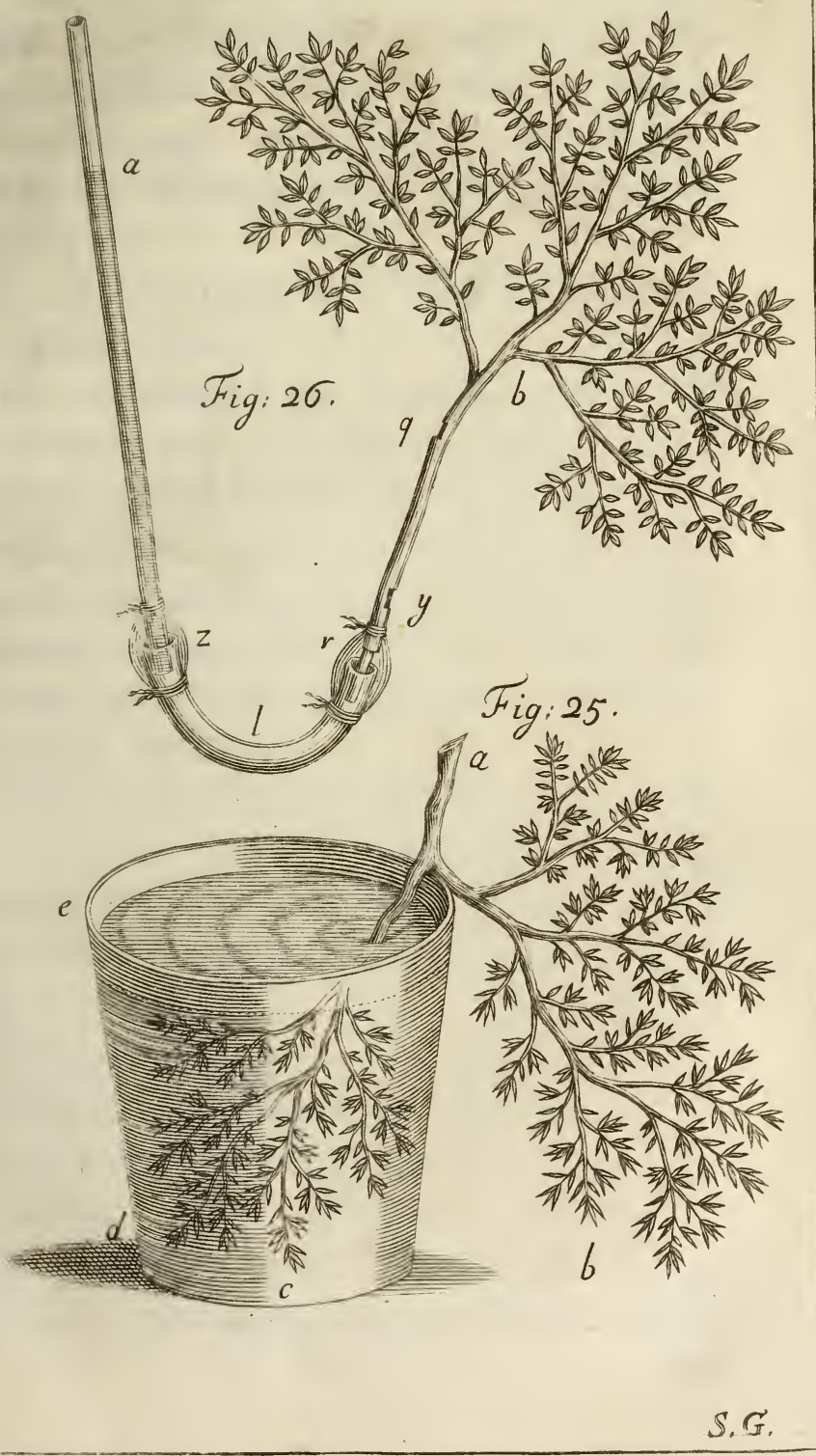





\section{Vegetable Staticks.}

I repeated this Experiment with a large Duke-Cherry branch, but could not perceive more moifture at the upper, than the lower part of the gap, which oughe to have been, if the fap defcends by the laft year's wood or the bark.

It was the fame in a Quince-branch as the Duke Cherry.

$N$. B. When I cut a notch in either of thefe branches, 3 feet above $r$, at $q$, I could neither fee nor feel any moifture, notwithftanding there was at the fame time a great quantity of water pafling by; for the branch imbibed at the rate of 4,3 or 2 inches per minute, of a column of water which was half inch diameter.

The reafon of which drynefs of the notch $q$ is evident from Experiment II, viz. becaule the upper part of the branch above the notch imbibed and perfpired 3 or 4 times more water, than a column of 7 feet height of water in the tube could in.pell from the bottom of the ftem to $q$, which was 3 feet length of ftem; and confequently, the notch muft neceffarily be dry, notwithftanding fo large a fream of water was paffing by; viz. becaufe the branch 
and ftem above the notch was in a frongly imbibing ftate, in order to fupply the great perfpiration of the leaves.

\section{EX P ER I MENT XLIV.}

Auguft gth at ro a.m. I fix'd in the fame manner (as in the foregoing Experiment) a Duke.Cherry branch s feet high, and I inch diameter, but did not cut away any of the bark or wood at the great end; I filled the tube with water, and then cut a flice off the bark an inch long, 3 inches above the great end; it bled at the lower part moft freely, while the upper part continued dry.

The fame day I tryed the fame Experiment on an Apple-branch, and it had the fame effect.

From thefe Experiments 'tis probable that the fap afcends between the bark and wood, as well as by other parts.

And fince by other Experiments it is found that the greateft part of the fap is raifed by the warmth of the Sun on the leaves, which fecm to be made broad and thin for that purpole; for the fame realon, it's molt probable, it thould rife alfo in thofe parts 


\section{Vegetable Staticks.}

which are moft expored to the Sun, as the bark is.

And when we confider, that the rap veffels are fo very fine, as to reduce the fap almoft to a vapour, before it can enter them, the Sun's warmth on the bark fhould moft eafily difpofe fuch rarified fap to afcend, inftead of defcending.

\section{EXPERIMENT XLV.}

Fuly 27 th, I took feveral branches of $C$ urrans, Vines, Cherry, Apple, Pear and Plumtree, and fet the great ends of each in veffels of water $x$, (Fig. 3 I.) but firft took the bark for an inch off one of the branches, as at $z$, to try whether the leaves above $z$ at $b$ would continue green longer than the leaves of any of the other branches $a, c, d$; but I could find no difference, the leaves withering all at the fame time: Now, if the return of the fap was ftopped at $z$, then it would be expected, that the leaves at 6 Thould continue green, longer than thofe on the other branches, which did not happen, neither was there any moifture at $\not$. 
132 Vegetable Staticks.

\section{EXPERIMENT XLVI.}

In Auguft, I cut off the bark for an inch round, of a young thriving Oak-branch, on the North-Weft fide of the tree. The leaves of this and another branch, which had the bark cut at the fame time, fell early, viz. about the latter end of October, when the leaves of all the other branches of the fame tree, except thore at the very top of the tree, continued on all the winter.

This is a further proof, that lefs fap goes to branches which have the bark cut off, than to others.

The 19th of April following, the buds of this branch were 5 or 7 days forwarder than thofe of other branches of the fame tree; the reafon of which may probably be, becaufe lefs frefh crude fap coming to this branch than the others, and the peripirations in all branches being ceteris paribus nearly equal, the leffer quantity of fap in this branch mut fooncr be infpiffated into a glutinous fubftance, fit for new productions, than the fap of other branches, thas abounded 


\section{Vegetable Staticks.}

abounded with a greater plenty of freth thin fap.

The fame is the reafon why Apples, Pears, and many other fruits, which have fome of their great fap veffels eaten afunder by infeets bred in them, are ripe many days before the reft of the fruit on the fame trees; As alfo that fruit, which is gathered fome time before it is ripe, will ripen fooner than if it had hung on the tree, tho' it will not be fo good; becaufe in thefe cafes the wormeaten fruit is deprived of part of its nourithment, and the green gathered fruit of all.

And for the fame reafon fome fruits are fooner ripe towards the tops of the trees, than the other fruit on the fame tree; viz. not only, becaufe they are more expofed to the fun; but alfo, becaufe being at a greater diftance from the root, they have fomewhat lefs nourifhment.

And this is, doubtlefs, one reafon why plants and fruits are forwarder in dry, fandy or gravelly foils, than in moifter foils; viz. not only, becaufe thofe foils are warmer on account of their drynefs; but allo, becaufe lefs plenty of moifture is conveyed up the plants; which plenty of moifture, tho 


\section{I34 Vegetable Staticks.}

it promotes their growth, yet retards their coming to maturity. And for the fame reafon, the uncovering the roots of trees for fome time, will make the fruit be confderally the forwarder.

And on the other hand, where trees abound with too great a plenty of frefh drawn fap, as is the cafe of trees whofe roots are planted too deep in cold moint earth, as alfo of too luxuriant Peach and other Wall trees; or which comes almont to the fame, where the fap cannot be perfpired off in a due proportion; as in Orchards, where trees ftand too near each other, fo as to hinder perfpiration, whereby the fap is kept in too thin and crude a ftate; in all thefe cafes little or no fruit is produced.

Hence alfo in moderately dry fummers, cateris paribus, there is ufually greateft plenty of fruit; becaufe the fap in the bearing twigs and buds is more digefted, and brought to a better confiftence, for hooting out with vigour and firmrefs, than it is in cool moift fummers: And this obfervation has been verified in the years 1723,1724 , and 1725 . See an account of them under it. Exp. 20. 


\section{$V$ Vegetable Staticks.}

But to return to the fubject of the motion of the fap; when the fap has firft paffed thro' that thick and fine ftrainer, the bark of the root, we then find it in greateft quantities, in the moft lax part, between the bark and wood, and that the fame thro the whole tree. And if in the early fpring, the Oak and feveral other trees were to be examined near the top and bottom, when the fap firft begins to move, fo as to make the bark eafily run, or peel off, I believe it would be found, that the lower bark is firft moiftened ; whereas the bark of the top branches ought firf to be moiftened, if the fap defcends by the bark: As to the Vine, I am pretty wcll affured that the lower bark is firft moiftened.

We fee in many of the foregoing Experiments, what quantities of moifture trees do daily imbibe and perfpire: Now the celerity of the fap muft be very great, if that quantity of moifture muft, moft of it, af: cend to the top of the tree, then defcend, and afcend again, before it is carried off by perfipiration.

The defect of a circulation in vegetables feems in fome meafure to be fupplied by the much greater quantity of liquor, which

$$
\mathrm{K} 4 \text { the }
$$


I 36 Vegetable Staticks.

the vegetable takes in, than the animal, whereby its motion is accelerated; for by $E x$ periment Ift, we find the Sunflower, bulk for bulk, imbibes and perfpires 17 times more frefh liquor than a man every 24 hours.

Befides, nature's great aim in vegetables being only that the vegetable life be carried on and maintained, there was no occafion to give its fap the rapid motion, which was neceffary for the blood of animals.

In animals, it is the heart which fets the blood in motion, and makes it continually circulate; but in vegetables, we can difcover no other caufe of the fap's motion, but the ftrong attraction of the capillary fap veffels, affifted by the brisk undulations and vibrations, caufed by the fun's warmth, whereby the fap is carried up to the top of the talleft trees, and is there per(pired off thro' the leaves: But when the furface of the tree is greatly diminifhed by the lofs of its leaves, then alfo the perfpiration and motion of the fap is proportionably diminifhed, as is plain from many of the foregoing Experiments: So that the afcending velocity of the fap is principally accelerated by the plentiful perfipiration of the leaves, thereby making room for 


\section{Vegetable Staticks.}

for the fine capillary veffels to exert their vaftly attracting power, which perfpiration is effected by the brisk rarifying vibrations of warmth: A power that does not feem to be any ways well adapted, to make the fap defcend from the tops of vegetables by different veffels to the root.

If the fap circulated, it muft needs have been feen defcending from the upper part of large gathes, cut in branches, fet in water, and with columns of water preffing on their bottoms in long glafs tubes, in Exp. 43, and 44. In both which cafes, it is certain that great quantitie of water paffed thro' the ftem, fo that it mult needs have been feen defcending, if the return of the fap downwards were by trufion or pulfion, whereby the blood in animals is returned thro' the veins to the heart: And that pulfion, if there were any, mut neceffarily be exerted with prodigious force, to be able to drive the fap thro' the finer capillaries. So that if there be a return of the fap downwards, it muft be by attraction, and that a very powerful one, as we may fee by many of thefe Experiments, and particularly by Experiment I1. But it is hard to conceive, 


\section{$13^{8}$ \\ Vegetable Staticks.}

what and where that power is which can be equivalent to that provifion nature has has made for the afcent of the fap in confequence of the great perfpiration of the leaves.

The inftances of the Jeffamine tree, and of the Paffion tree, have been looked upon as ftrong proofs of the circulation of the fap, becaufe their branches, which were far below the inoculated Bud, were gilded: But we have many vifible proofs in the Vine and other bleeding trees of the fap's receding back, and pufhing forwards altcrnately, at different times of the day and night. And there is great reafon to think, that the fap of all other trees has fuch an alternate, receding and progreffive motion, occafioned by the alternacies of day and night, warm and cool, moift and dry.

For the fap in all vegetables does probably recede in fome meafure from the tops of branches, as the Sun leaves them; becaufe its rarifying power then ceafing, the greatly rarified fap, and air mixt with it, will condenfe and take up lefs room than they did, and the dew and rain will then be ftrongly imbibed by the leaves, as is probable from Exper. 42 , and feveral others;

whereby 


\section{Vegetable Staticks.}

whereby the body and branches of the vegetable which have been much exhaufted by the great evaporation of the day, may at night imbibe fap and dew from the leaves; for by feveral Experiments in the firft chapter, plants were found to increafe confiderably in weight, in dewy and moift nights. And by other Experiments on the Vine in the third chapter, it was found, that the trunk and branches of Vines were always in an imbibing ftate, caufed by the greatperfpiration of the leaves, except in the bleeding feafon; but when at night that perfpiring power ceares, then the contrary imbibing power will prevail and draw the fap and dew from the leaves, as well as moifture from the roots.

And we have a furthcr proof of this in Experiment I2, where by fixing mercurial gages to the ftems of feveral trees, which do not bleed, it is found, that they are always in a ftrongly imbibing fate, by drawing up the mercury feveral inches: Whence it is eafie to conceive, how fome of the particles of the gilded Bud, in the inoculated Jeffamine, may be abforbed by it, and thereby communicate their gilding Miarma to the 
fap of other branches; efpecially when fome months after the inoculation, the ftock of the inoculated Jeffamine is cut off a little above the Bud; whereby the ftock, which was the counter acting part to the ftem, being taken way, the ftem attracts more vigorouny from the Bud.

Another argument for the circulation of the fap, is, that fome forts of graffs will infect and canker the ftocks they are grafted on: But by Exper. I 2 and 37, where mercurial gages were fixed to frefh cut ftems of trees, it is evident, that thofe ftems were in a ftrongly imbibing ftate; and confequently the cankered ftocks might very likely draw rap from the graff, as well as the graff alternately from the ftock; juft in the fame manner as leaves and branches do from each other, in the viciffitudes of day and night. And this imbibing power of the ftock is fo great, where only fome of the branches of a tree are grafted, that the remaining branches of the ftock will, by their ftrong attraction, ftarve thofe graffs; for which reafon it is ufual to cut off the greateft part of the branches of the ftock, leav. ing 


\section{Vegetable Staticks.}

ing only a few fmall ones to draw up the fap.

The inftance of the Ilex grafted upon the Englifh Oak, feems to afford a very confiderable argument againft a circulation. For if there were a free uniform circulation of the fap thro' the Oak and Ilex, why fhould the leaves of the Oak fall in winter, and not thofe of the Ilex?

Another argument, againt a uniform circulation of the fap in trees as in animals, may be drawn from Exper. 37. where it was found by the three mercurial gages fixt to the fame Vine, that while fome of its branches changed their ftate of protruding fap into a ftate of imbibing, others continued protruding fap, one nine, and the other thirteen days longer.

In the fecond Vol. of Mr. Lowthorp's Abridgment of the Philos. Tranfac. p. 708. is recited an Experiment of Mr. Brotherton's, viz. A young Hazel $n$, Fig. 27 , was cut into the body at $x z$ with a deep galh; the parts of the body below at $z$, and above at $x$, were cleft upwards and downwards, and the fplinters $x, z$ by wedges were kept off from touching each other, or the 


\section{Vegetable Staticks.}

reft of the body. The following year, the upper fplinter $x$ was grown very much, but the lower fplinter $z$ did not grow, but the reft of the body grew, as if there had been no galh made: I have not yet fucceeded in making this Experiment, the wind having broken at $x z$ all the trees I prepared for it: But if there was a Bud at $x$ which hot out leaves, and none at $z$, then by Exper. 41. 'tis plain, that thofe leaves might draw much nourifhment thro' $t x$, and thereby make it grow; and I believe, if, vice ver $\int a$, there were a leaf bearing Bud at $z$, and none at $x$, that then the fplinter $z$ would grow more than $x$.

The reafon of my conjecture, I ground upon this Experiment, viz. I chore two thriving thoots of a dwarf Pear-tree l l $a$ a. Fig. 28, 29. At three quarters of an inch diftance I took half an inch breadth of bark off each of them, in feveral places, viz. $2,4,6,8$, and at 10, 12, 14. every one of the remaining ringlets of bark had a leaf bearing bud, which produced leaves the following fummer, except the ringlet $I_{3}$, which had no fuch Bud. The ringlet 9 and I I of $a$ a grew and fwelled at their bottoms, 


\section{Vegetable Staticks.}

till Auguft, but the ringlet I 3 did not increafeat all, and in Auguft the whole thoot a $a$ withered and dyed; but the fhoot $l l$, lives and thrives well, each of its ringlets fwelling much at the bottom : Which fwellings at their bottoms muft be attributed to fome other caufe than the ftoppage of the fap in its return downwards, becaufe in the fhoot $l l$, its return downwards is intercepted three feveral times by cutting away the bark at 2, 4, 6. The larger and more thriving the leaf bearing Bud was, and the more leaves it had on it, fo much the more did the adjoining bark fwell at the bottom.

Fig. 30. Reprefents the profile of one of the divifions in Fig. 28. fplit in halves, in which may be feen the manner of the growth of the laft year's ringlet of wood thooting a litthe upwards at $x x$; and hooting downwards and fwelling much more at $z z$; where we may obferve, that what is fhot endways, is plainly parted from the wood of the preceding year, by the narrow interfices $x r, z r$, whence it hould reem, that the growth, of the yearly new ringlets 
144 Vegetable Staticks.

of wood confifts in the fhooting of their fibres lengthways under the bark.

That the fap does not defcend bet ween the bark and the wood, as the favourers of a circulation fuppofe, feems evident from hence, viz. that if the bark be taken off for 3 or 4 inches breadth quite round, the bleeding of the tree above that bared place will much abate, which ought to have the contrary effect, by intercepting the courfe of the refluent fap, if the fap defcended by the bark.

But the reafon of the abatement of the bleeding in this cafe may well be accounted for, from the manifert proof we have in thefe Experiments, that the fap is ftrongly attracted upwards by the vigorous operation of the perfpiring leaves, and attracting Capillaries: But when the bark is cut off for fome breadth below the bleeding place, then the fap, which is between the bark and the wood below that disbarked place, is deprived of the ftrong attracting power of the leaves, \& $c$. and confequently the blecding wound cannot be fupplied fo faft with fap, as it was before the bark was taken off.

Hence alfo we have a hint for a probable conjecture why in the alternately disbarked

fticks, 


\section{Vegetable Staticks.}

fticks, ll a a Fig. 28, 29. the bark fwelled more at the upper part of the disbarked places than at the lower, viz. becaufe thofe lower parts were thereby deprived of the plenty of nourithment which was brought to the upper parts of thofe difabled places, by the frong attradion of the leaves on the Buds 7 , \&c. of which we have a further confirmation in the ringlet of bark $N^{\circ}$. I 3. Fig. 29. which ringlet did not fwell or grow at either end, being not only dcprived of the atrraction of the fuperior leaves, by the bared placed No. I 2 . but alfo with_ out any leaf Bud of its own, whore branching fap Veffels, being like thore of other leaf Buds rooted downwards in the wood, might thence draw fap, for the nourifhment of its felf and the adjoining bark No. I 3. But had thefe rooting fap veffels run upwards, inftead of downwards, 'tis probable, that in that cafe the upper part of each ringlet of bark, and not the lower, would have fwelled, by having nourithment thereby brought to it from the inmoft wood.

We may hence alfo fee the reafon why, when a tree is unfruitful, it is brought to bear fruit, by the taking ringlets of bark off 


\section{Vegetable Siaticks.}

from its branches, viz. becaufe thereby a lefs quantity of fap arifing, it is better didigefted and prepared for the nourifhment of the fruit; which from the greater quantity of oil, that is ufuaily found in the feeds, and their containing veffels, than in other parts of plants, Thews that more fulphur and air is requifite for their production, than there is for the production of wood and leaveș.

But the moft confiderable objection againft this progreffive motion of the fap, without a circulation, arifes from hence, viz. that it is too precipitate a courfe, for a due digeftion of the fap, in order to nutrition : Whereas in animals nature has provided, that many parts of the blood thall run a long courfe, before they are either applied to nutrition, or difcharged from the animal.

But when we confider, that the great work of nutrition, in vegetables as well as animals, (I mean after the nutriment is got into the veins and arteries of animals) is chiefly carried on in the fine capillary veffels, where nature felects and combines, as thall beft fuit her different purpofes, the feveral mutually attracting nutritious particles, which were hitherto kept disjoined by the motion 


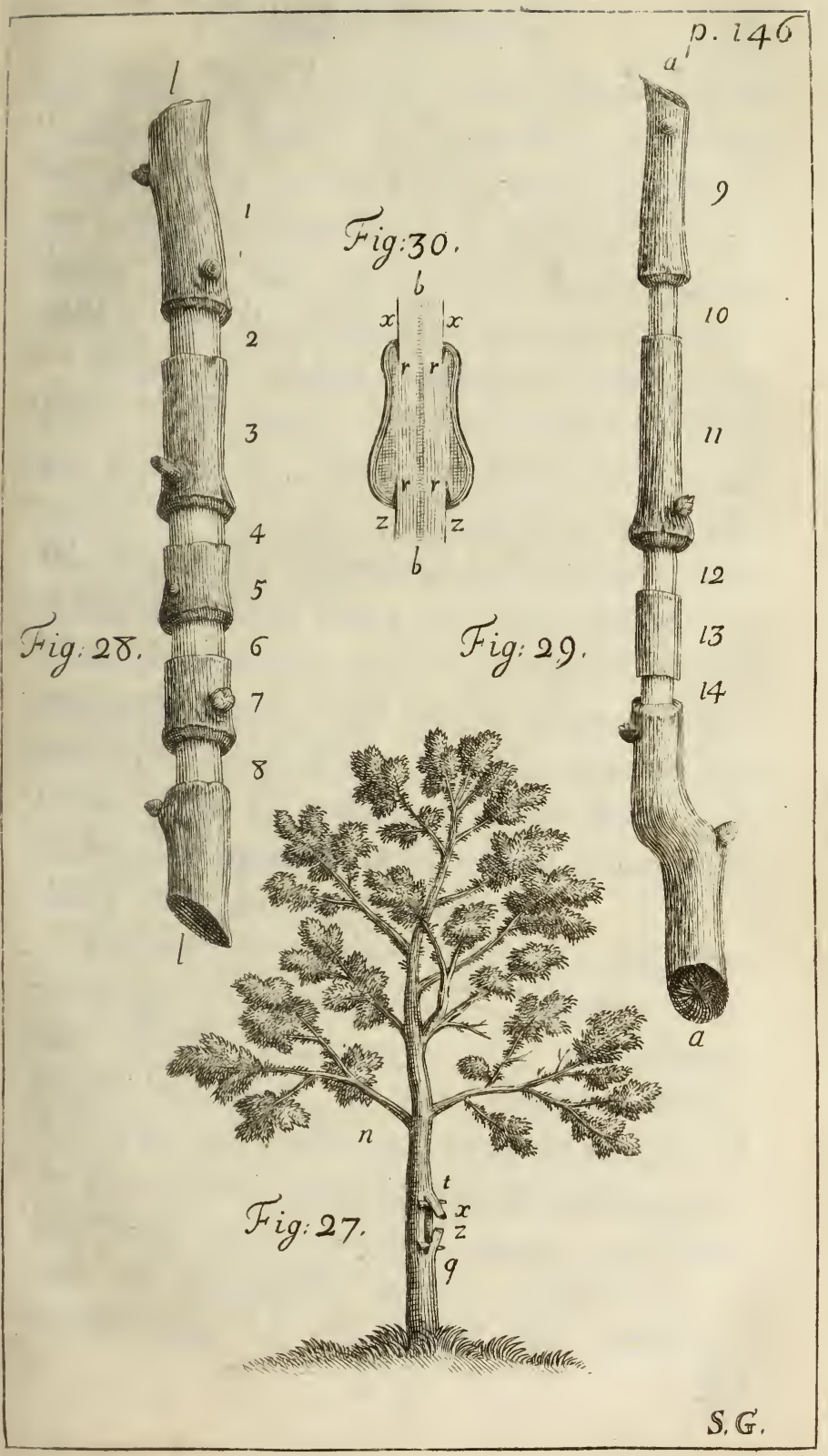





\section{Vegetable Staticks.}

of their fluid vehicle; we thall find that nature has made an abundant provifion for this work in the Atructure of regetables; all whofe compofition is made up of nothing elfe but innumerable fine capillary veffels, and glandulous portions or veficles.

Upon the whole, I think we have, from thefe experiments and obfervations, fufficient ground to believe that there is no circulation of the fap in vegetables; notwithftanding many ingenious perfons have been induced to think there was, from feveral curious obfervations and experiments, which evidently prove, that the fap does in fome meafure recede from the top towards the lower parts of plants, whence they were with good probability of reafon induced to think that the fap circulated.

The likelieft method effeetually and con: vincingly to determine this difficulty, whether the fap circulates or not, would be by ocular infpection, if that could be attained: And I fee no reafon we have to defpair of it, fince by the great quantities imbibed and perfpired, we have good ground to think, that the progreffive motion of the fap is confiderable in the largeft fap veffels of

$$
\text { I. } 2 \text { the }
$$




\section{I48 Vegetable Statick:}

the tranfparent ftems of leaves: And if our eyes, anifted with microfcopes, could come at this defirable fight, I make no doubt, but that we fhould fee the fap, which was progrefive in the heat of the day, would on the coming on of the cool evening, and the falling dew be retrograde in the fame veffels.

\section{H A P. V.}

Experimenis, whereby to prove, that a confiderable quantity of air is infpired by Plants.

T $T$ is well known that air is a fine elaA ftick fluid, with particles of very different natures floating in it, whereby it is admirably fitted by the great author of nature, to be the breath of life, of regetables, as weil as of animals; without which they can no more live, nor thrive than animals can.

In the Experiments on Vines, chapter III. we faw the very great quantity of air, which was continually afcending from the Vines, thro' the fap in the tubes; which manifertly thews what plenty of it is taken in by vegetables, and is perfpired off with the fap thro' the leaves. 


\section{Vegetable Staticks. \\ EXPERIMENT XIVII.}

Sept. 9 th, at 9 a. m. I cemented an Applebranch $b$ (Fig II.) to the glafs tube $r i$ $e z$ : I put no water in the tube, but fet the end of it in the ciftern of water $x$. Three hours after I found the water fucked up in the tube many inches to $z$; which thews, that a confidcrable quantity of air was imbibed by the branch, out of the tube riez: And in like manner did the Apricockbranch (Exper. 29.) daily imbibe air.

\section{EXPERIMENT XLVIII.}

I took a cylinder of Birch with the bark on, 16 inches long and $\frac{3}{4}$ diameter, and ce. mented it faft at $z$; (Fig. 32.) to the hole in the top of the air pump receiver $p p$, fetting the lower end of it in the ciftern of water $x$; the upper end of it at $n$ was well clofed up with melted cement.

I then drew the air out of the receiver, upon which innumerable air bubbles iffued continually out of the ftick into the water $x$. I kept the receiver exhaufted all that 


\section{iso Vegetable Staticks.}

day, and the following night, and till the next day at noon, the air all the while iffuing into the water $x$ : I continued it thus long in this ftate, that I might be well affured, that the air muft pars in thro' the baik, to fupply that great and long flux of air at $x$. I then cemented up $s$ old eyes in the fick, between $\approx$ and $n$, where little thoots had formerly been, but were now perifhed, yet the air ftill continued to flow freely at $x$.

It was obfervable in this, and many of the Experiments on Aticks of other trees, that the air which could enter only thro' the bark between $z$ and $n$, did not iffue into the water, at the bottom of the ftick, only at or near the bark, but thro' the whole and inmoft fubftance of the wood, and that chiefly, as I guefs by the largeners of the bafes of the hemifpheres of air thro' the largeft veffels of the wood; which obfervation corroborates Dr. Grew's and Malpighi's opinion, that they are air veffels.

I then cemented upon the receiver the cylindrical glafs $y y$, and filled it full of water, fo as to ftand an inch above the top r of the ftick. 


\section{Vegetable Staticks.}

The air ftill continued to flow at $x$, but in an hour's time it very much abated, and in two hours ceafed quite; there being now no paffage for frefh air to enter, and fupply what was drawn out of the ftick.

I then, with a glafs crane drew off the water out of the cylinder $y y$, yct the air did not iffue thro' the wood at $x$.

$I$ thercfore took the receiver with the ftick in it, and held it near the fire, till the bark was well dryed; after which I fet it upon the air pump, and exhauted the air, upon which the air iffued as freely at $x$ as it did before the bark had been wetted, and continued fo to do, tho' I kept the receiver exhaufted for many hours.

I fixed in the fame manner, as the preceding Birch ftick, three joynts of a Vine branch, which was two years old, the uppermoft knot $r$ being within the receiver; when I pumped the air paffed moft freely into the water $x x$.

I cemented faft the upper end of the ftick $n$ and then pumped, the air ftill iffued out at $x$, tho' I pumped very long, but there did not now pals the 2oth part of the air which paffed when the end $n$ was not cemented.

$$
\text { I 4. Ithen }
$$




\section{Is 2 Vegetable Staticks.}

Ithen inverted the fick, placing $n$ fix inches deep in the water, and covered all the bark from the furface of the water to $z$ the top of the receiver with cement; then pumping the air which entered at the top of the ftick, paffed thro' the immerfed part of the bark: When I ceafed pumping for fome time, and the air had ceafed iffuing out; upon my repeating the pumping it would again iffue out.

I found the fame event in Birch and Mulberry fticks, in both which it iffued moft plentifully at old eyes, as if they were the chief breathing places for trees.

And Dr. Grew obferves, that " the pores " arc fo very large in the trunks of fome " plants, as in the better fort of thick walk" ing canes, that they are vifible to a good " eye, without a glafs; but with a glafs the " cane feens as if it were fuck top full " of holes, with great pins, being fo large " as very well to refemble the pores of the " skin, in the end of the fingers and ball " of the hand.

"In the leaves of Pine they are like" wife, through a glafs, a very elegant fhew, "fanding all moft exactly in rank and file, 
"thro' the length of the leaves." Grew's Anatomy of Plants. p. I 27.

Whence it is very probable, that the air freely enters plants, not only with the principal fund of nourifhment by the roots; but alfo thro' the furface of their trunks and leaves, efpecially at night, when they are changed from a perfpiring to a ftrongly imbibing ftate.

I fix'd in the fame manner to the top of the air pump receiver, but without the cylindrical glafs $y y$, the young thoots of the Vine, Apple tree and Honyfuckle, both erected and inverted, but found little or no air came cither from branches or leaves, except what air lay in the furrows, and the innumerable little pores of the leaves, which are plainly vifible with the microfcope. I tryed alfo the fingle leaf of a Vine, both by immerfing the leaf in the water $x$, and letting the ftalk ftand out of the receiver, as alfo by placing the leaf out of the receiver, and the ftalk in the glafs of water $x$; but little or no air came either way.

I. obferve in all thefe Experiments, that the air enters very flowly at the bark of young thoots and branches, but much more freely 
thro old bark: And in different kinds of trees it has very different degrees of more or lefs free entrance.

I repeated the fame Experiment upon fe: veral roots of trees: The air paffed moft freely from $n$ to $x$; and when the glafs verfel $y y$ was full of water, and there was no water in $x$, the water paffed at the rate of 3 ounces in 5 minutes; when the upper end $n$ was cemented up, and no water in $y y$, fome air, tho' not in great plenty, would enter the bark at $\approx f$, and pars thro' the water at $x$.

And that there is fome air both in an elaftick and unelaftick ftate, mix'd with the earth, (which may well enter the roots with the nourifhment) I found by putting into the inverted glafs $z z a$ a full of water (Fig. 35.) fome earth dug up in an alley in the garden, which after it had ftood foaking for feveral days, yielded a little elaftick air, tho' the earth was not half diffolved. And in Experiment 68. we find that a cubick inch of earth yielded 43 cubick inches of air by diftillation, a good part of which was roufed by the action of the fire from a fix'd to an claftick ftate. 


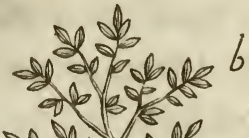

p. 154

' औै

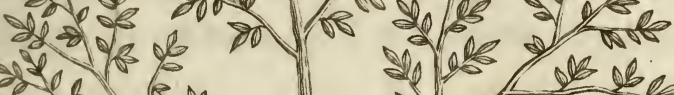

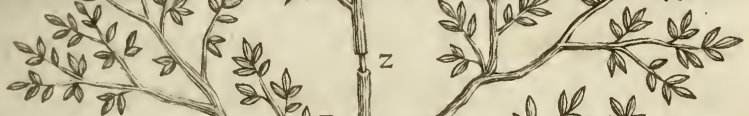

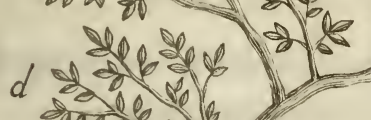
onde fle

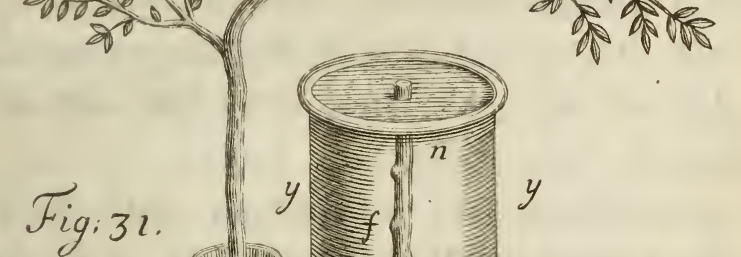

Fig.32. 


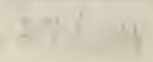

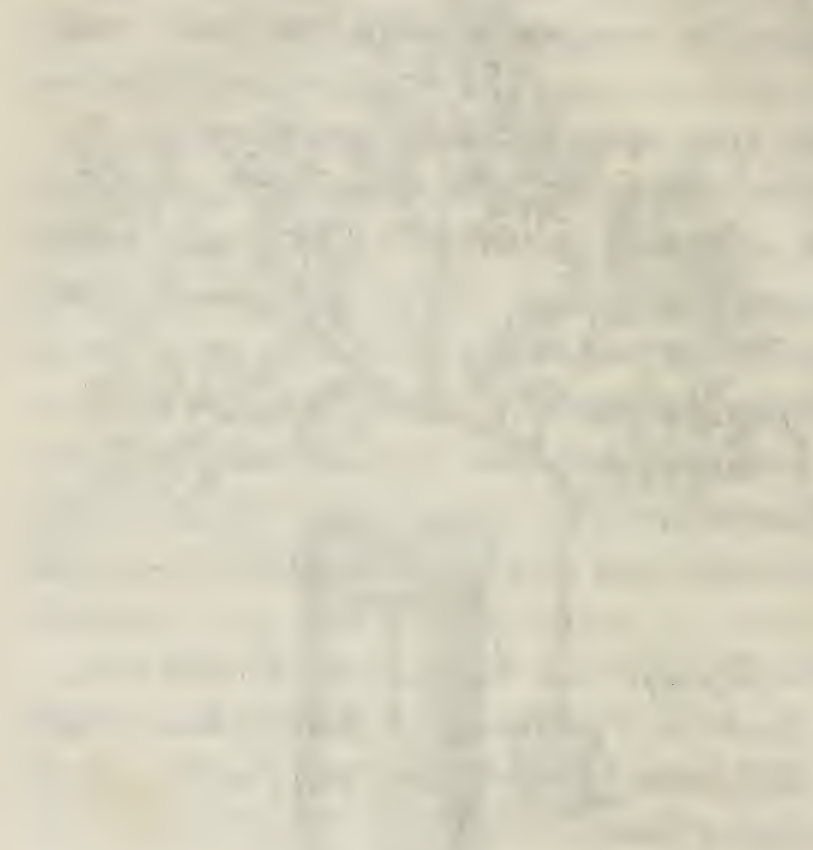

$+42$ 


\section{Analyfis of the Air.}

I fixed alfo in the fame manner young tender fibrous roots, with the fmall end upwards at $n$, and the vefrel $y y$ full of water; then upon pumping large drops of water followed each other fatt, and fell into the ciftern $x$, which had no water in it.

\section{H A P. VI.}

A Specimen of an attempt to analyze the Air by a great variety of chymio-ftatical $E x$ periments, which shew in how great a proportion Air is wrought into the compofition of animal, vegetable, and mineral Subftances, and withal bow readily it refumes its former elaftick ftate, when in the diffolution of those Subftances it is difingaged from them.

I AVING in the preceding chaptce 1 produced many Experiments, to prove that the Air is freely infpired by Vegetables, not only at their roots, but alfo thro' $\mathrm{fe}$ veral parts of their trunks and branches, which Air was moft vifibly feen afcending in great plenty thro' the fap of the Vine, in tubes which were affixed to them in the bleeding feafon; this put me upon making a more 


\section{6 \\ Analygis of the Air.}

particular inquiry into the nature of a Fluid, which is fo abfolutely ncceffary for the fupport of the life and growth of Animals and Vegetables.

The excellent Mr. Boyle made many Experiments on the Air, and among other difcovcrics, found that a good quantity of Air was producible from Vegctables, by putting Grapes, Plums, Goofeberries, Cherries, Peafe, and feveral other forts of fruits and grains into exhaufted and unexhauifed receivers, where they continued for feveral days emitting great quantities of Air.

Being defirous to make fome further re: fearches into this matter, and to find what proportion of this Air I could obtain out of the different fubftances, in which it was lodged and ircorporated, I made the following chymio-ftatical Experiments: For as, whaterer advance has here been made in the knowledge of the nature of Vegetables, has been owing to ftatical Experiments, fo fince nature, in all her opcrations, aets conformably to thofe mechanick laws, which were eftablifhed at her firft inftitution; it is thercfore reafonable to conclude, that the Jikelicft way to cnquire, by chymical ope-

rations, 


\section{Anaiyfis of the Air.}

rations, into the nature of a fluid, too fine to be the object of our fight, mutt be by finding out fome means to eftimate what influence the ufual methods of analyfing the animal, vegetable and mineral kingdoms, has on that fubtile fluid; and this I effected by affixing to retorts and boltheads hydroftatical gages in the following manner, vis.

In order to make an eftinate of the quantity of Air, which arofe from any body by diftillation or fufion, I firft put the matter which I intended to diftill into the fmall retort $r$ (Fig. 33.) and then at a ccmented fant to it the glafs veffel $a b$, which was very capacious at $b$, with a hole in the bottom. I bound bladder over the cement which was made of tobacco-pipe clay and bean flower, well mixed with fome hair, tying over all four fmall fticks, which ferved as fplinters to frengthen the joynt; fometimes, infead of the glafs veffel $a b$, I made ure of a large bolthead, which had a round hole cut, with a red hot iron ring at the botrom of it; through which hole was put one leg of an inverted fyphon, which reached up as far as z. Matters being thus prepared, holding the retort uppermoft, I immerfed the boit- 


\section{is 8 Analygis of the Air.}

head into a large veffel of water, to $a$ the top of the bolthead; as the water rufhed in at the bottom of the bolthead, the Air was driven out thro' the fyphon: When the bolthead was full of water to $z$, then I clofed the outward orifice of the fyphon with the end of my finger, and at the fame time drew the other leg of it out of the bolthead, by which means the water continued up to $z$, and could not fubfide. Then I placed under the bolthead, while it was in the water, the veffel $x x$, which done, I lifted the veffel $x x$ with the bolthead in it out of the water, and tyed a waxed thread at $z$ to mark the height of the water: And then approached the retort gradually to the fire, taking care to fereen the whole bolthead from the heat of the fire.

The defcent of the water in the bolthead thewed the fums of the expanfion of the Air, and of the matter which was diftilling: The expanfion of the Air alone, when the lower part of the retort was beginning to be red hot, was at a medium, nearly equal to the capacity of the retorts, fo that it then took up a double fpace; and in a white and almoft melting heat, the Air took. 


\section{Analyfis of the Air.}

up a tripple fpace or fomething more: For which reafon the leaft retorts are beft for thefe Experiments. The expanfion of the diffilling bodies was fometimes very little, and fometimes many times greater than that of the Air in the retort, according to their different natures.

When the matter was fufficiently diftilled; the retort $\delta c$. was gradually removed from the fire, and when cool enough, was carried into another room, where there was no fire. When all was throughly cold, either the following day, or fometimes 3 or 4 days after, I marked the furface of the water $y$, where it then ftood; if the furface of the water was below $z$, then the empty fpace between $y$ and $z$ thewed how much Air was generated, or raifed from a fix'd to an elaftick ftate, by the action of the fire in diftillation: But if $y$ the furface of the water was above $z$, the fpace between $z$ and $y$, which was filled with water, hewed the quantity of Air which had been abforbed in the operation, $i$. e. was changed from a repelling elaftick to a fix'd ftate, by the ftrong attraction of other particles, which I therefore call abforbing.

When 


\section{Analy is of the Air.}

When I would meafure the quantity of this new generated Air, I feparated the bolthead from the retort, and putting a cork in. to the fmall end of the bolthead, I inverted it, and poured in water to $z$. Then from another veffel (in which I had a known quantity of water by weight) I poured in water to $y$; fo the quantity of water which was wanting, upon weighing this veffel again, was equal to the bulk of the new generated Air. I chofe to meafure the quantities of Air, and the matter from whence it arofe, by one common meafure of cubick inches, eftimated from the fpecifick gravities of the feveral fubftances, that thereby the proportion of one to the other might the more readily be feen.

I made ure of the following means to meafure the great quantitics of Air, which were cither raifed and generated, or abforbed by the fermentation arifing from the mixture of variety of folid and fluid fubstances, whereby I could eafily eftimate the furprifing effects of fermentation on the air, viz.

I put into the bolthead 6 (Fig. 34.) the ingredients, and then run the long neck of the bolthead into the dcep cylindrical glafs ay, 


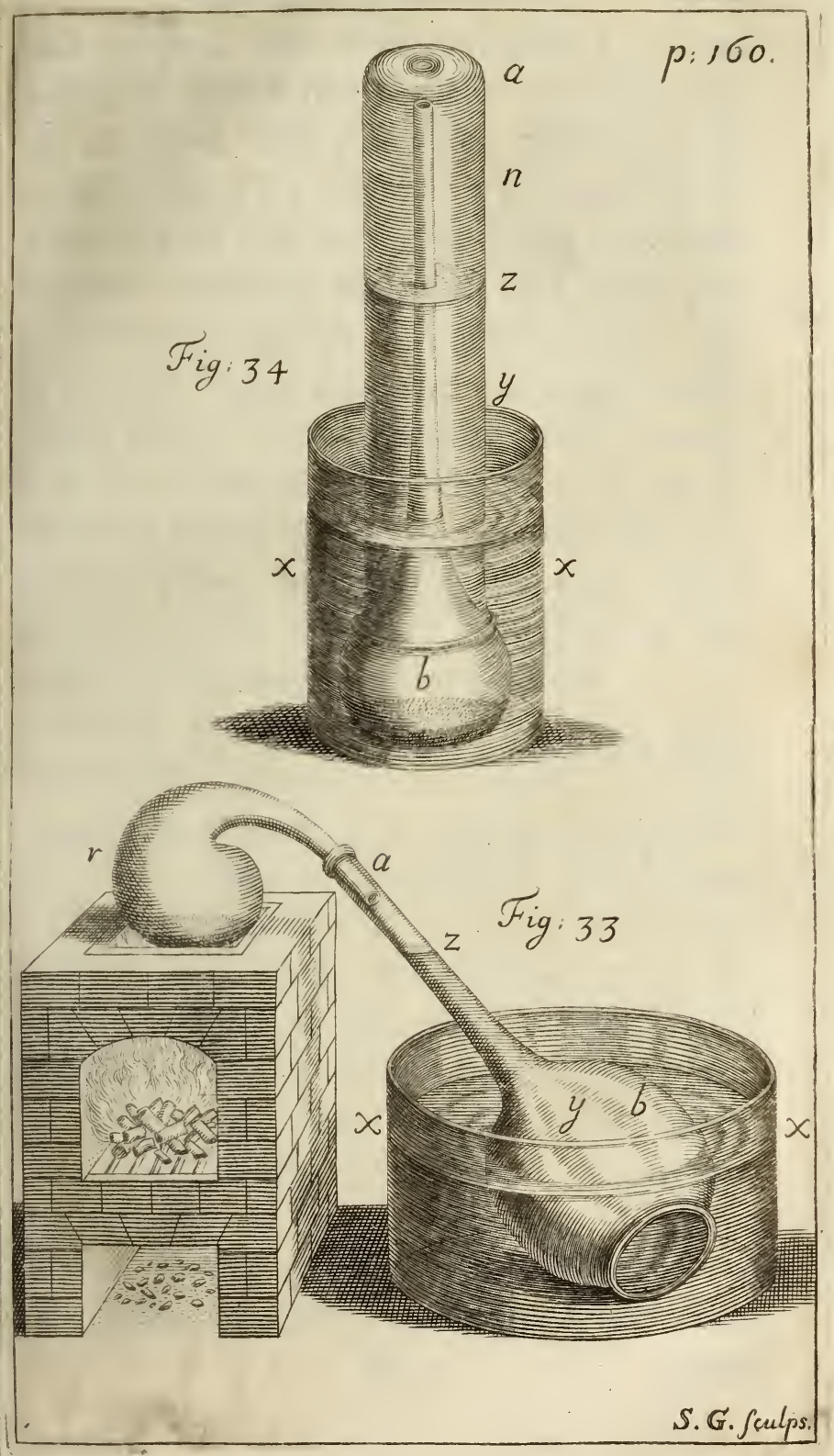





\section{Analyfis of the Air.}

and inclined the inverted glars $a y$, and bolthead almoft horizontally in a large veffel of water, that the water might run into the glafs $a y$; when it was almoft up to $a$ the top of the bolthead, I then immerfed the bottom of the bolthead, and lower part $y$ of the cylindrical glafs under water, raifing at the fame time the end $a$ uppermoft. Then before I took them out of the water, I fet the bolthead and lower part of the cylindrical glafs $a y$ into the earthen veffel $x x$ full of water, and having lifted all out of the great veffel of water, I marked the furface $z$ of the water in the glafs $a y$.

If the ingredients in the bolthead, upon fermenting generated Air, then the water would fall from $z$ to $y$, and the cmpty pace $z y$ was equal to the bulk of the quantity of Air generated: But if the ingredients upon fermentation did abforbe or fix the active particles of $\mathrm{Air}$, then the furface of the water would afcend from $z$ to $n$, and the fpace $z n$, which was filled with water, was equal to the bulk of Air, which was abforbed by the ingredients, or by the fume arifing from them: When the quantities of Air, either generated or abforbed, were very 


\section{I6 2 Analy/is of the Air.}

great, then I made ufe of large chymical receivers inftead of the glafs $a y$ : But if there quantities were very fmall, then inftead of the bolthead and deep cylindrical glafs a $y$, I made ufe of a fmall cylindrical glafs, or a common beer glafs inverted, and placed under it a Viol or Jelly glafs, taking care that the water did not come at the ingredients in them, which was eafily prevented by drawing the water up under the inverted glafs to what height I pleafed by means of a fyphon; I meafured the bulk of the rpaces $z y$ or $z n$, by pouring in a known quantity of water, as in the foregoing Experiment, and making an allowance for the bulk of the neck of the bolthead, within the fpace $z y$.

When I would take an eftimate of the quantity of Air abforbed and fix'd, or generated by a burning candle, burning brimftone or nitre, or by the breath of a living animal, $\delta c$. I firft placed a high ftand, or pedeftal in the veffel full of water $x x$; (Fig. 35.) which pedeftal reached a little higher than $\approx z$. On this pedeftal I placed the candle, or living animal, and then whelmed over it the large inverted glafs $z z a a$, 


\section{Analy is of the Air.}

which was furpended by a cord, fo as to have its mouth $r r$ three or four inches under water; then with a fyphon I fucked the Air out of the glafs veffel till the water rofe to $z z$. But when any noxious thing, as burning brimftone, aquafortis, or the like, were placed under the glafs; then by affixing to the fyphon the nofe of a large pair of bellows, whofe wide fucking orifice was clofed up, as the bellows were enlarged, they drew the Air briskly out of the glafs $z z$ a a thro' the fyphon; the other leg of which fyphon I immediately drew from under the glafs veffel, marking the height of the water $z z$.

When the materials on the pedeftal generated Air, then the water would fubfide from $z z$ to $a a$, which lpace $z z a a$ was equal to the quantity of Air generated: But when the materials deftroyed any part $\mathrm{cf}$ the Air's elafticity, then the water would rife from $a$ a (the height that $I$ in that cafe at firf fucked it to) to $z z$, and the fpace a $a z z$ was equal to the quantity of Air, whore elafticity was deftroyed.

I fometimes fired the materials on the pedeftal by means of a burning glafs, viz.

$$
\mathrm{M} 2
$$


164 Analy 2 is of the Air.

fuch as phofphorus and brown paper dipped in water, ftrongly impregnated with nitre and then dryed.

Sometimes I lighted the candle or large matches of brimftone before I whelmed the glafs $z z a$ a over them, in which cafe I inftantly drew up the water to $a a$, which by the expanfion of the heated Air would at firtt fubfide a little, but then immediately turned to a rifing ftate, notwithftanding the flame continued to heat and rarify the Air for 2 or 3 minutes: As foon as the flame was out, I marked the height of the water $z z$; after which the water would for 20 or 30 hours continue rifing a great deal above $z z$.

Sometimes when I would pour violently fermenting liquors, as aquafortis, $\delta c$. on any materials, I fuspended the aquafortis in a viol at the top of the glafs veffel $z z a a$, in fuch manner, that by means of a ftring, which came down into the veffel $x x$, I could by inverting the viol pour the aquafortis on the materials, which were in a veffel on the pedertal.

I thall now proceed to give an account of the event of a great many Experiments, which 


\section{Analyjis of the Air.}

which I made by means of there infruments, which I have here at firf defcribed, to avoid the frequent repetition of a defcription of 'em. It is confonant to the right method of philofophifing, firt, to analize the fubject, whofe nature and properties we intend to make any refearches into, by a regular and numerous ferics of Experiments: And then by laying the event of thofe Experiments before us in one view, thereby to fee what light their united and concurring evidence will give us. How rational this method is, the fequel of thefe Experiments will thew.

The illuftrious Sir Ifaac Newton (query zIft of his Opticks) obferves, that " true " permanent Air arifes by fermentation or " heat, from thofe bodies which the chy" mifts call fixed, whofe particles adhere by " a ftrong attraction, and are not therefore " feparated and rarified without fermenta" tion. Thofe particles receding from one " another with the greateft repulfive force, " and being moft difficultly brought toge" ther, which upon contact were moft ftrong"ly united. And query 30. denfe bodies by "fermentation ratify into feveral forts of

$$
\text { M } 3 \text { ". Air, }
$$




\section{I66 Analy 1 ss of the Air.}

"Air; and this Air by fermentation, and " fomctimes without it, returns into denfe " bodics." Of the truth of which we have cvident proof from many of the following Experiments, viz.

That I might be well affured that no part of the new Air which was produced in diftillation of bodies, arofe either from the greatly heated $A$ ir in the retorts, or from the fubftance of the heated retorts, I firft gave a red hot heat both to an empty glafs retort, and alfo to an iron retort made of a musket barrel; when all was cold,. I found the Air took up no more room than before it was heated: whence I was aflured, that no Air arofe, either from the fubftance of the retorts, or from the heated Air.

As to animal fubftances, a very confiderable quantity of permanent Air was produced by diftillation, not only from the blood and fat, but alfo from the mont folid parts of animals.

\section{EXPERIMENT XLIX.}

A cubick inch of Hog's blood, diftilled to dry fcoria, produced thirty three cubick inches 


\section{Analy is of the Air.}

inches of Air, which Air did not arife till the white fumes arole; which was plain to be feen by the great defent of the water at that time, in the receiver $a z y$ (Fig. 33.)

\section{EXPERIMENT L.}

Lefs than a cubick inch of Tallow, being all diftilled over into the receiver $a z y$ (Fig. 33.) produced 18 cubick inches of Air.

\section{EXPERIMENT LI.}

24I Grains, or half a cubick inch of the tip of a fallow Deer's horn, being diftilled in the iron retort, made of a musket barrel, which was heated at a Imith's forge, produced I 7 cubick inches, that is, 234 times its bulk of Air, which did not begin to rife till the white fumes arofe; but then rufhed forth in great abundance, and in good plenty, alfo with the foetid oil which came laft. The remaining calx was two thirds black, the reft afh coloured; it weighed i 28 grains, fo it was not half wafted, whence there muft remain much fulphur in it; the 
168 Analy is of the Air.

weight of water to Air, being nearly as 885 to one, as Mr. Hareksbee found it, by an accurate Expcriment. A cubick inch of Air will weigh $\frac{3}{7}$ of a grain, whence the weight of Air in the horn was 33 grains, that is, near $\frac{1}{7}$ part of the whole horn.

We may obferve in this, as alfo in the preceding Experiment, and many of the following ones, that the particles of new Air were detached from the blood and horn, at the fame time with the white fumes, which confitute the volatile falt: But this volatile falt, which mounts with great activity in the Air, is fo far from generating true claftick Air, that on the contrary it abforbs it, as I found by the following Ex: periment.

\section{EXPERIMENT LII.}

A dram of volatile falt of fal armoniack, foon diftilled over with a gentle heat; but tho' the expanfion in the receiver was double that of heated Air alone, yet no Air was gencrated, but two and an half cubick inches were abforbed. 


\section{Analyfis of the Air.}

\section{EXPERIMENT LIII.}

Half a cubick inch of Oyfterfhell, or 266 grains diftilled in the iron retort, generated 162 cubick inches, or 46 grains, which is a little more than $\frac{x}{6}$ part of the weight of the fhell.

\section{EXPERIMENT LIV.}

Two grains of Phosphorus eafily melted at fome diftance from the fire, flamed and filled the retort with white fumes, it abforbed three cubick inches of Air. A like quantity of Phosphorus, fired in a large receiver (Fig. 35.) expanded into a fpace equal to fixty cubick inches, and abforbed $28 \mathrm{cu}$ bick inches of Air: When 3 grains of Phofphorus were weighed, foon after it was burnt, it had loft half a grain of its weight ; but when two grains of Phojphorus was weighed, fome hours after it was burnt, having run more per deliquium by abforbing the moifture of the Air, it had increafed a grain in weight. 


\section{EXPERIMENT LV.}

As to vegetable Subftances, from half a cubick inch, or I 35 grains of heart of Oak, frem cut from the growing tree, was generated ros cubick inches of Air, i. e. a quantity equal to $21 \sigma$ times the bulk of the piece of $O a k$, its weight was above 30 grains, $\frac{3}{4}$ part of the weight of 135 grains of Oak. I took a like quantity of thin thavings from the fame piece of $\mathrm{Oak}$, and dryed them gently at fome diftance from a fire for 24 hours, in which time 44 grains weight of moifure had evaporated; which being deducted from the 135 grains, there remains 9 I grains for the folid part of the Oak: Then the 30 grains of Air, will be $\frac{1}{3}$ of the weight of the folid part of the Oak.

Eleven days after this Air was made, I put a live Sparrow into it, which died inftantly.

\section{EXPERIMENT LVI.}

From 388 grains weight of Indian Wheat, which grew in my garden, but was not 


\section{Analy is of the Air.}

come to full maturity, was generated 270 cubick inches of Air, the weight of which Air was 77 grains, viz. 4 of the weight of the Wheat.

\section{EXPERIMEN T LVII.}

From a cubick inch, or 3 is grains of Peafe, was generated 396 cubick inches of Air or I 3 grains, $i$.e. fomething more than $\frac{1}{3}$ of the weight of the Peafe.

Nine days after this Air was made, I lifted the inverted mouth of the recciver which contained it, out of the water, and put a lighted candle under it, upon which it inftantly flafhed: Then I immediately immerfed the mouth of the receiver in the water, to extinguilh the flame. This I repeated 8 or rotimes, and it as often flathed, after which it ceafed, all the fulphureous rpirit being burnt. It was the fame with Air of diftilled Oyfterthell and Amber, and with new diftilled Air of Peafe and Bees-wax. I found it the fame alfo with another like quantity of Air of Peafe; notwithrtanding I wafhed that Air no lels than eleven times, by pouring it fo often under water, upwards $s_{2}$ 
wards, out of the containing veffel, into another inverted receiver full of water.

\section{EXPERIMENT LVIII.}

There was raifed from an ounce or 437 grains of Muftard-Seed 270 cubick inches of air, or 77 grains, which is fomething more than $\frac{5}{6}$ part of the ounce weight. There was doubtlefs much more air in the feed; but it rofe in an unelaftick ftate, being not difentangled from the Oil, which was in fuch plenty within the gun-barrel, that when I heated the whole barrel red hot in order to burn it out, it flamed vigoroufly out at the mouth of the barrel. Oil alfo adhered to the infide of the barrel, in the diftillation of many of the other animal, vegctable and mineral fubftances; fo that the claftick air, which I meafured in the receiver, was not all the air contained in the feveral diftill'd fubftances; fome remaining in the Oil, for there is unelaftick air in Oil, part being alfo reforbed by the fulphureous fumes in the receiver. 


\section{Analy is of the Air.}

\section{EXPERIMENT IIX.}

From half a cubick inch of Amber, or I 35 grains, was raifed I 35 cubick inches of air, or 38 grains, viz. $\frac{r}{5.55}$ part of its weight.

\section{EXPERIMENT LX.}

From 142 grains of dry $\mathcal{T}$ obacco was raifed I 33 cubick inches of air, which is little lefs than $\frac{x}{3}$ of the whole weight of the Tobacco; yet it was not all burnt, part being out of the reach of the fire.

\section{EXPERIMENT LXI.}

Camphire is a moft volatile fulphureous fubftance, fublimed from the Rofin of a tree in the Eaft-Indies. A dram of it, melted into a clear liquor, at fome diftance from the fire, and fublimed in the form of white chryftals, a little above the liquor, it made a very fmall expanfion, and neither generated nor abforbed air. The fame Mr. Boyle found, when he burnt it in vacuo. Vol. 2 . p. 605 .

Ex- 


\section{EXPERIMENT LXII.}

From about a cubick inch of chymical Oil of Annifeed, I obtained 22 cubick inches of air; and from a like quantity of Oil of Olives 88 cubick inches of air. The reafon of which difference was, as I fuppofe, this, viz. finding that the Oil of Annifeed came plentifully over into the receiver, in the diftillation of the Oil of Olives, I raifed the neck of the retort a foot higher, by which means the Oil could not fo eafily afcend, but fell back again into the hotcft part of the retort, whereby more air was feparated; yet in this cafe good ftore of Oil came over into the receiver; in which there was doubtlefs plenty of unelaftick air: Whence by comparing this with Experiment 58. we fee that air is in greater plenty feparated from the Oil, when in the Muftard-feed, than it is from expreffed or chymical Oil.

\section{EXPERIMENT LXIII.}

From a cubick inch, or 359 grains of $\mathrm{Ho}$. 
ney, mixed with calx of bones, there arofe I 44 cubick inches of air, or 4I grains, viz. a little more than $\frac{1}{9}$ part of the weight of the whole.

\section{EXPERIMENT LXIV.}

From a cubick inch of ycllow Bees-wax; or 243 grains, there arofe 54 cubick inches of air, or Is grains; the $\frac{1}{16}$ part of the whole.

\section{EXPERIMENT LXV.}

From 373 grains, or a cubick inch of the coarfeft Sugar, which is the effential falt of the fugar-cane, there arofe 126 cubick inches of air, equal to 36 grains, a little more than $\frac{\underline{x}}{10}$ part of the whole.

\section{EXPER IMENT LXVI.}

I found very little air in 54 cubick inches of Brandy, but in a like quantity of Wellwater I found one cubick inch. In Pier. mont-waier there is near twice as much air, as in Rain or common water, which air 


\section{Analy is of the Air.}

contributes to the brisknefs of that and many other mineral waters. I found thefe feveral quantities of air, by inverting the nofes of bottles, full of thefe feveral liquors, into fmall glafs cifterns full of the fame liquor. And then fetting them all together in a boyler, where having an equal heat, the air was thereby feparated and afcended to the upper parts of the bottles.

\section{E XPERIMENT LXVII.}

By the fame means alfo, 1 found plenty of air might be obtained from minerals. Half a cubick inch, or 158 grains of Newcaftle coal, yielded I 80 cubick inches of air, which arofe very faft from the coal, efpecially when the yellowith fumes afcended. The wcight of this air is 5 I grains, which: is nearly $\frac{1}{3}$ of the weight of the coals.

\section{EXPERIMENT LXVIII.}

A cubick inch of frefh dug untried earth off the common, being well burnt in diftillation, produced 43 cubick inches of air. From chalk alfo, I obtained air in the fame manner. 


\section{Analyjis of the Air.}

EXPERIMENT LXIX.

From a quarter of a cubick inch of $A n$ timony, I obtain'd 28 times its bulk of air. It was diftilled in a glafs retort, becaure it will demettalize iron.

\section{EXPERIMENT LXX.}

I procured a hard, dark, gray Pyrites, a mineral fubftance, which was found 7 feet under ground, in digging for fprings on Walton-heath, for the fervice of the Right Honourable the Earl of Lincoln, at his beautiful feat at Oatlands in Surrey; this mineral abounds not only with fulphur, which has been drawn from it in good plenty, but alfo with faline particles, which fhoot vifibly on its furface. A cubick inch of this mineral yiclded in diftillation $8_{3} \mathrm{Cu}$ bick inches of air.

\section{EXPERIMENT LXXI.}

Half a cubick inch of well decrepitated fea-falt mixt with double its quantity of calx of bones generated 32 times its bulk of air : It had fo great a hear given it, that 


\section{I7 Analyjis of the Air.}

all being diftilled over, the remaining fcoria did not run per deliquizum. I cleared the gun-barrel of thefe and the like fcoria, by ftriking long on the outfide with a hammer.

\section{EXPERIMENT LXXII.}

From 2 I I grains or half a cubick inch of Nitre, mixed with calx of bones, there arofe 90 cubick inches of air, i. e. a quantity cqual to 180 times its bulk; fo the weight of air in any quantity of nitre is about $\frac{x}{8}$ part. Vitriol diftilled in the fame manner yields air too.

\section{EXPER I M EN T LXXIII.}

From a cubick inch or 443 grains of Renifh Tartar, there arofe very faft $504 \mathrm{cu}$ bick inches of air; fo the weight of the air in this Tartar was 144 grains, i. e. $\frac{1}{3}$ part of the weight of the whole: The remaining fcoria which was very little, run per deliquium, an argument that there remained fome Sal Tartar, and confequently more air; for

\section{EXPERIMENT LXXIV.}

Half a cubick inch or 304 grains of Sal 


\section{Analy is of the Air. $\quad 179$}

Tartar, made with nitre and tartar, and mixed with a double quantity of calx of bones, yielded in diftillation I 2 cubick inches of air; that is, 224 times its bulk of air, which I 12 cubick inches weighing 32 grains, is nearly $\frac{1}{9}$ part of the weight of the Sal Tartar. There is a more intenfe degree of heat required to raife the air from Sal Tartar than from nitre.

Hence we fee, that the proportion of air in equal bulks of $S_{a l}$ T Tartar and nitre is as 224 to r 80. But weight for weight, nitre contains a littie more air in it, than this Sal Tartar made with nitre. But Sal Tartar made without nitre, has probably a little more air in it than this had, becaufe it is found to make a greater explofion in the Pulvis Fulminans, than the nitrated SalTartar. Bur fuppofing, as is found by this Experiment, that Sal Tartar, according to its ipecifick gravity, contains $\frac{1}{5}$ part more in it than nitre; yet this excel's of air is not fufficient to account for the vaftly greater explofion of SalTartar than of nitre; which feems principally to arife from the more fixt nature of Sal Tartar; which therefore requires a more intenfe degree of fire, to feparate the

$$
\mathrm{N}=\text { air }
$$


I 80

Analy is of the Air.

air from the ftrongly adhering particles; than is found requifite to raife the air from nitre. Whence the air of Sal Tartar muft neceffarily thereby acquire a greater claftick force, and make a more violent explofion, than that of nitre. And from the fame reafon it is, that Aurum Fulminans gives a louder explofion than Pulvis Fulminans. The fcoria of this operation did not run per deliquium, a proof that all the SalT artar was diftilled over.

From the little quantity of air which is obtained by the diftillation of fea-falt in Experiment $7 \mathrm{r}$. in comparifon of what arifes from nitre and Sal Tartar, we fee the reafon why it will not go off with an explofive force, like thore when fired. And at the fame time we may hence obferve, that the air included in nitre and SalTartar, bears a confiderable part in their explofion. For feafalt contains an acid fpirit as well as nitre; and yet that without a greater proportion of air does not qualify it for explofion, tho' mixed like nitre in the compofition of gunpowder, with fulphur and charcoal.

Mr. Boyle found that Aqua-fortis poured on a ftrong folution of falt of tartar did 


\section{Analyfis of the Air. $18 \mathrm{r}$}

not thoot into fair cryftals of falt-petre, till it had been long expofed to the open air, whence he fufpeeted that the air contributed to that artificial production of falt-petre. And fays, " whatever the air hath to do in " this Experiment, we have known fuch " changes made in fome faline concretes; " chiefly by the help of the open air, as "very few would be apt to imagine." Vol. I. p. 302. and Vol. 3. p. 80.

We fee from the great quantity of air, which is found in falts, of what ufe it is in their cryftalization and formation, and particularly how neceffary it is in making falt-petre from the mixture of falt of tartar and fpirit of nitre. For fince by Experiment 72 and 73 , a great deal of air flies away, in the making of SalT artar, either from nitre and tartar, or from tartar alone: It muft needs be neceffary, in order to the forming of nitre from the mixture of Sal Tartar and fpirit of nitre, that more air thould be incorporated with it, than is contained either in the Sal Tartar or fpirit of nitre. 


\section{EXPERIMENT LXXV.}

Near half a cubick inch of componind $A$ qua-fortis, which bubbled and made a confidcrable expanfion in diftillation was foon diftilled off: As it cooled the expanfion abated very faft, and a little air was abforbcd. Whence it is evident that the air ge. nerated by the diftillation of nitre, did not arife from the volatile fpirituous particles.

Hence alfo it is probable that there is fome air in acid fpirits, which is reforbed and fixt by them in diftillation. And this is further confirmed from the many air bubbles which arre from Aqua-regia, in the fulution of gold; for fince gold lofes nothing of its weight in being diffolved, the air cannot arife from the metalline part of the gold, vut muft either arife from the Aqua-regia or from latent air in the pores of the gold.

$$
\text { EXPERIMENT LXXVI. }
$$

A cubick inch of common Brimftone cxpanded very little in diftilation in a glafs 


\section{Analy is of the Air.}

retort; notwithftanding it had a great heat given it, and was all diffilled over into the receiver without flaming. It abforbed fome air, but flaming brimftone by Expcriment ${ }_{10}$, abforbs much air.

A good part of the air thus raifed from feveral bodies by the force of fire, was ape gradually to lofe its elafticity, in ftanding feveral days; the reafon of which was (as will appear more fully hereafter) that the acid fulphureous fumes raifed with that air, did reforb and fix the elaftick particles.

\section{EXPERIMENT LXXVII.}

To prevent which I made ufe of the following method of diftillation, viz. I fixt a leaden fyphon, Fig. 38. to the nofe of the iron retort $r r$; and then having immerfed the fyphon in the veffel of water $x x$, I placed over the open end of the fyphon the inverted chymical receiver $a b$ which was full of water; fo that as the air which was raifed in diftillation, paffed thro' the water up to the top of the receiver $a b, a$ good part of the acid fpirit and fulphureous fumes were by this means intercepted and retain. 
ed in the water; the confequence of which was, that the new generated air continued in a more permanently elaftick fate, very little of it lofing its elafticity, viz. not above a I 5 th or 18 th part, and that chiefly the firf 24 hours; after which the remainder continued in a conftantly elaftick ftate; excepting the air of tartar, which in 6 or 8 days loft conftantly above one third of its elafticity; after which the remainder was permanently elaftical.

That the great quantities of air which are thus obtained from thefe feveral fubftances by diftillation are true air, and not a mere flatulent vapour, I was affured by the following tryals; viz. I filled a large receiver which contained 540 cubick inches, with air of tartar; and when it was cool, I furpended the receiver while its mouth was inverted in water. Then upon lifting the mouth of the receiver out of water, I immediately covered it by tying a piece of bladder over it. When I had found the exact weight, I blew out all the air of tartar with a pair of bellows which had a long additional nofe that reached to the bottom of the receiver. And then tying the bladder on, I weighed 


\section{Analy is of the Air. $\quad 185$}

it again, but could find no difference in the fpecifick gravity of the two airs, and it was the fame with an air of tartar which was ro days old.

As to the other property of the air, elanticity, I found it exactiy the fame in the air of tartar, which was is days old, and common air; by filling two equal tubes with thefe different airs, the tubes were Io inches long and fealed at one end; I placed them at the fame time in a cylindrical glafs condenfing receiver, where I compreffed them with two additional atmorpheres, taking care to fecure myfelf from danger in cafe the glafs fhould burft, by placing it in a decp wooden veffel, the water rofe to cqual heights in both tubes. This receiver was gently annealed and thereby toughened, by being boiled in Urine where it lay till all was cold.

I put alfo into the fame tubes fome new made air of tartar, both the tubes ftanding in cifterns of water; the air of one of thefe tubes I compreffed in the condenfing engine for fome days, to try whether in that compreffed ftate, more of the air's elanticity would be deftroyed by the abforbing va-

pours 
pours than in an uncompreffed fate; but I did not perceive any fenfible difference.

Lemery, in his courfe of chymitry, p. 592. obtained in the diftillation of 48 ounces of Tartar, 4 ounces of phlegm, 8 of fpirits, 3 of oil, and 32 of Scoria, i. e. two thirds of the whole, fo one ounce was loft in the operation.

In my dintillation of 443 grains of $\mathcal{T}$ ar. tar in Exper. 73. there remained but 42 grains of Scoria, which is little more than to of the Tartar; and in this remainder, there was by Exper. $74 \mathrm{Air}$, for there was Sal Tartar, it running per deliquium.

Whence by comparing Lemery's and my diftillation together, we thall find, that there remained in this 32 ounces of Scoria, and in the ounce that was lont, (which was doubtlefs mont of it air) fubftance cnough to account for the great quantity of air, which in Exper. 73. was raifed from Tartar; efpecially, if we takc irto the account the proportion of air, which was contained in the oil, which was $\frac{1}{16}$ part of the whole Tartar, for there is much air in oil.

The bodies which I diftilled in this manner (Fig. 38.) were Horn, calculus bumanus, Oyfter- 


\section{Analy is of the Air.}

Oyfterfhell, Oak, Muftard-feed, Indian-wheat, Peafe, Tobacco, oil of Annifeci, oil of Olives, Honey, Wax, Sugar, Amber, Coal, Earth, Walton Mineral, fea Salt, Salt-petre, Tartar, Sal Tartar, Lead, Minium. The greateft part of the Air obtained from all which bodies was very permanent, except what the Air of Tartar loft in ftanding feveral days. Particularly, that from nitre loit little of its elafticity, whereas mont of the Air ob. tained from nitre, in diftilling with the receiver ( Fig. 33.) was reforbed in a few days, as was alfo the $A$ ir which was generated from detonized nitre in Experiment 102. Hence alfo we fee the reafon, why 19 parts in 20 , of the Air which was gencrated, by the firing of Gunpowder, was in I 8 days reforbed by the fulphureous fumes of the Gunpowder. As Mr. Hazeksbee obferved, in his phyficomechanical Experiments, page 83.

In the diftillation of Horn, it was obfervable, that when towards the end of the operation the thick foetid oil arofe, it formed very large bubbles, with tough unctuous skins, which continued in that fate fome time; and when they broke, there arofe out of them volumes of fmoak, as out of a chimney, 


\section{Analy is of the Air.}

and it was the fame in the diftillation of Multard-reed.

AN ACCOUNT OF SOME EXPERIMENTS MADE ON STONES TAKEN OUT OF HUMAN URINE and Gall Bladders.

T AVIVG, while thefe Sheets were 1 printing off, procured by the favour of Mr. Ranby, Surgeon to His Majefty'sHousbold, fome calculi bumani, I made the following Experiments with them, which I thall here infert, viz.

I diftilled a calculus in the iron retort (Fig. 38.) It weighed 230 grains, which is fomething lefs in bulk than $\frac{3}{4}$ of a cubick inch: There arofe from it very briskly, in diftillation, 5 I 6 cubick inches of elaftick Air, that is, a bulk equal to 645 times the bulk of the Stone; fo that above half the Stone was raifed by the action of the fire into elaftick Air; which is a much greater proportion of Air, than I have ever obtained by fire, from any other fubftances, whether animal, vegetable or mineral. The remaining calx weighed 49 grains, that is $\frac{1}{4.69}$ part of the calculus; which is nearly the fame 


\section{Analy is of the Air.}

proportion of calx, that the worthy Dr. Slare found remaining, after the diftilling and calcining two ounces of calculus, "one ounce, " and three drams of which (he fays) eva"porated in the open fire (a material cir" cumftance, which the Chymifts rarely en"quire after) of which we have no ac" count." Philof. Tranfact. Lowthorp's $A$ bridgment. Vol. III. p. 179. The greateft part of which was, we fee by the prefent Experiment, raifed into permanently elaftick Air.

By comparing this diftillation of the calculus with that of Renifs Tartar in Exper. 73. We fee that they both afford more Air in diftillation, than any other fubftances: And it is remarkable, that a greater proportion of this new raifed Air from thefe two fubftances, is reforbed and lofes its elafticity, in ftanding a few days, than that of any other bodies, which are ftrong fymptoms that the calculus is a true animal Tartar. And as there was very confiderably lefs oil, in the diftillation of Renifb Tartar, than there was in the diftillation of the Seeds and folid parts of vegetables; fo I found that this calculus contained much lefs oil than the blood or folid parts of animals. 
I difilled in the fame manner, as the above mentioned calculus, fome ftones taken out of a human gall bladder, they weighed 52 grains, fo their bulk was equal to $\frac{1}{6}$ part of a cubick inch, as I found by taking their fpecifick gravity. There was 108 cubick inches of elaftick Air raifed from them in diftillation, a quantity equal to 648 times their bulk; much the fame quantity that was raifed from the calculus. About $\frac{1}{6}$ part of this claftick Air was in 4 days reduced into a fix'd ftate. There arole much more oil in the diftillation of thefe Stones, than from the Calculus, part of which oil did arife from the Gall which adhered to, and was dryed on the furfaces of the Stones, which oil formed large bubbles, like thore which arofe in the diftillation of Deers Horn p. I87.

A fmall Stone of the Gall Bladder, which was as big as a Pea, was diffolved in a Lixivium of Sal Tartar in feven days, which Lixisium will alfo diffolve Tartar; yet it will not diffolve the Calculus, which is more firmly united in its parts.

A quantity of Calcuilus equal to one half of what was diftilled, viz. I I grains, did, 


\section{Analyjis of the Air.}

when a cubick inch of fpirit of nitre was poured on it, diffolve in 2 or 3 hours, with a large froth, and generated 48 cubick inches of Air, none of which loft its elanticity, tho it ftood many days in the glais veffel. (Fig. 34.) And a like quantity of Tartar being mixed with fpirit of nitre, was in the fame time diffolved, but no elaftick Air was generated, notwithetanding $T$ artar abounds fo much with Air.

Small pieces of Tariar and Calculus were in $\mathrm{I}_{2}$ or $\mathrm{I}_{4}$ days both diffolved by oil of Vitriol; the like pieces of Tartar and Calculus were diffolved in a few hours by oil of Vitriol, into which there was gradually poured near an equal quantity of fpirit of Harts-horn, made with Lime, which caufed a confiderable ebullition and heat.

Tho' the remaining calx of the diftillation of Tartar, in Exper. 73. run per deliquinu, and had therefore Sal Tartar in it; and tho' the calx of the diftilled Calculus did not run per deliquium, and had confequently no Sal Tartar in it; yet it cannot thence be inferred, that the Calculus is not a tartarine fubftance: Becaufe by Exper. 74. it is evident, that Sal Tartar it felf, when 


\section{Analygis of the Air.}

mixed with an animal calx, diftills all over, fo that the calx will not afterwards run per deliquium.

By the great fimilitude there is therefore in fo many refpects between thefe two fubflances, we may well look upon the Calculus, and the Stone in the Gall Bladder, as true animal Tartars, and doubtlefs Gouty concretions are the fame.

From the great quantities of Air, that are found in thefe Tartars, we fee that unelaftick Air particles, which by their frongly attracting property are fo infrumental in forming the nutritive matter of Animals and Vegetables, is by the fame attractive power apt fometimes to form anomalous concretions, as the Stone, \&c. in Animals, efpecially in thore places where any animal fluids are in a ftagnant ftate, as in the Urine and Gall Bladders. The like tartarine con. cretions are alfo frequently formed in fome fruits, particularly in Pears; but they do then efpecially coalefec in greateft plenty, when the vegetable juices are in a ftagnant ftate, as in wine veffels, \&uc.

This great quantity of Atrongly attracting; unelaftick air particles, which we find in the 


\section{Analy is of the Air.}

Calculus, thould rather encourage than difcourage us, in fearching after fome proper diffolvent of the Stone in the Bladder, which, upon the analyfis of it, is found to be well ftored with active principles, fuch as are the principal agents in fermentation. For Mr. Boyle found therein a good quantity of volatile falt, with fome oil, and we fee by the prefent Experiment, that there is ftore of unelaftick air particles in it. The difficulty feems chiefly to lay, in the over proportion of thefe laft mentioned particles, which are firmly united together by fulphur and falt, the proportion of caput mortuum, or earth being very fmall.

\section{EXPERIMENT LXXVIII.}

One eighth of a cubick inch of Mersury made a very infenfible expanfion in diftillation, notwithftanding the iron retort had an almoft melting heat given it, at a fnfith's forge, fo that it made an ebullition, which could be heard at fome diffance, and withal fhook the retort and receiver. There was no air generated, nor was there any expanfion of air in the following Exper. viz. 
194 Analy is of the Air.

\section{EXPERIMENT LXXIX.}

I put into the fame retort half a cubick inch of Mercury, affixing to the retort a very capacious receiver, which had no hole in the bottom. The wide mouth of the receiver was adapted to the fmall neck of the retort (which was made of a musket barrel) by means of two large pieces of cork which entered and filled the mouth of the receiver, they having holes bored in them of a fit fize for the neck of the retort; and the juneture was farther fecured, by a dry fupple bladder tyed over it : For I purpofely avoided making ufe of any moint lute, and took care to wipe the infide of the receiver very dry with a warm cloth.

The Mercury made a great ebullition, and came fome of it over into the receiver, as foon as the retort had a red heat given it, which was increared to a white and almoft melting heat, in which ftate it continued for half an hour. During which time, I frequently cohobated fome part of the Mercury, which condenfed, and was lodged on an horizontal level, about the middle of 
the neck of the retort: And which upon raifing the receiver, flowed down into the bottom of the retort, and there made a frefh ebullition, which had ceafed, when all the Mercury was diftilled from the bottom of the retort. When all was cool, I found about two drams of Mercury in the retort, and loft. in the whole 43 grains, but there was not the leaft moifture in the receiver.

Whence it is to be fufpected that Mr. Boyle and others were deceived by fome unheeded circumftance, when they thought they $\mathrm{cb}$ tained a water from Mercury in the diftillation of it ; which he fays he did once, but conld not make the like Experiment afterterwards fucceed. Boyle Vol. III. p. 4I6.

I remember that about 20 years fince I was concerned with feveral others, in making this Experiment at the elaboratory in Trinity College Cambridge, when imagining there would be a very great expanfion, we luted a German earthen retort, to 3 or 4 large Alodals, and a capacious receiver; as Mr. Wilfon did in his courfe of Chymiftry. Four pounds of Mercury was poured by little and little into the red hod retort, thro a tobacco-pipe purpofely affixed to it. The 


\section{Analy/s of the Air.}

event was, that we found fome fpoons full of water with the Mercury in the Alodals, which I then furpected to arife from the moifture of the earthen retort and lute, and am now confirmed in that furpicion. It rained inceffantly all the day, when I made this prefent Experiment; fo that when water is obtained in the diftillation of Mercury, it cannot be owing to a moifter temperature of the Air.

The effects of Fermentation on the Air.

AVING from the forcgoing ExperiI ments feen very evident proof of the production of confiderable quantities of true elaftick air, from liquors and folid bodies, by means of fire; we thall find in the following Experiments many inftances of the production; and alfo of the fixing or abforbing of great quantities of air by the fermentation arifing from the mixture of variety of folids and fluids: Which method of producing and of abforbing, and fixing the elaftick particles of air, by fermentation, feems to be more according to nature's ufual way of prosceding, than the other of fire. 
Analyfis of the Air.

\section{EXPERIMENT LXXX.}

I put into the bolthead $b$ (Fig. 34.) $16 \mathrm{cu}$ bick inches of Sheeps blood, with a little water to make it ferment the better. I found by the defcent of the water from $z$ to $y$ that in 18 days fourteen cubick inches of air were generated.

\section{EXPERIMENT LXXXI.}

Volatile Salt of Sal Ammoniac, placed in an open glafs ciftern, under the inverted glals $z z a$ a (Fig. 35.) neither generated nor abforbed air. Neither did feveral other volatile liquors, as fpirits of Harts-horn, fpirits of Wine, nor compound Aquafortis, generate any air. But Sal Ammoniac, $S_{a l}$ Tartar, and fpiris of Wine mixed together, generated 26 cubick inches of air, two of which was in 4 days reforbed, and after that generated again.

EXPERIMENT LXXXII.

Half a cubick inch of Sal Ammoniac, and O 3 double 
double that quantity of oil of Vitriol, generated the firft day; or 6 cubick inches: But the following days it abforbed is cubick inches, and continued many days in that ftate.

Equal quantities of fpirits of Turpentine, and oil of Vitriol, had near the fame effect, except that it was fooner in an abforbing ftate than the other.

Mr. Geoffroy thews, that the mixture of any vitriolic falts, with inflammable fubftances, will yield common Brimftone; and by the different compofitions he has made of fulphur; and particularly from oil of Vitriol, and oil of Turpentine; and by the Analyfis thercof, when thus prepared, he difcovered it to be nothing but vitriolic falt, united with the combuftible fubftance. French Memoirs, Anno i 704.p. 38 I, or Boyle's Works, Vol. III. p. 273 . Notes.

\section{EXPERIMENT LXXXIII.}

In February I poured on fix cubick inches of powdered Oyfterfbell, an equal quantity of common white-wine Vinegar. In 5 or 6 minutes it generated 17 cubick inches of air, 


\section{Analy is of the Air.}

air, and in fome hours 12 cubick inches more, in all 29 inches. In nine days it had nowly reforbed 2 I cubick inches of air. The ninth day I poured warm water into the veffel $x x$, (Fig. 34.) and the following day, when all was cool, I found that it had reforbed the remaining 8 cubick inches. Hence we fee that warmth will fometimes promote a reforbing, as well as a gencrating ftate, viz. by raifing the reforbing fumes, as will appear more hereafter.

Half a cubick inch of Oyfterfiell, and a cubick inch of oil of Vitriol, generated 32 cubick inches of air.

Oyfter/bell, and 2 cubick inches of Sour Rennet, of a Calve's ftomach, generated in 4 days II cubick inches. But Oyfterfbell, with fome of the liquor of a Calve's ftomach, which had fed much upon hay, did not generate air. It was the fame with Oyfterfhell and Ox-gall, Urine and Spittle.

Half a cubick inch of Oyfterghell and Sevil Orange juice generated the firft day $\mathrm{I} 3 \mathrm{cu}$ bick inches of air, and the following days it reforbed that, and 3 or 4 more cubick inches of air, and would fometimes generate again. It was the fame with Limon juice.

$$
\mathrm{O}_{4} \quad \text { Oyfter. }
$$


Oyfter hbell and Milk generated a little air: But Limon juice and Milk did at the fame time abforb a little air; as did alfo Calves Rennet and Vinegar; fome of the fame Rennet alone generated a little air, and reforbed it again the following day. It had the fame effect when mixed with crums of bread.

\section{EXPERIMENT LXXXIV.}

A cubick inch of Limon juice, and near an cqual quantity of jpirits of Harts-born, per $\int e, i$. e. not made with Lime, did in 4 hours abforb 3 or 4 cubick inches of air; and the following day it remitted or generated two cubick inches of air: The third day turning from very warm to cold, it again reforbed that air, and continued in an abforbing ftate for a day or two.

That there is great plenty of air incor: porated into the fubftance of Vegetables, which by the action of fermentation is rouzed into an elaftick ftate, is evident by thefe following Experiments, viz.

EXPER I MENT LXXXV.

March the $2 \mathrm{~d}$, I poured into the bolt: head $b$ (Fig. 34.) forty two cubick inches of 


\section{Analy is of the Air.}

of Ale from the Tun, which had beer there fet to ferment 34 hours before: From that time to the 9 th of Fune it generated 639 cubick inches of air, with a very unequal progreflion, more or lefs as the weather was warm, cool, or cold, and fometimes upon a change from warm to cool, it reforbed air, in all 32 cubick inches.

\section{EXPERIMENT LXXXVI。}

March the 2d, I 2 cubick inches of $M a$ laga Raifins, with 18 cubick inches of water generated by the I 6 th of April 4 I I cubick inches of air, and then in 2 or 3 cold days it reforbed 35 cubick inches. From the 2 Ith of April to the 16 th of May it generated 78 cubick inches; after which to the 9 th of Fune it continued in a reforbing ftate, fo as to reforb I 3 cubick inches; there were at this feafon many hot days, with much Thunder and Lightning, which deftroys the air's elafticity; fo there was generated in all 489 cubick inches, of which 48 were reforbed. The liquor was at laft 7ery vapid. 
From the great quantity of air generated from Apples, in the following Experiment, 'tis probable, that much more air would have rifen from the laxer texture of ripe undryed Grapes, than did from thefe Raifins.

We fee from thefe Experiments on Raifins and Ale, that in warm weather Wine and Ale do not turn vapid by imbibing air, but by fermenting and generating too much, whereby they are deprived of their cnlivening principle, the air ; for which reafon thefe liquors are beft preferved in cool cellars, whercby this active invigorating principle is kept within due bounds, which when they exceed, Wines are upon the fret and in danger of being fpoiled.

\section{EXPERIMENT LXXXVII.}

Twenty-fix cubick inches of Apples being mafhed Auguft ro. they did in I 3 days generate 968 cubick inches of air, a quantity equal to 48 times their bulk; after which they did in 3 or 4 days reforb a quantity equal to their bulk, notwithlanding it was very hot weather; after which they were

ftationary? 


\section{Analyfis of the Air. $\quad 203$}

ftationary, neither reforbing nor gencrating air in many days.

A very coarfe brown-fugar, with an equal quantity of water, generated nine times its bulk of air; Rice-flower fix times its bulk; Scurvy-grafs leaves generated and abforbed air; Peafe, Wheat and Barley did in Fermentation alfo generate great quantities of Air.

That this Air, which arifes in fuch great quantities from fermenting and difolving vegetables is true permanent Air, is certain, by its continuing in the fame expanded claftick ftate for many weeks and months; which expanding watry vapours will not do, but foon condenfe when cool. And that this new generated air is elaftical is plain, not only by its dilating and contracting with heat and cold, as common air does, but allo by its being compreflible, in proportion to the incumbent weight, as appears by the two following Experiments, which thew what the great force of thefe aerial particles is, at the inftant they efcape from the fermenting vegetables. 


\section{EXPERIMENT LXXXVIII.}

I filled the ftrong Hungary-water Bottle $b c$ Fig. 36 . near half full of Peafe, and then full of water, pouring in firf half an inch depth of Mercury; then I fcrewed at $b$ into the bottle the long flender tube $a z$, which reached down to the bottom of the bottle; the water was in two or three days all imbibed by the Pcafe, and they thereby mucis dilated; the Mercury was alfo forced up the nender glafs tube near 80 inches high; in which ftate the new generated Air in the bottle was compreffed with a force equal to more than two Atmorpheres and an half; if the bottle and tube were fwung too and fro, the Mcrcury would make long vibra. tions in the tube between $z$ and $b$, which proves the great elanticity of the compreffed air in the bottle.

\section{EXPERIMENT LXXXIX.}

I found the like elattick force by the following Experiment, viz. I provided a ftrong iron pot $a b c d$ Fig. 37. which was 2 and $\frac{a}{4}$ inches 


\section{Analyfis of the Air. 205}

inches diameter within fide, and five inches deep. I poured into it half an inch depth of Mercury; then I put a little coloured honey at $x$, into the bottom of the glafs: tube $z x$, which was fealed at the top. I fet this tube in the iron cylinder $n n$, to fave it from breaking by the fwelling of the Peare. The pot being filled with Peafe and water, I put a leathern collar between the mouth and lid of the pot, which were both ground even, and then preffed the lid hard down in a Cyder-prefs: The third day I opened the pot and found all the water imbibed by the Peafe; the Honey was forced up the glafs-tube by the Mercury to $z$, (for fo far the glafs was dawbed) by which means I found the preffure had been equal to two atmofpheres and $\frac{1}{4}$; and the diameter of the pot being $2+\frac{3}{4}$ inches, its area was fix fquare inches, whence the dilating force of the air againft the lid of the pot was equal to 189 pounds.

And that the expanfive force of new generated air is vaftly fuperior to the power with which it acted on the Mercury in thefe two Experiments is plain from the force with which fermenting Muft will burft the 


\section{6 \\ Analy is of the Air.}

ftrongeft veffels; and from the vaft explofive force with which the air generated from nitre in the firing of gun-powder, will burft afunder the ftrongeft bombs or cannon, and whirl fortifications into the air.

This fort of mercurial gage, made ufe of in Experiment 89, with fome unetuous matter, as Honey, Treacle, or the like, on the Mercury in the tube, to note how high it rifes thcre, might probably be of fervice, in finding out unfathomable depths of the Sea, viz. by fixing this rea-gage to fome buoyant body which thould be funk by a weight fixt to it, which weight might by an eafie contrivance be detached from the buoyant body, as foon as it touched the bottom of the fea; fo that the buoyant body and gage would immediatcly afeend to the furface of the water; the buoyant body ought to be pretty large, and much lighter than the water, that by its greater eminence abore the water it might the better be fecn; For 'tis probable that from great depths it may rife at a confiderable diftance from the Ship, tho' in a calm.

For greater accuracy it will be needful, firft to try this fea-gage, at feveral different depths, 


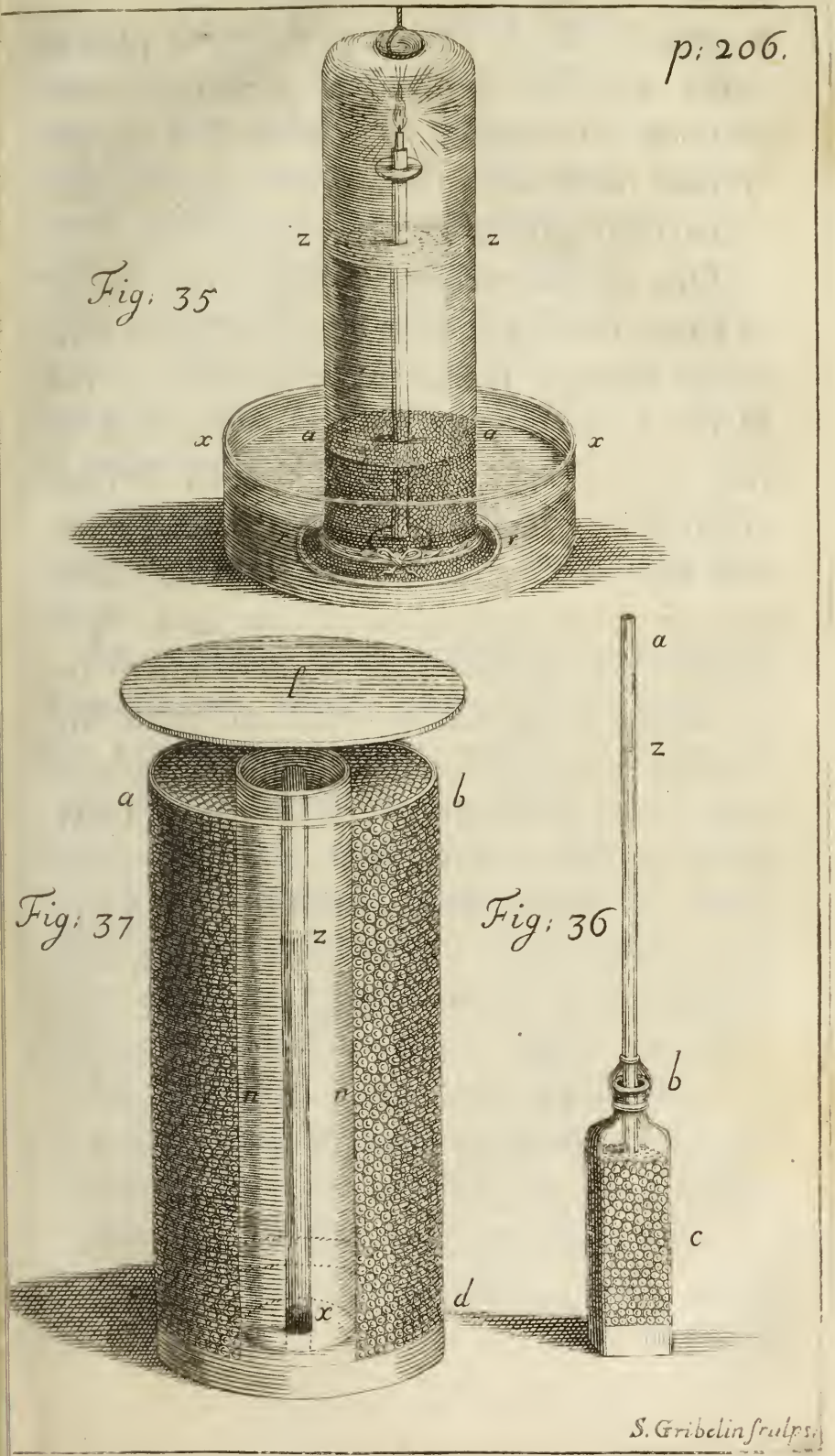




\section{Analyfis of the Air.}

depths, down to the greateft depth that a line will reach, thereby to difcover, whether or how much the fpring of the air is difturbed or condenfed, not only by the great preffure of the incumbent water, but alfo by its coldnefs at great depths; and in what proportion, at different known depths, and in different lengths of time, that an allowance may accordingly be made for it at unfathomable depths.

This gage will alfo readily thew the degrees of compreffion in the condenfing engine.

But to return to the fubject of the two laft Experiments, which prove the elafticity of this new generated air; which elafticity is fuppoled to confift in the active aerial particles repelling each other with a force, which is reciprocally proportional to their diftances. That illuftrious Philofopher, Sir Ifaac Newton, in accounting how air and vapour is produced, Opticks Quer. 3 I. fays, "The particles when they are thaken off "from bodies by heat or fermentation fo "foon as they are beyond the reach of the " attraction of the body receding from it, "s as alfo from one another, with grear 
208 Analyjis of the Air.

"Atrength and keeping at a diftance, fo as

" fometimes to take up above a million of " times more fpace than they did before in " the form of a denfe body, which vaft " contraction and expanfion feems unintel" ligible, by feigning the particles of Air " to be fpringy and ramous, or rolled up " like hoops, or by any other means than "by a repulfive power." The truth of which is further confirmed by thefe Experiments, which fhew the great quantity of air emitted from fermenting bodies; which not only proves the great force with which the parts of thofe bodies muft be diftended; but thews alfo how very much the particles of air muft be coiled up in that ftate, if they arc, as has been fuppoled; fpringy and ramous.

To inftance in the cale of the pounded Apples which generated above 48 times their bulk of Air; this air, when in the Ap'ples, muft be compreffed into lefs than a forty eighth part of the fpace it takes up, when freed from them, and it will confequently be 48 times more denfe; and fince the force of compreffed air is proportional to its denfity, that force which com. 


\section{Analy is of the Air.}

preffes and confines this air in the Apples, muft be equal to the weight of 48 of our atmorpheres, when the Mercury in the Barometer ftands at fair, that is 30 inches high.

Now a cubick inch of Mercury weighing 3580 grains, thirty cubick inches (which is equal to the weight of our atmofphere on an area of a cubick inch) will weigh is pounds, 5 ounces, 2 Is grains; and 48 of them will weigh above 736 pounds; which is therefore equal to the force with which an inch fquare of the furface of the Apple would comprefs the air, fuppofing there were no other fubftance but air in the Apple: And if we take the furface of an Apple at 16 fquare inches, then the whole force with which that furface would comprefs the included air, would be i 776 pounds. And fince action and re action are equal, this would be the force, with which the air in the Apple would endeavour to expand it felf, if it were there in an elaftick and ftrongly compreffed ftaie: But fo great an expanfive force in an Apple would certainly rend the fubftance of it with a ftrong explofion, efpecially when that force was increafed, by the vigorous influence of the Sun's warmth. 
We may make a like eftimate alfo, from the great quantitics of air which arofe either by fermentation, or the force of fire from feveral other bodies. Thus in Exp. 55. there arofe from a picce of heart of Oak, 2 I 6 times its bulk of air. Now 2 I 6 cubick inches of air, compreffed into the fpace of one cubick inch, would, if it continued there in an elaftick ftate, prefs againft one fide of the cubick inch, with an expanfive force equal to 3310 pounds weight, fuppofing there were no other fubltance but air contained in it; and it would prefs againt the fix fides of the cube, with a force equal to I 9860 pounds, a force fufficient to rend the Oak with a valt explofion : 'tis very reafonable therefore to conclude, that moft of there now active particles of the new gencrated air, were in a fix'd ftate in the Ap. ple and Oak before they were roufed, and put into an anive repcling ftate by fermen. ration and fire.

The wight of a cubick inch of Apple bcing 59 I grains, the weight of a cubick inch of air $\frac{2}{7}$ of a grain, 48 times that weight of air is nearly equal to the fourteenth part of the weight of the Apple. 


\section{Analyfis of the Air.}

And if to the air thus generated from a veffel of any vegetable liquor, by fermenta. tion, we add the air that might afterwards be obtained from it, by heat or diftillation i and to that alfo the vant quantity of air $_{2}$ which by Experiment 73 is found to be contained in its Tartar, which adheres to the fides of the vefiel; it would by this means be found that air makes a very confiderable part of the fubftance of Vegetables, as well as of Animals.

But tho' from what has been faid, it is reafonable to think, that many of thefe particles of air were in a fixt ftate, ftrongly adhering to and wrought into the fubitance of Apples; yet on the other hand it is mort evident from Exper. 34 and 38 , where innumerable bubbles of air inceffantly arofe through the fap of Vines, that there is a confiderable quantity of air in Vegerables, upon the wing, and in a very active ftate, efpecially in warm weather, which enlarges the fphere of their activity. 
The effects of the Fermentation of mineral Subftances on the Air.

HAVE above thewn that air may be produced from mineral Subftances, by the action of fire in diftillation. And we have in the following Experiments many inftances of the great plenty of air, which is generated by fome fermenting mixtures, abforbed by others, and by others alternately generated and ablorbed.

\section{EXPERIMENT XC.}

I poured upon a middle fized Gold Ring, bcat into a thin plate, two cubick inches of Aqua Regia; the Gold was all diffolved the next day, when I found 4 cubick inches of air generated; for air bubbles were continually arifing during the folution: But fince Gold lofes nothing of its weight in being thus diffolved, the 4 cubick inches of air, which weighed more than a grain, muft arife either out of the pores of the Gold, or from the Aqua Regia, which makes it probable, that there are air particles in acid fpirits; 


\section{Analy is of the Air.}

fpirits; for by Experiment 75, they abforb air, which air particles regained their elafticity, when the acid fpirits which adhered to them were more ftrongly attracted by the gold, than by the air particles.

\section{EXPERIMENT XCI.}

A quarter of a cubick inch of Antimony, and two cubick inches of Aqua-regia, gencrated 38 cubick inches of air, the firft 3 or 4 hours, and then abforbed 14 cubick inches in an hour or two; after which it was ftationary, till I let into the glafs veffel a $y$ (Fig. 34.) about a quart of frefh air: Upon which it abforbed fo faft, as to make the water rife very vifibly in $a y$, whereby it abforbed 30 cubick inches more. It is very obfervable, that air was generated while the ferment was fmall, on the firft mixing of the ingredients: But when the ferment was greatly increafed, fo that the fumes rofe very vifibly, then there was a change made from a generating to an abforbing ftate; that is, there was more air abforbed than generated. 
That I might find whether the air was ab: forbed by the fumes only of the Aqua-regia, or by the acid fulphurcous vapours, which afcended from the Antimony, I put a like quantity of Aqua.regia into a bolthead b, (Fig. 34.) and heated it by pouring a large quantity of hot water into the ciftern $x x$, which ftood in a larger veffel, that retained the hot water about it, but no air was abforbed; for when all was cold, the water ftood at the point $z$, where I firf placed it: Yet in the diftillation of compound Aquafortis, Exper. 75. a little was abforbed. Hence therefore it is probable, that the greateft part, if not all the air, was abforbed by the fumes, which arofe from the Antimony.

\section{EXPER I MENT XCII.}

Some time in February, the weather very cold, I poured upon a quarter of a cubick inch of powdered Antimony, a cubick inch of compound or double Aqua-fortis in the bolthead 6 , ( Fig. 34.) in the firft 20 hours it generated about 8 cubick inches of air; after that, the weather being fomewhat warmer, it fermented fafter, fo as in 2 or 3

hours 


\section{Analy is of the Air.}

hours to generate 82 cubick inclies of air more; but the following night being very cold, little was generated : So the next morning I poured hot water into the vefiel $x x$, which renewed the ferment, fo that it generated 4 cubick inches more, in all $\mathrm{I} 30 \mathrm{cu}$ bick inches, a quantity equal to 520 times the tulk of the Antimony.

The fermented mals looked like Brimftone, and when heated over the fire, there fublimed into the neck of the bolthead a red fulphur, and below it a yellow, which fulphur, as Mr. Boyle obferves, Vol. III. p. 272. cannot be obtained by the bare action of fire, without being firft well digefted in oil of Vitriol, or fpirit of Nitre. And by comparing the quantity of air obtained by fermentation in this Experiment, with the quantity obtained by the force of fire in Exper. 69. we find that five times more air was generated by fermentation than by fire, which thews fermentation to be a more fubtile diffolvent than fire; yet in fome cafes there is more air generated by fire than by fermentation.

Half a cubick inch of oil of Antimony, with an equal quantity of compound Aqua-

$$
\mathrm{P}_{4}
$$

fortis, 


\section{Analy is of the Air.}

fortis, generated 36 cubick inches of elaftick air, which was all reforbed the follow. ing day.

\section{EXPERIMENT XCIII.}

- Some time in February, a quarter of a cubick inch of filings of Iron, and a cubick inch of compaund Aqua fortis, without any watcr, did in 4 days abforb 27 cubick inches of air. It having ceafed to abforb, I poured hot water into the veffel $x x$, to try if I could renew the ferment. The effect of this was, that it generated 3 or 4 cubick inches of air, which continued in that ftate for fome days, and was then again reforbed.

I repeated the fame Experiment in warm weather in April, when it more briskly abforbed i 2 cubick inches in an hour.

\section{EXPERIMENT XCIV.}

March 12 th, $\frac{x}{4}$ of a cubick inch of flings of Iroin, with a cubick inch of compound Aqua-fortis, and an equal quantity of water, for the firft half hour abforbed $s$ or 6 cubick inches of air; but in an hour more it had 


\section{Analy is of the Air.}

emitted that quantity of air; and in two hours more it again reforbed what had been juft before emitted. The day following it continued abforbing, in all $\mathrm{I} 2$ cubick inches: And then remained ftationary for is or 20 hours. The third day it had again remitted or generated 3 or 4 cubick inches of air, and thence continued ftationary for five or fix days.

A like quantity of flings of Iron, and oil of Vitriol, made no fenfible ferment, and generated a very little air ; but upon pouring in an equal quantity of water, it generated in 21 days 43 cubick inches of air ; and in 3 or 4 days more it reforbed 3 cubick inches of air; when the weather turned warmer it was generated again, which was again rcforbed when it grew cool.

$\frac{x}{4}$ th Of a cubick inch of filings of Iron, and a cubick inch of oil of Vitriol, with three times its quantity of $W$ ater, generated ros cubick inches of air.

Filings of Iron, with Jpirit of Nitre, either with an equal quantity of water, or without water, abforbed air, but moft with. out water. 


\section{$2: 8$ Analyjes of the Air.}

th Of a cubick inch of flings of Iron, and a cubick inch of Limon juice, abforbed two cubick inches of air.

It is remarkable, that the fame mixtures mould change from generating to abforbing, and from abforbing to generating ftates; fometimes with, and fometimes withour any fenfible alteration of the temperature of the air.

\section{EXPERIMEN I XCV.}

Half a cubick inch of Spirits of Harts. horn, with filings of Iron abforbed I $+\frac{x}{2}$ cubick inches of air, with flings of Copper double that quantity of air, and made a very deep blue tincture, which it retained long, when expofed to the open air. It was the fame with Jpirit of Sal Ammoniac, and filings of Copper.

A quarter of a cubick inch of flings of Iron, with a cubick inch of powdered Brimftone, made into a pafte with a little water, abforbed 19 cubick inches of air in two days. $N$. B. I poured hot water into the ciftern $x x$, (Fig. 34.) to promote the ferment. 


\section{Analy/is of the Air.}

A like quantity of flings of Iron, and powdered Nerwcaftle Coal, did in 3 or 4 days generate 7 cubick inches of air. I could not perceive any fenfible warmth in this mixture, as was in the mixture of Iron and Brimftone.

Powdered Brimftone and Newcaftle Coal neither generated nor abforbed.

Filings of Iron and Water abforbed 3 or 4 cubick inches of air, but they do not abforb fo much when immerfed deep in water; what they abforb is ufually the firft 3 or 4 days.

Filings of Iron, and the above mentioned Walton Pyrites in Exper. 70. abforbed in 4 days a quantity of air nearly equal to double their bulk.

Copper Oar, and compound Aqua-fortis, neither generated nor abforbed air, but mixed with water it abforbed air.

A quarter of a cubick inch of $T$ in, and double that quantity of compound Aquafortis, gencrated two cubick inches of air; part of the $T$ in was diffolved into a very white fubftance.

E $\quad$ Ex-




\section{EXPERIMENT XCVI.}

April I 6th, A cubick inch of the aforementioned Walton Pyrites powder'd, with a cubick inch of compound Aqua-fortis, expanded with great violence heat and fume into a fpace equal to 200 cubick inches, and in a little time it condenfed into its former fpace, and then abforbed 85 cubick inches of air.

But the like quantity of the fame Mineral, with equal quantities of compound Aqua-fortis and Water, fermented more violently, and gencrated above 80 cubick inches of air. I repeated thefe Experiments feveral times, both with and without waier, and found conftantly the fame effect.

Yet oil of Vitriol and Water, with fome of the fame Mineral, abforbed air. It was very warm, but did not make a great ebul-lition.

$\therefore$ :

EXPERIMENT XCVII.

I chofe two equal fized boltheads, and put into each of them a cubick inch of pow: 


\section{Analy is of the Air.}

powdered Walton $P$ yrites, with only a cubick inch of compound Aqua-fortis into one, and a cubick inch of Water and compound Aqua-fortis into the other: Upon weighing all the ingredients and veffels exactly, both before and after the fermentation, I found the bolthead with compound Aqua fortis alone had loft in fumes I dram 5 grains: But the other bolthead with Water and compound Aqua-fortis, which fumed much more, had loft 7 drams, I fcruple, 7 grains, which is fix times as much as the other loit.

\section{EXPERIMENT XCVIII.}

A cubick inch of Nerwcaftle Coal pow: dered, and an equal quantity of compound Aqua-fortis poured on it, did in 3 days abforb 18 cubick inches of air; and in 3 days more it remitted and generated $12 \mathrm{cu}$ bick inches of air; and on pouring warm water into the veffel $x \times$ (Fig. 34.) it rémitted all that had been abforbed.

Equal quantities of Brimftone and compound Aqua-fortis neither generated nor abforbed any air, notwithftanding hot water was poured into the veffel $x \times$. 
A cubick inch of fincly powdered Flint; and an equal quantity of compound Aquafortis, abforbed in $S$ or 6 days 12 cubick inches of air.

Equal quantities of powdered Brifol Diamond, and compound Aqua-fortis, and Water abforbed I 6 times their bulk of air.

The like quantities without water ab. forbed more nowly 7 times their bulk of air.

Powdered Briftol Marble (viz. the thell in which thofe Diamonds lay) covered pretty deep with water, neither generated nor abforbed air; and it is well known that Briftol water does not fparkle like fome other Mineral waters.

\section{EXPERIMENT XCIX.}

When Aqua-regia was poured on Oleum Tartari per Deliquizim much air was genesated, and that probably chiefly from the Oleum Tartari; for by Exper. 74. Sal Tartar has plenty of air in it.

It was the fame when oil of Vitriol was poured on Ol. Tartari; and Ol. Tartari drop. ped on boyling $T$ artar generated much air.

When 


\section{Analy is of the Air.}

When equal quantities of Water and oil of Vitriol were poured on the fea falt it abforbed is cubick inches of air; but when in the like mixture the quantity of water was double to that of the oil of Vitriol, then but half fo much air was abforbed.

\section{EXPERIMENTC.}

I will next thew, what effeats feveral $A l$. kaline Mineral bodies had on the air in fermenting mixtures.

A folid cubick inch of unpowdered Chalk, with an equal quantity of oil of Vitriol, fermented much at firt, and in fome degree for 3 days; they generated 3 I cubick inches of air. The Chalk was only a little diffolved on its furface.

Yet Lime made of the fame Chalk abforb: ed much air ; when oil of Vitriol was poured on it, and the ferment fo violent that it breaking the glafs veffels, I was obliged to put the ingredients in an Iron veffel.

Two cubick inches of frefh Lime, and four of common white wine Vinegar abforbed in is days 22 cubick inches of air. 
224 Analy is of the Air.

The like quantity of frefh Lime and $W a$ ter abforbed in 3 days 10 cubick inches of air.

Two cubick inches of Lime, and an equal quantity of Sal Ammoniac ablorbed it is cubick inches.

A quart of unflaked Lime, left for 44 days, to flaken gradually by it felf without any mixture, abforbed no air.

March $3 \mathrm{~d}$, A cubick inch of powdered Belemnitis, taken from a Chalk pit, and an equal quantity of oil of Vitriol, generated in 5 minutes 35 cubick inches of air. March sth, it had generated 70 more. March 6th, it being a hard froft, it reforbed 12 cubick inches, fo it gencrated in all 128 inches, and reforbed 12 .

Powdered Belemnitis and Limon juice generated plenty of air too; as did alfo the Star Stone, Lapis Fudaicus, and Selenitis with oil of Vitriol.

\section{EXPERIMENT CI.}

Gravelled, that is well burnt, Wood-afhes, decrepitated Salt, and Colcothar of Vitriol, plac'd feverally under the inverted glafs $z z a a$

(Fig. 35.) 


\section{Analy is of the Air.}

(Fig. 35.) increafed in weight by imbibing the floating moiftire of the air: But they abforbed no claftick air. It was the fame with the remaining lixivious Salt of a diftillation of Nitre.

But 4 or 5 cubick inches of powdered frefh Cynder of Neweraftle Coal did in feven days abforb $s$ cubick inches of elaftick air. And 13 cubick inches of air were in $s$ days abforbed by Pulvis Urens, a powder which immediately kindles into a live Cole, upon being expofed to the open air.

\section{EXPERIMENT CII.}

What cffect burning and flaming bodies, and the refpiration of Animals have on the air, we fhall fee in the following Experiments, viz.

I fix'd upon the pedeftal under the inverted glafs $z z$ a a (Fig. 35.) a piece of Brown Paper, which had been dipped in a folution of Nitre, and then well dryed; I fet fire to the Paper by means of a burning glass: The Nitre detonized and burnt briskly for fome time, till the glafs $z z$ a a was very full of thick fumes, which extin. 


\section{Analyfis of the Air.}

guithed it. The expanfion caufed by the burning Nitre, was equal to more than two quaits: When all was cool, there was near so cubick inches of new generated air, which arofe from a fmall quantity of detonized $\mathrm{Ni}$ tre; but the elafticity of this new air daily decreared, in the fame manner as Mr. Haukfbee obferved the air of fired Gunpowder to do, Pbyfico-mecharical Exper.p. 83. Fo that he found 19 of 20 parts occupied by this air to be deferted in I 8 days, and its fpace filled by the afcending water; at which ftation it refted, continuing there for 8 days without altrration: And in like manner, I found that a confiderable part of the air, which was produced by fire in the diftillation of feveral fubftances, did gradually lofe its elafticity in a few days after the diftillation was orer; but it was not fo when I diftilled air thro' water, as in Experiment 77 . (Fig. 38.)

\section{EXPERIMENT CIII.}

I placed on the fame pedeftal large Matches made of linen rags dipped in melted Brimflone: The capaciry of the velfel, (Fig. 35.) above 


\section{Analyjis of the Air.}

above $z \approx$ the furface of the watcr, was equal to 2024 cubick inchcs. The quantity of air which was abforbed by the burning Match was 198 cubick inches, equal to $\frac{1}{10}$ part of the whole air in the veffel.

$I$ made the fame Experiment in a leffer veffel $z z a a$ (Fig. 35.) which contained but 594 cubick inches of air, in which I 50 cubick inches were abforbed, i. e. full $\frac{2}{4}$ part of the whole air in the recciver: So that tho' more air is abforbed by burning Matches in large veffels, where they burn longeft, than in fmall ones, yct more air, in proportion to the bulk of the veffel, is abforbed in fmall than in large veffels : If a freth Match wcre lighted, and put into this infeeted air, tho' it would not burn $\frac{x}{5}$ part of the time that the former Match burnt in freth untainted air, yet it would abforb near as much air in that fhort time; and it was the fame with Candles.

\section{EXPERIMENT CIV.}

Equal quantities of filings of Iron and Brimftone, when let fall on a hot Iron on the pedeftal under the inverted glafs $z \approx a_{a} a_{3}$

$$
\text { Q } 2
$$

(Fig. 35.) 
(Fig. 35.) did in burning abforb much air; and it was the fame with Antimony and Brimfrone: Whence it is probable, that Vulcano's, whofe fewel confift chicfly of Brimfone, mix'd with feveral mineral and metaline fubftances, do not generate, but rather abforb air.

We find in the foregoing Experiment 102 on Nitre, that a great part of the new generated air is in a few days reforbed, or lofes its elafticity: But the air which is abforbed by burning Brimftone, or the flame of a Candle, docs not recover its clafticity again, at lcalt, not while confined in my ghafies.

\section{EXPERIMENT CV.}

I made feveral attempts to try, whether air full of the fumes of burning Brimftone was as compreflible as common frefh air, by comprefling at the fame time tubes full of each of thefe airs in the condenfing engine; and I found that clear air is very little more comprefible, than air with fumes of Brimftone in it: But I could not come to an exact certainty in the matter, becaufe the 


\section{Analygis of the Air.}

fumes were at the fame time defroying the clafticity of the air. I took care to make the air in both tubes of the fame tempera. ture, by firf immerfing them in cold wate:, bcfore I comprefied them.

\section{EXPERIMENT CVI.}

I fet a lighted tallow Candle, which was about $\frac{6}{10}$ of an inch diameter, under the inverted receiver $z \approx a a$, (Fig. 35.) and with a fyphon I immediately drew the water up to $z z$ : Then drawing out the fyphon, the water would defeend for a quarter of a minute, and after that afcend, notwithftanding the Candle continued burning, and heating the air for near 3 minutes. It was obfervable in this Expcriment, that the furface of the water $z z$ did not afcend with an equal progreffion, but would be fometimes ftationary; and it would fometimes move with a flow, and fometimes with an accelerated motion; but the denfer the fumes the fafter it afcended. As foon as the Candle was out, I marked the height of the water above $z z$, which difference was equal to the quantity of air, whore elaf-

$$
\text { Q3 }
$$

ticity 
ticity was deftroyed by the burning Candle. As the air cooled and condenfed in the receiver, the water would continue rifing above that mark, not only till all was cool, but for 20 or 30 hours after that, which height it kept, tho' it ftood many days; which fhews that the air did not recover the elafticity which it had loft.

The event was the fame, when for greate: accuracy I repeated this Experiment by lighting the Candle after it was placed under the receiver, by means of a burning glafs, which fet fire to a fmall piece of brown paper fixed to the wick of the Candle, which paper had been firft dipped in a ftrong folution of Nitre in Water, and when well dryed, part of it was dipped in melted BrimAtone; it will alro light the Candle without bcing dipped in Brimftone. Dr. Mayou's found the bulk of the air lefiened by $\frac{1}{30}$ part, but does not mention the fize of the glafs vefiel under which he put the lighted Candle, De Sp. Nitro-aereo. p. 101. The capacity of the veffel above $z z$, in which the Candle burnt in my Experiment, was equal to 2024 cubick inches; and the elapticity of the $\frac{1}{26}$ part of this air was deftroyed. 
The Candle cannot be lighted again in this infected air by a burning glars : But if I firf lighted it, and then put it into tine fame infected air, tho' it was extinguifhed in $\frac{2}{5}$ part of the time, that it would burn in the fame veffel, full of frelh air; yet it would deftroy the clafticity of near as much air in that fhort time, as it did in five times that fpace of time in frefh air; this I repeated feveral times, and found the fame event: Hence a grofs air which is loaded with vapours, is more apt in equal times to lofe its elafticity in greater quantities, than a clear air.

I obferve that where the veffels are cqual, and the fize of the Candles unequal, the elatticity of more air will be dentroyed by the large than by the fmall Candle: And where Candles are equal, there moft air in proportion to the bulk of the veffel will be abforbed in the rmalleft veffel: Tho with equal Candles there is always moft elattick air deftroyed in the largeft veffel, where the Candle burns longeft.

I found alfo in fermenting liquors, that ceteris paribus, more air was either generated or abforbed in large, than in fmall

$$
\text { Q 4 vefiels }
$$


veffels, by generating or abforbing mixtures. As in the mixture of Aqua regia and Antimony in Experiment 9I, by enlarging the bulk of the air in the veffel, a greater quantity of air was abforbed. Thus alfo flings of Iron and Brimiftone, which in a more capacious veffel abforbed 19 cubick inches of air, abforbed very little when the bulk of air above the ingredients was but 3 or 4. cubick inches: For I have often obferved, that when any quantity of air is faturated with abforbing vapours to a certain degree, then no more elaftick air is abforbed: Notwithftanding the fame cuantity of abforbing fubftances would, in a larger quantity of air, have abforbed much more air; and this is the reafon why I was never able to deftroy the whole elafticity of any included bul's of air, whether it was common air, or ne generated air.

\section{EXPERIMENT CVII.}

May 18, which was a very hot day, I repeated Dr. Mayow's Experiment, to find how much air is abforbed by the breath of Animals inclofed in glaffes, which he found with a moufe to be $\frac{1}{1^{2}}$ part of the whole 


\section{Analy is of the Air.}

air in the glafs vefiel De Sp. Nitro-acro, p. 104.

I placed on the pedeftal, under the inverted glafs $z \approx a$ a, (Fig. 35.) a full grown Rat. At firft the water fubfided a litrle, which was occafioned by the rarifafion of the air, caufed by the heat of the Animal's body. But after a few minutes the watcr began to rife, and continucd rifing as long as the Rat lived, which was about 14 hours. The bulk of the Air in which the Rat lived fo many hours was 2024 cubick inches; the quantity of elaftick air which was abforbed was 73 cubick inches, above $\frac{1}{27}$ part of the whole, nearly what was abforbed by a Candle in the fame veffel, in Experiment 106.

I placed at the fame time in the fame manner another almoft half grown $R a t$ under a veffel, whofe capacity above the furface of the water $\approx \approx$ (Fig. 35.) was but $59+$ cubick inches, in which it lived 10 hours; the quantity of elaftick Air which was ablorbed, was equal to 4,5 cubick inches, vi ${ }^{2}$ part of the whole air, which the Rat breathed in: A Cat of 3 months old lived an hour in the fame re-

cciver, 
ceiver, and abforbed 16 cubick inches of air, viz. $\frac{1}{30}$ part of the whole; an allowance being made in this eftimate, for the bulk of the Cat's body. A candle in the fame veffel continued burning but one minure, and abforbed 54 cubick inches, $\frac{3}{2}$ part of the whole air.

And as in the cafe of burning Brimftone and Candles, more air was found to be abforbed in large veffels, than in fmall ones; and vice verfa, more $A$ ir in proportion to the capacity of the veffel was abforbed in fmall, than in large veffels; fo the fame holds true here too in the cafe of animals.

\section{EXPERIMENT CVIII.}

The following Experiment will thew, that the elafticity of the Air is greatly deftroyed by the refpiration of buman lungs, viz.

I made a bladder very fupple by wetting of it, and then cut off fo much of the neck, as would make a hole wide enough for the biggeft end of a large forfet to enter, to which the bladder was bound faft. The bladder 


\section{Analy is of the Air.}

and foffet contained 74 cubick inches. Having blown up the bladder, I put the fmall end of the foffet into my mouth; and at the fame time pinched my nofrils clofe that no air might pafs that way, fo that I could only breath to and fro the air contained in the bladder. In lefs than half a minute I found a confiderable difficulty in breathing, and was forced after that to fetch my breath very faft; and at the end of the minute, the fuffocating uneafinefs was fo great, that I was forced to take away the bladder from my mouth. Towards the end of the minute, the bladder was become fo flaccid, that I could not blow it above half full with the greateft expiration that I could make: And at the fame time I could plainly perceive that my lungs were much fallen, juft in the fame manncr as when we breath out of them all the air we can at once. Whence it is plain that a confiderable quan. tity of the elafticity of the air contained in my lungs, and in the bladder was deftroyed: Which fuppofing it to be $20 \mathrm{cu}$ bick inches, it will be $\frac{1}{13}$ part of the whole Air, which I breathed to and fro: for the bladder contained 74 cubick inches, and the 


\section{Analyfis of the Air.}

lungs by the following Experiment about I 66 cubick inches, in all 240.

There effects of refpiration on the elafticity of the air, put me upon making an attempt to meafure the inward furface of the lungs, which by a wonderful artifice are admirably contrived by the divine artificer, fo as to make their inward furface to be commenfurate to an expanfe of Air many times greater than the animal's body; as will appear from the following eftimate, viz.

\section{EXPERIMENT CIX.}

I took the lungs of a Calf and cut off the heart and windpipe an inch above its branching into the lungs; I got nearly the fpecifick gravity of the fubftance of the lungs, (which is a continuation of the branchings of the windpipe, and blood veffels) by finding the fpecifick gravity of the windpipe, which I had cut off; it was to Well-water as I.OS to I. And a cubick inch of water weighing 254 grains; I thence found by weighing the lungs the whole of their folid fubrtance to be equal to $37+\frac{1}{2}$ cubick inches, 


\section{Analy is of the Air.}

I then filled a large earthen veffel brim full of water, and put the lungs in, which I blew up kecping them under water with a pewter plate. Then taking the lungs out and letting the plate drop to the bottom of the water, I poured in a known quantity of water, till the veffel was brimful again; that watcr was 7 pounds 6 ounces and $\frac{1}{2}$ cqual to 204 cubick inches; from which dcdueting the fpace occupied by the folid fubftance of the lungs, viz. $37+\frac{x}{2}$ cubick inches, there remains $166+\frac{1}{2}$ cubick inches for the cavity of the lungs. But as the Pulmonary Veins, Arteries and Lymphaticks will, when they are in a natural ftate repleat with blood and lymph, occupy more fpace than they do in their prefent empty ftate; thercfore fome allowance muft a!fo be made, out of the above taken cavity of the lungs, for the bulk of thofe fluids; for which $25+\frac{2}{2}$ cubick inches feems to be a fufficient proportion, out of the 166 $+\frac{1}{2}$ cubick inches; fo there remains $14 \mathrm{I}$ cubick inches for the cavity of the lungs.

I poured as much water into the Browchice as they would take in, which was I pound 8 ounces, equal to 4 I cubick inches; 


\section{Analyfis of the Air.}

this deducted from the above found cavity of the lungs, there remains roo cubick inches for the fum of the cavity of the veficles.

Upon viewing fome of thefe veficles with a microfcope, a middle fized one feems to be about $\tau^{\frac{x}{0}}$ - part of an inch diameter; then the fum of the furfaces in a cubick inch of thefe fmall veficles (fuppofing them to be fo many little cubes, for they are not ípherical) will be 300 fquare inches; which multiplied by the fum of the cavity of all the veficles in the lungs, viz. 100 cubick inches, will produce 30000 fquare inches; one third of which mult be deducted, to make an allowance for the abfence of two fides in each little veficular cube, that there might be a free communication among them for the Air to pafs to and fro; fo there remains 20000 fquare inches for the fum of the furface of all the veficles.

And the Broncbia containing 41 cubick inches, fuppofing them at a medium to be cylinders of $\frac{T}{5}-$ of an inch diameter, their furface will be 1635 fquare inches, which added to the furface of the veficles makes the frum of the furface of the whole lungs to be 21635 fquare inches, or 


\section{Anatyjes of the Air.}

iso fquare feet, which is equal to to times the furface of a man's body, which at a medium is computed at Is fquarc feet.

I have not had an opportunity to take in the fame manner the capacity and dimenfions of human lungs; the bulk of which Dr. Fames Keill in his Tentamina Medicophysica, p. 80. found to be equal to $226 \mathrm{cu}-$ bick inches. Whence he eftimated the fum of the furface of the veficles to be 21906 fquare inches, which is nearly the fame with my eftinate of the Calve's lungs. But the bulk of human lungs is much more capacious than 226 cubick inches: For Dr. furin, by an accurate Experiment, found that he breathed out, at one large expiration, 220 cubick inches of Air; and I found it nearly the fame, when I repeated the like Experiment in another manner: So that there mut be a large allowance made for the bulk of the remaining Air, which could not be expired from the lungs; and aifo for the fubftance of the lungs.

Suppofing then, that according to Dr. Jurin's eftimate (in Mott's Abridgment of the Philosophical Tranfac. Vol. I. p. 4IS.) we draw in at each common infpiration 40 


\section{2 ;0 Analygis of the Air.}

cubick inches of air, that will be $48000 \mathrm{ctr}$. bick inches in an hour, at the rate of $20 \mathrm{in}$ fipirations in a minutc. A confiderable part of the ennicity of which air is, we fee by the forcgoing Experiment, conftantly defiroyed, and that chichly among the veficles, where it is charged with much vapour.

Dut it is not cafie to detcrminc how much is doftroyed. I attenipted to find it out by the following Experiment, which I fhall here give an account of, tho' it did not fucceed fo well as I could have withed, for want of much larger vefels; for if it was repeated with more cappacious veffels, it would detcrmine the matter pretty accurately; becaufe by this artifice freth air is drawn into the lungs at every infpiration, as well as in the frec open air.

\section{EXPERI MENT CX.}

I made ufe of the fyphon (Fig. 39.) taking away the bladders, and diaphragms $i$ i $n n 0$ : I fixed by means of a biadder one end of a fhort leaden fyphon to the lateral foffet $i$ : Then I faftened the large fyphon in a veficl, and filled it with water, till it rofe 


\section{Analyfis of the Air.}

rofe within two inches of $a$ and covered the ather open end of the fhort fyphon, which was depreffed for that purpore. Over this orifice I placed a large inverted chymi. cal receiver full of water; and over the other legos of the great fyphon, I whelmed another large empty receiver, whofe capacity was equal to 1234 cubick inches; the mouth of the receiver being immerfed in the water, and gradually let down lower and lower by an affiftant, as the water afcended in it. Then ftopping my noftrils, I drew in breath at $a$, thro' the fyphon from the empty receiver: And when that breath was expired, the valve $b i$ ftopping its return down thro' the fyphon, it was forced thro' the valve $r$, and thence thro' the fmall leaden fyphon into the inverted receiver full of water, which water defcended as the breath afcended. In this manner I drew all the air, except $s$ or 6 cubick inches, out of the empty receiver at $o$, the water at the fame time afcending into it and filling it; by which means all the air in the empty receiver, as alfo all the air in the fyphon os $b$, was infpired into my lungs, and breathed out thro' the valve $r$ into the receiver, which was at firt full 


\section{Analy/is of the Air.}

of water. I marked the boundary of air and water, and then immerfed the whole receiver, which had the breath in it, under water, and there gradually poured the contained breath up into the other full receiver, which ftood inverted over $o s$; whereby I could readily find, whether the air had lont any of its elafticity: And for greater furety, I alfo meafured the bulk of breath by filling the receiver with a known quantity of water up to the above mentioned mark; making alfo due allowance for a bulk of air, equal to the capacity of the large fyphon $0 s b$, which was at laft fucked full of water.

The event was, that there was is cubick inches of air wanting; but as thefe receivers were much too fmall to make the Experiment with accuracy; that fome allowance may be made for crrors, I will fet the lofs of elattick air at 9 cubick inches, which is but $\frac{x}{136}$ part of the whole air refpired, which will amount to 353 cubick inches in one hour, or roo grains, at the rate of 45000 cubick inches infpired in an hour, or one ounce and a half in twenty four hours.

By pouring the like quantity of air to and fro under water, I found that little or none 


\section{Analyfis of the Air. 243}

of it was loft ; fo it was not abforbde by the water : To make this tryal accurately, the air muft be detained fome time under water, to bring it firft to the fame temperature with the water. Care alfo muft be taken in making this Experiment, that the lungs be in the fame degrce of contraction, at the laft breathing, as at the firft, elfe a confiderable error may arife from thence.

But tho' this be not an exact eftinate, yet it is evident from the foregoing Experiments on refpiration, that fome of the clafticity of the air, which is infpired, is deftroyed; and that chiefly among the veficles, where it is mott loaded with vapours; whence probabiy fome of it, together with the acid fpirits; with which the air abounds, are conveyed to the blood, which we fee is by an admirable contrivance there fpread into a vaft cxpanfe, commenfurate to a very large furface of air, from which it is parted by very thin partitions; fo very thin, as thereby probably to admit the blood and air particles (which are there continually changing from an elaftick to a frongly attracting ftate) within the reach of each other's attraction,

$$
\text { R } 2
$$

whereby 


\section{Analy is of the Air.}

whereby a continued fucceflion of frefh air may be abforbed by the blood.

And in the analyfis of the blood, either by fire or fermentation in Exper. 49 and 80 , we find good plenty of particles ready to refume the elaftick quality of air: But whether any of thefe air particles enter the blood by the lungs, is not cafie to determine; becaufe there is certainly great ftore of air in the food of animals, whether it be vegetable or animal food. Yet when we confider how much air continually lofes its elafticity in the lungs, which feem purpofely framed into innumerable minute meanders, that they may thereby the better feize, and bind that volatile Hermes: It makes it very probable, that thofe particles which are now changed from an elaftick repulfive, to a ftrongly attracting ftate, may eafily be attracted thro' the thin partition of the veficles, by the fulphureous particles which abound in the blood.

And nature feems to make ufe of the like artifices in vegetables, where we find that air is freely drawn in; not only with the principal fund of nourifhment at the root, but 


\section{Analy is of the Air.}

but alfo thro' feveral parts of the body of the vegetable above ground, which air was feen to afcend in an elaftick ftate moft freely and vifibly thro' the larger trachea of the Vine; and is thence doubtlefs carried with the fap into minuter veffels, where being intimately united with the fuiphureous, faline and other particles, it forms the nutritive ductile matter, out of which all the parts of vegetables do grow.

\section{EXPERIMENT CXI.}

It is plain from thefe effects of the fumes of burning Brimftone, lighted Candle, and the breath of Animals on the elafticity of the air, that its clafticity in the veficles of the lungs muft be continually decreafing, by reafon of the vapours it is there loaded with; fo that thofe veficles would in a little time fubfide and fall flat, if they were not frequently replenifhed with frefh elartick air at every infpiration, thro' which the inferior heated vapour and air afcends, and leaves room for the frefh air to defcend into the veficles, where the heat of the lungs make it expand about $\frac{t}{8}$ part; which degree 


\section{Analyfis of the Air.}

of expanfion of a temperate air, I found by inverting a fmall glass bubble in water, a little warmer than a Thermometer is, by having its ball held fome time in the mouth, which may reafonably be taken for the degree of warmth in the cavity of the lungs. When the bubble was cool, the quantity of water imbibed by it was equal to $\frac{x}{s}$ of the cavity of the whole bubble.

But when inftead of thefe frequent recruits of frefh air, there is infpired an air, furcharged with acid fumes and vapours, which not only by their acidity contrad the exquifitely fenfible veficles, but alfo by their groffnefs much retard the free ingrefs of the air into the veficles, many of which are exceeding fmall, fo as not to be vifible without a microfcope; which fumes are alfo continually rebating the elafticity of that air; then the air in the veficles, will by Exp. Io? and 108 lofe its elafticity very faft, and confequently the veficles will fall fat, notwithftanding the cndeavours of the cxtending. Thorax to dilate them as ufual; whereby the motion of the blood thro" the lungs, be: ing ftopped, inftant death enfues. 


\section{Analyjis of the Air.}

Which fudden and fatal effect of there noxious vapours, has hitherto been fuppofed to be wholly owing to the lofs and wafte of the vivifying spirit of air; but may not unreafonably be alfo attributed to the lofs of a confiderable part of the air's clafticity, and the groffnefs and denfity of the vapours, which the air is charged with; for mutually attrading particles, when floating in fo thin a medium as the air, will readily coalefee into groffer combinations: Which effect of thefe vapours, having not been duly obferved before, it was concluded, that they did not affect the air's elafticity; and that confequently, the lungs muft needs be as much dilated in infpiration by this, as by a clcar air.

But that the lungs will not rife, and dilate as ufual, when they draw in fuch noxious air, which decreafes faft in its clafticity, I was affured by the Experiment I made on my felf in Expcr. 107. for when towards the latter end of the minute, the fuffocating quality of the air in the bladder was grea. teft, it was with much difficulty that I could dilate my lungs a very little. 
$248 \quad$ Analy is of the Air.

From this property in the vapours, arifing from animal bodies, to rebate and deftroy part of the clafticity of the air, a probable account may be given, of what becomes of a redundant quantity of air, which may at any time have gotten into the cavity of the Thorax ; either by a wound, or by fome defeet in the fubftance of the lungs, or by very violent exercife. Which if it was to continue always in that expanded ftate, would very much incommode refpiration, by hindering the dilatation of the lungs in infpiration. But if the vapours, which do continually arife in the cavity of the Thorax, deftroy fome part of the elatticity of the air, then there will be room for the lungs to heave: And probably, it is in the fame manner, that the winds are reforbed, which in their elaftick ftate fly from one part of the boely or limbs to another, caufing by their diftention of the veffels much pain.

\section{EXPERIMENT CXII.}

I have by the following Experiment found, that the air will pafs here and there thro' the fubftance of the lungs, with a very fmall force, viz.

I cut 


\section{Analy is of the Air.}

I cut afunder the bodies of feveral young and fmall animals juft below the Diaphragm, and then taking care not to cut any veffel belonging to the lungs, I layed the Thorax open by taking away the Diphragm, and fo much of the ribs, as was needful to expore the lungs to full view, when blown up. And having cut off the head, I fattned the windpipe to a very fhort inverted leg of a glafs fyphon; and then placed the inverted lungs and fyphon in a large and deep glafs veffcl $x$ full of water (Fig. 32.) under the air pump recciver $p p$, and paffing the longer leg of the fyphon thro' the top of the receiver, where it was cemented faft at $z$, as I drew the air out of the recciver, the lungs dilated, having a free communication with the outward air, by means of the glafs fyphon; fome of which air would here and there pals in a few places thro' the fubftance of the lungs, and rife in fmall ftreams thro' the water, when the recciver was exhaufted no more than to make the Mercury in the gage rife lefs than two inches. When I exhaunted the receiver, fo as to raife the Mercury 7 or 8 inches, tho' it made the air rulh with much more violence thro' 


\section{0 \\ Analy is of the Air.}

thro' thofe fmall apertures in the furface of the lungs, yet I did not perceive that the number of thofe apertures were increafed, or at leaft very little. An argument that thofe apertures were not forcibly made by exhaufting the receiver lefs than two inches, but were originally in the live animal; and that the lungs of living animals are fometimes raifed with the like force, efpecially in violent excrcife, I found by the following Experiment, viz.

\section{EXPERIMENT CXIII.}

Ityed down a live $\mathcal{D}$ og on his back, near the edge of a Table, and then made a fmall hole thro' the intercoftal mufcles into his Thorax, near the Diapbragm. I cemented faft into this hole the incurvated end of a glafs tube, whofe orifice was covered with a little cap full of holes, that the dilatation of the lungs might not at once fop the orifice of the tube. A fmall vial full of fpirit of Wine was tyed to the bottom of the perpendicular tube, by which means the rube and vial could eafily yield to the motion of the Dog's body, without danger of

breaking 


\section{Analyfis of the Air.}

breaking the tube, which was 36 inches long. The event was, that in ordinary infpirations, the fpirit rofe about fix inches in the tube; but in great and laborious infpirations, it would rife 24 and 30 inches, viz. when I ftopped the Dog's noftrils and mouth, fo that he could not breathe: This Experiment thews the force with which the lungs are raifed by the dilatation of the Thorax, either in ordinary or extraordinary and laborious infpirations. When I blew air with fome force into the Thorax, the Dog was juft ready to expire.

By means of another fhort tube, which had a communication with that which was fixed to the Thorax near its infertion into the Thorax, I could draw the air out of the Thorax, the height of the Mercury, inftead of fpirit in the tube, thewing to what degree the Thorax was exhaufted of air : The Mercury was hereby raifed nine inches, which would gradually fubfide as the air got into the Thorax thro' the lungs.

I then layed bare the windpipe, and having cut it off a little below the Larynx, I affixed to it a bladder full of air, and then continued fucking air out of the Thorax,

with? 
with a force fufficient to keep the lungs pretty much dilated. As the Mercury fubfided in the gage, I repeated the fuction for a quarter of an hour, till a good part of the air in the bladder was either drawn thro the fubftance of the lungs into the Thorax, or had loft its elafticity. When I preffed the bladder, the Mercury fubfided the fafter; the Dog was all the while alive, and would probably have lived much longer, if the Experiment had been continued; as is likely from the following Experiment, viz.

\section{EXPERIMENT CXIV.}

I tyed a middle fized Dog down alive on a table, and having layed bare his windpipe, I cut it afunder juft below the Larynx, and fixed faft to it the rmall end of a common forfet; the other end of the foffet had a large bladder tyed to it, which contained $1 \sigma_{2}$ cubick inches; and to the other end of the bladder was tyed the great end of another forfer, whofe orifice was covered with a valve, which opened inward, fo as to admit any air that was blown into the bladder, but none could return that way; yet for fur- 


\section{Analy is of the Air.}

ther fecurity, that paffage was alfo ftopped with a fpiggot.

As foon as the firft foffet was tyed faft to the windpipe, the bladder was blown full of air thro' the other foffet; when the Dog had breathed the air in the bladder to and fro for a minute or two, he then breathed very faft, and thewed great uneafinels, as being almoft fuffocated.

Then with my hand I preffed the bladder hard, fo as to drive the air into his lungs with fome force; and thereby make his $A b$ domen rife by the preffure of the Diaphragm, as in natural breathings : Then taking alter'nately my hand off the bladder, the lungs with the Abdomen fubfided; I continued in this manner, to make the Dog breathe for an hour; during which time I was obliged to blow frefh air into the bladder every five minutes, three parts in four of that air being either abforbed by the vapours of the lungs, or efcaping thro' the ligatures, upon my preffing hard on the bladder.

During this hour, the Dog was frequently near expiring whenever I preffed the air but weakly into his lungs; as I found by his pulfe, which was very plain to be felt 


\section{Analyfis of the Air.}

in the great crural artery near the groin; which place an affiftant held his finger on moft part of the time; but the languid pulfe was quickly accelcrated, fo as to beat faft; foon after I dilated the lungs much, by preffing hard upon the bladder, efpecially when the motion of the lungs was promoted by preffing alternately the Abdomen and the bladder, whereby both the contraction and dilatation of the lungs was increafed.

And I could by this means roufe the languid pulfe whenever I pleafed, not only at the end of every 5 minutes, when more air was blown into the bladder from a man's lungs, but alfo towards the end of the $s$ minutes, when the air was fulleft of fumes.

At the end of the hour, I intended to try whether I could by the fame means have kept the Dog alive fome time longer, when the bladder was filled with the fumes of burning Brimftone : But being obliged to ceafe for a little time from preffing the air into his lungs, while matters were preparing for thisadditional Experiment, in the mean time the Dog dyed, which might otherwife have lived longer, if I had continued to force the air into his lungs.

Now, 


\section{Analy is of the Air. $\quad 255$}

Now, tho' this Experiment was fo frequently difturbed, by being obliged to blow more air into the bladder twelve times during the hour; yet fince he was almoft fuffocated in lefs than two minutes, by breathing of himfelf to and fro the firt air in the bladder, he would by Experiment 106 on Candles, have dyed in lefs than two minutes, when one fourth of the old air remained in the bladder, immediately to taint the new admitted air from a man's lungs; fo that his continuing to live thro' the whole hour, muft be owing to the forcible dilatation of the lungs, by comprefling the bladder, and not to the vivifying Jpirit of air. For without that forcible dilatation, he had, after the firft $s$ or Io minutes, been certainly dead in lefs than a minute, when his pulfe was fo very low and weak, which I did not find to be revived barely by blowing 3 parts in 4 of ncw air from the lungs of a man into the bladder: But it was conftantly roufed and quickned, whenever I increafed the dilatations of the lungs, by comprefing the bladder more vigorouly; and that whether it was at the beginning or end of each 5 minutes, yet it was more eafily quickned, 


\section{Analyjes of the Air.}

when the bladder was at any time newly filled, than when it was near empty.

From thefe violent and fatal effeas of very noxious vapours on the refpiration and life of animals, we may fee how the refpiration is proportionably incommoded, when the air is loaded with leffer degrees of vapours, which vapours do in fome meafure clog and lower the air's elafticity; which it beft regains by having thefe vapours difpelled by the ventilating motion of the free open air, which is rendered wholefome by the agitation of winds: Thus what we call a clofe warm air, fuch as has been long confined in a room, without having the vapours in it carried off by communicating with the open air, is apt to give us more or lefs uneafinefs, in proportion to the quantity of vapours which are floating in it. For which reafon the German ftoves, which heat the air in a room without a free admittance of frefh air to carry off the vapours that are raifed, as alfo the modern invention to convey heated air into rooms thro' hot flues, feem not fo well contrived, to favour a free refpiration, as our common method of fires in open chimneys, which 


\section{Analyfis of the Air.}

fires are continually carrying a large ftream of heated air out of the rooms up the chimney, which ftream muft neceflarily be fupplied with equal quantities of frefh air, thro' the doors and windows, or the cranies of them.

And thus many of thore who have weak lungs, but can breath well enough in the frefh country air, are greatly incommoded in their breathing, when they come into large cities where the air is full of fuliginous vapours, arifing from innumerable coal fires, and ftenches from filthy lay-ftalls and fewers: And even the moft robuft and healthy in changing from a city to a country air, find an exhilarating pleafure, arifing from a more free and kindly infpiration, whereby the lungs being lefs loaded with condenfing air and vapours, and thereby the veficles more dilated, with a clearer and more elaftick air, a freer courfe is thereby given to the blood, and probably a purer air mixed with it; and this is one reafon why in the country a ferene dry conftitution of the air is more exhilarating than a moift thick air.

And for the fame reafon, 'tis no wonder, that peftilential, and other noxious epide- 


\section{Anily is of the Air.}

mical infections are conveyed by the breath to the blood (when we conlider what great quantities of the airy vehicle lofes its elafticity among the veficles, whereby the infectious Miafma is lodged in the lungs.

When I reflect on the great quantities of elaftick air, which are deftroyed by burning fulphur; it feems to me not improbable, that when an animal is killed by lightning without any vifible wound, or immediate ftroke, that it may be done by the air's elafticity, being inftantly deftroyed by the fulphureous lightning near the animal, whereby the lungs will fall flat, and caufe fudden death; which is further confirmed by the flatnefs of the lungs of animals thus killed by lightning, theirveficles being found upon diffection to be fallen flat, and to have no air in them: The burnting alfo of glafs windows outwards, feems to be from the fame cffect of lightning on the air's clafticity.

It is likewife by deftroying the air's elafticity in fermented liywors, that lightning renders them flat and vapid: For fince fulphureous fteams held near or under veffels will check reduadant fcrmentation, as well 


\section{Analyfis of the Air.}

as the putting of fulphureous mixtures into the liquor, 'tis plain, thofe ftcams can eafily penetrate the wood of the containing veffels. No wonder then, that the more fubtile lightning thould have the like effect. I know not whether the common practice of laying a bar of iron on a veffel, be a good prefervative againft the ill effeets of lightning on liquors I thould think that the covering a veffel with a large cloth dipped in a ftrong brine, would be a better prefervative; for falts are known to be ftrong attracters of fulphur.

The certain death which comes on the explofion of Mines, feems to be effected in the fame manner: For tho' at firft there is a great expanfion of the air, which mult dilate the lungs, yet that air is no fooner filled with fuliginous vapours, but a good deal of its elafticity is immediatcly deftroyed: As in the cafe of burning Matches in Experiment 103 , the heat of the flame at firft expanded the air; but notwithftanding the flame continued burning, it immediately contracted, and loft much of its elafticity, as foon as fome quantity of fulphureous fteams afsended in it. 
Which fteams have doubtlefs the fame effect on the air, in the lungs of Animals held over them; as in the Grotto di cani, or when a clofe room is filled with them, where they certainly fuffocate.

It is found by Experiments 103, 106, and 107, that an air greatly charged with vapours lofes much of its elafticity, which is the reafon why fubterraneous damps fuffocate Animals, and extinguifh the flame of Candles. And by Experiment 106, we fee that the fooner a Candle goes out, the fafter the air lores its elafticity.

\section{EXPERTMENT CXV.}

This put me upon attempting to find fome means to qualify and rebate the deadly noxious quality of there vapours: And in order to it, I put thro' the hole, in the top of the air pump receiver (Fig. 32.) which contained two quarts, one leg of an iron fyphon made of a gun barrel, which reached near to the bottom of the receiver: It was cemented fant at $\approx$, I tyed three folds of woollen cloth over the orifice of the fyphon, which was in the receiver. The Candle went out in lefs than two minutes, tho' I conti- 


\section{Analyjis of the Air.}

nued pumping all the while, and the air paffed fo freely thro' the folds of cloth into the receiver, that the Mercury in the gage did not rife above an inch.

When I put the other end of the fyphon into a hot iron pot, with burning Brimftone in it; upon pumping, the Candle went out in I $s$ feconds of a minute; but when I took away the 3 folds of cloth, and drew the fulphurcous fteams thro' the open fyphon, the light of the Candle was inftantly extinguifhed; whence we fee the 3 folds of cloth preferved the Candle alight is". And where the deadly quality of vapours in Mines is not fo ftrong as thefe fulphureous ones were, the drawing the breath thro' many folds of woollen cloth may be a means to preferve life a little langer, in proportion to the more or lefs noxious quality of the damps.

When, inftead of the 3 folds of cloth, I immerfed the end of the fyphon 3 inches deep in water in the veffel $x$, (Fig. 32.) tho' upon pumping the fuiphureous fumes did afcend vifibly thro' the water, yet the Candle continued burning half a minute, i.e. double the time that it did when fumes paffed thro' folds of woollen cloth.

$$
S_{3}
$$

Ex: 


\section{EXPERIMENT CXVI.}

I bored a hole in the fide of a large wooden foffet $a b$, (Fig. 39.) and glewed into it the great end of another foffet $i i$, covering the orifice with a bladder valve $r$ : Then I fitted a valve $b i$, to the orifice of the iron fyphon $\iint$, fixing the end of the fyphof faft at $b$ into the foffet $a b$ : Then by means of narrow hoops I placed four Diaphragms of flannel at half an inch diftance from cach other, into the broad rim of a fieve, which was about 7 inches diameter. The fieve was fixed to, and had a free communication with both orifices of the fyphon, by means of two large bladders i in no.

The inftrument being thus prepared, pinching my noftrils clofe, when I drew in breath with my mouth at $a$, the valve $i b$ being thereby lifted up, the air paffed freely thro the fyphon from the bladders, which then fubfided, and Thrunk confiderably : But when $I$ breathed air out of my lungs, then the valve $i b$ clofing the orifice of the fyphon, the air paffed thro' the valve $r$ into the bladders, and thereby dilated them; by which 


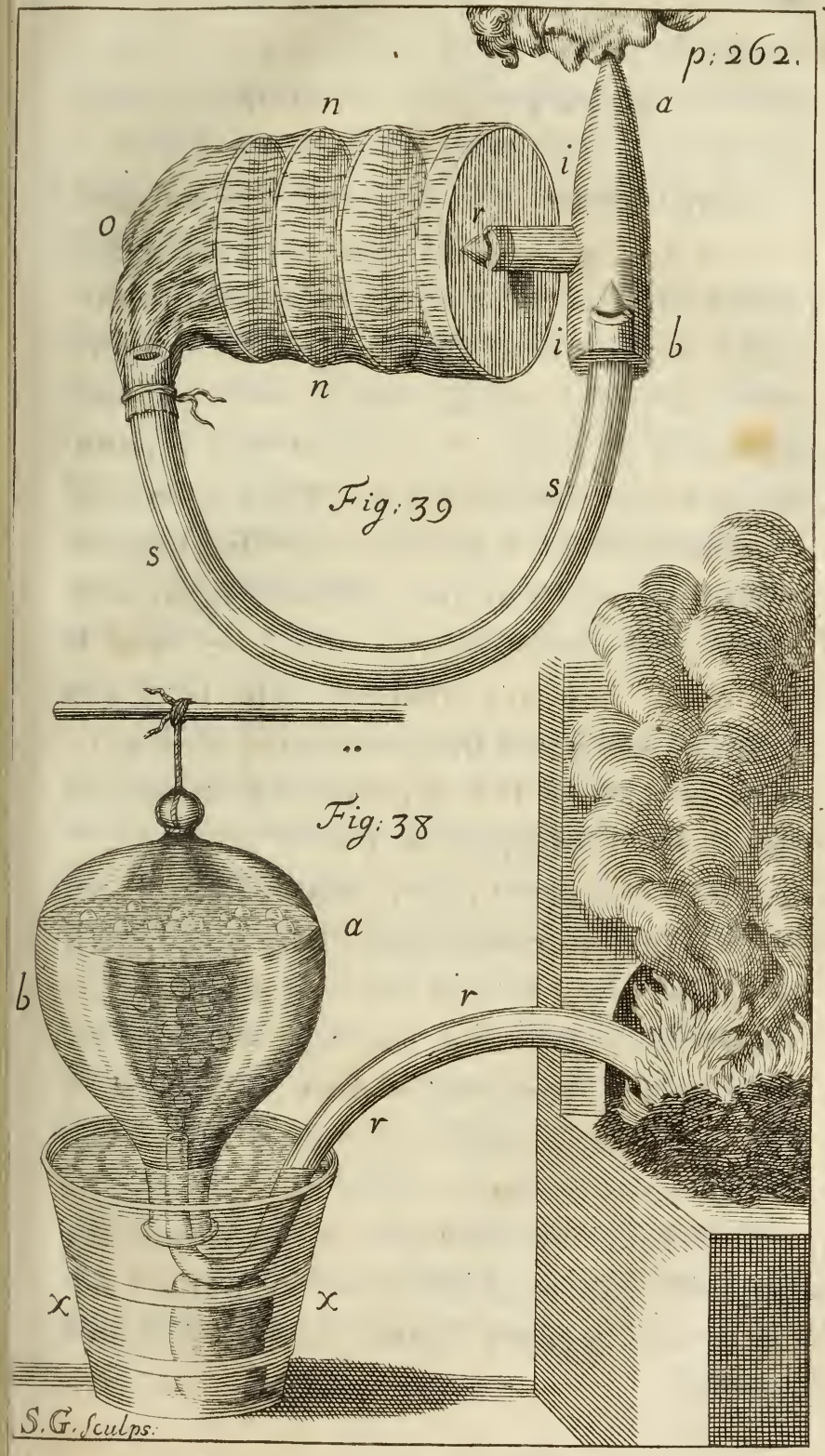





\section{Analy/as of the Air.}

artifice the air which I expired mun neceffarily pafs thro' all the Diaphragms, before it could be infpired into my lungs again. The whole capacity of the bladders and fy. phon was 4 or 5 quarts.

Common fea falt, and Sal Tartar, being Atrong inbibers of fulphureous fteams, I dipped the four Diaphragms in ftrong folutions of thofe falts, as alfo in white wine vinegar, which is looked upon as a good anti-peftilential: Taking care after each of thefe Experiments to cleanfe the fyphon and bladder well from the foul air, by filling them with water.

I could breath too and fro the air inclofed in this infrument for a minute and half, when there were no Diaphragms in it; when the 4 Diaphragms were dipped in vinegar, 3 minutes; when dipped in a frong folution of fea falt, 3 minutes and an half. In a Lixivium of Sal Tartar, 3 minutes; when the Diaphragms were dipped in the like Lixivium, and then well dryed, $s$ minutes; and once $8+\frac{x}{2}$ minutes, with very highly calcined SalTartar; but whether this was owing to the Tartar's being greatly calcined, whereby it might more ftrongly attract fulphureous 
264 Analy is of the Air.

phureous grofs vapours, or whether it was occafioned by fome unheeded paffage for the air thro' the ligatures, I am uncertain; neither did I care to afcertain the matter by repeated Experiments, fearing I might thereby rome way injure my lungs, by frequently breathing in fuch grofs vapours.

Hence Sal Tartar fhould be the beft prefervative againft noxious vapours, as being a very ftrong imbiber of fulphureous, acid and watry vapours, as is fea falt alfo: For having carefully weighed the 4 Diaphragms, before I fixt them in the inftrument, I found that they had increared in weight 30 grains in five minutes; and it was the fame in two different tryals; fo they increafed in weighe at the rate of 19 ounces in 24 hours. From which deducting $\frac{1}{\circ}$ part for the quantity of moifture, which I found thofe Diaphragms attracted in $s$ minutes in the open air; there remains is $+\frac{2}{3}$ ounces, for the weight of the moifture from the breath in 24 hours: But this is probably too great an allowance, confidering that the Diphragms might attract more than $\frac{1}{6}$ part from the moifture of the bladders and of the fyphon.

I have 


\section{Analyfis of the Air.}

I have found that when the Diaphragms had fome fmall degree of dampnefs, they increafed in weight fix grains in 3 minutes; but they made no increafe in weight in the fame timc, when in the open air : which fix grains in 3 minutes, is at the rate of about $6+\frac{1}{2}$ ounces in 24 hours; and this is nearly the fame proportion of moifture that I obtained by breathing into a large receiver full of fpunges. But the 6 grains imbibed by the four Diapbragms in $3 \mathrm{mi}$ nutes, was not near all the vapours which were in that bulk of inclofed air; for at the end of the 3 minutes, the often refpired air was fo loaded with vapours, which in that floating ftate were eafily, by their mutual attraction, formed into combinations of particles, too grofs to enter the mi nute veficles of the lungs, and was therefore unfit for refpiration; fo that it is not eafie to determine what proportion is carried off by refpiration, efpecially confidering that fome of the infpired air, which has loft its elafticity in the lungs, is mingled with it. But fuppofing $6+\frac{T}{2}$ ounces to be the quantity of moifture carried off by refpiration in 24 hours, then the furface of the lungs

being 


\section{Analy is of the Air:}

being found as above 21635 fquare inches only $\frac{3}{1966}$ part of an inch depth, will be evaporated off their inward furface in that time, which is but $3 \frac{3}{9}$ part of the depth of what is perfpired off the furface of a man's body in that time.

If then life can by this means be fupported for 5 minutes with 4 Diaphragms and a gallon of air, then doubtlefs, with double that quantity of air and 8 Diaphragms we might well expect to live at leaft io minutes. It was a confiderable difadvantage that I was obliged to make ufe of bladders, which had been often wetted and dried, fo that the unfavory fumes from them nuit needs have contributed much to the unfitting the included air for refpiration: Yet there is a neceflity for making ure of either bladder or leather in thefe cafes; for we cannot breath to and fro the air of a veffel, whofe fides will not dilate and contract in conformity with the expirations and infpirations, unlefs the veffel be very large, and roo big to be conveniently portable.

Having ftopped up the wide fucking orifice of a large pair of kitchen bellows, they being firt dilated, I could breathe to and fro 


\section{Analy is of the Air.}

at their nofe, the air contained in them for 3 minutes, without much inconvenience, they heaving and falling very eafily by the action of refpiration. Some fuch like infrument might be of ufe in any cafe where a room was filled with fuffocating vapours, where it might be neceffary to enter for a few minutes, in order to remove the caufe of them, or to fetch any perfon or thing out; as in the cafe when houfes are firft beginning to fire, in the chymirts elaboratories; and in many other cafes where places were filled with noxious deadly vapours, as in the care of ftink pots thrown into thips, in mines, \&rc.

But in every apparatus of this kind great care muft always be taken, that the infpiration be as free as poflible, by making large paffages and valves to play moft eafily. For tho' a man by a peculiar action of his mouth and tongue may fuck Mercury 22 inches, and fome men 27 or 28 high; yet I have found by experience, that by the bare infpiring action of the Diapbragm, and dilating Thorax, I could fcarcely raife the Mercury 2 inches. At which time the Diaphragm muttact with a force equal to the weight 


\section{Analy is of the Air.}

weight of a Cylinder of Mercury, whofe bafe is commenfurate to the area of the Diaphragm, and its height 2 inches, whereby the Diaphragm muft at that time fuftain a weight equal to many pounds. Neither are its counter-acting mufcles, thofe of the Abdomen, able to exert a greater force.

For notwithftanding a man, by ftrongly compreffing a quantity of air included in his mouth, may raife a column of Mercury in an inverted fyphon, to 5 or 7 inches height, yet he cannot with his utmoft ftrainings raife it above 2 inches, by the contracting force of the mufcles of the Abdomen; whence we fee that our loudeft vociferations are made with a force of air nogreater than this. So that any fmall impediment in breathing will haften the fuffocation, which confifts chiefly in the falling flat of the lungs, occafioned by the groffnefs of the particles of a thick noxious air, they being in that floating ftate moft eafily attracted by each other: As we find in the foregoing experiments that fulphur and the elaftick repelling particles of air do: And confequently unelaftick, fulphureous, faline and other floating particles will moft eafily coalefce, 


\section{Analy is of the Air.}

coalefce, whereby they are rendred too grofs to enter the minute veficles; which are alfo much contracted, as well by the lofs of the elarticity of the contained air, as by the contraction occafioned by the ftimulating, acid, fulphureous vapours. And 'tis not improbable that one great defign of nature, in the ftructure of this important and wonderful vifcus, was to frame its veficles fo tery minute, thereby effectually to hinder the ingrefs of grofs feculent particles, which might be injurious to the animal ceconomy.

This quality of falts ftrongly to attract fulphureous, acid and other noxious particles, might make them very beneficial to mankind in many other refpects. Thus in feveral unwholfome trades, as the fmelters of metals, the ceruifs-makers, the plumbers, $\delta c$. it might not unlikely be of good fervice to them in preferving them in fome meafure at leaft, from the noxious fumes of the materials they deal in, which by many of the foregoing experiments we are affured mult needs coalefce with the elaftick air in the lungs, and be lodged there; to prerent which inconvenience the workmen might, while they are at work, make ufe of pretty 
broad mufflers, filled with 2,4 , or more Diaphragms of flannel or cloth dipped in a folution of Sal Tartar, or Pot-ajh, or Sea Salt and then dryed.

The like mufflers might alfo be of fervice in many cafes where perfons may have urgent occafion to go for a thort time into an infectious air: Which mufflers might, by an eafy contrivance, be fo made as to draw in breath thro' the Diaphragms, and to breathe it out by another vent.

In there and the like cares this kind of mufflers may be very ferviceable; but in the cafe of the damps of mines they are by no means to be depended on, becaufe they are not a fufficient fcreen from fo very noxious vapours.

\section{EXPERIMEN T CXVII.}

We have from the following Experiment a good hint, to make thefe Salts of fervice to us in fome other refpects, \& $c$.

I fet a lighted Candle under a large receiver (Fig. 35.) which contained about 4 gallons, it continued burning for $3+\frac{3}{2}$ minutes, in which time it had ablorbed about 


\section{Analy is of the Air.}

a quart of air. I then filled the receiver with frefh air, by pouring it full of water, and then emptying of it; when having wiped it dry, I lined all the infide with a piece of flannel dipped in a lixivium of $\mathrm{Sal}$ Tartar, and then dryed; the flannel was extended with little hoops made of pliant twigs. The Candle continued burning under the receiver thus prepared $3+\frac{x}{2}$ minutes, yet it abforbed but two thirds of the quantity of air which it abforbed when there was no flannel in the receiver.

The realon of which difference in the quantities of elaftick air abforbed, appears from Experiment 106. where leaft air was always abforbed in leaft receivers, which was the prefent cafe: For the flannel lining, befides the fpace it took up, could not be fo clofely adapted, but that there was left a full third of the capacity of the receiver, between the lining and the receiver: So that the Candle burnt in a bulk of air lefs by one third than the whole capacity of the receiver; for which reafon lefs air alfo was ablorbed.

And we may further obferve, that fince the Candle continued burning as long in a quantity of air, equa! but to two thirds of 


\section{Analy is of the Air.}

the receiver, as in the whole air of the re: ceiver; this muft be owing to the Sal T artar in the flannel lining, which muft needs have abforbed one third of the fuliginous vapours, which arofe from the burning Candle. Hence we may not unreafonably conclude, that the pernicious quality of noxious vapours in the air might, in many cafes, be much rebated and qualified by the ftrongly abforbing power of Salts.

Whether Salts will have a good effect in all, or any of thefe cafes, experience will beft inform us. There is certainly fufficient ground, from many of the foregoing Experiments, to encourage us to make the tryal, and they may at leaft be hints for further improvements.

We fee that Candles and burning Brimftone do in a much greater degree deftroy the elafticity of the air, than the breath of Animals; becaufe their vapours are more plentiful, and abound more with acid fulphureous particles, and are alfo lefs diluted with watry vapours, than the breath of Animals is: In which alfo there are fulphureous particles, tho' in leffer degrees, for the animal fluids, as well as folids, are ftored with 


\section{Analyfis of the Air.}

them: And therefore the Candle and Matches ceafing to burn, foon after they are confined in a fmall quantity of air, feems not to be owing to their having rendred that air effete, by having confumed its vivifying fpirit; but fhould rather be owing to the great quantity of acid fuliginous vapours, with which that air is charged, which deftroy a good deal of its elafticity, and very much clog and retard the elaftick motion of the remainder.

And the effect the half exhaufting of a receiver has upon the elafticity of the remaining half of the air, feems to be the reafon why the flame of a Candle does not continue burning, till it has filled the receiver it ftands in with fumes, but goes out the quicker, the fooner the air is drawn out to that degree; which feems therefore to be owing to this, that an air rarified to double its fpace, will not expand fo briskly with the warmth of flame, as a more condenfed air will do: And confequently action and re-action being reciprocal, will not give fo brisk a motion to the flame, which fubfifts by a conftant fucceffion of frefh air, to fupply the place of the either abforbed, or much dilated air, which is continually flying off.

$$
\text { I }
$$




\section{Analy is of the Air.}

And the quicker the fucceffion of this frefh air is, by blowing, the more vigoroully does a fire burn.

If the continuance of the burning of the Candle be wholly owing to the vivifying Jpirit, then fuppofing in the cafe of a receiver, capacious enough for a Candle to burn a minute in it, that half the vivifying Jpirit be drawn out with half the air, in ten feconds of time; then the Candle fhould not go out at the end of thore ro feconds, but burn 20 feconds more, which it does not; therefore the burning of the Candle is not wholly owing to the vivifying Spirit, but to certain degrees of the air's elafticity. When a wholly exhaufted receiver was by means of a burning glafs firf filled with the fumes of brown paper with Nitre, and then filled with frefh air, the nitrous paper upon applying the burning glafs did freely detonize; and a Candle put into a like air, burnt for $28^{\prime \prime}$; which in a frefh air, in the fame receiver, burnt but 43 "; but when the fame receiver with air in it, was filled full of fumes of detonized Nitre, and a Candle placed in that thick vapour, it went out inftantly, for a Candle will not burn, nor the 


\section{Analyfis of the Air.}

the Nitre detonize in a very rare, nor a very thick air; whence the reafon why the Nitre detonized, and the Candle burnt, when placed in the receiver, after frefh air was let in upon the fumes which were made in vacuo, was that thofe fumes were much difperfed and condenfed on the fides of the glafs, upon the rufhing in of the frefh air, for the fumes were then much more rare aud tranfparent, than before the air was let in.

That a Fire which is fupplied with a hot air will not burn fo briskly as a Fire which is fed by a cool air is evident from hence; that when the Sun thines on a Fire, and thereby too much rarifies the ambient air, that Fire will not burn well, nor will a fmall Fire burn fo well near a large one as at fome diftance from it. And e contra, it is a common obfervation, that in very cold frofty weather Fires burn moft briskly; the reafon of which feems to be this, that the elaftick expanfion of the cold condenfed air to a rarified ftate, when it enters the Pire, is much brisker than that of an air already rarified in a good meafure by heat, before it enters the Fire; and confequently a continued fuc-

$$
\text { I } 2 \text { ceflion }
$$




\section{Analy is of the Air.}

ceflion of cold air muft give a brisker motion to the Fire, than the like fucceflion of hot air: And fuch colder and more condenfed air will alfo (as Sir I Jaac Neruton obferves, qu. Ir.) by its greater weight check the afcent of the vapours and exhalations of the Fire, more than a warmer lighter air. So that between the action and re-action of the air and fulphur of the fuel, and of the colder and denfer cirumambient air, which rarifies much upon entering the Fire, the heat of the Fire is greatly increafed.

This continual fupply of freth air to the fuel feems hence alfo very neceffary for kecping a Fire alive; becaufe it is found, that a Brimftone Match will not take Fire in avacuum, but only boil and fmoak; nor will Nitre incorporated into Brown Paper then detonize, except here and there a fingle grain; that part only of the Paper turning black on which the focus of the burning glars falls; nor would they burn when a half exhauted receiver with fumes in it was filled with frefh air added to thofe fumes: In which cafe it is plain, that a good quantity of the fuppofed vivifying fpirit of air mult enter the receiver with the frelh air, and confe- 


\section{Analyjis of the Air.}

quently thofe fubftances fhould take fire, and burn for a thort time at leaft, which yet they did not.

And that the air's elafticity conduces much to the intenfe burning of Fires, feems evident from hence; that Spirit of Nitre (which by Experiment $7 \mathrm{~s}$ has but little elaftick air in it) when poured upon live Coals, extinguifhes inftead of invigorating them: But Spirit of Nitre, when by being mixt with Sal Tartar it is reduced to Nitre, will then flame, when thrown into the Fire, viz. becaufe Sal Tartar abounds with elaftick aereal particles, as appears by Experiment 74, where 224 times its bulk of air arofe from a quantity of Sal T artar. And for the fame reafon it is that common Nitre, when thrown into the Fire, flames, tho' its Spirit will not, viz. becaufe there is much elaftick air in it, as appears from Experiment 72 , as well as from the great quantity of it, generated in the firing of Gun-powder.

The reaion why Sal Tartar, when thrown on live Coals, does not detonize and flame like Nitre, (notwithftanding by Experiment 74 plenty of elaftick particles did arife from it) is this, viz. becaufe by the fame Experi-

$$
\text { T } 3
$$

ment, 


\section{8 \\ Analy is of the Air.}

ment, compared with Experiment 72 , it is found, that a much more intenfe degree of heat was required to extricate the elaftick air from Sal Tartar, the more fix'd body, than from Nitre; the great degree of Fire with which Sal Tartar is made, rendering the cohefion of its parts more firm: For it is well known that fire, inftead of difuniting, does in many cafes infeparably unite the parts of bodies: And hence it is that Pulvis Fulminans, which is a mixture of SalTartar, Nitre and fulphur, gives a greater explofion than Gun-powder: Becaule the particles of the Sal Tartar, cohering more firmly in a fix'd ftate than thofe of Nitre, they are therefore thrown off with a greater repulfive force, by the united action and re-action of all thofe ingredients armed each with its acid Spirit.

\section{EXPERIMENT CXVIII.}

Which acid Spirits confifting of a volatile acid Salt diluted in phlegm do contribute much to the force of explofion; for when heat: ed to a certain degree, they make a great explofion, like water heated to the fame degree, 


\section{Analy/is of the Air.}

as I found by dropping a few drops of Spirit of Nitre, oil of Vitriol, water, and fpittle on an Anvil; and then holding over thore drops a piece of Iron which had a white heat given it; upon ftriking down the hot Iron with a large Hammer, there was a very great explofion made by each of thofe liquors: But frothy fpittle, which had air in it, made a louder explofion than water; which thews that the valt explofion of the Nitre and Sal Tartar, which are compofed of elaftick air particles, included in an acid Spirit, is owing to their united force.

We may therefore from what has been faid, with good reafon conclude, that Fire is chicfly invigorated by the action and re-action of the acid fulphureous particles of the fuel, and the elaftick ones which arife and enter the Fire, either from the fuel in which they abound, or from the circumambient air: For by Experiment 103, and many others, acid fulphureous particles act vigorouny on air; and finceaction and re-action are reciprocal, fo muft air on fulphur; and there is, we fee, plenty of both, as well in mineral as vegetable fuel, as alfo in animal fub?tances, for which reafon they will burn.

$$
\text { I } 4
$$

Bat 


\section{Analyjis of the Air.}

But when the acid fulphur, which we fee acts vigorounly on air, is taken out of any fuel, the remaining Salt, $W$ ater and Earth are not inflammable, but on the contrary quench and retard fire; and as air cannot produce fire without fulphur, fo neither can fulphur burn without air: Thus Charcoal heated to an intenfe degree for many hours in a clofe veffel will not burn as in the open air, it will only be red hot all the time like a mafs of Gold without wanting: But no fooner is it expofed to the free air, but the fulphur, by the violent action and re-action between that and the elaftick air, is foon feparated and carried off from the Salt and Earth, which are thereby reduced from a folid and hard to a foft impalpable calx.

And when a Brimftone Match which was placed in an exhaufted receiver was heated by the focus of a burning glafs fo as to melt the Brimftone, yet it did not kindle into fire nor confume, notwirhitanding the ftrength and vigour of the action and reaction that is obferved between light and fulphureous bodies. Which is affigned by the illuftrious Sir Ifaac Nerwton, as " one reafon "why fulphurcous bodies take fire more " readily, 
"readily, and burn more vehemently than "other bodies do, qu. 7. What his notion of fire and flame is, he gives us in qu. 9. and 10. qu. 9. "Is not fire a body heated "fo hot as to emit light copiouny? For "what elfe is a red hot Iron than fire? And " what elfe is a burning Coal, than red hot "Wood? Qu. Io. Is not flame a vapour, " fume or exhalation heated red hot, that is, " fo hot as to flame? For bodics do not flame " without emitting a copious fume, and " this fume burns in the flame. - Some " bodics heated by motion or fermentation, " if the heat grow intenfe, fume copiouny, " and if the heat be great enough, the fumes "will thine and become flame: Metals in "fufion do not flame for want of a copious " fume, except fpelter which fumes copiouny, " and thereby flames: All flaming bodies, " as Oil, Tallow, Wax, Wood, foflil Coals, "Pitch, Sulphur, by flaming wafte and vanifh " into burning fmoak; which fmoak, if the " flame be put out, is very thick and vifible, " and fometimes fmells ftrongly, but in "flame lores its fmell by burning; and ac" cording to the nature of the fmoak the "flame is of feveral colours, as that of " fulphur, 


\section{Analyjis of the Air.}

" fulphur, blue; that of copper opened with "fublimate, green; that of tallow, yellow; " that of camphire, white; fmoak paffing " thro" flame cannot but grow red hot, and " red hot fmoak can have no other appea" rance than that of flame."

But Mr. Lemery the younger fays, "that " the matter of light produces fulphur, be" ing mixt with compofitions of falt, earth " and water, and that all inflammable mat" ters are fuch only in vertue of the par" ticles of fire which they contain. For in " the Analyfis, fuch inflammable bodies " produce falt, earth, water, and a certain " fubtle matter, which paffes thro" the clofeft "veffels, fo that what pains foever the ar" tift ufes, not to lofe any thing, he ftill " finds a confiderable diminution of weight. "Now thefe principles of falt, earth and " water are inactive bodies, and of no ufe, " in the compofition of inflammable bo" dies, but to detain and arreft the parti" cles of fire, which are the real and only " matter of flame. "It appears thcrefore to be the matter " of flame that the artift lofes in decom"pounding inflammable bodies, Mem. de "I Acad. Anno I 7 I 3.".

But 


\section{Analyjis of the Air.}

But by many of the preceding Experiments, it is evident, that the matter loft in the Analyfis of thefe bodies was elafsick air, a very active principle in fire, but not an elemental fire, as he fuppofes.

"Mr. Geoffrey compounded fulphur of " acid Salt, Bitumen, a little Earth and oil "of Tartar." Mem. de l" Acad. Anno I $70_{3}$. In which oil of Tartar there is much air by Experiment 74, which air was doubtlefs by its elafticity very inftrumental in the inflammability of this artificial fulphur.

If fire was a particular diftinet kind of body inherent in fulphur, as Mr. Homberg, Mr. Lemery, and fome others imagin, then fuch fulphureous bodies, when ignited, thould rarify and dilate all the circumambient air; whereas it is found by many of the preceding Experiments, that acid fulphureous fuel conftantly attracts and condenfes a confiderable part of the circumambient elaftick air. An argument, that there is no fire endued with peculiar properties inherent in fulphur; and alfo that the heat of fire confifts principally in the brisk vibrating action and reaction, between the elaftick repelling air, and the ftrongly attracting acid fulphur, which fulphur 
284 Analyjis of the Air.

fulphur in its Analyfis is found to contain an inflammable oil, an acid Salt, a very fixt carth, and a little metal.

Now fulphur and air are fuppofed to be acted by that ethereal medium, " by which " (the great Sir Ifaac Newoton fuppofes) " light is refracted and reflected, and by " whofe vibrations light communicates heat " to bodies, and is put into fits of cafie " reflection, and eafie tranfmiffion: And " do not the vibrations of this medium " in hot bodies contribute to the intenfe"nefs and duration of their heat? And do " not hot bodies communicate their heat " to contiguous cold ones, by the vibra" tions of this medium, propagated from " them into cold ones? And is not this " medium exceedingly more rare and fub"the than the air, and exceedingly more " claftick and active? And does it not rea" dily pervade all bodies, Optick qu. I 8 . "The elaftick force of this medium, in "proportion to its denfity, muft be above " 490,000,000,000 times greater than the " elaftick force of the air is, in propor" tion to its denfity, ibid. qu. 2I." A force fufficient to give an intenfe degree of heat, 


\section{Analyfis of the Air. 285}

efpecially when its elafticity is much increafed by the brisk action and re-action of particles of the fuel and ambient air.

From this manifeft attraction, action and reaction, that there is between the acid, fulphureous and elaftick aereal particles, we may not unreafonably conclude, that what we call the fire particles in Lime, and feveral other bodies, which have undergone the fire, are the fulphureous and elaftick particles of the fire fixt in the Lime; which particles, while the Lime was hot, were in a very active, attracting and repelling ftate; and being, as the Lime cooled, detained in the folid body of the Lime, at the feverad attracting and repelling diftances, they then happened to be at, they muft neceffarily continue in that fixt ftate, notwithftanding the ethereal medium, which is fuppored freely to pervade all bodics, be continually folliciting them to action: But when the folid fubftance of the Lime is diffolved, by the affufion of fome liquid, being there. by emancipated, they are again at libcrty to be influenced and agitated by each other's attraction and repulfion, upon which a vio. lent ebullition enfues, from the action and

re-action 
re-action of thefe particles, which ebullition ceafes not, till one part of the elaftick particles are fubdued and fix'd by the ftrong attraction of the fulphur, and the other part is got beyond the Pphere of its attraction, and thereby thrown off into true permanent air: And that this is a probable folution of the matter, there is good reafon to conclude, from the frequent inftances we have in many of the foregoing Experiments, that plenty of elaftick air is at the fame time both generated and abforbed by the fame fermenting mixture; fome of which were obferved to generate more air than they abforbed, and others $e$ contra abforbed more than they generated, which was the cafe of Lime.

\section{EXPERIMENT CXIX.}

And that the fulphureous and aereal par. ticles. of the fire are lodged in many of thofe bodies which it acts upon, and thereby confiderably augments their weight, is very evident in Minium or Red Lead, which is obferved to increafe in weight about $\frac{1}{20}$ part in undergoing the action of the fire. The asquired 


\section{Analy/is of the Air.}

acquired rednefs of the Minium, indicating the addition of plenty of fulphur in the operation: For fulphur, as it is found to act moft vigoroufly on light, fo it is apt to refleat the Arongeft, viz. the red rays; and that there is good ftore of air added to the Minium, I found by diftilling firft 1922 grains of Lead, from whence I obtained only feven cubick inches of air; but from 1922 grains, which was a cubick inch of Red Lead, there arofe in the like fpace of time 34 cubick inches of air; a great part of which air was doubtlefs abforbed by the fulphureous particles of the fuel, in the reverberatory furnace, in which the $\mathrm{Mi}$ nium was made; for by Experiment 106. the more the fumes of a fire are confined, the greater quantity of elaftick air they $a b$. forb.

It was therefore doubtlefs this quantity of air in the Minium which burft the hermetically fealed glaffes of the excellent Mr. Boyle, when he heated the Minium contained in them by a burning glafs; but the pious and learned Dr. Nieusventyt attributes this effect wholly to the expanfion of the fire particles lodged in the $\mathrm{Mi}_{\mathrm{i}}$. 
288 Analy is of the Air.

nium, " he fuppofing fire to be a parti: " cular fluid matter, which maintains its.

" own effence, and figure, remaining always

" fire, tho" not always burning. Religious

"Philosopher, p. 3 10."

To the fame caufe alfo, exclufive of the air, he attributes the vaft expanfion of a mixture of compound Aqua fortis and oil of Carraways, whereas by Exper. 62. there is a great quantity of air in all oils. And by pouring fome compound Aqua-fortis on oil of Cloves, the mixture expanded into a fpace equal to 720 times the bulk of the oil, that part of the expanfion, which was owing to the watry part of the oil and $\int p i$ rit was foon contracted; whereas the other part of the expanfion, which was owing to the claftick air of the oil, was not all contracted, till the next day, by which time the fulphureous fumes had reforbed it.

The learned Boerbaave would have it, that putrefaction is the effect of inherent fire. He fays, " that vegetables alone are " the fubject of fermentation, but both "vegetables and animals of putrefaction; " which operations he attributes to very " different caufes, the immediate caufe of fermen: 
"fermentation is (he fays) the motion of " the air intercepted between the fluid and "vifcous parts of the fermenting liquor; "but the caufe of putrefaction is fire it "felf, collected or included within the "putrefying fubject, Process. 77." But I do not fee why thefe may not reafonably $e_{-}$ nough be looked upon as the effeets of different degrees of fermentation; nutrition being the genuine effect of that degree of it, in which the fum of the attracting action of the particles is much fuperior to the fum of their repulfive power: But when their repelling force far exceeds their attractive, then the component parts of vegetables are diffolved. Which diffolving fubftances, when they are diluted with much liquor, do not acquire a great heat in the diffolution, the brisknefs of the inteftine motion being checked by the liquor: But when they are only moift, like green and damp Hay, in a large heap, then they acquire a violent heat, fo as to fcorch, burn and flame, whereby the union of their conftituent parts being more throughly diffolved, they will neither produce a vinous, nor an acid fpirit: Which great degrec of folution may well be effected 
290 Analyfis of the Air.

by this means, without the action of a fire; fuppored to be included within the putrefying fubject. Wherefore according to the old Axiom, Entia non funt temere neque absque necefsitate multiplicanda.

If the notion of fermentation be reftrained to the greater repelling degrees of fermentation, in which senfe it has commonly been underftood; then it is as certain, that the juices of vegetables and animals do not ferment in a healthy ftate, as it is, that they do not at the fame time coalefce and difunite: But if fermentation be taken in a larger fenfe, for any the fmalleft to the greateft degree of inteftine motion of the particles of a fluid, then all vegetable and ani. mal fluids are in a natural ftate, in fome degree of ferment, for they abound both with claftick and fulphureous particles: And it may with as much reafon be argued, that there is no degree of warmth in animals and vegetables, becaure a great degree of heat will caufe a folution of continuity, as to fay, there is no degree of ferment in the fluids of thofe bodies, becaule a great repelling degree of ferment will moft certainly diffolve them. 


\section{Analyjis of the Air.}

That illuftrious Philofopher Sir Ifaac Newton, in his thoughts about the nature of $\mathrm{a}^{-}$ cids, gives this rational account of the nature of fermentation. "The particles of " acids-are endewed with a great attractive "force, in which force their activity con"fifts-By this attractive force they get " about the particles of bodies, whether " they be of a metallick or ftony nature, " and adhere to them molt clofely on all "fides, fo that they can fcarce be feparated " from them, by diftillation or fublination; "when they are attracted and gathered to"gether about the particles of bodies, they "raife, disjoyn, and thake them one from " another, that is, they diffolve thofe bodies. "By their attractive force alfo, by which

" they rufh towards the particles of bodies, " they move the fluid, and excite heat, and " they thake afunder fome particles, fo much sc as to turn them into air, and generate " bubbles: And this is the reafon of diffo"lution, and all violent fermentation. Har"ris Lexicon Tech. Vol. II. introduction."

Thus we have from thefe Experiments many manifett proofs of confiderable quantities of true permanent air, which are by

$$
\mathrm{U} 2
$$
means 
means of fire and fermentation raifed from? and abforbed by animal, vegetable and mineral fubftances.

That this air confifts of particles which are in a very active ftate, repelling each other with force, and thereby conftituting the fame kind of elaftick fluid with common air, is plain from its raifing the Mercury in Experiment 88 and 89 , and from its continuing in that elaftick ftate for many months, tho' cooled by fevere frofts; whereas watry vapours, tho' they expand much with heat, yet are found immediately to condenfe into their firft dimenfions when cold.

The air generated by fire was not, in many inftances, feparated without great vio. lence from the fix'd bodies, in which it was incorporated; as in the care of Nitre, Tartar, SalTartar and Copperas: whence it fhould feem, that the air generated from thefe Salts, may probably be very inftrumental in the union of Salts, as well as that central, denfer and compacter particle of earth, which Sir Ifaac Neroton obferves, does by its attraction make the watry acid flow round it, for compofing the particles of Salt. qu. 3 I. For fince upon the diffolution 


\section{Analy is of the Air.}

of the conftituent parts of Salt by fire, it is found, that upon feparating and volatilizing the acid fpirit, the air particles do in great abundance rufh forth from a fixt to a repelling elaftick ftate; it muft needs be, that thefe particles did in their fixt ftate ftrongly attract the acid fpirits, as well as the fulphureous earthy parts of the Salt; for the moft ftrongly repelling and elaftick particles are obferved, in a fixt ftate, to be the moft ftrongly attracting.

But the watry acid, which when feparated from Salt by the action of fire, makes a very corrofive fuming fpirit, will not make elaftick air, tho' its parts were put into a brisk motion by fire in Exper. 75. And the event was the fame with feveral other volatile fubftances, as volatile Salt of Sal Ammoniac, Campbire and Brandy, which tho' diftilled over with a confiderable heat, yet generated no elaftick air, in Exper. 52, 6I, 66. Whence 'tis plain, the acid vapours in the air only float in it like the watry vapours; and when ftrongly attracted by the elaftick particles of the air, they firmly adhere to them, and make Salts. 
Thus in Experiment 73 we fee by the vaft quantity of air there is found in Tartar, that tho' it contains the other principles of vegetables, yet air with fome volatile Salt feems to make up a confiderable part of its compofition; which air, when by the action of fire it is more firmly united with the earth, and acid fulphureous particles, requires a more intenfe degree of heat, to extricate it from thofe adhering fubftances, as we find in the diftillation of Sal Tartar, Exper. 74. which Air and volatile Salt are moft readily feparated by fermentation.

And by Experiment 72, pienty of air arifes alfo from Nitre, at the fame time that the acid fpirit is feparated from it by the action of fire.

We find alfo by Experiment $7 \mathrm{I}$, that fome air is by the fame means obtained from common fea Salt, tho' not in fo great plenty, nor fo eafily, as from $\mathcal{T}$ artar and $\mathrm{Ni}$ tre, it being a more fixt body, by reaion of the fulphur which abounds in it; neither is it fo eafily charged in animal bodies, as other Salts are, yet fince it fertilizes ground, it muft needs be changed by vegetables. 


\section{Analy/is of the Air.}

There is good reafon alfo to fufpect, that thefe acid fpirits are not wholly free from air particles, notwithftanding there were no elaftick ones produced, when they were put into a brisk motion, by the action of fire in Experiment 75. which might be occafioned by the great quantity of acid fpirit, in which they were involved. For we fee in Experiment 90, that when the acid fpirit of Aqua Regia was more frongly attracted by the diffolving gold, than by the air particles, then plenty of air particles, which were thus freed from the acid fpirit, did continually arife from the Aqua Regia, and not from the gold, at leaft not from the metal. lick particles of the gold, for that lofes nothing of its weight in the folution; fo that if any does arife from the gold, it munt be what may be latent in the pores of the gold. Whence it is probable, that the air which is obtained by the fermenting mixture of acid and alkaline fubftances may not arife wholly from the diffolved alkaline body, but in part alfo from the acid. Thus the great quantity of elaftick air, which in Exper. 83. is generated from the mixture of Vinegar and Oyfterfhell, may as well arife in part

$$
\text { U. }
$$

from 


\section{Analy fis of the Air.}

from the Tartar, to which Vinegar owes its acidity, as from the diffolved Oyfterthell. And what makes it further probable is, that the Vinegar lofes its acidity in the ferment, that is its Tartar: for difolving menftruums are generally obferved to be changed in fermentation, as well as the difiolved body.

Have we not reafon alfo hence to conclude, that the energy of acid fpirits may in fome meafure be owing to the frongly at trafting air particles in them; which active principles may give an impetus to the acid fpicule, as well as the carthy oily matter, which is found in there acid fpirits?

There are we fee alfo great frore of air particles found in the Analy fis of the blood, which arifes doubtelefs as well form the ferum as from the craffamentum, for all the animal fluids and folids have air, and fulphur in them: Which frongly attracting principles feem to be more intimatcly united together in the more perfect and elaborate part of it, its red globules; fo that we may not unreaConably conclude, that air is a band of union here, as well as in Salts: And accordingly We find the greateft plenty of air in the mof: folid parts of the body, where the cohefion of 


\section{Analyfis of the Air.}

of the parts is the ftrongeft: For by comparing Experiment 49 and SI. we fee that much more air was found in the difillatrion of horn than of blood. And the cohefion of animal fubftances was not, as. we find by the fame Experiment, diffolved even in the blood, without confiderable violence of fire; tho' it is fometimes done to a fatal degree in our blood, by that more fubtile diffolvent fermentation: But we may obferve, that volatile Salts, Spirits, and fulphureous Oil, which are at the fame time feparated from thefe fubftances, will not make elaftick air.

\section{EXPERIMENT CXX.}

As elaftick air is thus generated by the force of fire, from thefe and many other fubftances; fo is the elafticity of the air greatly deftroyed by fulphureous bodies. Sir Ifaac Newton obferves, " that as light acts upon "fulphur, fo fince all action is mutual, ful"phurs ought to act moft upon light." And the fame may be obferved of air and ful: phur; for by Experiment $\mathrm{IO}_{3}$, it is found that burning fulphur, which is a very ftrongly attracting 


\section{Analyfis of the Air.}

attracting fubftance, powerfully attracts and fixes the elaftick particles of air; fo that there muft needs be a good quantity of un-elaftick air particles in oil and flower of fulphur : The firft of which is made by burning fulphur under a bell, the other by fublimation: In further confirmation of this it is obferved, that Oleum Sulpburis per Campanam is with more difficulty made in a dry than a moift air; and I have found by Experiment purporely made, that a Candle which burnt $70^{\prime \prime}$ in a very dry receiver, burnt but $64^{\prime \prime}$ in the fame receiver, when filled with the fumes of hot water; and yet abforbed one fifth part more air, than when it burnt longer in the dry air.

Sulphur not only abforbs the air when burning in a homogeneal mafs, but alfo in many fermenting mixtures; and as Sir Ifaac Newton obferved the attractive and refractive power of bodies to be greater or lefs, as they partook more or lefs of fulphureous óily particles; fo there is good reafon from thefe Experiments to attribute the fixing of the elaftick particles of the air to the ftrong attraction of the fulphureous particles with which he fays it's probable that all bodies abound more or lefs. 


\section{Analy is of the Air.}

That great plenty of air is united with fulphur in the oil of vegetables, is evident from the quantity of air that arofe from the diftillation of oils of Annifecds and Olives, in Experiment 62. When by fermentation the conftituent parts of a vegetable are feparated, part of the air flies off in fermentation into an claftick ftate; part unites with the effential Salt, Water, Oil and Earth, which conftitute the Tartar which adhere to the fides of the veffel; the remainder which continues in the fermented liquor, is there, fome of it, in a fix'd, and fome in an elantick ftate, which gives brisknefs to the liquor; their expanding bubbles rifing of a very vifible fize when the weight of the incumbent air is taken off the liquor in a vacuum.

And as there was found a greater quantity of air in the deer's horn, than in blood; we may alfo obferve it to be in a much greater proportion in the more folid parts of vegetables, than in their fluid: For we find in Experiment 55. 57. and 60. that near one third part of the fubftance of the Peafe, heart of Oak and Tobacco, were by the ac. tion of fire changed from an un-elaftick Atate, to an elantick air: And fince a much 
greater proportion of air is found in the folid than the fluid parts of bodies; may we not with good reafon conclude, that it is very inftrumental, as a band of union in thofe bodies, "Thofe particles (as Sir Ifaac Neruton obferves) " receding from one " another with the greateft repulfive force, " and being moft difficultly brought together, " which upon contact cohere moft ftrongly. q14. 31 ." And if the attraction of cohefion of an un-claftick air particle be proportionable to its repulfive force in an elaftick ftate; then fince its elaftick force is found to be fo vaftly great, fo muft that of its cohefion be alfo. Sir Ifaac Nerwton calculates from the inflection of the rays of light, that the attracting force of particles, near the point of contal, is $10000,0000,0000,0000$ greater than the force of gravity.

Sulphur in a quiefcent fix'd ftate in a large body does not abforb the elaftick air, for a hard roll of Brimftone docs not abforb air: But when fome of that Brimftone, by being powdered and mixt with filings of fron, is fet a fermenting, and thereby reduced into very minute particles, whofe attraction increafes, as their fize decreafes; then it abforbs 


\section{Analyfis of the Air. $\quad 30 \mathrm{r}$}

abforbs elaftick air vigorouny: As may be feen in many inftances under Experiment 95.

The Walton mineral, in which there is a good quantity of fulphur, did, when Compound Aqua-fortis was pour'd on it, in Experiment 96, make a confiderable fermentation, and abforb a great quantity of claftick air: But when the ferment was much increafed, by adding an equal quantity of watcr to the like mixture, then inftead of abforbing 85 cubick inches as before, it generated 80 cubick inches of air : So that fermenting mixtures, which have fulphur in them, do not always abforb, but fometimes generate air: The reafon of which in the Experiment now under confideration feems to be this, viz. in the firft cafe a good quantity of. elaftick air was generated, by the inteftine motion of the fermenting ingredients; but there arifing thence a thick, acid fulphureous fume, this fume abforbed a greater quantity of elaftick air than was before generated: And we find by Experiment 103 that the fulphureous particles which fly off in the air, do by their attraction deftroy its elafticity; for in that Experiment burning Brimftone greatly deftroyed the air's elafticity; 


\section{Analyjas of the Air.}

which muft be done by the flame, and afcending fumes; becaufe in the burning of any quantity of Brimftone, the whole mals is in a manner wafted, there remaining only a very little dry Earth: And therefore the abforbed air cannot remain there, but muft be abforbed by the afcending fumes which then attract moft ftrongly, when reduced ad minima: And 'tis well known that a Candle in burning flies all off into flame and vapour, fo that what air it abforbs mult be by thofe fumes.

\section{EXPERIMENT CXXI.}

And further Ihave found that thefe fumes deftroy the air's elafticity, for many hours after the Brimftone Match, which made then, was taken out of the vefiel, $z z a a$ : (Fig. 35.) Thofe fumes being firt cooled by immerfing that veffel and its ciftern $x x$, or an inverted wine Flask, full of the fumes, under cold water for fome time; then marking the furface of the water $z \approx I$ immerfed the veffels in warm water: And when all was cold again the following day, I found agood quantity of the air's clafticity w'as deftroyed 


\section{Analy is of the Air.}

ftroyed by the water's afcending above $z z$. And the event was the fame upon frequent repetitions of the fame Experiment.

But if inftead of the fumes of burning Birmftone, I filled a Flask full of fumes from the fmoak of wood, after it had done flaming, then there was but half as much air abforbed by thore fumes, as there was by the fumes of Brimfone; viz. becaufe the fmoak of wood was much diluted with the watry vapour which afcended with it out of the wood. And this is doubtlers the reafon why the fmoak of wood, tho' it incommodes the lungs, yet it will not fuffocate like that of Charcoal, which is withal more fulphureous, without any mixture of watry. vapours.

And that new generated elaftick air is reforbed by thefe fumes, I found by attempting to fire a Match of Brimftone with a burning glars, by means of a pretty large piece of Brown Paper which had been dipped in a frong folution of Nitre, and then dryed: Which Nitre in detonizing generated near two quarts of air, which quantity of air, and a great deal more, was abforbed, when the Brimftone took fire and flamed vigoroung. 


\section{Analy is of the Air.}

So that the $8 ;$ cubick inches of air, Experiment 96 , which I found upon meafuring was abforbed by the Walton mineral and com. pound Aqua-fortis, was the excers of what was abforbed by thofe fumes above what was generated by the fermenting mixture.

And the reafon is the fame in filings of Iron and Spirit of Nitre, Experiment 94, which alfo abforbed more than they generated, whether with or without water: The reafon of which will appear prefently.

Hence alfo we fee the reafon why filings of Iron and compound Aqua-fortis in the fame 94 Experiment abforbed air ; and why when mixed with an equal quantity of water is moftly abforbed, but did fometimes generate, and then abforb again: And it was the fame with Oil of Vitriol, filings of Iron and Water, and New-caftle Coal and compound Aqua-fortis and others: viz. At firt, when the ferment was brisk, the abforbing fumes rofe fafteft, whereby more air was abforbed than generated; but as the ferment abated, to fuch a degree as to be able ftill to generate elaftick air, but not to fend forth a proportionable quantity of fumes, in that cafe more air would be generated than abforbed. 


\section{Arialyfis of the Air.}

And in Experiment 95, there ate feveral inftances of the air's being in like manner abforbed in leffer degrees, by other fermenting mixtures: As in the mixture of Spitit of Harts-horn with filings of Iron, and with filings of Copper: And Spirit of Sal Ammoniac with filings of Copper; and alfo filings of Iron and Water; powdered Flint and Compound Aqua-fortis; powdered Briftol Diamond with the fame liquor.

It is probable from Experiment $\mathrm{IO}_{3}$ and I06, where it was found that the thicker the fuliginous vapours were, the fafter they abforbed the air; that if the above-mentioned fermenting mixtures had not been confined in clofe veffels, but in the open air, where the vapours would have been lefs denfe, that in that cafe much lefs air would have been abforbed, perhaps a great deal lefs than was generated.

In the fecond cafe of the Walton mineral, Experiment 96, when inftead of abforbing; it generated air, the parts of the Compound Aqua fortis were then more at liberty to act by being diluted with an equal quantity of water; whereby the ferment being more violent, the particles which conftXX

tuted 


\section{Analyfis of the Air.}

tureci the new elaftick air were thereby thrown off in greater plenty, and perhaps with a greater degree of elafticity, which might carry them beyond the fphere of attraction of the fulphureous particles.

This is further illuftrated by Experiment 94, where filings of Iron and oil of Vitriol alone generated very little; but the like quantities of filings of Iron, with an equal quantity of water, generated 43 cubick inches of air; and the like ingredients, with three times that quantity of water, generated 108 cubick inches.

And tho' the quantity of the afcending fumes (which was in this cafe of the Walton mineral very great) muft needs in their afcent abforb a good deal of elaftick air, for they will abrorb air; yet if where the ferment was fo much greater, more elaftick air was generated by the fermenting mixture than was abrorbed by the afcending fumes; then the quantity of new generated air, which I found between $z z$ and $a$ a, (Fig. 35.) when I meafured it, was equal to the excers of what was generated above what was abforbed.

And probably in this cafe the air was not abforbed fo much in proportion to the denfity 


\section{Analyjis of the Air.}

of the fumes as in the firft cafe; becaufe here the fulphureous fumes were much blended with watry vapours: For we find in Experiment 97 , that fix times more was wafted in fumes in this care than in the other; and there. fore probably a good part of the cubick inch of water afcended with the vapour, and might thereby weaken its abforbing power: For watry vapours do not abforb elaftick air as the fulphureous ones do ; tho' by Experiment 120 , a Candle abforbed more in a damp. than in a dry air.

And'tis from thefe diluting watry vapours that filings of Iron with Spirit of Nitre and Water, abforbed lefs than with Spirit of Nitre alone, for in both cafes it abforbs more than it generates.

Thus alfo oil of Vitriol and Chalk generate air, their fume being fmall, and that much diluted with the watry vapours in the Chalk.

But Lime with oil of Vitriol, or WhiteWine Vinegar or Water, make a confiderable fume, and abforb good quantiries of air: Lime alone left to Raken gradually, as it makes no fume, fo it abforbs no air.

We fee in Experiment 92, where the fer$\mathrm{X} 2$ ment 


\section{Analy/s of the Air.}

ment was not very fudden nor violent, nor the quantity of abforbing fumes large, that the Antimony and Aqua-fortis generated a quantity of air equal to 520 times the bulk of the Antimony; thus alfo in the mixture of Aqua-regia and Antimony, in Experiment $9 \mathrm{I}$, while at firft the ferment was fmall, then air was generated; but when with the increafing ferment plenty of fumes arofe, then there was a change from a generating to an abforbing fate.

Since we find fuch great quantities of elaftick air generated in folution of animal and vegetable fubftances; it muft need sbe that a good deal does conftantly arife, from the diffolving of thefe aliments in tixe ftomach and bowels, which diffolution it greatly promotes: Some of which may very probably be re-forbed again, by the fumes which arife with them; for we fee in Experiment 83 that Oyfter Thell and Vinegar, Oyfter-thell and Rennet, Oyfter-fhell and Orange juice, Rennet alone, Rennet and Bread, firft generated and then abrorbed air; but Oyfter-hell with fome of the liquor of a Calve's ftomach which had fed much upon Hay, did not generate air; and it was the fame with Oyfter-fhell and 


\section{Analy/is of the Air.}

Ox gall, and fpittle, and urine; Oyfter-hell and Milk generated a little air, but Limon juice and Milk did at the fame time abforb a little: Thus we fee that the variety of mixtures in the ftomach appear fometimes to generate, and fometimes to abforb air ; that is, there is fometimes more generated than abforbed, and fometimes an equal quantity, and fometimes lefs according to the proportion the generating power of the diffolving aliments bears to the abforbing power of the fumes which arife from them. In a true kindly digetion, the generating power exceeds the abforbing power but a little: But whenever the digettion deviates in fome degree from this natural ftate, to generate a greater proportion of elaftick air, then are we troubled more or lefs with diftending Flatus's I had intended to make thefe and many more Experiments relating to the nature of digertion in a warmth equal to that of the ftomach, but have been hitherto prevented by purfu. ing other Experiments.

Thus we fee that all thefe mixtures do in fermentation generate elaftick air, but thofe which emit thick fumes, charged with fulphur, reforb more than was generated

$$
\mathrm{X}_{3}
$$


in proportion to the fulphureournefs and thicknefs of thofe fumes.

I have alfo fhewn in many of the fore going Experiments, that plenty of truc permanent elantick air is generated from the fermenting mixtures of acid and alkaline fubftances, and efpecially from the fermentation and diffolution of animal and vegetable bodies: Into whofe fubftances we fee it is in a great proportion intimately and firmly incorporated; and confequently, great quantities of elaftick air mutt be continually expended in their production, part of which does we fee refume its elantick quality, when briskly thrown off from thofe bodies by fermentation, in the diffolution of their texture. But part may probably never regain its elafticity; or at leaft not in many centuries, that efpecially which is incorporated into the more durable parts of animals and vegetables. However we may with pleafure fee what immenfe treafures of this noble and important element, endued with a moft active principle, the all-wife Providence of the great Author of nature has provided; the conftant wafte of it bcing abundantly fupplyed by heat and fermentation from in- 
numerable denfe bodies; and that probably from many of thofe bodies, which when they had their afcending fumes confined in my Glaffes, abforbed more air than they generated, but would in a more free, open fpace generate more than they abforbed.

I made fome attempts both by fire, and alfo by fermenting and abforbing mixtures, to try if I could deprive all the particles of any quantity of elaftick air of their clafticity, but I could not effect it: There is therefore no direct proof from any of thefe Experiments, that all the elaftick air may be abforbed, tho' tis very probable it may, fince we find it is in fuch great plenty generated and abforbed; it may well therefore be all abforbed and changed from an elaftick to a fixt ftate: For as Sir IsAac Newron obferves of light, " that nothing more " is requifite for producing all the variety of " colours, and degrees of refrangibility, than " that the rays of light be bodies of different "fizes; the leaft of which may make the " weakeft and darkeft of the colours, and " be more eafily diverted, by refracting fur"faces from the right courfe; and the reft, $\approx$ as they are bigger and bigger, may make

$$
X_{4} \text { "s the }
$$


" "the ftronger and more lucid coloursments "s and be more and more difficultly diverted. "Qu. 29. So Q11.30, he obferves of air, that " denfe bodies by fermentation rarify into " feveral forts of air, and this air, by fer" mentation, and fometimes without, returns " into denfe bodies." And fince we find in fact from thefe Experiments, that air arifes from a great varicty of denfe bodies, both by fire and fermentation, it is probable that they may have very different degrees of elafticity, in proportion to the different fize and denfity of its particles, and the different force with which they were thrown off inro an claftick ftate. "Thofe particles (as "Sir Isaac Newton obfcrves) receding "from one another, with the greateft re"pulfive force, and being moft difficultiy " brought together, which upon contact "cohere moft ftrongly." Whence thofe of the weakent elanticity, will be leaft able to refift a counter-acting power, and will therefore be fooneft changed from an elaftick to a fixt fate. And 'tis confonant to reafon to think, that the air may confitt of infinite degrees of thefe, from the mort elaftick and sepelling, till we come to the more fugginh, 


\section{Analyfis of the Air.}

watry and other particles, which float in the air ; yet the repelling force of the leaft elaftick particle, near the furface of the earth, while it continues in that elaftick ftate, mut be fuperior to the incumbent preffure of a column of air, whore height is equal to that of the atmolphere, and its bafe to the furface of the fphere of its elaftick activity.

Thus upon the whole, we fee that air abounds in animal, vcgetable and mineral fub. ftances; in all which it bears a confiderable part : if all the parts of matter were only endued with a ftrongly attracting power, whole nature would then immediately become one unactive cohering lump; wherefore it was abfolutely neceffary, in order to the actuating and enlivening this vaft mafs of attracting matter, that there fhould be every where intermixed with it a due proportion of ftrongly repelling elaftick particles, which might enliven the whole mafs, by the inceffant action between them and the attracting particles: And fince thefe elaftick particles are continually in great abundance reduced by the power of the ftrong attracters, from an elaftick, to a fixt ftate; it was therefore neceffary that thefe particles hould be enduẹ 


\section{Analy is of the Air.}

endued with a property of refuming their elaftick ftate, whenever they were difengaged from that mars, in which they were fixed; that thereby this beautiful frame of things might be maintained, in a continual round of the production and diffolution of animal and vegetable bodies.

The air is very inftrumental in the production and growth of animals and vegetables, both by invigorating their feveral juices, while in an elaftick active ftate, and alfo by greatly contributing in a fix'd ftate to the union and firm connection of the feveral conftituent parts of thofe bodies, viz. their water, falt, fulphur and earth. This band of union, in conjunction with the external air, is alfo a very powerful agent in the diffolution and corruption of the fame bodies, for it makes one in every fermenting mixture; the action and re-action of the acreal and fulphurcous particles is in many fermenting mixtures fo great, as to excite a burning heat, and in others a fudden flame: And it is we fee by the like action and re-acaction of the fame principles, in fuel and the ambient air, that common culinary fires are produced and maintained.

Tho 


\section{Analyfis of the Air.}

Tho' the force of its elanticity is fo great, as to be able to bear a prodigious preffure, without lofing that elafticity, yet we have from the foregoing Experiments evident proof, that its elafticity is eafily, and in great abundance deftroyed; and is thereby reduced to a fixt ftate, by the ftrong attraction of the acid fulphureous particles, which arife either from fire or from fermentation: And therefore elafticity is not an effential immutable property of air particles; but they are, we fee, eafily changed from an elaftick to a fixt ftate, by the ftrong attraction of the acid, fulphureous and faline particles which abound in the air. Whence it is reafonable to conclude, that our atmorphere is a Chaos, confifting not only of claftick, but alfo of unelantick air particles, which in great plenty float in it, as well as the fulphureous, faline, watry and earthy particles, which are no ways capable of being thrown off into a permanently elaftick ftate, like thofe particles which conftitute true permanent air.

Since then air is found fo manifertly to abound in almoft all natural bodies; fince we find it fo operative and active a principle in every chymical operation, fince its con-

ftituent 


\section{16 Analy 25 of the Air.}

ftituent parts are of fo durable a nature, that the moft violent action of fire, or fermentation, cannot induce fuch an alteration of its texture, as thereby to difqualify it from refuming, either by the means of fire, or fermentation, its former elaftick ftate; unlefs in the cafe of vitrification, when with the vegetable Salt and Nitre, in which it is incorporated, it may perhaps fome of it with other chymical principles be inmutably fixt : Since then this is the cafe, may we not with good reafon adopt this now fixt, now volatile Proteus among the chymical principles, and that a very active one, as well as acid fulphur; notwithftanding it has hitherto been overlooked and rejected by Chymifts, as no way intitled to that denomination?

If thofe who unhappily fpent their time and fubftance in fearch after an imaginary production, that was to reduce all things to gold, had, inftead of that fruitlefs purfuit, bettowed their labour in fearching after this much neglected volatile Hermes, who has fo often efcaped thro' their burft receivers, in the difguife of a fubtile fpirit, a meer flatulent explofive matter; they would then inftead of reaping vanity, have found their refearches 
refearches rewarded with very confiderable and ufeful difcoveries.

\section{H A P. VII.}

\section{Of Vegetation.}

W $E$ are but too fenfible, that our reafonings about the wonderful and intricate operations of nature are fo full of uncertainty, that as the wire-man truly obferves, hardly do we guess aright at the things that are upon earth, and with labour do we find the things that are before us. Wifdom Chap. ix. v. I6. And this obferva. tion we find fufficiently verified in vegetable nature, whofe abundant productions, tho' they are moft vifible and obvious to us, yet are we much in the dark about the nature of them, becaufe the texture of the veffels of plants is fo intricate and fine, that we can trace but few of them, tho' affifted with the beft microfcopes. We have however good reafon to be diligent in making farther and farther refearches; for tho' we can never hope to come to the bottom and firft principles of things, yet in fo inexhauftible a fubiect, where 


\section{8

every the fmalleft part of this wonderful fabrick is wrought in the moft curious and beautiful manner, we need not doubt of having our inquiries rewarded, with fome further pleafing difcovery; but if this thould not be the reward of our diligence, we are however fure of entertaining our minds after the molt agreeable manner, by feeing in every thing, with furprifing delight, fuch plain fignatures of the wonderful hand of the divine architect, as muft neceflarily difpore and carry our thoughts to an act of adoration, the beft and nobleft employment and entertainment of the mind.

What I hall here fay, will be chiefly founded on the following experiments; and on feveral of the preceding ones, without repeating what has already been occafionally obferved on the fubject of vegetation.

We find by the chymical analy fis of vegetables, that their fubftance is compored of fulphur, volatile fait, water and earth; which principles are all endued with mutually attracting powers, and alfo of a large portion of air, which has a wonderful property of ftrongly attrading in a fixt ftate, or of repelling in an elaftick ftate, with a power which 


\section{Of Vegetation.}

which is fuperior to vaft compreffing forces; and it is by the infinite combinations, action and re-action of thefe principles, that all the operations in animal and vegetable bodies are effected.

Thefe active aereal particles are very ferviceable in carrying on the work of vegetation to its perfection and maturity. Not only in helping by their elafticity to diftend each ductile part, but alfo by enlivening and invigorating their fap, where mixing with the other mutually attracting principles they are by gentle heat and motion fer at liberty to affimilate into the nourifhment of the refpective parts : "The foft and moift nourifh" ment eafily changing its texture by gentle " heat and motion, which congregates "homogeneal bodies, and reparates hete"rogeneal ones." Newton's Opticks, qu. 3I. The fum of the attracting power of thefe mutually acting and re-acting principles being, while in this nutritive ftate, fuperior to the fum of their repelling power, whereby the work of nutrition is gradually advanced by the nearer and nearer union of thefe principles, from a lefier to a greater degree of confiftency, till they are advanced to that 
vifcid ductile ftate, whence the feveral parts of vegetables are formed; and are at length firmly compacted into hard fubftances, by the flying off of the watry diluting vehicle; fooner or later, according to the different degrees of cohefion of thefe thus compacted principles.

But when the watry particles do again foak into and dif-unite them, and their repellingpower is thereby become fuperior to their attracting power; then is the union of the parts of vegetables thereby fo throughly diffolved, that this ftate of putrefaction does by a wife order of Providence fit them to refufcitateagain, in newvegetable productions; whereby the nutritive fund of nature can never be exhaufted: Which being the fame both in animals and vegetables, it is thereby admirably fitted by a little alteration of its texture to nourifh either.

Now, tho' all the principles of vegetables are in their due proportion neceffary to the production and perfection of them; yet we generally find greater proportions of Oil in the more elaborate and exalted parts of vegetables: And thus Seeds are found to abound with Oil, and confequently with fulphus 
fulphur and air, as we fee by Exper. $5 \sigma$, 57,58 . which Seeds containing the rudiments of future vegetables, it was neceffary that they thould be well ftored with principles that would both preferve the Seed fiom putrefaction, and alfo be very aitive in promoting germination and vegetation. Thus alfo by the grateful odours of flowers we are aflured, that they are ftored with a very fubrile, highly fublimed Oil, which perfumes the ambient air, and the fame may be ooferved from the high taftes of fruits.

And as Oil is an excellent prefervative againt the injuries of cold, fo it is found to abound in the fap of the more northern trees; and it is this which in ever-greens keeps their leaves from falling.

But plants of a lefs durable texture, as they abound with a greater proportion of Salt and Water, which is not fo ftrongly attracting as fulphur and air, fo are they lefs able to endure the cold; and as plants are obferved to have a greater proportion of Salt and Water in them in the fpring, than in the autumn, fo are they more eafily injured by cold in the fpring, than in a more advanced 


\section{2 \\ of Vegetation.}

age, when their quantity of oil is increafed, with their greater maturity.

Whence we find that nature's chief burtnefs, in bringing the parts of a vegetable, efpecially its fruit and feed to maturity, is to combine together in a due proportion, the more active and noble principles of fulphur and air, that chiefly conftitute oil, which in its mont refined ftate is never found without fome degree of earth and falt in it.

And the more perfect this maturity is, the more firmly are the fe noble principles united. Thus Rhenifh Wines, which grow in a more northern climate, are found to yield their Tartar, i. e. by Exper. 73. their incorporated air and fulphur in greater plenty, than the Atronger Wines of hotter countries, in which thefe generous principles are more firmly united: And particularly in Madera Wine, they are fixt to fuch a degree, that that Wine requires a confiderable degree of warmth, luch as would foure many other Wines, to keep it in order, and give it a gencrous tafte; and 'tis from the fame reafon, that fmall French Wines are found to yield more fpirit in diftillation, than ftrong Spanifh Wines.

But 


\section{Of Vegetation.}

But when, on the other hand, the crude watry part of the nutriment bears too great a proportion to the more noble principles, either in a too luxuriant ftate of a plant, or when its roots are planted too deep, or it ftands in too thady a pofition, or in a very cold and wet fummer; then it is found, that cither no fruit is produced, or if there be any, yet it continues in a crude watry ftate; and never comes to that degree of maturity, which a due proportion of the more noble principies would bring it to.

Thus we find in this, and every other part of this beautiful feene of things, when we attentively confider them, that the great Author of nature has admirably tempered the conftituent principles of ratural bodies, in fuch due proportions as might beft fit them for the ftate and purpoles they were intended for.

It is very plain from many of the foregoing Experiments and Obfervations, that the leaves are very ferviceable in this work of vegetation, by being inftrumental in bringing nourifhment from the lower parts, within the reach of the attraction of the growing fruit; which like young animals is furnifhed 


\section{Of Vegetation.}

with proper inftruments to fuck it thence. But the leaves feem alfo defigned for many other noble and important fervices; for nature admirably adapts her infruments fo as to be at the fame time ferviccable to many good purpofes. Thus the leaves, in which are the main excretory ducts in vegetables, feparate and carry off the redundant watry fluid, which by being long detained, would turn rancid and prejudicious to the plant, leaving the more nutritive parts to coalefce; part of which nourifhment, we have good reafon to think, is conveyed into vegetables thro' the leaves, which do plentifully imbibe the Dew and Rain, which contain Salt, Sulphur, \&oc. For the air is full of acid and fulphureous particles, which when they abound much, do by the action and re-action between them and the elaftick air caufe that fultry heat, which ufually ends in lightning and thunder: And thefe new combinations of air, fulphur and acid fpirit, which are conftantly forming in the air, are doubtlefs very ferviceable, in promo. ting the work of vegetation; when being imbibed by the leaves, they may not improbably be the materials out of which the 


\section{of Vegetation.}

more fubtile and refined principles of vegetables are formed: For fo fine a fluid as the air feems to be a more proper medium, wherein to prepare and combine the more cxalted principle of vegetables, than the groffer watry fluid of the fap; and for the fame reafon, 'tis likcly, that the moft refined and active principles of animals are alfo prepared in the air, and thence conveyed thro' the lungs into the blood; and that there is plenty of thefe fulphureo-acreal particles in the leaves, is evident from the fulphurcous exu. dations, which are found at the edges of leaves, which Bees are obferved to make their waxen cells of, as well as of the duft of flowers: And that wax abounds with fulphur is plain from its burning freely, $\& c$.

We may therefore reafonably conclude, that one great ufe of leaves is what has been long fufpected by many, viz. to perform in fome meafure the fame office for the fupport of the vegetable life, that the lungs of animals do, for the fupport of the animal life; Plants very probably drawing thro' their leaves fome part of their nourifhment from the air. 


\section{Of Vegetation.}

But as piants have not a dilating and contracting Thorax, their infpirations and expirations will not be fo frequent as thore of Animals, but depend wholly on the alternate changes from hot to cold, for infpiration, and vice ver $\int \hat{a}$ for expiration; and 'tis not improbable, that plants of more rich and racy juices may imbibe and aflimilate more of this aereal food into their conftitutions, than others, which have more watry vapid juices. We may look upon the Vine as a good inftance of this, which in Exper. 3. peripired lefs than the Apple-tree. For as it delights not in drawing much watry nourifhment from the earth by its roots, fo it muft therefore neceffarily be brought to a more ftrongly imbibing ftate at night, than other trees, which abound more with watry nourifhment; and it will therefore confequently imbibe more from the air. And likely this may be the reafon, why plants in hot countries abound more with fine aromatick principles, than the more northern plants, for they do undoubtedly imbibe more dew.

And if this conjecture be right, then it gives us a farther reafon, why trees which abound with moifure, either from too haded

a po: 


\section{Of Vegetation.}

a pofition, or a too luxurious ftate are unfruitful, viz. becaufe, being in thefe cafes more replete with moifture, they cannot imbibe fo ftrongly from the air, as others do, that great bleffing the dew of Heaven.

And as the moft racy generous taftes of fruits, and the grateful odours of flowers, do not improbably arife from thefe refined aereal principles, fo may the beautiful co. lours of flowers be owing in a good meafure to the fame original; for it is a known obfervation, that a dry foil contributes much more to their variegation than a ftrong moift one does.

And may not light alfo, by freely entring the expanded furfaces of leaves and flowers, contribute much to the ennobling the principles of vegetables; for Sir Ifaac Newton, puts it as a very probable query, "Are " not grofs bodies and light convertible into " one another? and may not bodies receive " much of their adivity from the particles " of light, which enter their compofition? "The change of bodies into light, and of " light into bodies, is very conformable to " the courfe of nature, which feems de"lighted with tranfmutations. Opt.qu. 30." 
328 Of Vegetation.

\section{EXFERIMENT CXXII.}

That the leaves of plants do imbibe elaftick air, I have fome reation to fufpect from the following Experiment, viz. In May I fet fome well rooted plants of fpear-mint in two glafs cifterns full of watcr, which cifterns were fet on pedeftals, and had inverted chymical reccivers put over them, as in (Fig. 35.) the water being drawn up to $a$, half way their necks: In this inclofed moilt ftate the plants looked pretty florid for a month, and made, as I think, fome few weak lateral Thoots, tho' they did not grow in height; they were not quite dead till after fix weeks, when it was found that the water was rifen in both glaffes from a a towards $z \approx$, in bulk about 20 cubick inches: But as there was not fo exant an account taken of the different temperature of the air, as to heat and cold, as there ought to have been, I am not certain, whether that rifing of the water might not be owing to a greater coolnefs of the air at the fix weeks end, than when they were firft placed under the glaffes; and therefore do not depend 
pend on this Expcriment; but thought it proper to mention it, as well deferving to be repeated with greater accuracy, both with Mint, and other proper plants, by noting the temperature of the air on a Thermometer, hanging near the receivers, and obferving after fome time, whether the water $a a$ be rifen, notwithftanding the air be no cooler than when the Mint was firf placed under the glafs. And for greater certainty, it will be advifeable to fufpend in the fame manner another like receiver with no Mint, but only water in it, up to $a a_{\text {. }}$

\section{EXPERIMENT CXXIII.}

In order to find out the manner of the growth of young thoots, I firft prepared the following inftrument, viz. I took a.fmali ftick $a$, (Fig. 40.) and at a quarter of an inch diftance from each other, I run the points of five pins, I, 2, 3, 4, 5, thro' the ftick, fo far as to ftand $\frac{1}{4}$ of an inch from the ftick, then bending down the great ends of the pins, I bound them all faft with waxed thread; I provided alfo fome red lead mixed with oil. 
In the fpring, when the Vines had made fhort thoots, I dipped the points of the pins in the paint, and then pricked the young fhoot of a Vine, (Fig. 4I.) with the five points at once, from $t$ to $p$ : I then took off the marking inftrument, and placing the loweft point of it in the hole $p$, the uppermoft mark, I again pricked frefh holes from $p$ to $l$, and then marked the two other points $i b$; thus the whole fhoot was marked every $\frac{2}{4}$ inch, the red paint making every point remain vifible.

(Fig. 42.) Thews the true proportion of the fame fhoot, when it was full grown, the September following; where every correrponding point is noted with the fame letter.

The diftance from to to $s$ was not enlarged above $\frac{1}{60}$ part of an inch; from $s$ to $q$, the $\frac{1}{16}$ of an inch; from $q$ to $p, \frac{3}{8} ;$ from $p$ to $0, \frac{3}{8}$; from 0 to $n, \frac{6}{10}$; from $n$ to $m \frac{2}{10}$; from $m$ to $l, I+\frac{A}{10}$ of an inch; from $l$ to $i, x+\frac{3}{10}$ inch nearly; and from $i$ to $b$ three inches.

In this Experiment we fee that the firf joint to $r$ extended very little; it being almolt hapdened, and come near to its full growth, 


\section{Cf Vegetation.}

growth, when I marked it : The next joint, from $r$ to $n$, being younger, extended fomething more; and the third joynt from $n$ to $k$ extended from $\frac{3}{4}$ of an inch, to $3+\frac{1}{2}$ inches; tut from $k$ to $h$, the very tende joynt, which was but $\frac{x}{4}$ inch long, when I marked it, was when full grown three inches long.

We may obferve, that nature in order to furnifh thefe young growing thoots with plenty of ductile matter is very careful to furnifh at fmall diftances the young fhoots of all forts of trees, with many leaves throughout their whole length, which ferve as fo many joyntly acting powers placed at different ftations, thereby to draw with more eafe plenty of fap to the exiending thoot.

The like provifion has nature made in the Corn, Grafs, Cane, and Reed kind; the leafy fpires, which draw the nourifhment to each joynt, being provided long before the ftem fhoors, which flender ftem in its tender ductile ftate would moft eafily break and dry up too foon, fo as to prevent its due growth, had not nature to prevent both thefe inconveniences provided ftrong Thecas or Scabbards, which both fup- 


\section{2

port and keep long in a fupple ductile ftate the tender extending ftem.

I marked in the fame manner as the Vine, at the proper feafons, young Honeyfuckle fhoots, young Ajparagus, and young Sunflowers; and I found in them all a gradual fcale of uncqual extenfions, thofe parts extending mont which were tenderent. The white part of the Afparagus, which was under ground, extended very little in length, and accordingly we find the fibres of the white part very tough and ftringy: But the grcateft cxtenfion of the tender green part, which was about 4 inches above the ground when I marked it, feparated the marks from a quarter of an inch, to twelve inches diftance; the greatelt diftenfion of the Sunflower was from $\frac{x}{4}$ inch, to four inches difrance.

From thefe Experimeats, it is evident, that the growth of a young bud to a fhoot confirts in the gradual dilatation and extenfion of every part; the knots of a thoot being very near each other in the bud, as may plainly and diftinetly be feen in the fit bud of the Vine and Fig tree; but by this gradual diftention of every part, they are ex- 
tended to their full length. And we may eafily conceive how the longitudinal capillary tubes ftill retain their hollownefs, notwithftanding their being diffended, from the like effect in melted glafs tubcs, which retain a hollownefs, tho' drawn out to the fineft thread.

The whole progrefs of the firf joynt $r$ is very fhort in comparifon of the other joynts; becaufe, at firft fetting out its leaves being very fmall, and the feafon then cooler than afterwards; 'tis probable, that but little fap is conveyed to it, and therefore it extending but flowly, its fibres are in the mean time grown tough and hard, before it can arrive to any confiderable length. But as the feafon advances, and the leaves inlarge, greater plenty of nourifhment being thereby conveyed, the fecond joynt grows longer than the firt, and the $3 \mathrm{~d}$ and 4th ftill on gradually longer than the preceding; thefe do therefore in equal times make greater advances than the former.

The wetter the feafon, the longer and larger thoots do vegetables ufually make; becaufe their foft ductile parts do then continue longer in a moift, tender ftate; but 


\section{4 \\ Of Vegeiation.}

in a dry feafon the fibres fooner harden, and fiop the further growth of the fhoot; and this may probably be one reafon why the two or three laft joynts of every fhoot are ufually fhorter than the midale joynts; viz. becaufe they fhooting out in the more advanced hot dry fummer feafon, their fibres are foon hardened and dryed, and are withal checked in their growth by the cool autumnal nights: I had a vine thoot of one year's growth which was i 4 feet long, and had 39 joynts, all pretty nearly of an equal length, except fome of the firft and laft.

And for the fame reafon, Beans and many other plants, which ftand where they are nuch thaded, being thereby kept continually moif, do grow to unufual heights, and are drawn up as they call it by the over thadowing Trees, their parts being kept long, foft and ductile: But this very moift thaded ftate is ufually attended with fterility; very long joynts of vines are alfo obferved to be unfruitful.

This Experiment, which thews the manner of the growth of Thoots, confirms Borelli's opinion, who in his Book De motu Animalium, part fecond Chap. I3, fuppoles 
pofes the tender growing thoot to be diftended like foft wax by the expanfion of the moifture in the fpongy pith; which dilating moifture, he with good reafon concludes is hindered from returning back, while it expands by the fponginefs of the pith. without the help of valves. For 'tis very probable that the particles of water, which immediately adhere to, and are frongly imbibed into, and attracted by every fibre of the fpongy pith, will fuffer fome degree of expanfion before they can be detached by the fun's warmth from each attracting fibre, and confequently the mafs of fpongy fibres, of which the pith confints, muft there: by be extended.

And that the pith may be the more ferviceable for this purpole, nature has provided in moft thoots a ftrong partition at every knot, which partitions ferve not only as plinths, or abutments for the dilating pith to exert its force on, but alfo to prevent the rarified fap's too free retreat from the pith.

But a dilating fpongy fubftance, by equally expanding it felf every way, would not produce an oblong thoot, but rather a globofe one, like an Apple; to prevent which 


\section{Of Vegetation.}

inconvenience we may obferve, that nature has provided feveral Diaphragms, befides thofe at each knot, which are placed at fmall diftances acrofs the pith; thereby preventing its too great lateral dilatation. There are very plain to be feen in Walnut-tree fhoots; and the fame we may obferve in the pith of the branches of the fun-flower, and of feveral other plants; where tho' thefe Diaphragms are not to be diftinguirhed while the pith is full and replete with moifture, yet when it drys up, they are often plain to be feen; and it is further obferved, that where the pith confints of diftinct veficles, the fibres of thofe veficles are often found to run horizontally, whereby they can the better refift the too great lateral dilatation of the thoot.

We may obferve that nature makes ufe of the fame artifice, in the growth of the feathers of Birds, which is very vifible in the great pinion feathers of the wing, the fmaller and upper part of which is extended by a fpongy pith, but the lower and bigger quill part, by a feries of largeveficles, which when replete with dilating moifture do cxtend the quill, but when the quill is full grown, thefe 
veficles are always dry; in which ftate we may plainly obferve every veficle to be contracted at each end by a Diaphragm or Sphincter, whereby its too great lateral dilatation is prevented, but not its diftenfion lengthwire.

And as this pith in the quill grows dry and arelefs after the quill is full grown, we may obferve the fame in the pith of trees, which is always fucculent and full of moifture while the thoot is growing, by the expanfion of which the tender ductile thoot is diftended in every part, its fibres being at the fame time kept fupple by this moifture; but when each year's thoot is full grown, then the pith gradually drys up, and continues for the future dry and kikfey, its veficles being ever after empty; nature always carefully providing for the fucceeding year's growth by preferving a tender ductile part in the bud replete with fucculent pith.

And as in vegetables, fo doubtlefs in animals, the tender ductile bones of young animals are gradually increafed in every part, that is not hardened and offified; but fince it was inconfiftent with the motion of the joynts to have the ends of the bones foft and ductile as in vegetables; therefore na- 


\section{$33^{8}$ \\ Of Vegetation.}

ture makes a wonderful provifion for this at the glutinous ferrated joyning of the heads to the thanks of the bones; which joyning while it continues ductile the animal grows, but when it offifies then the animal can no longer grow. As I was affured by the following Experiment, viz. I took a half grown Chick, whofe leg-bone was then two inches long, and with a tharp pointed Iron at half an inch diftance I pierced two fmall holes through the middle of the fcaly covering of the leg, and shin-bone; two months after I killed the Chick, and upon laying the bone bare, I found on it obfcure remains of the two marks I had made at the fame diftance of half an inch: So that that part of the bone had not at all diftended lengthwife, fince the time that I marked it : Notwithftanding the bone was in that time grown an inch more in length, which growth was moftly at the upper end of the bone, where a wonderful provifion is made for its growth at the joyning of its head to the fhank, called by Anatomifts Symphyfis.

And as the bones grow in length and fize; fo muft the membranous, the mufclar, the 


\section{of Vegetation.}

nervous, the cartilaginous and vaícular fibres of the animal body neceffarily cxtend and expand, from the ductile nutriment which nature furnifhes every part withal ; in which repects animal bodies do as truly vegetate as do the growing vegetables. Whence it muft needs be of the greateft confequence, that the growing animal be fupplicd with proper nourifhment for that purpore, in order to form a ftrong athletick conftitution: For when growing nature is deprived of proper materials for this purpofe, then is the under a neceffity of drawing out very nender threads of life, as is too often the caic of young growing perfons, who by indulging in fpirituous liquors, or other excefies, do thereby greatly deprave the nutritive ductile matter, whence all the diftending fibres of the body are fupplied.

Since we are by thefe Experiments affured that the longitudinal fibres, and rap vefiels of wood in its firft year's growth, do thus diftend in length by the extenfion of every part; and fince nature in fimilar productions makes ufe of the fame or nearly the fame methods: Thefe confiderations make it not unreafonable to think, that the fecond and 


\section{Of Vegetation.}

following years additional ringlets of wood are not formed by a meerly horizontal dilatation of the veffels; for it is not eafy to conceive, how longitudinal fibres and tubular fap-vetfels fhould thus be formed; but rather by the thooting of the longitudinal fibres lengthways under the bark as young fibrous thoots of roots do, in the folid Earth. The obfervations on the manner of the growth of the ringlets of wood in Experiment 46 (Fig. 30.) do further confirm this. I intended to have made father refearches into this matter by proper Experiments, but have not yet found time for it.

But whether it be by an horizontal or longitudinal thooting, we may obferve that nature has taken great care to keep the parts between the bark and wood always very rupple with nimy moifure, from which ductile matter the woody fibres, veficles and buds are formed.

Thus we fee that nature, in order to the production and growth of all the parts of animals and vegetables, prepares her ductile matter : In doing of which the feleets and combines particles of very different degrees of mutual attraction, curioufy proportion- 


\section{Of Vegetation. $\quad 34 \mathrm{I}$}

ing the mixture according to the many different purpoles the defigns it for; either for long or more lax fibres of very different degrees in animals, or whether it be for the forming of woody or more foft fibres of various kinds in vegetables.

The great varicty of which different fubftances in the fame vegetable prove, that there are appropriated veffels for conveying very different forts of nutriment. And in many vegetables fome of thofe appropriate veffels are plainly to be feen replete either with milky, yellow, or red nutriment.

Dr. Keill, in his account of animal fecretion, page 49 , obferves, that where nature intends to feparate a vifcid matter from the blood, the contrives very much to retard its motion, whereby the inteftine motion of the blood being allayed, its particles can the better coalefce in order to form the vifcid fecretion. And Dr. Grew, before him, ob. ferved an inftance of the fame contrivance in vegetables where a fecretion is intended, that is to compofe a hard fubftance, viz. in the kernell or feed of hard ftone fruits, which does not immediately adhere to, and grow from the upper part of the ftone,

$$
\mathrm{Z}_{3}
$$

which 
which would be the fhorteft and neareft way to convey nourifhment to it; but the fingle umbilical veffel, by which the kernel is nourifhed, fetches a compais round the concaye of the ftone, and then enters the kernel near its cone, by which artifice this veffel being much prolonged, the motion of the fap is thereby retarded, and a vifcid nutriment conveyed to the feed, which turns to hard fubstance.

The like artifice of nature we may obferve in the long capillary fibrous veffels which lie between the green hull, and the hard fhell of the Walnut, which are analogous to the fibrous Mace of Nutmegs, the ends of whofe hairy fibres are inferted into the angles of the furrows in the WalnutThell: Their ufe is therefore doubtlefs to carry in thofe long diftinct veffels the very vifcous matter which turns, when dry, to a hard thell; whereas were the fhell inmediately nourifhed from the foft pulpous hull that furrounds it, it would certainly be of the fame foft conftitution: The ufe of the hull being only to keep the fhell in a foft ductile ftate till the Nut has done growing. We may obferve the like effeat of a lower motion 


\section{Of Vegetation.}

motion of the fap in Ever-greens, which perfpiring little, their fap moves much more nowly than in more perfpiring Trees; and is therefore much more vifcid, whereby they are better enabled to outlive the winter's cold. It is obferved that the fap of Evergreens in hot Countries is not fo vifcous as the fap of more Northern Ever-greens, as the fir, \& c. for the fap in hotter Countries muft have a brisker motion, by means of its greater perfpiration.

\section{EXPERIMENT CXXIV.}

In order to enquire into the manner of the expanfion of leaves, I provided a little Oaken board or fpatula, $a b c d$ of this thape and fize, (Fig. 43.) thro' the broad part at a quarter of an inch diftance from each other; I run the points of 25 pins $x x$ which ftood $\frac{2}{4}$ inch thro', and divided a fquare inch into 16 equal parts.

With this inftrument in the proper feafon, when leaves were very young, I pricked feveral of them thro' at once, with the points of all there pins, dipping them firft in the . red lead, which made lafting marks.

$$
\text { Z } 4
$$


(Fig. 44.) reprefents the fhape and fize of a young Fig-leaf, when firft marked with red points, $\frac{x}{4}$ inch diftance from each other.

(Fig. 45.) reprefents the fame full grown leaf, and the numbers anfwer to the correfponding numbers in the young leaf : Whereby may be feen how the feveral points of the growing leaf were feparated from cach other, and in what proportion, viz. from a quarter of an inch, to about three quarter's of an inch diftance.

In this Experiment we may obferve that the growth and expanfion of the leaves is owing to the dilatation of the veficles in every part, as the growth of a young thoot was fhewn to be owing to the fame caufe in the foregoing Experiment 8 ; and doubtlefs the cafe is the fame in all fruits.

If thefe Experiments on leares were further purfued, there might probably be many curious obfervations made in relation to the fhape of leaves: By obferving the difference of the progreflive and lateral motions of thefe points in different leaves, that were of very different lengths in proportion to their breadiths. 


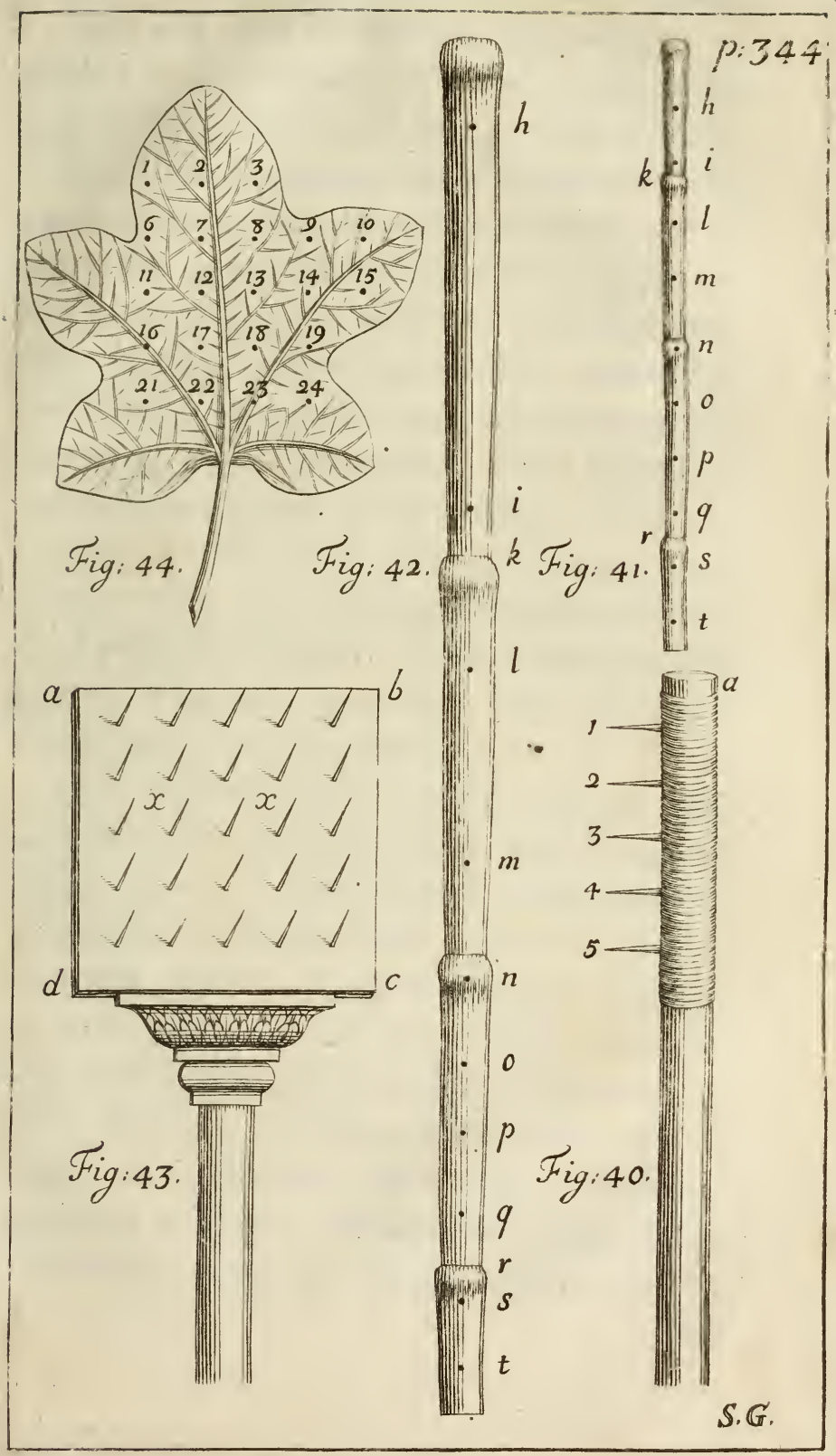



That the force of dilating fap and air, included in the innumerable little veficles of young tender fhoots and leaves, is abundantly fufficient for the extcnding of fhoots, and exa panding of leaves, we have evident proof from the great force we find in the fap of the Vine, chap. $3 \mathrm{~d}$. and from the vaft force, with which infinuating moifture expanded the Peafe. Experiment 32. we fee the great power of expanding water, when heated in the engine to raife water by fire: And water with air and other active particles in capillary tubes, and innumerable fmall veficles, do doubtlefs act with a great force, tho' expanded with no more heat than what the Sun's warmth gives them.

And thus we fee that nature exerts a confiderable, tho feçret and filent power, in carrying on all her productions; which demonftrates the wifdom of the Author of nature in giving fuch due proportion and direction to thefe powers, that they uniformly concur to the production and perfection of na. tural Beings; whereas were fuch powers under no guidance, they muft neceffarily produce a Chaos, inftead of that regular and beautiful fyftem of nature which we fee. 


\section{6 \\ Of Vegetation.}

We may plainly fee the influence of the Sun's warmth in expanding the fap in all the parts of vegetables, as well in the roots as the body that is above ground, by the influence it has on the fix Thermometers defcribed under Experiment 20, five of which were fixed at different depths from two in. ches, to two feet under ground, the other being expofed to the open air.

When in the greatent noon tide heat the fpirit of that which was expofed to the Sun was rifen, fince the early morning, from 2 I to 48 degrees; then the fipirit in the fecond Thermometer, whofe ball was two inches under ground, was at 45 degrees, and the $3^{\mathrm{d}}$, 4 th, and sth Thermometers were gradually of lefs and lefs degrees of heat, as they were placed lower in the ground to the fixth Thermometer, which was two feet under ground, in which the fpirit was 3 I degrees high. In this ftate of heat on all the parts of the vegetable, we fee the Sun muft have a very confidcrable influence in expanding the fap in all its parts. The warmth was much greater on the body above ground, than on the roots which were two feet deep; thore roots, and parts of roots which are deepeft? 


\section{Of Vegetation.}

decpent, as they feel much lefs of the Sun's warmth, fo are they not fo foon, nor fo much affected by the alternacies of day and night, warm and cold: But that part of vegetables, which is above ground, mult have its fap confiderably rarified, when the heat increafed from morning to two a clock afternoon, fo much as to raife the fpirit in the Ift Thermometer from 21 to 48 degrees a. bove the freezing point.

When in the coldeft days of the winter 1724 , the froft was fo intenfe, as to freeze the furface of ftagnant water near an inch thick, then the fpirit in the Thermometer which was expofed to the open air, was fallen four degrees below the freezing point; the fpirit of that whofe ball was two inches under ground, was four degrees above the freczing point; the $3 \mathrm{~d}$, 4 th and sth Thermometers were proportionably fallen lefs and lefs, as they were deeper, to the 6th Thermometer, which being two feet under ground, the fpirit was Io degrees above the freezing point. In this ftate of things the work of vegetation feemed to be wholly at a ftand, at leaft within the reach of the froft: 


\section{$34^{8}$ \\ Of Vegetation.}

But when the cold was fo far relaxed, as to have the fpirit in the firf Thermometer but $s$ degrees above the freezing point, the fecond 8 degrees, and the 6 th 13 degrees, tho' it was ftill very cold, yet this being fome advance from freezing towards warm, and there being confequently fome expanfion of the fap, feveral of the hardy vegetables grew, viz. fome Ever-greens, Snowdrops, Crocus's, \&c. which forward hardy plants do probably partake much of the nature of Ever-greens in perfpiring little; and the motion of their fap being confequently very llow, it will become more vifcous, as in Ever-greens; and thereby the better able to refift the winter's cold: And the fmall cxpanfive force, which this fap acquires in the winter, is moftly exerted in extending the plant, little of it being wafted in proportion to the fummer's perfpiration.

Supported by the evidence of many of the foregoing Experiments, I will now trace the vegetation of a tree from its firt feminal plant in the Seed to its full maturity and production of other Seeds, without entring into a particular defcription of the fructure of the parts of vegetables, which has already 


\section{Of Vegetation.}

ready been accurately done by Dr. Grew and Malpigbi.

We fee by Experiment $56,57,58$, on diftilled Wheat, Peafe and Muftard.feed, what a wonderful provifion nature has made, that the Seeds of Plants fhould be well ftored with very active principles, which principles are there compacted together by him, who curiounly adapts all things to the purpofes for which they are intended, with fuch a juft degree of cohefion as retains them in that ftate till the proper feafon of germination; for if they were of a more lax conftitution, they would too foon diffolve like the other tender annual parts of plants: And if they were more firmly connected, as in the heart of Oak, they muft neceffarily have been many years in germinating, tho' fuppled with moifture and warmth.

When a Seed is fown in the ground, in a few days it imbibes fo much moifture, as to fwell with very great force; as we fee in the Experiment on Peafe in an iron pot, this forcible fwelling of the lobes of the Seed a r, ar (Fig. 46.) does probably protrude moifture and nourifhment from the capillary veffels $r$, which are called the 


\section{0

Seed roots, into the radicle $c, z, d$, which radicle, when it has thot fome length into the ground, does then imbibe nourifhment from thence; and after it has acquired fufficient ftrength, as this tender ductile root is extending from $z$ to $c$, it muft neceffarily carry the expanding Seed-lobes upwards, at the fame time that the dilating from $z$ to $d$ makes it hoot downwards; and when the root is thus far grown, it lupplies the Plume $b$ with nourifhment, which thereby fwelling and extending opens the lobes $a r$, $a r$, which are at the fame time raifed above ground with the Plume; where they by expanding and growing thinner turn to green leaves, (except the Seeds of the pulfe kind) which leaves are of fuch importance to the yet tender Plume, that it perifhes, or will not thrive if they are pulled off; which makes it probable, that they do the fame office to the Plume, that the leaves adjoyning to Apples, Quinces and other fruits do to them, viz. they draw fap within the reach of their attraction; fee Exper. 8 and 30. But when the Plume is fo far advanced in growth, as to have branches and expanded leaves to draw up nourifhment; 


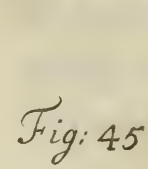

$p: 350$

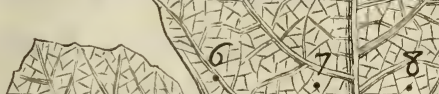

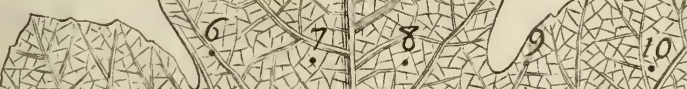

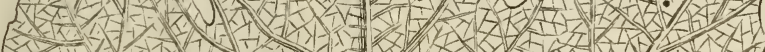

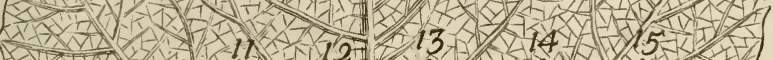

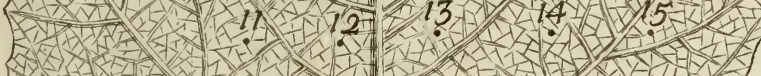

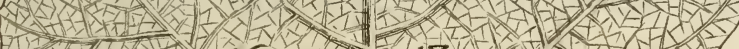
H.

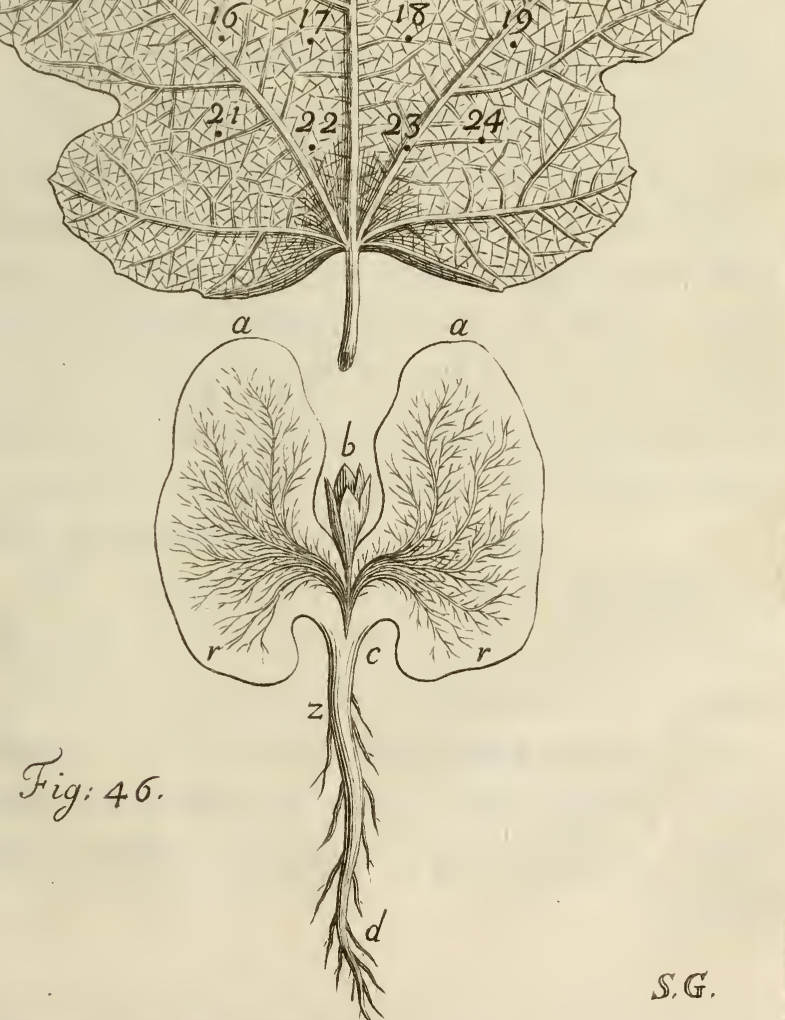





\section{Of Vegetation.}

then thefe fupplemental feminal leaves, ar, ar, being of no farther ufe, do perifh; not only becaufe the now grown and more expanded leaves of the young plant or tree, do fo overhadow the fupplemental leaves, that their former more plentiful perfpiration is much abated; and thereby alfo their power of attracting fap fails; but alfo becaufe the fap is drawn from them by the leaves, and they being thus deprived of nourifhment, do perifh.

As the tree advances in ftature, the firft, fecond, third, and fourth order of lateral branches fhoot out, each lower order being longer than thofe immediately above them; not only on account of primogeniture, but alfo becaufe being inferted in larger parts of the trunk, and nearer the root, they have the advantage of being ferved with greater plenty of fap, whence arifes the beautiful parabolical figure of trees.

But when trees ftand thick together in Woods or Groves, this their natural thape is altered, becaufe the lower lateral branches being much fhaded, they can perfpire little; and therefore drawing little nourifhment, they perifh; but the top branches, being expored 
cxpoled to a free drying air, they perfpite plentifully, and thereby drawing the fap to the top, they advance much in height: But vice verf $\hat{a}$, if when fuch a Grove of tall tiees is cut down, there be left here and there a fingle tree, that tree will then thoot out latcral branches; the leaves of which branches now perfpiring freely, will attract plenty of fap, on which account the top being deprived of its nourifhment, it ufually dies.

And as trees in a Grove or Wood grow only in length, becaufe all the nourifhmerit is by the leaves drawn to the top, moft of the fmall lateral fhaded branches in the mean time perifhing for want of peripiration and nutrition; fo the cafe is the very fame in the branches of a tree, which ufually making an angle of about 45 degrees with the ftem of the tree, do thereby beautifully fill up at equal and proper diftances the fpace between the lower branches, and the top of the tree, forming thereby as it wcre a parabolical Grove, or Thicket; which fhading the arms, the fmall lateral hoots of thofe arms ufually perifh for want of duc perfpiration; and therefore the arms continue naked like the bodies 


\section{Of Vegetation:}

bodies of Trees in a grove; all the nourinment being drawn up to the tops of the feveral branches by the leaves which are there expofed to the warm fun and free drying air, whereby the branches of Trecs expand much.

And where the lateral branches are very vigorous, fo as to make ftrong thoots, and attract the nourithment plentifully, there the tree ufually abates in its height: But where the tree prevails in height, as in groves, there commonly its lateral branches are fmalleft. So that we may look upon a tree as a complicated Engine which has as many different powers as it has arms and branches, each drawing from their common fountain of life the root: And the whole of each yearly growth of the tree will be proportionable to the fum of their attracting powers, and the quantity of nourinment the root a But this attracting power and nourifhment will be more or lefs, according to the different ages of the tree, and the more or lefs kindly feafons of the year.

And the proportional growth of their lateral and top branches, in relation to each other, will much depend on the difference

$$
\text { A a of }
$$


of their feveral attracting powers. If the perfpiration and attraction of the lateral branches is little or nothing, as in woods and groves, then the top branches will mightily prevail; but when in a free open air, the perfpiration and attraction of the lateral branches comes nearer to an equality with that of the top, then are the afpirings of the top branches greatly checked. And the cafe is the fame in moft other vegetables, which. when they ftand thick together, grow much in length with very weak latcral thoots.

And as the leaves are thus ferviceable in promoting the growth of a tree, we may obferve that nature has placed the pedals of the leaves-ftalks where molt nourifhment is wanting, to produce leaves, fhoots and fruit; and fome fuch thin leafy expanfion is fo neceffary for this purpofe, that nature provides fmall thin expanfions, which may be called primary leaves, that ferve to proted and draw nourifhment to the young fhoo: and leaf-buds before the leaf it felf is expanded.

And herein we fee the admirable contrivance of the Author of nature in adapting her different ways of conveying nourih- 


\section{of Vegeiation.}

ment to the different circumftances of her productions. For in this embrio ftate of the buds a fuitable provifion is made to bring nourifhment to them in a quantity fufficient for their then fmall demands: But when they are in fome degree increafed and formed, a much greater quantity of nourifhment, is neceffary, in proportion to their greater increafe: Nature, that the may then no longer fupply with a fcanty hand, immediately changes her method, in order to convey nourifhment with a more liberal hand to her productions; which fupply daily increafes by the greater expanfion of the leaves, and confequently the more plentiful attraction and fupply of fap, as the grearer growth and demand for it increafes.

We find a much more elaborate and beautiful apparatus, for the like purpore, in the curious expanfions of bloffoms and flowers, which feem to be appointed by nature not only to protect, but alfo to draw and convey nourifhment to the embrio fruit and. feeds. But as foon as the Calix is formed into a fmall fruit, now impregnated with its minute feminal tree, furnifhed with its Secondine, Corion and Amnion, (which 


\section{Of Vegetation.}

new fet fruit may in that ftate be looked upon as a compleat egg of the tree, containing its young unhatched tree, yet in embrio) then the bloffom falls off, leaving this new formed egg, or firft fet fruit in this infant ftate, to imbibe nourifhment fufficient for. it felf, and the Fætus with which it is impregnated: Which nourifhment is brought within the reach and power of its fuction by the adjoyning leaves.

If I may be allowed to indulge conjecture in a care, in which the moft diligent inquirers are as yet, after all their laudable refearches, advanced but little farther than meer conjecture, I would propore if to their confideration, whether from the manifent proof we have that fulphur ftrongly attracts air, a hint may not be taken, to confider whether this may not be the primary ufe of the Farina fecundans, to attract and unite with it felf elaftick or other refined active particles. That this Farina abounds with fulphur, and that a very refined fort, is pro: bable from the fubtile oil which chymifts obtain from the chives of faffron. And if this be the ufe of it, was it poffible that it could be more aptly placed for the purpofe on very 


\section{of Vegetation.}

moveable Apices fixt on the flender points of the Stamina, whereby it might eafily with the leaft breath of wind be difperfed in the air, thereby furrounding the plant, as it were, with an Atmofphere of fublimed fulphurcous pounce? for many trees and plants abound with it, which uniting with the air particles, they may perhaps be infpired at feveral parts of the plant, and efpecially at the Piftillum, and be thence conveyed to the Capjula Seminalis, efpecially towards evening, and in the night when the beautiful Petala of the flowers are clofed up, and they, with all the other parts of the vegetable, are in a ftrongly imbibing ftate. And if to thefe united fulphureous and acreal particles we fuppofe fome particles of light to be joyned, for Sir IJaac Newton has found that fulphur attracts light ftrongly, then the refult of thefe three by far the moft active principles in nature will be a Punctum Saliens to invigorate the feminal plant: And thus we are at laft conducted by the regular Analyfis of vegetable nature to the firft enlivening principle of their minuteft origin. 


\section{The Conchution.}

T $\mathrm{E}$ have from the foregoing Experiments many proofs of the very great and different quantities of moifture imbibed and peripired by different kinds of Trees, and alfo of the influence of the feveral ftates of the air, as to warm or cold, wet or dry, have on that perfpiration. We fee alfo what ftores of moifture nature has provided in the Earth againft a dry feafon, to anfwer this great expence of it in the production and fupport of vegetables; how far the dew can contribute to this fupply, and how infufficient its fmall quantity is towards making good the great demands of perfpiration: And that plants can plentifully imbibe moifture thro' their ftems and leaves as well as perfpire it.

We fee with what degrees of warmth the fun, that kindly natural genius of vegetation, acts on the feveral parts of vegetables, from their tops down to their roots two feet under ground.

We have alfo many proofs of the great force with which plants and their feveral branches and leaves imbibe moifture, up their 
the ir capillary fap veffels: The great influence the perfpiring leaves have in this work, and the care nature has taken to place them in fuch order, and at fuch proper diftances, as may render them moft ferviceable to this purpofe, efpecially in bringing plenty of nourifhment to the young growing fhoots and fruit whofe ftem is ufually furrounded with them near the fruit's infertion into the twig.

We fee here too that the growth of fhoots; leaves and fruit, confilts in the extenfion of every part; for the effecting of which, nature has provided innumerable little veficles, which being replete with dilating moifure, it does thereby powerfully extend, and draw out every ductile part.

We have here alfo many inftances of the great force of the afcending fap in the vine in the bleeding feafon; as alfo of the fap's freely either afcending or defcending, as it thall happen to be drawn by the perfpiring leaves; and alfo of its ready lateral motion thro" the laterally communicating fap veffels; together with many proofs of the great plenty of air drawn in and mixed with the fap and incorporated into the fubltance of vegetables.

If therefore thefe Experiments and ObferA 24

vations 


\section{The Conchufion.}

vations give us any farther infight into the nature of plants, they will then doubtlefs be of fome ufe in Agriculture and Gardening, either by ferving to rectify fome miftaken notions, or by helping farther to explain the reafons of many kinds of culture, which long repeated experience has found to be good, and perhaps by leading us to make fomeadvances therein : But as it requires a long feries and great variety of frequently repeated Experiments and Obfervations, to make a very fmall advance in the knowledge of the nature of vegetables; fo proportionably we are from thence only to expect fome gradual improvements in the culture of them.

The rpecifick differences of vegetables, which are all futtained and grow from the fame nourifhment, is doubtlefs owing to the very different formation of their minute veffels, whereby an almoft infinite variety of combinations of the common principles of vegetables is made; whence fome abound more with fome principles and fome with others. Hence fome are of a warmer and more fulphureous, others of a more watry, faline, therefore colder nature; fome of a more firm and lafting, others of a more lax and perifhable conftitution. Hence alfo it is that

fome 
fome plants flourith beft in one climate, and others in another; that much moifture is kindly to fome, and hurtful to others; that fome require aftrong, rich, and others a poor, fandy foil ; fome do beft in the fhade, and others in the fun, $\& c$. And could our eyes attain to a fight of the admirable texture of the parts on which the fpecifick differences in plants depends, what an amazing and beautiful feene of inimitable embroidery fhould we behold? what a variety of mafterly ftrokes of machinery? what evident marks of confummate wirdom fhould we bc entertained with ?

We may obferve that the conftitution of plants is curiounly adapted to the prefent ftate of things, fo as to be moft flourifhing and vigorous in a middle ftate of the air, viz. when there is a due mixture and proportion of warm and cold, wet and dry ; but when the feafons deviate far to any extream of thefe, then are they lefs or more injurious to the feveral forts of vegetables according to the very different degrees of hardinefs, or healthy latitude they enjoy.

The different feafons in which plants thrive beft, feems to depend, among other caufes, on the very different quantities imbibed and perfpired by different

kinds 


\section{$3^{62}$ The Conclufion.}

kinds of plants. Thus the Ever-greens perfpiring little, and having thereby a thick, vifcid, oily fap, they can the better endure the winter's cold, and fubfift with little frefh nourifhment: They feem many of them to flourifh moft in the temperate feafons of the year, but not fo well in the hotteft part of Summer, becaufe their perffiration is then fomewhat too great, in proportion to the flow afcent of the fap, which makes fome of them at that feafon to abate of their vigor: Thus fome plants, which grow and thrive with the flow perfpisation of Fanuary and $F_{e}$ bruary, perifh as the fpring advances, and the warmth and perfpiration is too great for them. And thus Garden Peafe and Beans, which are fown in what is found to be their proper feafon, viz. in November, Fanuary, or February, tho' they make but a flow prosrefs in their growth upwards, during the cold feafon, yet their roots, as alfo thofe of winter corns, do in the mean time fhoot well into the warmer Earth, fo as to be able to afford plenty of nourifhment when the feafon advances, and there is a greater demand of it both for nutrition and perfpiration. But when Peale are fown in Fune, in order for a 
crop in September, they rarely thrive well, unlefs in a cool moift fummer, by reafon of the too great perfpiration caufed by the fummer's heat, which drys and hardens their fibres before they are full grown.

Tho' we have from thefe Experiments, and from common obfervation, many proofs of the great expanfive force, with which the fibrous roots of plants thoot, yet the lefs refiftance thefe tender fhoots meet with, the greater progrefs they will certainly make in equal times: And therefore one confiderable ure of fallowing and trenching ground, and of mixing therewith feveral forts of com. poft, as Chalk, Lime, Marle, Mold, \& c. is not only thereby to replenifh it with rich manure, but alfo to loofen and mellow the foil, not only that the air may the more eafily penetrate to the roots, but alfo that the roots may the more readily make vigorous thoots. And the greater proportion the furface of the roots bears to the furface of the plants above ground, fo much the greater quantity of nourifhment they will afford, and confequently the plants will be the more vigorous, and better able to weather it out, againft unkindly feafons, than thofe plants whole 


\section{$3^{6} 4$ The Conclufion.}

whofe roots have made much fhorter fhoots. Herein therefore confins the great care and skill of the Husbandman, to adapt his different forts of Husbandry to the very different foils, feafons and kinds of grain; that the feveral forts of earth, from the very ftiff and frong ground, to the loofe light earths, may be wrought to the bett temper they are capable of, for the kindly thooting and nourifhing of the roots. And probably the Husbandman might get many ufeful hints, to direct him in adapting the feveral kinds of manure, and different. forts and feafons of culture to his different foils and grains: If in the feveral ftages and growth of his Corn, he would not only make his obfervations, on what appears above ground, but would alfo frequently dig up, compare and examin the roots of plants of each fort, efpecially of thofe which grew in different foils, and were any how cultivated in a different manner from each other; this would inform them alfo, whether they fowed their Corn too thick or too thin, by comparing the branchings and extent of each root, with the fpace of ground allotted it to grow in. 


\section{The Conclufion.}

And fince we find fo great a quantity of air infpired and mixt with the fap, and wrought into the fubftance of vegetables, the advantage of ploughing and fallowing ground feems to arife not only from the killing the weeds, and making it more mellow, for the thooting of the roots of Corn; but it is thereby alfo the better expoled to have the fertilizing, fulphureous, acreal and acid particles of the air mixt with it, which make land fruitful, as is evident from the fertility which the fword or furface of land acquires, by being long expofed to the air, without any culture or manure whatever.-

We have feen many proofs of the great quantities of liquor imbibed and perfpired by plants, and the very fenfible influence which different ftates of the air had on their more or lefs free perfpiration : A main intention therefore to be attended to in the culture of them, is to take due care, that they be fown or planted in proper feafons and foils, fuch as will afford them their due proportion of nourihment; which foils, as they are exhaufted, munt, as 'tis well known, from time to time, be replenifhed with frefh compolt, fuch as is full of faline, 


\section{The Conclufion.}

fulphureous and aereal particles, with which common dung, lime, afhes, fword, or burn: bated turf abound: As alfo fuch manures as have nitrous and other falts in them; for tho' neither nitre nor common falt be found in vegetables; yet fince they are obferved to promote fertility, it is reafonable to conclude, that their texture is greatly altered in vegetation, by having their acid volatile falts feparated from the attracting central air and earthy particles, and thereby making new combinations with the nutritive juice; and the probability of this is further confirmed from the great plenty of air and volatile falt, which is found in another combination of them, viz. in the Tartar of fetmenting liquors: For it is the opinion of Chymifts, that there is but one volatile fale in nature, out of which all other kinds of falts are formed by very different combinations, all which nutritive principles do by various combinations with the cultivated earth, compofe that nutritive ductile matter, out of which the parts of vegetables are formed, and without which the watry vehicle alone cannot render a barren foil fruitful. 


\section{The Conclufion.}

Nor is this the only care, the thriving and fertility of plants and trees depends much upon the happy influence and concurrence of a great variety of other circumftances. Thus many trees are unfruitful by being planted too deep, whereby their roots being in too moift a fate, and too far from the proper influence of the Sun, whofe power greatly decreafes the deeper we go, as we fee in Experiment 20. they imbibe too much crude moifure, which tho' productive of wood, is yet unkindly for fruit.

Or if when not planted too deep, they are full of crude fap, either by being too luxurious, or too much íhaded; or are planted in a moift, when they delight in a dry foil, then the fap is not fo fufficiently digefted by the Sun's warmth, as to be in that ductile ftate, which is proper for the producing of fruit.

And thus the Vine, which is known to thrive well in a dry, gravelly, rocky foil, will not be fo fruitful in a moift, ftiff, clay ground: And accordingly we may obferve in Experiment the 3d, that tho' the Vine imbibed and perfpired more than the Evergreen, yet it perfpired lefs than the Apple- 


\section{The Conclufion.}

tree, which delights in, and bears beft in a ftrong brick-earth clay; for tho' the Vine bleeds moft freely in its feafon, produces many long fucculent fhoots, and bears great plenty of a very juicy fruit, yet from that Experiment it is plain, that it is not a great perfpirer, and therefore thrives beft in a dry, rocky, or gravelly foil.

The confiderable quantity of moifture, which by Experiment 16 . is perfpired from the branches of trees, during the cold winter feafon, plainly thews the reafon, why in a long feries of cold north-eafterly winds, the bloffoms, and tender young fet fruit and leaves, are in the early fpring fo frequently blafted, viz. by having the moifture exhaled fafter than it can be fupplied from the trees; for doubtlefs that moifture rifes the flower from the root, the colder the feafon is, tho it rifes in fome degree all the winter, as is evident from the fame Experiment.

And from the fame caufe it is, that the leafy fpires of Corn are by thefe cold drying winds often faded and turned yellow; which makcs the Husbandman, on thefe occafions, with for fnow; which tho' it be very cold, yet it not only defends the root from

being 


\section{The Conclusion.}

being frozen, but alfo fcreens the Corn from thefe drying winds, and keeps it in a moift, florid, fupple itate.

It feems therefore to be a very reafonable direction which is given by fome of the Authors who write on Agriculture and Gardening, viz. during thefe cold drying winds, when little dew falls, to water the trees in dry foils, in the bloffoming feafon, and while the young fet fruit is tender; and provided there is no immediate danger of a froft, or in cafe of continued froft, to take care to cover the trees well, and at the fame time to fprinkle them with water, which is imitating nature's method of watering every part: But if the fuccels of this practice in cold weather may be thought a little doubtful; yet the fprinkling the bodies and leaves of trees, in a very hot and dry fummer feafon, feems moft reafonable, for by Exper. 42 . they will imbibe much moifture.

As to floping fhelters over Wall-trees, I have often found, that when they are fo broad as to prevent any rain or dew coming at the trees, they do more harm than good, in thefe long eafterly drying winds; becaufe they prevent the rain and dews falling on them, which would not only 


\section{The Conclufion.}

refrefh and fupple them, but alfo convey nourifhment to them: But in the care of Tharp frofts after fhowers of rain, thele thel. ters and other fences muft needs be of excellent ure to prevent the almoft total deAtruction which is occafioned by the freezing of the tender parts of vegetables, when they are full faturate with rain.

The full proof we have from thefe Experiments, of the ferviceablenefs of the leaves in drawing up the fap, and the care we fee nature takes, in furnifhing the twigs with plenty of them, principally near the fruit, may inftruat us on the one hand, not to be too lavin in pruning them off, and to be cver mindful to leave fome on the branch beyond the fruit; and on the other hand, to bc as careful to cut off all fuperfluous fhoots, which we are affured do draw off in wafte great quantity of nourifhment. And might it not be advifeable, among many other ways which are prefcribed, to try whether the too great luxuriancy of a tree or branch could not be much checked by pulling off fome of its leaves? How many experience will beft teach us, the pulling all off will endanger the killing the branch or tree.

There is another very confiderable ufe of 
the leaves, viz. to keep the growing fruit in a fupple ductile ftate, by defending it from the Sun and drying winds, which by toughning and hardening its fibres fpoil its growth, when too much expofed to them; but when full grown, or near it, a little more Sun is often very needful to ripen it. In hotter climates fruits want more fhade than in this country, and here too, more thade is needful in a hot dry fummer, than in a wet cool one.

The confideration of the ftrong imbibing power of the branches of trees, and the readinefs with which we fee the fap paffes to and fro, to follow the ftrongeft attraction, may perhaps give fome ufeful hints to the Gardincr, in the pruning and thaping of his trees, in checking the too luxuriant, and helping and encouraging the unthriving partsof trees.

Ir is a conftant rule among Gardiners, founded on long experience, to prune weak trees early in the winter, becaufe they find that late pruning checks them; and for the fame reafon to prune luxuriant trees late in the fpring, in order to check their luxuriancy. Now it is evident that this check does not proceed from any confiderable lofs of fap at the wounds of the pruned tree, er-

$\mathrm{B} b 2$

cepting 
cepting the care of a few bleeding trees when cut in that feafon, but munt arife from fome other caufe; for by Experiment 12 and 37. where mercurial gages were fixed to the fems of frem cut trees, thofe wounds were conftantly in a firongly imbibing ftate, except the Vine in the bleeding reafon.

When a weak reee is pruned early in the beginning of the winter, the orifices of the fap-vefels are clored uplong before the fpring, as is evident from many Experiments in the If, $2 \mathrm{~d}$ and $3 \mathrm{~d}$ chapters; and confequently when in the fpring and fummer the warm weather advances, the attracting force of the perfpiring leaves is not then weakened by many inlets from frefh wounds, but is wholly cxerted in drawing fap from the root. Whereas on the other hand, when a luxuriant rree is pruned late in the fpring, the force of its leaves to attract fap from the foot will be much fpent and loft at the feveral frefh cut inlets.

Befides, the early pruned tree being eafed of feveral of its twigs or branches, has thereby the advantage of ftanding thro' the whole winter, with a head better proportioned to its weak root. And fince by Exper. 16. the fap is found to afcend in the winter, lefs of 
that than cold crude juice is drawn thro the roots and ftem, to fupply the perfpiration of the remaining boughs, whereby the fap of the tree is probably lefs depauperated than it would have been, if all the boughs had remained on. For thefe rea. fons, early pruning thould in the main, and excepting fome eafes, be better than late.

And the reafonablenefs of this practice is further confirmed by the experience of Mr. Palmer, a curious Gentleman of Chelfea, who has found, that by pruning his Vines, and pulling all the leaves off them in September, as foon as the fruit was off, they have born greater plenty of Grapes than other Vines, particularly in the year 1726 . when by reafon of the extreme wetnefs and cold. nefs of the preceding fummer, the unripe shoots produced generally very little fruit.

From many Experiments in the fecond Chapter, the Gardiner will fee with what force his grafts imbibe fap from the flock, efpecially that ductile nourifhme nt from between the bark and wood; which correfponding parts he well knows by conftant experience mult be carefully adapted to each other in grafting, thofe grafts being always beft whofe buds are not far afunder, viz. be. 


\section{The Conclufion:}

caufe their cxpanding leaves; can therefore draw up fap the more vigoroufly.

The great quantities of moifure which we find by Experiment 12 are imbibed at wounds where branches are cut off, thews the reafonablenefs of the caution ufed by many who are defirous to preferve their trees, viz. either by plaiftring or covering with Sheet-lead the very large wounds of trees, to defend their trunks from being rotted by the foaking in of rain.

And from the fame i2th Experiment a hint may be taken to make fome attempts to give an artificial tafte to fruits, by making trees imbibe in the fame manner fome ftrongly ringed or perfumed liquor, which is not fpirituous, for that we fee will kill the trec. I have made the ftem of a branch of a tree imbibe tivo quarts of water without killing it; If any are defirous to make this Experiment they fhould take care to cut the ftump which is to imbibe the liquor as long as they can, that there may be the more room, from time to tinie, to cut off an inch or two of the top, when it is grown fo faturate with liquor that more will not pafs.

Tho' Ever-greens are found to imbibe and perfpire much lefs than other trees, yet is the 


\section{The Conclufion.}

the quantity they perfpire fo confiderable, that it has always been one of the greatert difficulties in the ordering of a Green-houfe to let in frefh air enough without expofing the plants to too much cold. For fince the perfpiration of trees will not be free and kindly in a clofe damp air, the fap will be apt to ftagnate, which will make the plants grow moldy, or they will be fickly, by imbibing fuch damp rancid vapours; for by Mr. Miller's curious obfervations on the perfpiration of the Plantain tree of the Weft-Indies, and of the Alve under Experiment $s$, plants will often imbibe moifture in the night as well in ftoves as common Grcenhoufes without fire; it is certainly of as great importance to the life of the plants to difcharge that infected rancid air, by the admittance of frefh, as it is to defend them from the extream cold of the outward air, which will deftroy them if let in immediately upon them. It feems therefore to be a very reafonable method which fome ufe, viz. to cover fome of the inlets of their Green-houfes on all fides with canvals, and in extream cold weather with thutters made of reed or ftraw, through which the air can only pafs in little Atreams: The like contrivance would probably 


\section{The Conclufion.}

bably alfo be of good fervice to purify gradually the thick rancid fumes which arife from the dung of hot beds, and are often very deftructive of the tender plants: This is to imitate nature, which while the provides for the defence of living creatures againft the cold, by a good covering of Hair, Wool, or Feathers, at the fame time the takes care that the air may have admittance through innumerable narrow meanders in fuch quantities as may be fufficient to carry off the perfpiring matter.

I have herc, and as occafion offered under feveral of the foregoing Experiments, only touched upon a few of the moft obvious inftances, wherein thefe kind of refearches may poflibly be of fervice in giving us ufeful hints in the culture of plants: Tho' I am very fenfible, that it is from long experience chiefly that we are to expect the moft certain rules of practice, yet it is withal to be remembred, that the likelieft method to enable us to make the mont judicious obfervations, and to put us upon the moft probable means of improving any art, is to get the beft infight we can into the nature and properties of thofe things which we are defirous to cultivate and improve.

$$
\text { FIN I } S \text { 。 }
$$


$+1$
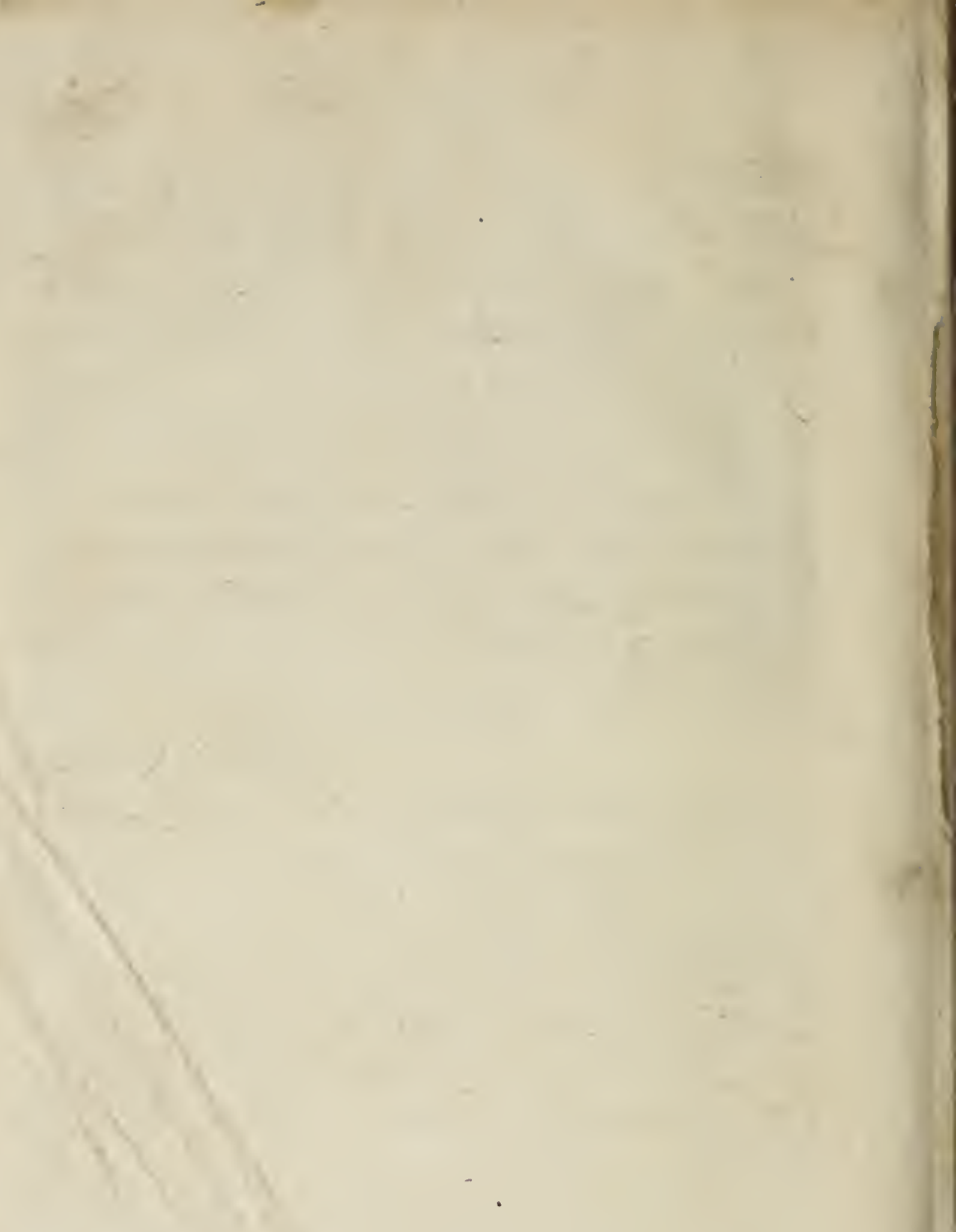


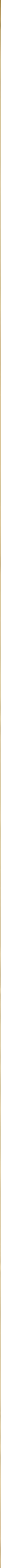


